United States Department of Commerce Technology Administration

National Institute of Standards and Technology

NIST Special Publication 873

\title{
Joint DoD/NIST Workshop on International Manufacturing Systems Research and Development
}

John D. Meyer, Editor

$Q C$ 

in the development of technology ... needed to improve product quality, to modernize manufacturing processes, to ensure product reliability ... and to facilitate rapid commercialization ... of products based on new scientific discoveries."

NIST, originally founded as the National Bureau of Standards in 1901, works to strengthen U.S. industry's competitiveness; advance science and engineering; and improve public health, safety, and the environment. One of the agency's basic functions is to develop, maintain, and retain custody of the national standards of measurement, and provide the means and methods for comparing standards used in science, engineering, manufacturing, commerce, industry, and education with the standards adopted or recognized by the Federal Government.

As an agency of the U.S. Commerce Department's Technology Administration, NIST conducts basic and applied research in the physical sciences and engineering, and develops measurement techniques, test methods, standards, and related services. The Institute does generic and precompetitive work on new and advanced technologies. NIST's research facilities are located at Gaithersburg, MD 20899, and at Boulder, CO 80303. Major technical operating units and their principal activities are listed below. For more information contact the Public Inquiries Desk, 301-975-3058.

\section{Office of the Director}

- Advanced Technology Program

- Quality Programs

- International and Academic Affairs

\section{Technology Services}

- Manufacturing Extension Partnership

- Standards Services

- Technology Commercialization

- Measurement Services

- Technology Evaluation and Assessment

- Information Services

\section{Materials Science and Engineering} Laboratory

- Intelligent Processing of Materials

- Ceramics

- Materials Reliability

- Polymers

- Metallurgy

- Reactor Radiation

\section{Chemical Science and Technology}

\section{Laboratory}

- Biotechnology

- Chemical Kinetics and Thermodynamics

- Analytical Chemical Research

- Process Measurements ${ }^{2}$

- Surface and Microanalysis Science

- Thermophysics

\section{Physics Laboratory}

- Electron and Optical Physics

- Atomic Physics

- Molecular Physics

- Radiometric Physics

- Quantum Metrology

- Ionizing Radiation

- Time and Frequency'

- Quantum Physics'
Manufacturing Engineering Laboratory

- Precision Engineering

- Automated Production Technology

- Intelligent Systems

- Manufacturing Systems Integration

- Fabrication Technology

Electronics and Electrical Engineering Laboratory

- Microelectronics

- Law Enforcement Standards

- Electricity

- Semiconductor Electronics

- Electromagnetic Fields'

- Electromagnetic Technology ${ }^{1}$

- Optoelectronics ${ }^{1}$

Building and Fire Research Laboratory

- Structures

- Building Materials

- Building Environment

- Fire Safety

- Fire Science

Computer Systems Laboratory

- Office of Enterprise Integration

- Information Systems Engineering

- Systems and Software Technology

- Computer Security

- Systems and Network Architecture

- Advanced Systems

Computing and Applied Mathematics Laboratory

- Applied and Computational Mathematics ${ }^{2}$

- Statistical Engineering ${ }^{2}$

- Scientific Computing Environments ${ }^{2}$

- Computer Services

- Computer Systems and Communications ${ }^{2}$

- Information Systems

'At Boulder, CO 80303.

${ }^{2}$ Some elements at Boulder, CO 80303. 


\section{NIST Special Publication 873}

\section{Joint DoD/NIST Workshop on International Manufacturing Systems Research and Development}

John D. Meyer, Editor

Manufacturing Engineering Laboratory

National Institute of Standards and Technology

Gaithersburg, MD 20899-0001

October 1995

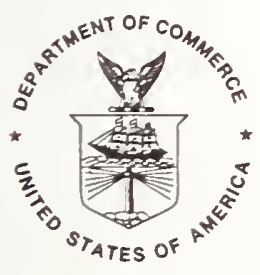

U.S. Department of Commerce

Ronald H. Brown, Secretary

Technology Administration

Mary L. Good, Under Secretary for Technology

National Institute of Standards and Technology Arati Prabhakar, Director 
National Institute of Standards

and Technology

Special Publication 873

Natl. Inst. Stand. Technol.

Spec. Publ. 873

237 pages (Oct. 1995)

CODEN: NSPUE2
U.S. Government Printing Office

Washington: 1995
For sale by the Superintendent of Documents

U.S. Government Printing Office Washington, DC 20402 


\section{Preface}

An international workshop was held in Rockville, Maryland, on November 3-5, 1992 to discuss major research and development programs in manufacturing systems technology. Approximately 25 leading experts attended the workshop, which was co-sponsored by the U. S. Department of Defense's Manufacturing Technology Program.

Several papers, each covering a specific geographic region or topic, were presented at the workshop. Copies of the presentations are included in these proceedings.

In addition to individual $R \& D$ programs and technology sources in North America, Western Europe, Eastern Europe, and Asia, the workshop participants also discussed R\&D needs, priorities, underlying motivations, and opportunities for international collaboration. The results of these discussions will be summarized in a separate report. Information about the summary report may be obtained from the editor of these proceedings.

J. D. Meyer

Gaithersburg, Maryland

October 1992 



\section{Final Participants List}

\section{MANUFACTURING SYSTEMS RESEARCH \& DEVELOPMENT WORKSHOP \\ National Institute of Standards and Technology \\ Gaithersburg, Maryland \\ Woodfin Suites Hotel}

November 3-5, 1992

Peter Brown

NIST

Bldg. 220, Rm A217

Gaithersburg, MD 20899

301/975-3515

Fax: 301/258-9749

Bernard Chern

National Science Foundation 1800 G St., N.W.

Washington, DC 20550

202/357-7373

Fax: 202/357-1056

Hank Grant

National Science Foundation 1800 G St., N.W.

Room 1128

Washington, DC 20550

202/357-7676

Fax: 202/357-5166

Bernd E. Hirsch

Bremen Univ. (BBA)

Hochschulring 20

2800 Bremen 33

Germany

$+49-421-2183384$

Fax: +49-421-2200979

Michael Hitchcock

Air Force Man Tech

WL/MTI

WPAFB, OH 45433-6533

513/255-7371

Fax: 513/476-4420
Albert Jones

NIST

Bldg. 220, Rm B310

Gaithersburg, MD 20899

301/975-3554

Fax: 301/948-5668

Fumihiko Kimura

The University of Tokyo

Hango 7-3-1 Bunkyo Ku

Tokyo 113, Japan

+81-3-3812-2111 ext. 6455

Fax: +81-3-3812-8849

Charles Kimzey

OASD (P\&L)

8000 Defense Pentagon

Rm 3B253

Washington, DC 20301-8000

703/697-0957

Fax: 703/693-6990

Lloyd Lehn

OASD (P\&L) PR/MM

8000 Defense Pentagon

Rm 3B253

Washington, DC 20301-8000

703/614-4783

Fax: 703/693-6990

Thomas Mahoney

National Science Foundation

2101 Constitution Ave.

Washington, DC 20418

202/334-2570

Fax: 202/334-2571 
Charles McLean

NIST

Bldg. 220, Rm Al27

Gaithersburg, MD 20899

301/975-3511

Fax: 301/258-9749

John Meyer

NIST

Bldg 245, Rm B 102

Gaithersburg, MD 20899

301/975-3371

Fax: 301/926-8730

Frederick Michel

Society of Mfg Engineers

8409 Felton Lane

Alexandria, VA 22308

703/360-7665

Fax: 703/360-7665

Eugene Ovsyannikov

St. Petersburg Institute

for Informatics \& Automation

39, 14th Line

St. Petersburg, 199178

Russia

Leo Plonsky

U.S. Navy

NAVIRSA; Bldg. 75-2

Naval Base

Philadelphia, PA 19112

215/897-6684

Fax: 215/897-5949

Stan Settles

OSTP/White House Office

Old Executive Office Bldg.

$\mathrm{Rm} 428$

17th \& Pennsylvania Ave., N.W.

Washington, DC 20500

202/395-1408

Fax: 202/395-3719
K. (Cheena) Srinivasan

National Science Foundation 1800 G St., N. W.

Room 1128

Washington, DC 20550

James Solberg

Purdue University

Potter Bldg.

Engineering Bldg.

W. Lafayette, IN 47907

317/494-7715

Fax: 317/494-0811

Brent Starkey

U.S. Army

Rock Island Arsenal

Attn: AMSMC-PRS-L

Rock Island, IL 61299-6000

309/782-1391

Fax: 309/782-0295

David Stieren

OASD (P\&L)

8000 Defense Pentagon

Rm 3B253

Washington, DC 20301-8000

703/695-7580

Fax: 703/693-6990

Julie Tsao

Defense Logistics Agency

Cameron Station

PRM 4B 190

Alexandria, VA 22304-6100

Nathan Tupper

Consultant

4317 Appleton $\mathrm{Pl}$.

Kettering, OH 45540

513/294-4930

Fax: 513/294-7438 


\section{Table of Contents}

Page

Preface $\ldots \ldots \ldots \ldots \ldots \ldots \ldots \ldots \ldots \ldots \ldots \ldots \ldots$ iii

Final Participants List $\ldots \ldots \ldots \ldots \ldots \ldots \ldots$

Introductory Remarks

John Meyer, National Institute of Standards and Technology

Gaithersburg, MD. . . . . . . . . . . . . . . . 1

North American R\&D in Manufacturing

James Solberg, Purdue University

West Lafayette, IN . . . . . . . . . . . . . . . . 5

Western European R\&D for Manufacturing Systems

Bernd Hirsch, Bremen University

Bremen, Germany . . . . . . . . . . . . . . . . . 23

Eastern European R\&D in Manufacturing

Eugene Ovsyannikov, Institute for Informatics and Automation

St. Petersburg, Russia . . . . . . . . . . . . . . . . 95

Asian R\&D in Manufacturing

Fumihiko Kimura, University of Tokyo

Tokyo, Japan . . . . . . . . . . . . . . . . . . . . 115

Manufacturing Systems R\&D Study Results 



\title{
Introductory Remarks
}

\author{
John Meyer \\ Manufacturing Engineering Laboratory \\ National Institute of Standards and Technology \\ Gaithersburg, MD 20899
}

It is widely recognized that most of the costs of manufacturing a product are not attributable to direct labor expenses or the costs of purchased materials and components. Instead, the primary cost drivers are often "above-the-shopfloor" types of expenses for such functions as production scheduling and control, material and supplier management, quality assurance, manufacturing engineering and other overhead categories. In addition to representing major cost elements, these non-direct functions also have a major impact on the overall effectiveness and efficiency of the entire manufacturing operation, and therefore are doubly important in determining a company's ability to compete successfully in world markets.

For the purposes of this workshop, these non-direct functions are referred to as "manufacturing systems" technologies, where the term "systems" is used in its broadest context and is not limited strictly to computer-based production processes or techniques. Included in this definition are the many approaches to integration of manufacturing systems and the engineering tools and methods for designing processes, manufacturing equipment, facilities, and enterprises.

Major advances in manufacturing systems technologies are being pursued by numerous organizations around the world. Undoubtedly, these research efforts will yield new and improved methods and technologies that will enable companies to manufacture products parts more flexibly, with better quality and lower costs in smaller volumes.

In the midst of this high level of on-going international research, there is a need for a mechanism for examining such efforts on a worldwide basis in an open forum, with an eye towards identifying collaborative research opportunities among regions. Workshops serves as one such mechanism.

To this end, a workshop was jointly sponsored by the U.S. Department of Defense (DoD) and the National Institute of Standards and Technology (NIST). Both DoD and NIST are actively involved in the development and implementation of advanced manufacturing technologies and each is interested in exploring international collaborative research projects in this field. 
The purpose of the workshop was to provide an international forum for discussing major research and development programs in manufacturing systems technology. Specifically, the objectives of the workshop were to:

1. Identify major R\&D programs and sources of advanced manufacturing systems technology in Europe, Asia, North America and other parts of the world.

2. Determine the approximate level of resources being expended in each $R \& D$ area.

3. Examine the goals and strategies of these R\&D programs, as well as the underlying reasons and motivations for undertaking such efforts.

4. Explore any unmet needs or high-impact research opportunities that may exist in the area of manufacturing systems technology.

5. Discuss the potential for international collaborative $R \& D$ projects and any key issues associated therewith.

For the purposes of this workshop, the term "manufacturing systems" was very broadly defined and included the following topics:

-- Production scheduling and control

-- Material management

-- Supplier management

-- Quality assurance

-- Manufacturing and industrial engineering

-- Tool and equipment design

-- Facilities and enterprise design

-- Information management

-- Equipment justification

-- Manufacturing strategies

Other "above-the-shop-floor" costs, such as marketing and sales expenses, general management, equipment depreciation, and financing were considered to be outside the scope of the workshop.

Because of the focused and specific nature of the workshop's objectives, the meeting was conducted on a "by-invitation-only" basis. The total number of participants was limited to a maximum of 25 people. Each individual was expected to be an active participant in the discussions. Thus, only knowledgeable experts in the field were invited to participate in the meeting. The workshop was truly international in flavor, with leading observers from all regions of the world taking part in the meeting. 
The meeting spanned a three-day period. The agenda was as follows:

Day 1:

Morning: Registration and individual presentations and questions Afternoon: Individual presentations and questions

Day 2:

Morning: Group discussion of R\&D framework and research programs Afternoon: Group discussion of R\&D needs and priorities

Day 3:

Morning: Group discussion of collaboration opportunities Afternoon: Adjourn

Approximately 25 people attended the workshop. A list of the attendees is included in this proceedings.

As can be seen from the agenda, a considerable portion of the workshop was devoted to group discussions of various issues concerning manufacturing systems R\&D. A separate report summarizing these discussions is planned for preparation in 1993. More information about the report is available from the editor of these proceedings. 



\title{
North American R\&D in Manufacturing
}

\author{
James J. Solberg \\ Engineering Research Center for \\ Intelligent Manufacturing Systems \\ Purdue University
}

\section{INTRODUCTION}

The American approach to manufacturing research is widely diverse, distributed, and unorganized. Not only do we lack a central authority or government body with responsibility for coordinating the work, there is not even a single source to find out what is happening. If outside observers find this confusing, so do insiders. But this typically American pluralistic approach has served us well in many other cases, so we live comfortably with more confusion that other cultures might allow. In particular, we resist centralized planning and control even when the altemative seems irrational and chaotic.

Before attempting to make some sense of the very complex picture relating to manufacturing research in the U.S. today, I must acknowledge several factors that limit my perspective. Although I am reasonably familiar with what is happening in several of the relevant government agencies, in universities, and in a few government labs, the total picture is too big and complicated for anyone to have a full grasp of the situation. Even if I were able to offer complete knowledge of the current situation, it is changing so rapidly that any conclusions could only be temporary. Indeed, one of the few statements that I can confidently make is that change is occurring rapidly. Any perspective on these issues can only be a personal one; many people could look at the same issues and interpret them very differently.

Having given those warnings, I will nevertheless attempt to interpret what I know in as bold a manner as possible. I will identify the principal players, as I see them, and try to sort out the roles of each. I will also state what I see as the major themes that emerge from the totality of all the manufacturing research going on today. I will even offer some predictions.

\section{HISTORICAL BACKGROUND}

By tradition and broad public preference over the period from 1950 to 1990 , the U.S. government has not played a significant direct role in industrial affairs. Of course, government imposed tax policies and regulations have had a big effect, but in comparison to other industrialized nations, there has been relatively little governmental support for industry. The only interactions between business and government tended to be adversarial (that is, govemment was taxing or regulating industry), so the business community generally preferred less rather than more interaction. In order to understand this posture, one needs only to realize that U.S. supremacy in manufacturing was 
unchallenged for several decades following World War II. So, while other countries were pursuing aggressive industrialization policies, aided by a wide variety of government programs intended to stimulate development, the U.S. was content with things as they were. Therefore, for the last forty five years we have accepted the concept that business will thrive best if the role of government is minimized. These conditions prevailed so long that they came to be taken for granted. In fact, virtually all of the present workforce and management have spent their entire working careers knowing only these conditions.

Similarly, and for some of the same reasons, there has been relatively little interaction between universicies and industry over the same period. During the 1950's and 1960 's, most universities gradually eliminated their manufacturing laboratories and courses. Few American-educated students showed an interest in manufacturing, preferring instead the glamour of space, computers, and pure science. Manufacturing jobs were looked upon as routine, uninspiring, and inappropriate for college-educated people. The brightest young people, if they had any interest in a career in business, gravitated toward law, marketing, or finance. Most of our current corporate leaders came from such a background.

All of that began to change in the 1970's, when it became apparent that the rest of the industrialized world was catching up in manufacturing. Still, it was hard to break the patterns of thought and behavior that our entire population had grown up with. Through most of the 1980's, the mood was one of denial. Our failures were either blamed on others ("unfair practices") or rationalized as unimportant ("we are becoming a service economy anyway"). The Reagan and Bush administrations strongly resisted any form of industrial policy, believing that the best long run strategy is to allow free market forces to operate without government intervention. More and more, however, even the Bush administration came to accept the concept that a new relationship between government and industry was needed. Although there is still a deeply rooted bias in the American culture against direct federal involvement in private business, there is now widespread support for the idea that the government should engage in pre-competitive generic research that will benefit American industry.

We are now in a period of re-examination of our basic instrtutions and their role in promoting or facilitating industrial strength. The public, the political leaders, and industry itself have finally awakened to the importance of the task. We know that things have changed, but have not yet achieved consensus on what to do. Out of the many mixed views, conflicting directions, and imaginative proposals. I expect the U.S. to develop a strong, but still pluralistic, approach to industrial modernization.

\section{WHO SUPPORTS MANUEACTURING RESEARCH?}

There are many organizations, public and private, that purport to speak for the manufacturing community. In fact, to list them would require a large directory. For the most part, the companies that do manufacturing see themselves as independent of any of these organizations. Nevertheless, they are looking more openly toward partnership arrangements, and are attentive to what the universities and government are doing.

\section{A. Private Organizations}

In many companies, the term "research" is taken to mean "finding out what others have done", rather than "creating something new." This view is certainly appropriate for a company that wants to mimic the leaders (a reasonable strategy) or cannot afford its own original work. But it should not confuse us about the real meaning of research or 
distract us from concern about the creative energies that drive innovation. According to [1], approximately half of the total R\&D expenditures in the U.S. come from private industry. (Industry spends about three quarters of the R\&D, but part of this comes from the govermment) Of the roughly $\$ 89$ billion that private industry spends in R\&D, mostperhaps $\$ 70$ billion-is attributed to manufacturing. However, this accounting treats food, chemicals, lumber, petroleum, and many other industries as manufacturing, leaving only a few of the Standard Industry Classification industries as non-manufacturing. It is difficult to estimate what portion of privately funded R\&D is associated with is normally considered product manufacturing, and of that, what portion is really concerned with true innovation as opposed to routine product development and equipment replacement. However, it is safe to assume that the reported figures for the amount of money spent on $R \& D$ by industry grossly exaggerate the effort, simply because the category is so loosely defined.

In their best days, many of the giant corporations, such as General Motors, Ford, IBM, General Electric, AT\&T, and Xerox, maintained large research laboratories that conducted long range research only remotely related to company products. Most of those laboratories are greatly reduced today, and almost all of the work is pressured by immediate market demands. Perhaps because of the low stature of manufacturing during past decades, most of the privately supported research is related to product, rather than process, improvements. It has been reported and widely accepted that the balance between product and process research is roughly four or five to one in the U.S. versus the exact opposite proportions in Japan. [2]

Although attention naturally turns to large companies in discussions of research, small companies account for much of the infusion of new technology into the marketplace. Both as suppliers of new technology and as users who can adopt innovations more readily than large organizations, they often appear at the beginnings of the growth curves for new technology. The U.S. cherishes its small businesses. Compared to other countries, the U.S. makes it remarkably easy to start new businesses on a small scale, with a minimum of interference. Apple Computer and Microsoft are two examples of companies that started only about 15 years ago with the ideas and work of just a few people and grew quickly to industrial giants. Such success stories are held up as demonstrations that anyone can become rich in America through hard work.

Despite these extreme examples, most manufacturing companies are squeezed by economic forces that they cannot control and only dimly understand. For most, maintaining the broad based research to support innovation across their product and process lines in a sufficiently aggressive manner to remain competitive is simply too expensive. Consequently, they are turning more and more to various kinds of partnership arrangements. For example, Sematech (Semiconductor Manufacturing Technology) , a consortium of companies working together to keep semiconductor manufacturing competitive in the U.S., operates at a level of $\$ 200$ million annually. [3] The Department of Defense pays half the cost. MCC (Microelectronics and Computer Technology Corporation) is another large consortium, drawing $\$ 65$ million from 20 member companies. There are now many industrial consortia working on such technologies as batteries for electric vehicles, composites, plant biotechnology, and superconductivity.

There are, of course, many professional associations that deal with issues related to manufacturing research. They generate very little financial support for research, but have a lot to do with communications and professional networking. Prominent among these are the Society of Manufacturing Engineers (SME), the American Society of Mechanical Engineers (ASME), the Institute of Industrial Engineers (IIE), the Association for 
Manufacturing Technology (AMT, formerly the National Machine Tool Builders Association), the National Coalition for Advanced Manufacturing (NACFAM), the Electronic Industries Association (EIT), the National Association of Manufacturers (NAM), the Aerospace Industries Association (AIA), the National Electrical Manufacturers Associations (NEMA), and many more. I would not attempt to give a complete listing; only to illustrate that there are many.

Among the organizations of private citizens that give formal advice to the government, the National Academy of Engineering (NAE) and the National Academy of Sciences (NAS) carry particular authority, because their membership consists of the country's most distinguished scientists and engineers. The NAE has had a special emphasis on manufacturing in its program for the past seven or eight years. The most recent annual meeting reaffirmed this emphasis. [4] Although it does not engage in very many studies, it has funded a few that were directly aimed at identifying manufacturing research needs. [5, 6]

The National Research Council (NRC) is an independent organization, operated through the NAS and NAE, whose function is to conduct impartial studies on technical matters for the government. The Boards and Committees are constituted of experts in specific areas assembled carefully to reflect balanced viewpoints as well as technical expertise. Their reports are subjected to a formal review process before release to the public. Most of the manufacturing-related studies are carried out under the Commission on Engineering and Technical Systems (CETS). Under this Commission, there are thirteen Boards, including the Manufacturing Studies Board (MSB), the National Materials Advisory Board (NMAB), the Board on Army Science and Technology (BAST), and others. Recent studies include [7-9]. The Manufacturing Studies Board is currently considering an expansion of its traditional role.

Several private non-profit foundations, such as the Sloan Foundation, the Carnegie Commission, and the Hudson Institute have directed significant funds to the addressing the needs of manufacturing. [10]

\section{B. Universities}

As mentioned above, academic research in the U.S. has been mostly oriented in directions that had little to do with manufacturing. There has been a small and active community of university researchers; however, they have operated primarily as individuals. A few universities, including Purdue, the University of Wisconsin, Rensselaer Polytechnic Institute, MIT, Georgia Tech, and Ohio State, are noteworthy exceptions to the general pattern because they retained research and education programs in manufacturing through the years when others were eliminating them. Now, of course, most engineering schools are attempting to build up their capabilities in manufacturing, and many new research and education programs have been started in the last five years. The primary factor impeding this progress seems to be the limited availability of qualified faculty. Only a handful of universities have either research or education programs in manufacturing that involve more than a few faculty members. Of course in academic circles, small programs can be important. Individual professors of particular distinction, such as K. K. Wang at Cornell, Dell Allen at Brigham Young, Sam Wu at Michigan, Roger Nagel at Lehigh, and several others, have been influential forces in manufacturing research for several decades.

At least part of the reason for renewed interest in manufacturing on university campuses relates to funding pressures. Since the late 1950 's, when engineering began its uransition to a more science-based group of disciplines, it dependence on federal funding 
for research has grown steadily. Over the last fifteen years, federal funds for university research has grown from $\$ 4$ billion to $\$ 17$ billion. During this time, graduate programs in engineering (which, incidentally, have been increasingly populated by foreign-born students) were funded largely out of federal research funds. This system is now coming under close scrutiny to determine whether national interests are really best served by such a system. [11] It appears that federal funding for university research in general is likely to flatten out or even decrease over the next decade. On the other hand, the emphasis on economic competitiveness is likely to produce an increase in federal funding for manufacturing research. Funding from industry is virtually certain to take the same direction. The resulting shifts may produce a "last water hole in the desert" phenomenon, in which previously uninterested researchers begin to cluster around the only sources of support.

In attempting to establish credential for participating in the new priorities, many universities will undoubtedly relabel past work as manufacturing-related. Presently, I estimate that no more than $\$ 250$ million is being spent in universities on manufacturing research from both federal and industrial sources.

\section{Government}

The elections which have just passed are likely to unleash profound changes in the national priorities and mechanisms for research. Concern for the health of the economy and awareness of the more aggressive federal support by international competitors were prominent in the campaigns of all of the presidential candidates. Congress also "got the message" and will be eager to demonstrate positive actions.

\section{The President and the Executive Office}

The President and the branch of government that he controls, the Executive Branch, has a great deal of authority and latitude in carrying out programs within the limits established by Congress. Matters related to manufacturing technology are handled through the Office of Science and Technology Policy (OSTP), which is headed by the Assistant to the President for Science and Technology Policy (usually just called the President's Science Advisor). A good current reference on the views of the Bush administration Science Advisor, Dr. D. Allan Bromley, is [12].

Another important body in the Executive branch is the Federal Coordinating Council for Science, Engineering, and Technology (FCCSET- pronounced "fix-it"). It consists of high level executive branch officials and is charged with the responsibility of coordinating federal activities in science and technology that cut across the missions of more than one agency. It has existed for some time, but only during the last four years has taken on a more powerful role. Of particular importance for the present discussion is the FCCSET's method for bringing together agency activities in "crosscuts". A crosscut is a national initiative in some large technical area. Prior crosscuts involved Global Change, Math and Science Education, High Performance Computing, Advanced Materials, and Biotechnology. Manufacturing is scheduled to take effect as the next crosscut in 1994. Officially, FCCSET has no authority to either fund or require any particular actions. However, the mere fact that it focuses attention on a problem area and brings a sense of order to the subject tends to raise the priority of that area in the Congressional budgeting process.

Other organizations that have reported to the President on manufacturing issues are the President's Commission on Competitiveness, the Council on Competitiveness, and the Fresident's Council of Advisors on Science and Technology (PCAST). Just recently a 
new organization called the Critical Technologies Institute was created to conduct strategic planning. It remains to be seen, at the time of this wring, what effect the Clinton administration will have upon these organizations. Many observers believe that large changes are likely. The pre-election Clinton plan promised to "create a civilian advanced technology agency modeled after the successful Defense Advanced Research Projects Agency (DARPA)." [13]

\section{Congress}

Congress controls, through appropriations, the money that is available for use by the agencies of the federal government. In addition to a complicated set of committee and staff work, Congress receives advice from the National Research Council (mentioned above) and another organization called the Office of Technology Assessment (OTA). This organization, like the NRC, provides impartial technical advice, but it responds only to requests from Congress. A recent OTA report on the manufacturing needs of the country [14] documents the nature of the problem and makes several policy recommendations .

Both the House of Representatives and the Senate have members who are vocal advocates of manufacturing research and the institurions that support it. Representative George E. Brown, Jr., who is chairman of the Committee on Science, Space, and Technology recently published a very thoughtful paper on the way that the research community must adjust to address social needs. [15] Senators Bingaman, Hollings, and Rockefeller have been strong advocates of various new ideas in supporting manufacturing innovation.

Overall, there is great concern in the Congress that the traditional modes of conducting research are not as effective as they should be. In a time of tight budgets, they are looking for new approaches that are both less expensive and more productive.

\section{The Department of Commerce}

The governmental agency most naturally responsible for commercial activity would be the Department of Commerce. Historically, however, it has been more concerned with regulation than with research or innovation. However, within the Department of Commerce is an organization now called the National Institute for Standards and Technology (NIST), formerly the National Bureau of Standards. The name change, which came in 1988 as part of a congressional bill entitled the "Omnibus Trade and Competitiveness Act" clearly signaled the intention of Congress to change the basic mission and attitude of the Department of Commerce.

Since the 1970's, a group of programs under the Manufacturing Engineering Laboratory (MEL) has conducted standards-related research (broadly construed) in advanced manufacturing. It constructed a test and demonstration facility called the Advanced Manufacturing Research Facility (AMRF). This facility and the people associated with it provided an exemplary model which attracted a good deal of national attention.

Partly because of the visible success of the AMRF, Congress instituted a program for Manufacturing Technology Centers (MTCs) whose original purpose-since broadened-was to serve as regional technology transfer sites to move the resulis of NIST research into use. There are currently seven MTCs administered through NIST, and there are plans for up to fifty. Another program administered by NIST, aimed more at 
supporting particular R\&D projects by groups of companies, is the Advanced Technology Program (ATP). Thirty eight of these awards were made in 1991 and 1992. One example is the ATP on Rapid Response Manufacturing, conducted through the National Center for Manufacturing Sciences (NCMS) in Ann Arbor, Michigan, and involving Texas Instruments, Ford, General Motors, United Technologies, Oak Ridge Laboratory, Parametric Technology, Spatial Technology, Aries, CIMPLEX, ICAD, and CIMFlex Teknowledge. Even in a tight budget year, Congress saw fit to increase funding for these NIST programs by $55 \%$ in FY '93. [16]

\section{The Department of Defense}

The Department of Defense (DOD) is struggling with the issue of downsizing the entire military establishment in the wake of the end of the cold war. [17-19] This is a massive adjustment that affects the entire economy. Even leaving aside the political pressures to maintain unneeded activities for the sake of preserving jobs, the challenge is enormous. For example, if the military services were to live off of inventories for the next ten years, the suppliers of military products would go out of business. Then, when they might be needed, there would be neither capacity nor capability to produce highly specialized military products. Furthermore, there is recognition that future conflicts are likely to take a different form. The DOD is charged with the responsibility for maintaining whatever military capability might be needed, but to do so with a budget that is reduced by at least one third.

A few simple concepts seem to dominate the discussions of basic strategy in reducing the cost of defense. One is the greater use of civilian suppliers for all but the most specialized military products. In terms of the technologies supported by the R\&D expenditures, a priority will be placed on so-called "dual-use technologies," so that the costs and benefits of the research can be shared between the civilian and military sectors. A study commissioned by the Office of the Secretary of Defense Manufacturing Technology (MANTECH) program and carried out by a group of industry representatives led to a vision of "agile manufacturing" that would service both civilian and military needs. [20] Another basic strategy is to be ready to produce quickly in time of need, but avoid investing more in actual production than is absolutely necessary. This means that new weapons systems will continue to be developed to the stage of proven effectiveness and then put "on the shelf" in readiness for full scale production. The effect of this strategy will be to reduce procurements, but preserve or even slightly increase the R\&D expenditures.

Historically, each of the services has maintained separate programs to improve the manufacturing base that supplies military products. They have been conducted relatively independently. For example, the Air Force Manufacturing Technology (MANTECH) program focuses on the industries that supply Air Force weapons systems, the Army MANTECH program on Army needs, and so forth. Research in advanced technologies that would be applicable to all services has been supported by the Defense Advanced Research Projects Agency (DARPA). With the reexamination of the roles of these various programs in the light of the downsizing pressures, it appears that relatively more of the research will be managed centrally. At the least, the MANTECH programs will be more closely coordinated than they were in the past.

Partly as a result of past successes in developing advanced technology for military applications (with many side benefits to civilian applications), Congress and many outside commentators have been advocating a "civilian DARPA" to address the research needs of manufacturing. The best current reference on Congressional thinking on this 
issue that I am aware of is by Senator Bingaman. [21] As mentioned earlier, the Clinton plan also uses similar language. It seems likely that something new along these lines will emerge in the months ahead. Whether this will take the form of an entirely new agency, a revised mission for DARPA, NIST, or NSF, or some coordinating body for the existing agencies remains to be seen. The most recent (FY '93) defense appropriations bill contained provisions for several hundred million dollars worth of programs in extension centers, dual use technologies, and manufacturing education.

\section{The National Science Foundation}

Compared to other agencies, the National Science Foundation does not have much money to spend. However, NSFs influence is great, because of the respect it commands and its role as the primary source of university research funding. Out of a total budget of about $\$ 2,500$ million, approximately $\$ 90$ million goes to fund research that can by some stretch of imagination be associated with manufacturing. If one were really being strict, perhaps one third to one half of that would be something that manufacturing companies would see as relevant to their needs.

Most of the manufacturing research is carried out through the Engineering Directorate, a smaller portion through the Computer and Information Science and Engineering Directorate, and just a little in five other directorates. In the Engineering Directorate, there is a Division of Design and Manufacturing Systems, which supports individual investigators through three programs: Operations Research and Production Systems, Design and Computer Integrated Engineering, and Manufacturing Processes and Equipment. The annual budget for the Division is around $\$ 6.5$ million. There has been an annual Grantees meeting for the investigators in this program for the past fifteen years. The most recent Proceedings [22] contains 175 reports of grants to single investigators or small teams.

The NSF started in 1985 a program to establish Engineering Research Centers. These are large cross-disciplinary university-based centers focused on various topics of importance to national economic competitiveness. Each has funding from NSF and industry totaling from $\$ 2$ to $\$ 5$ million per year. There are currently eighteen ERCs, of which four relate directly to manufacturing. They are managed through the Division of Engineering Education and Centers (until recently called the Division of Cross Disciplinary Research), within the Engineering Directorate. The ERCs have been independently evaluated by several study groups and found to be fulfilling their intended goals well. [23]

Table 1. NSF Engineering Research Centers Focused on Manufacturing

\begin{tabular}{|l|l|}
\hline \multicolumn{1}{|c|}{ University } & \multicolumn{1}{c|}{ Theme } \\
\hline Carnegie Mellon & Engineering Design \\
Ohio State University & Net Shape Manufacturing \\
Purdue & Intelligent Manufacturing Systems \\
Wisconsin & Plasma-Aided Manufacturing \\
\hline
\end{tabular}

Using the Purdue ERC as an example, the Engineering Research Center for Intelligent Manufacturing Systems conducts an integrated cross-disciplinary program of research, education, and industrial interaction involving over sixty companies, forty faculty members, and two hundred students. There is a long range strategic plan to create, implement, and educate personnel for a new generation of manufacturing capability called Intelligent Manufacturing Systems. The concept involves an integrated 
enterprise which is capable of responding quickly and correctly to changing requirements. ("Agility" and "rapid response manufacturing" are terms appearing recently that refer to much the same issues.)

Another program that is operated through the same Division of NSF is for IndustryUniversity Cooperative Research Centers (IUCRCs). These involve relatively minor start-up funding from NSF and must become essentially self-supporting through industry memberships. Their research agendas are driven by the member companies. About 50 of these now exist, of which the seven shown in the table below relate directly to manufacturing. Only $\$ 4$ million of NSF funds support all of the IUCRCs.

Table 2. NSF IUCRCs Focused on Manufacturing

\begin{tabular}{|l|l|}
\hline \multicolumn{1}{|c|}{ University } & \multicolumn{1}{c|}{ Theme } \\
\hline Georgia Tech & Material Handling \\
U. of Southern California & Manufacturing Automation \\
U. of Michigan & Optical and Mechanical Measurement \\
U. of Connecticut & Grinding \\
Ohio State U. & Welding \\
Iowa State U. & Non-destructive Evaluation \\
Oklahoma State U. & Web Handling \\
\hline
\end{tabular}

Another variation of the centers concept is found in the State IUCRCs. These centers involve matching funds from states as well as industry in three equal shares. The program is new; there are currently six.

A program called the Strategic Manufacturing Initiative, administered through the Division of Design and Manufacturing Systems, funds medium sized groups to work on issues identified as strategically important to manufacturing. [24] A somewhat similar program exists in Canada's NSERC (Natural Science and Engineering Research Council of Canada), which is the Canadian equivalent of NSF. It is called the Strategic Grants Program for Advanced Technologies and funds work in information systems; biotechnology; industrial materials, products, and processes; manufacturing systems; and energy.

The NSF is currently considering its future role in supporting research. The Director, Walter Massey, laid out three options: (1) to revert to its traditional base as a small agency supporting individuals and small groups, (2) to continue its present course of exploratory and special programs, such as centers, or (3) to expand its role with a broader portfolio, including areas of economic priority. A special Commission was formed to study the options and report before the end of 1992. The entire research community is presently wrestling with the implications of the three options. [25] Meanwhile the National Science Board, which is the governing board of the NSF, recently issued a report that seems to endorse the third option. [26] An indication of Congress' view is contained in this year's appropriations bill. The overall funding was essentially flat at $\$ 2,733$ million; with certain funding restrictions specified by Congress, there is actually less available than last year. There was language in the bill, kept out at the last minute, that would have placed minimum funding linuts for manufacturing, highspeed computing, and interdisciplinary environmental science.

\section{The Department of Energy}

One might be surprised to see the Department of Energy even mentioned in connection with manufacturing research. It is not obvious from either its name or its past 
emphasis that the DOE would be involved. However, it is likely that the agency will have a lot to do with future manufacturing research in the U.S. The reason is that the agency has created some 21 large national laboratories with an array of talent and facilities that are truly impressive. They employ 23,000 scientists and engineers, have $\$ 100$ billion worth of facilities in place, and have annual budgets totaling $\$ 22$ billion (drawing from many sources, but especially defense). DOE's budget for research this year is about $\$ 2.4$ billion. In the past, their efforts were focused on nuclear power and weapons systems, but these missions are generally viewed, rightly or wrongly, as declining in importance. As the funding for these missions declines, the labs will almost surely try to reorient to civilian needs, including manufacturing. It remains to be seen whether they can adjust to such radically different requirements.

The largest labs, which are most likely to play a major role in manufacturing R\&D, are Sandia Laboratories (with an annual budget of $\$ 1.2$ billion and 3600 researchers), Lawrence Livermore (with $\$ 1.1$ billion and 3300 researchers), and Oak Ridge (\$0.5 billion and 2000 researchers).

\section{States}

All of the states have programs that support science and technology development, with perhaps a greater emphasis on technology transfer than original research. The Benjamin Franklin Institutes in Pennsylvania and the Edison Institutes in Ohio are among the most prominent of these. Prior to 1980 , only three states had such programs; by 1991 , every state had created one. Figure 1 reflects this rapid growth during the 80 's. Usually these programs are aimed more at economic development than at research per se. That is, the motives for funding work have more to do with creating an attractive climate so that companies will locate within the state than with creating knowledge and sharing it broadly.

Figure 1. The Growth of State Programs for Industrial Support

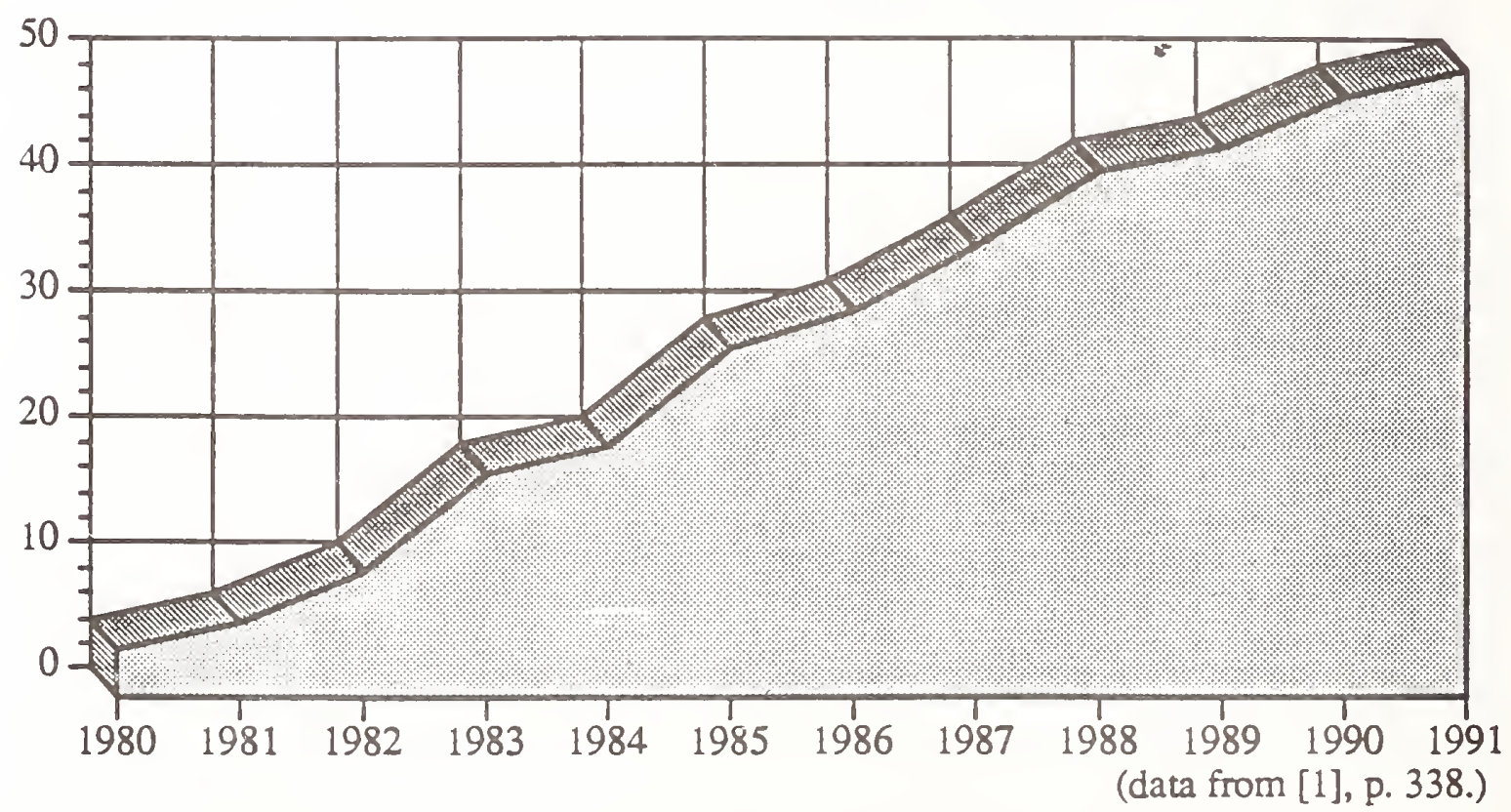




\section{E. Funding Summary}

In table 3 below, I have attempted to estimate how much is spent on manufacturing R\&D by the various govemment agencies, drawing upon a number of sources. I have also indicated by arrows my own guesses about whether the amounts are likely to increase, decrease, or stay about the same. Before interpreting these data, I must emphasize that the figures are highly questionable even as estimates. For example, I know that a lot of the research that is categorized as manufacturing R\&D in the National Science Foundation is placed there only because it is administered by the Division of Design and Manufacturing Systems, while in reality a good deal of the research in this program has little to do with manufacturing. Other agencies are similar. These flaws in the data are not deliberate deception; they are simply artifacts of the accounting procedures.

Table 3. 1992 Expenditures in Manufacturing (in \$ millions)

\begin{tabular}{|c|c|c|c|c|c|c|}
\hline Source & \multicolumn{2}{|c|}{ Total Budget } & \multicolumn{2}{|c|}{ R\&D Expenditures } & \multicolumn{2}{|c|}{ Manufacturing } \\
\hline $\mathrm{DOD}$ & $\$ 300,000$ & $t_{1}$ & $\$ 38,000$ & $q^{\pi}$ & $\$ 553$ & 7 \\
\hline DOE & 11,400 & $\star_{1}$ & 6,000 & \pm & 501 & 7 \\
\hline $\mathrm{DOC}$ & 3,000 & $T^{\top}$ & 550 & $\nabla^{7}$ & 104 & $r^{7}$ \\
\hline NSF & 2,700 & $\leftrightarrow$ & 1,900 & $\infty$ & 90 & 7 \\
\hline Other Federal & 883,000 & $\rightarrow$ & 11,000 & $\rightarrow$ & 153 & 7 \\
\hline Total Fed. & $1,200,000$ & $\leftrightarrow$ & 68,000 & $m$ & 1,400 & 7 \\
\hline Non-Federal & $4,300,000$ & - & 89,000 & - & 70,000 & - \\
\hline Total U.S. & $\$ 5,000,000$ & (NP) & $\$ 157,000$ & & 71,400 & 9 \\
\hline
\end{tabular}

In absolute terms, it is clear that the Department of Defense and the Department of Energy are the largest federal supporters of Manufacturing R\&D, although even these pale by comparison to the private sector. Figure 2 illustrates the agency comparisons.

Figure 2. Federal Support for Manufacturing R\&D, 1992 (in \$ millions)

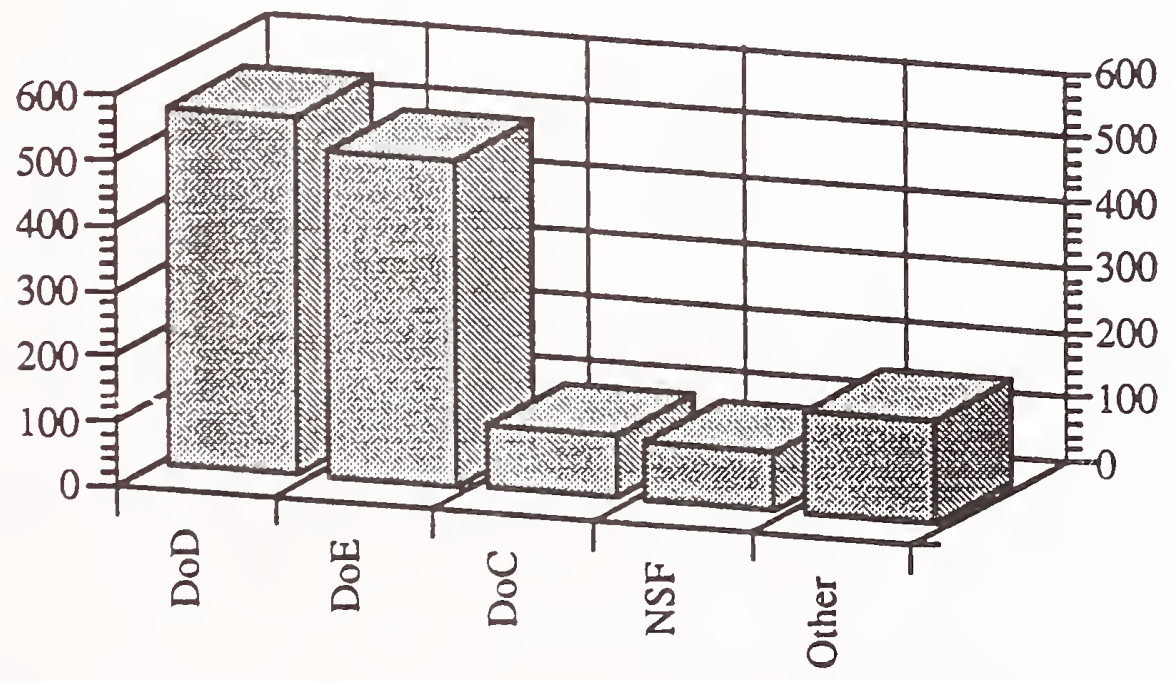


A different picture emerges, however, if one looks at the relative fraction that manufacturing R\&D is relative to total R\&D, as shown in Figure 3. Here, the Deparment of Commerce stands out. Yet another picture appears if one compares the manufacturing R\&D budgets to the total budget of the agency, as shown in Figure 4 . The Department of Energy, the Deparment of Commerce, and the National Science Foundation all spend about three to four percent of their total budget on manufacturing R\&D, while the Department of Defense and other agencies spend only tiny fractions of their budgets in this category.

Figure 3. Fraction of R\&D Budget Devoted to Mfg. R\&D, 1992

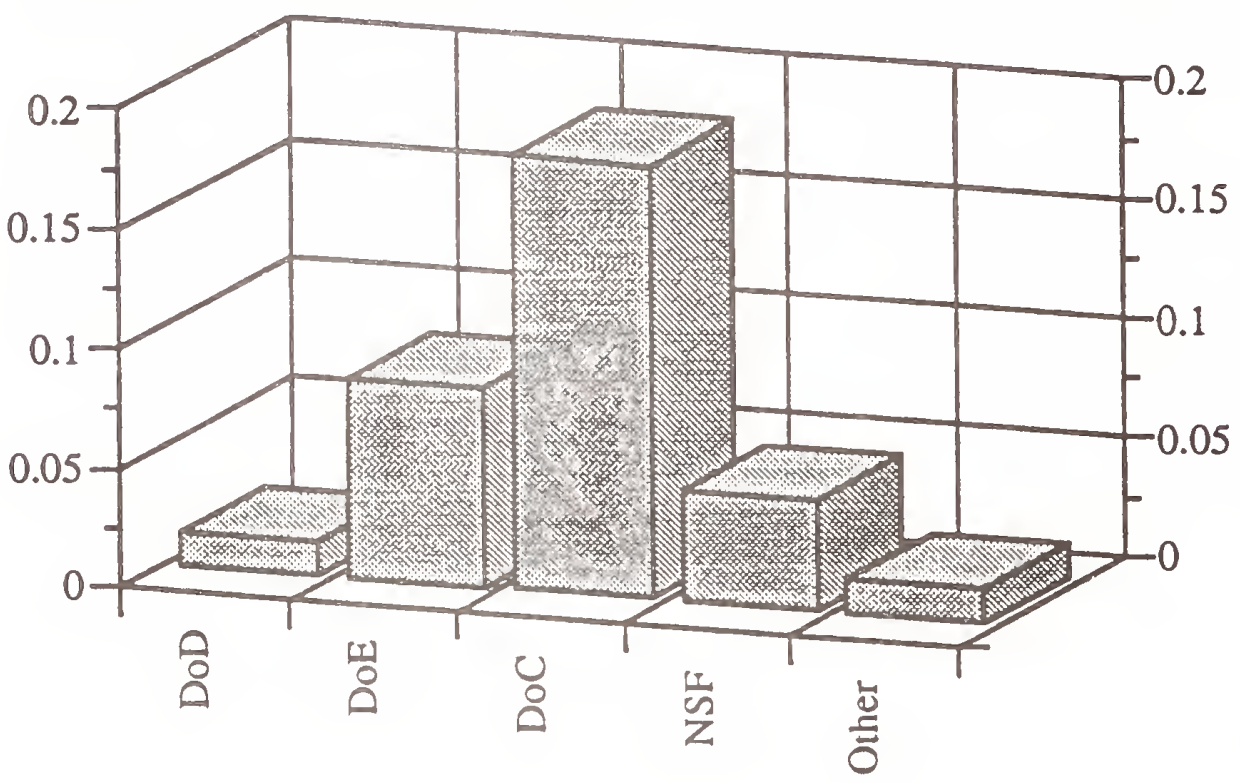

Figure 4. Fraction of Total Budget Devoted to Mfg. R\&D, 1992

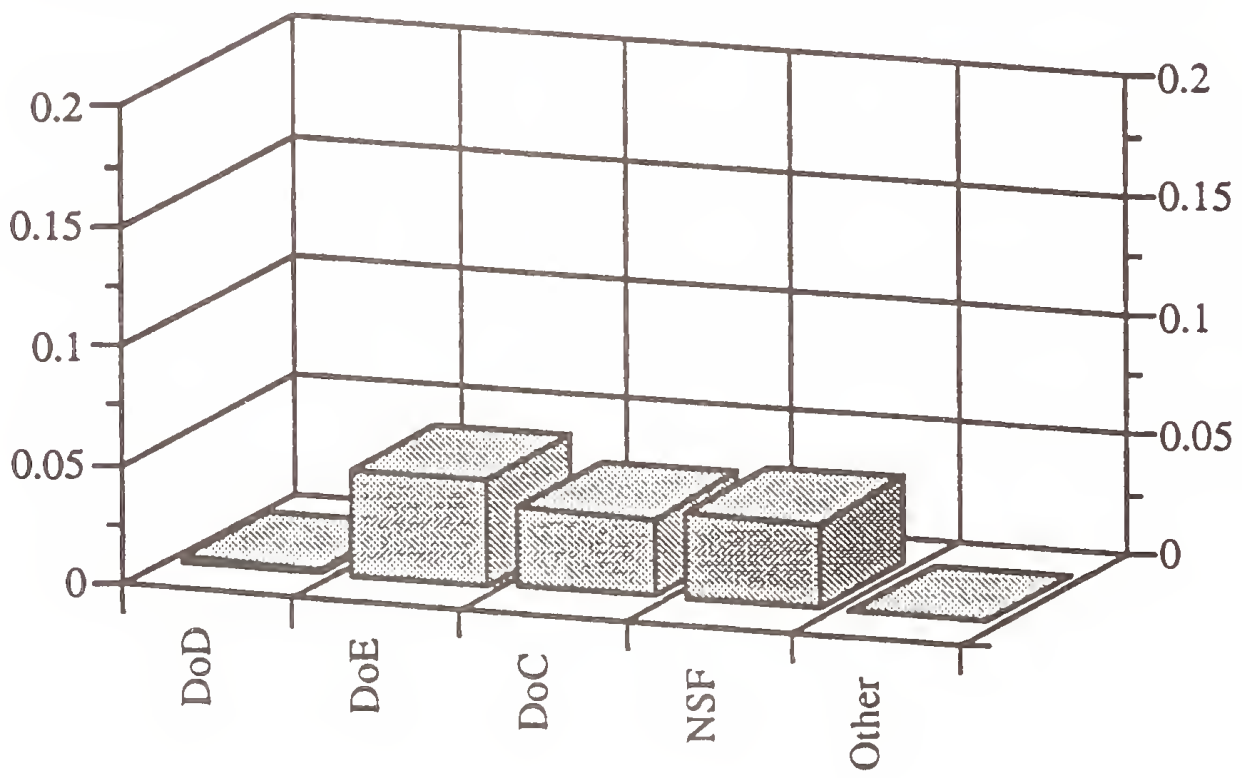




\section{THEMES}

The U.S. has acknowledged its manufacturing problems and is attempting to do something about them. This fact alone is significant because it was not true five years ago. Along with the obvious fact that foreign competitors were capturing market share in U.S. markets, domestic companies have come to realize (slowly at first) that the basis of competition is not price alone. First, there was a realization in the past decade that our products were sometimes inferior in quality to what the best in the world could offer. This realization led to a broad-based "quality movement" that has now reached almost every manufacturing company in the U.S. Then, just within the past three or four years, companies began to realize that speed was also an important factor. "Time-to-market" and "time based competition" became driving influences for change in the product development process. Many companies have now gone beyond time, cost, and quality criteria to more abstract aspects of competitiveness, such as flexibility and volumeindependence. The important point is that the companies have discarded the old simplistic, one-dimensional notion of cost-based competition and replaced it with a still evolving but much more sophisticated notion of multi-dimensional competition.

If there is any single issue that dominates all others, it would be change. Virtually all aspects of manufacturing are being reexamined, from the processes and technologies employed to the scope, scale, and organization of companies.

\section{A. Technical Issues}

As manufacturing companies have struggled with the fundamental issues of what to keep, what to discard, and what to create, the research community has also attempted to sort out priorities for manufacturing R\&D. Almost all of the many organizations that deal with manufacturing research have issued reports in the past two years that attempt to lay out strategic agendas for future work. Most of the studies call attention to the fact that the problem is not entirely technical.

Several organizations have produced lists of "critical technologies" that deserve special emphasis for reasons of national interest. [27] Manufacturing always appears on these lists, along with such issues as communications networks or new materials. In Table 4, I have extracted the manufacturing-related themes mentioned in several of these studies and noted the commonalities. Having participated in numerous workshops where such lists were generated, I can attest to two contrasting conclusions. First, one has to be very cautious about taking such lists as true indicators of the most important issues. The workshop format tends to produce a kind of lowest-common-denominator conventional wisdom, rather than inspired thinking or deep analysis. Also, they are political events, with advocates of certain kinds of research speaking for their own interests. Secondly, despite these wamings and despite differences in these lists, I detect that there is a shared sense of what needs to be done.

First, there is a great need for much better understanding of basic manufacturing processes. Most are poorly understood by scientific standards, and obtaining better control and improved quality from them requires much more than the experience-based knowledge that manufacturers now rely upon. New processing methods, such as micro and nano-fabrication or composites forming, promise to open up whole new methods of manufacturing. We need new kinds of sensors and the methods to interpret the data they produce. In these areas and others, the critical technologies lists suggest a rich research agenda at the processing level.

Another category of need focuses on the product development process, with an emphasis on speed. There are fundamental issues of design representation, software 
integration, rapid prototyping, simulation and modeling, and knowledge capture that all could contribute to much faster development of products. These information-intensive activities are also key to achieving the "agility" or "intelligence" that many companies aspire to.

The theme of integration is another common thread. Integration of computer programs (which are notoriously incompatible), integration of the design to manufacturing transition, integration of customers and suppliers to the manufacturing organization, and integration of enterprises are all variations on the same theme. Many of the studies call out "systems behavior" or "systems management" as critical issues, suggesting a widespread feeling that out methods have not brought enough together to deal with the complexities that modern manufacturing involves.

These days, almost all technologies involve computers, so it is not surprising that computer hardware and software issues appear on the critical technologies lists. However, one must not assume that programming current knowledge is sufficient. In many if not most cases, current manufacturing practices are so ad hoc that to automate them would only speed up the rate of mistakes.

Table 4. Critical Technologies Lists Compared.

\begin{tabular}{|c|c|c|c|c|c|c|}
\hline Theme & $\begin{array}{l}\text { National } \\
\text { Critical } \\
\text { Tech. }\end{array}$ & $\begin{array}{l}\text { Counctl on } \\
\text { Compet. } \\
\text { Crit. Tech. }\end{array}$ & $\begin{array}{c}\text { Commerce } \\
\text { Emerging } \\
\text { Tech. }\end{array}$ & $\begin{array}{l}\text { DOD } \\
\text { Critical } \\
\text { Tech. }\end{array}$ & $\begin{array}{l}\text { NSF } \\
\text { STRAT- } \\
\text { MAN }\end{array}$ & IMS \\
\hline $\begin{array}{l}\text { Manufacturing Processes } \\
\text { Micro and Nanotechnology } \\
\text { Advanced Sensors } \\
\text { Precision Engineering } \\
\text { Process Modeling } \\
\text { Flexible Manufacturing } \\
\text { Intelligent Machines \& Robotics } \\
\text { Clean Manufacturing }\end{array}$ & $\begin{array}{l}x \\
x\end{array}$ & $x$ & $x$ & $x$ & $x$ & $\begin{array}{l}x \\
x \\
x \\
x\end{array}$ \\
\hline $\begin{array}{l}\text { Design Methodology } \\
\text { Integrated Product/Process Dev. } \\
\text { Rapid Prototyping } \\
\text { Product \& Process Representation }\end{array}$ & & $x$ & & & $\begin{array}{l}x \\
x \\
x \\
\end{array}$ & $\begin{array}{l}x \\
x \\
x \\
\end{array}$ \\
\hline $\begin{array}{l}\text { Software/Integration } \\
\text { Software Development } \\
\text { Simulation } \\
\text { Sensor Fusion } \\
\text { Arificial Intelligence } \\
\text { Enterprise Integration }\end{array}$ & $\begin{array}{l}x \\
x \\
x\end{array}$ & $x$ & $x$ & $\begin{array}{l}x \\
x \\
x\end{array}$ & $\begin{array}{l}x \\
x\end{array}$ & $\begin{array}{l}x \\
x \\
x \\
x \\
\end{array}$ \\
\hline $\begin{array}{l}\text { Humar and Organizational } \\
\text { Human-Machine Interaction } \\
\text { Teams } \\
\text { System Management } \\
\text { Global Manufacturing }\end{array}$ & $x$ & & & & $x$ & $\begin{array}{l}x \\
x \\
x \\
x \\
\end{array}$ \\
\hline
\end{tabular}

\section{B. Infrastructure Issues}

There is also a good deal of agreement on some of the non-technical needs. We know that, compared to other indusurialized nations, we are slow and inefficient in implementing the results of our research. We feel generally confident about our ability to 
invent new things, but are frustrated by an apparent inability to gain a commercial advantage.

We are also frustrated by obvious weaknesses in our educational system, particularly with respect to mathematics and science. We feel that our university system is among the best in the world, but the elementary, high school, and vocational training systems are far below world standards.

We are only beginning to comprehend what it means to compete globally. Americans are unaccustomed to thinking of non-U.S. markets, so product designs, distribution, and marketing methods are often ill-suited to the foreign customer. Because there is no systematic program or government support, each company learns its own lessons the hard way.

All of these challenges are also opportunities. We are responding to our perceived weaknesses in ways that would have been hard to imagine ten years ago. There are many new experiments in infrastructure support for technology deployment, workforce education, globalization, and collaborative research. The old view that each company is best off taking care of its own needs is largely discredited now. In its place is a new search for strategic partnerships. The regulations that previously inhibited joint ventures (based on anti-trust fears) have been greatly relaxed. Many forms of partnerships are being tried, including company to company, groups of companies either within or between industry sectors, company to university, and many other forms. We are working out new ways to deal with the apparently contradictory notions of competition and collaboration.

\section{Emergent Issues}

Compared to both European and Asian efforts, the U.S. has placed remarkably little focus on research involving human issues. We still tend to emphasize technologies that replace workers or lower the level of skill required, instead of improving the skills of the workers. Most companies have now learned-some at great expense-that no technological improvement can succeed without the help of a prepared and willing workforce.

However, our research community has not yet focused on research contributions that would help with this problem. It demands not ergonomics or work methods, but a whole new approach to human factors research. Take, for example, the question of how to prepare an organization for a major innovation, viewed as a design problem. Field studies, designed experiments, and models could provide very helpful guidance in this common problem faced by industry. Although there is currently very little research activity along these lines, I predict that a new kind of human factors will emerge as a major research issue

Another class of issues that will grow enormously over the next decade is that related to environmental issues. Whether by choice or by force of law, manufacturing companies will have to contend with a host of issues that affect the design of products, the use of processes, the recycling of materials, the control of by-products, and systems to account for all of these things.

Finally, I would like to suggest that there is a beginning of a whole new way to look at manufacturing problems, generated out of the failures of the past. We have learned that reductionism does not work very well in the complicated world of contemporary manufacturing. That is, our standard method of breaking a complex problem down into 
manageable pieces and then working on the pieces independently does not yield results that make much sense in the whole. We have also leamed that none of these problems are susceptible to one-time solutions. None of the buzzword, slogan, and "silver bullet" approaches of the last decade has delivered on its promise. What we need is a way to work on problems gradually and holistically. Instead of looking for solutions, we need to be able to synthesize workable pathways to sustainable, continuous improvement. The methods that would allow and support such an approach is a research issue in itself.

\section{REEERENCES}

1. National Science Board, Science and Engineering Indicators - 1991. 10th ed. Washington, D.C.: U.S. Government Printing Office, 1991.

2. National Center for Manufacturing Sciences, Focus. Ann Arbor, Michigan: NCMS, May, 1992.

3. Corcoran, E., Semiready: A Consortium Prepares for the Second Half of the Battle. Scientific American, 267, 5, November, 1992. 121-122.

4. White, R.M. In Search of Technology Strategy. in 28th Annual Meeting. Washington, D.C.: National Academy of Engineering, 1992.

5. Compton, W.D., ed. Design and Analysis of Integrated Manufacturing Systems. Washington, D.C.: National Academy Press, 1988.

6. Heim, J.A. and W.D. Compton, ed. Manufacturing Systems: Foundations of World Class Practice. Washington, D.C.: National Academy Press, 1992.

7. National Research Council, Manufacturing Studies Board, Toward a New Era in U.S. Manufacturing: The Need for a National Vision. Washington, DC: National Academy Press, 1986.

8. National Research Council, The Competitive Edge: Research Priorities for U.S. Manufacturing. Washington, D.C.: National Academy Press, 1991.

9. National Research Council, STAR 21: Strategic Technologies for the Army of the Twenty-First Century. Washington, DC: National Academy Press, 1992.

10. Costello, R.B. and M. Emst, Regaining U.S. Manufacturing Leadership. Indianapolis, IN.: Hudson Institute, 1992.

11. Marshall, E. and J. Palca, Cracks in the Ivory Tower. Science, 257, 28 A ugust, 1992. 1196-1201.

12. Bromley, D.A., Science, Scientists, and the Science Budget. Issues in Science and Technology, 1992. (Fall), 41-48.

13. Clinton, B. and A. Gore, Putting People First. New York: Times Books, 1992. 
14. U.S. Congress and Office of Technology Assessment, Making Things Better:

Competing in Manufacturing. Washington, DC.: U.S. Government Printing Office, 1990,

15. Brown, G.E., Rational Science, Irrational Reality: A Congressional Perspective on

Basic Research and Society. Science, 258, 9 October, 1992. 200-201.

16. Marshall, E. and D.P. Hamilton, $R \& D$ Budget Collides With the Deficit. Science, 258, 9 October, 1992. 208-209.

17. U.S. Congress, Office of Technology Assessment, Redesigning Defense: Planning the Transition to the Future U.S. Defense Industrial Base. Washington, DC: U.S.

Government Printing Office, 1991.

18. U.S. Congress, Office of Technology Assessment, American Military Power: Future Needs, Future Choices--Background Paper. Washington, DC: U.S. Government Printing Office, 1991.

19. U.S. Congress and Office of Technology Assessment, Building Future Security: Strategies for Restructuring the Defense Technology and Industrial Base. Washington, D.C.: U.S. Government Printing Office, 1992.

20. Nagel, R. and R. Dove, 21st Century Manufacturing Enterprise Strategy, vol I and 2. Bethiehem, PA: Iacocca Institute, Lehigh University, 1991.

21. Bingaman, J. and B.R. Inman, Broadening Horizons for Defense R\&D. Issues in Science and Technology, 1992. (Fall): p. 80-85.

22. National Science Foundation, ed. Proceedings of the 1991 NSF Design and Manufacturing Systems Conference. Dearborn, MI.: Society of Manufacturing Engineers, 1991.

23. National Academy of Engineering, Assessment of the National Science Foundation's Engineering Research Centers Program. Washington, D.C.: National Academy of Engineering, 1989.

24. National Science Foundation, Research Priorities for Proposed NSF Strategic Manufacturing Research Initiative. Washington, D.C.: National Science Foundation, 1987.

25. Marshall, E., NSF: Being Blown Off Course? Science, 258, 6 November, 1992. 880882.

26. National Science Board, The Competitive Strength of U.S. Industrial Science and Technology: Strategic Issues. Washington, D.C.: National Science Board, 1992.

27. Mogee, M.E., Technology Policy and Critical Technologies. Washington, D.C.: The Manufacturing Forum, December, 1991. 

N I S T Manufacturing Systems

Research and Development

Workshop

Rockville, Md. November 3-5, 1992

\section{WESTERN EUROPEAN R\&D FOR \\ MANUFACTURING SYSTEMS}

Prof. Dr.-Ing. Bernd E. Hirsch

and

Dipl.-Soz. B. Hamacher

Dr.-Ing. K.-D. Thoben

B I B A

Bremer Institut fuer Betriebstechnik und angewandte Arbeitswissenschaft an der

Universitaet Bremen (Germany)

Tel.: +494212183384

Fax : +49 4212185510 


\section{TABLE OF CONTENTS}

0.

1.

1.1 The Programmatic Approach of the European Community for R\&D for Manufacturing Systems

1.1.1 From Single Research Projects to a European RTD-Framework Programme

1.1.2 Relevant R\&D programmes for Manufacturing Systems within the European Framework Programme

1.1.2.1 ESPRIT

1.1.2.2 BRITE/EURAM

1.1.2.3 RACE

1.1.2.4 Other relevant programmes

1.1.3 National R\&D-programmes for Manufacturing Systems in Western Europe

1.1.3.1 Overview

1.1.3.2 Coordinating Bodies

2. EUROPEAN INSTITUTES IN THE FIELD OF R\&D FOR MANUFACTURING SYSTEMS

3. RESEARCH AFTER MAASTRICHT: THE POLICY OF THE EUROPEAN COMMUNITY FOR EUROPEAN RTD

4. UNMET NEEDS AND OPPORTUNITIES IN WESTERN EUROPEAN R\&D

4.1 Global Needs for Future Cooperative Production Systems

4.2 Business and Economic Needs

4.3 One-of-a-Kind-Production Systems

4.4 Enterprise Integration and Enterprise Cooperation 
4.5 Environmental Life-Cycle Analysis for Product and Production Systems

4.6 Performance assessmient on the Basis of Scenario Techniques

4.7 Long Term Re-assessment of Industrial Potentiai

e.g. Maritime Industries

5. THE POTENTIAL FOR COLLABORATION FOR RTD IN THE PERSPECTIVE OF INCREASING GLOBALIZATION

LIST OF REFERENCES

LIST OF FIGURES 


\section{SUMMARY}

Research and Technology Development (RTD) in Western Europe is funded by public programmes. Of particular relevance to Advanced Manufacturing Technologies (AMT), a series of programmes has been initiated within the last ten years by the Commission of the European Communities (CEC) in order to coordinate RTD-activities on a European level.

This paper starts with a brief description of the RTD Framework-Programme of the Commission of the European Communities (CEC) and the major research programmes included. Subsequently an attempt is made to scan the major national activities for AMT in Western Europe, even though it is obviouly difficult to be complete and accurate.

In the second section AMT research institutes in Europe will be briefly presented to give an impression of the European competence and capacities. Again it is not claimed to be comprehensive as there are inventories on a European scale not yet available. More or less it reflects the overview of the authors compiled from own project cooperations.

The third section sketches motivations and European strategies in R\&D within this decade. The RTD-Framework of the CEC as a follow-up of the negotiations about the Treaty of Maastricht, will be described.

The fourth section outlines some unmet needs and shortcomings in the current R\&D activities. Of course, this is biased by the experiences and perceptions of the authors in this field.

Finally the fifth section describes the R\&D potential for cooperation in the light of the ongoing globalization of markets. 
1.

\section{RESOURCES FOR WESTERN EUROPEAN RESEARCH PROGRAMMES FOR MANUFACTURING SYSTEMS}

Up to the early eighties, Research and Development (R\&D) for manufacturing systems was mainly supported and managed independently by several national R\&D programmes in each European country. These programmes were, and are, usually public programmes, initiated and managed by national government organizations and oriented towards the needs of the respective national industries.

Up to the beginning of the eighties the European administration, namely the Commission of the European Communities (CEC) in Brussels, was not concerned with manufacturing industry oriented R\&D programmes on a broad scale. Early activities of the CEC were limited to the civil usage of nuclear power (EURATOM, CERN) and a European programme for aeronautics and space technologies, coordinated by the European Space Agency (ESA).

Although Article 235 of the European Economic Community (EEC) Treaty from 1957 gives the CEC the general opportunity to generate and develop policies for industrial $R \& D$, in the sixties and seventies this legal basis was not employed to set up industrial R\&D programmes.

A change in that understanding emerged with the "European Strategic Programme for Research and Development in Information Technology - ESPRIT". This programme, established in 1983, was the first R\&D programme at the community level aimed at the development and dissemination of information technology for European industry.

The rules and procedures for cooperation between industry and university, precompetitive research and goal oriented projects, developed by ESPRIT, created a pattern for most of the subsequent R\&D programmes in Europe.

In the eighties the success of ESPRIT and the growing insight into cross-national cooperation at all levels has led to a revised understanding and the development of a structured policy between national and European programmes.

In this process the authority for structured policies and $R \& D$-programmes was shifted more and more to the CEC. This was formally acknowledged and extended by the Treaty of Maastricht in 1992, 
where the new article $130 \mathrm{~F}$ was introduced stating:

"The Community shall have the objective of strengthening the scientific and technological bases of Community Industry and encouraging it to become more competitive at international levels, while promoting all the research activities deemed necessary by virtue of other Chapters of this Treaty."

Simultaneously it was also laid down in the Maastricht decisions that the

"Community and the member states shall coordinate their research and technological development activities so as to ensure that national policies and community policy are mutually consistent."

1.1 The Programmatic Approach of the European Community for R\&D on Manufacturing Systems

The Treaty of Maastricht has given the CEC a prominent role of defining goals for R\&D and to allocate the necessary money to reach these goals. In Maastricht it was confirmed as well that each R\&D activity should be embedded in a comprehensive programmatic approach for a consistent European development. This encompasses the obligation to create and continously update a Reference Framework for RTD.

\subsubsection{From Single Research Projects to a European RTD-Framework Programme}

Following the ESPRIT example, several R\&D programmes for industrial technologies, materials, communication technologies and training activities were initiated or conceptualized in the first half of the eighties. Each of these programmes has its own set of objectives, its own administration and, of course, its own clients. In 1984, the first attempt was made to launch a common R\&D framework, structuring single activities according to a common European innovation model as sketched in fig. 1 .

Fig. 1: The European Innovation Model

This innovation model interrelates the functions of High-Technologies, industries and infrastructures to a structure, where High-Technologies mainly have the double function of firstly supporting industries by process innovation and secondly developing infrastructures by product innovation. In this 
B.E. Hirsch et. al.: Western European R\&D for Manufacturing Systems

model, industry has the role to expand this model by development of complementary applications and services.

The intention to systemize community actions was basically already the overall objective of the first Framework Programme valid for the period from 1984 to 1987. In the second Framework Programme from 1987 to 1991 this approach was enhanced and focused on the needs and opportunities for European IT-industry (see fig. 2)

\section{Fig. 2: $\quad$ European Needs and Opportunities for IT-Industry}

Based on the community goals towards improved competitiveness and market commitment and considering the social and cultural needs of the different Member States a transnational infrastructure for Europe was proposed to support integration of national business potential into a common market after 1992. In this context Information and Communication Technologies (ICT) were considered as key technologies for realizing such a transeuropean infrastructure. Based on this objective, technologies were selected and the requirements for focused $R \& D$ were specified in detailed $R \& D$ programmes.

This focus is maintained in the current Framework Programme issued for the period from 1990 to 1994. In this third Framework Programme the objectives and procedures have been refined and stronger attention is paid to establishing cross-national cooperation, especially between small and medium-sized enterprises (SME's). The installation of networks and cross-national mobility-programmes play a favourite role in the current Framework Programme.

The subsequent table gives an impression of the scope and relative weight of the individual programmes in the current third Framework Programme. The table shows that enabling technologies, the management of natural resources and the management of intellectual resources are the major action lines. Within this scope the budget allocation stresses the importance of enabling technologies. But in the medium term more attention will be paid to human capital and environmental questions. 
B.E. Hirsch et. al.: Western European R\&D for Manufacturing Systems

\begin{tabular}{|c|c|c|c|c|}
\hline & CEC-Programme & period & $\begin{array}{c}\text { CEC } \\
\text { budget in } \\
\$ \mathbf{M}\end{array}$ & $\begin{array}{l}\% \text { of } \\
\text { total } \\
\text { budget }\end{array}$ \\
\hline \multicolumn{5}{|c|}{ I. Enabling Technologies } \\
\hline 1.1. & Information Technologies & $90-94$ & 1,731 & $23.7 \%$ \\
\hline 1.2 & Communication Technologies & $91-94$ & 626 & $8.6 \%$ \\
\hline 4.3 & Telematics Systems & $91-94$ & 486 & $6.7 \%$ \\
\hline 2.1 & Industrial and Materials Technologies & $91-94$ & 957 & $13.1 \%$ \\
\hline 2.2 & Measurement and Testing & $92-94$ & 179 & $2.5 \%$ \\
\hline \multicolumn{5}{|c|}{ II. Natural Resources } \\
\hline 3.1 & Environment & $91-94$ & 530 & $7.3 \%$ \\
\hline 3.2 & Marine Science & $91-94$ & 133 & $1.8 \%$ \\
\hline 4.1 & Biotechnology & $92-94$ & 210 & $2.9 \%$ \\
\hline 4.2 & Agriculture & $91-94$ & 426 & $5.8 \%$ \\
\hline 4.3 & Biomedical/Health Research & $91-94$ & 170 & $2.8 \%$ \\
\hline 4.4 & Life Sciences for Developing Countries & $91-94$ & 142 & $1.9 \%$ \\
\hline 5.1 & Non-nuclear Energies & $91-94$ & 201 & $2.8 \%$ \\
\hline 5.2 & Nuclear Fission Safety & $91-94$ & 255 & $3.5 \%$ \\
\hline 5.3 & Controlled Thermonuclear Fusion & $91-91$ & 586 & $8.0 \%$ \\
\hline \multicolumn{5}{|c|}{ III. Intellectual Resources } \\
\hline 6. & Human Capital and Mobility & $92-94$ & 663 & $9.1 \%$ \\
\hline \multicolumn{3}{|c|}{ Total budget } & 7,296 & $100.0 \%$ \\
\hline
\end{tabular}

Budget Allocation for the third CEC Framework Programme 
After eight years of programmatic RTD the Commission of the European Communities has developed its own methodologies, an appropriate administrative structure and many transnational networks supporting successful refinement of this approach. This of course enhances the potential to guide the integration process. The project to complete the Single Market by 1993 was first conceived from a legal and regulatory viewpoint. The basic idea was mutual recognition and minimal harmonization of legislation. This was indeed a necessary pre-condition, but not in itself sufficient. To achieve European integration, it is equally important to make sure that the basis of interconnecting infrastructures, based on the idea of interoperability, is in place.

This understanding appears as well in the new perception of a European industrial policy. Unlike the seventies, where industrial policy was perceived as a dirigistic approach, it is recognized today that public intervention in this area must take the form of horizontal activities to achieve the right climate and balance to support the competitiveness of European industry.

An example of this revised understanding is also the rule of "rolling programme" when defining the Framework Programme. This means an overlap of one or two years between two successive programmes. Again this originates from a non-dirigistic understanding of the programmes as integrating guidelines rather than prescriptive plans.

\subsubsection{Relevant R\&D programmes for Manufacturing Systems within the European Framework Programme}

Within the European Framework Programme, ESPRIT (European Strategic Programme for Research and Development in Information Technology), BRITE (Basic Research in Industrial Technologies for Europe) and RACE (Research and Development in Advanced Communications Technologies in Europe) are the most relevant programmes for R\&D in manufacturing systems. The budgets and their development are shown in figure 3.

Fig. 3: $\quad$ CEC Programmes Budget Development

\subsubsection{ESPRIT}

ESPRIT was started in 1983 with a preparatory phase for establishing the approach to be used for precompetitive R\&D in Information Technology (IT). Equipped with a budget of $\$ 14.7$ million, 16 pilot projects on advanced microelectronics, software technology, advanced information pro- 
B.E. Hirsch et. al.: Western European R\&D for Manufacturing Systems

cessing, office automation, computer integrated manufacturing and information exchange systems were selected.

The result of the preparatory phase was a detailed programme structure for the ESPRIT I phase from 1984 - 1988 (total budget: $\$ 960$ Million) specifying a catalogue of objectives and projects according to the above subjects.

The overall objective for the CIM area in ESPRIT I was to establish a technology base for progressive introduction of IT into all phases of the manufacturing cycle. The main emphasis was placed on manufacturing elements as needed for discrete batch manufacturing. In this CIM subprogramme 36 international projects were started.

In the second programme phase of ESPRIT, from 1987-1992, three general objectives were established:

- $\quad$ to provide European IT-industry with basic technologies

- $\quad$ to promote European industrial cooperation in IT R\&D

- $\quad$ to pave the way for internationally accepted standards.

According to these objectives "Microelectronic and Peripheral Electronics", "Information Processing Systems" and "IT Application Technologies" were selected as R\&D areas. The CIM activities were extended in scope, specifically including engineering as a R\&D subject. The overall budget for this phase was $\$ 2.1$ billion.

For the third phase of ESPRIT, from 1990 - 1994, emphasis has been placed on actions and projects accelerating the integration of advanced technologies in the business world. This phase comprises accompanying measures for technology transfer and training activities to increase the potential for participation especially in peripheral European regions. The total budget of this phase is $\$ 1.7$ billion.

Within the subprogramme of Computer Integrated Manufacturing and Engineering (CIME) the work programme for ESPRIT III distinguishes three main sub-areas:

1. Architecture and Infrastructure for CIME

2. Management and Design of Industrial Enterprises

3. Mechatronics, Robotics and Sensing Technologies 
B.E. Hirsch et. al.: Western European R\&D for Manutacturing Systems

The first sub-area comprises architectures, systems engineering and communications for CIME applications based on former ESPRIT projects like CIM-OSA, CNMA and CADEX.

The second sub-area encompasses design, engineering, production management and logistics with several tool development projects for design and evaluation of complex CIM systems.

The third sub-area addresses IT based automation and control systems for production processes, manufacturing units, autonomous mobile robots and mechatronics devices.

In 1991 the budget for this CIME area was $\$ 198$ million $($ CEC-contribution $=50 \%$ ).

ESPRIT is considered a very successful programme. In 1990 3,531 enterprises and universities were involved in various project consortia.

\subsubsection{BRITE/EURAM}

BRITE started as a programme in 1985 to encourage collaborative precompetitive R\&D on advanced technologies with basic R\&D and demonstration projects in the first phase. Areas of BRITE were: laser-technology, computer-aided testing, CAD/CAM-applications and application of new materials, particularly polymers in industry. The budget of this phase was $\$ 237$ million.

In the second phase from $1989-1992$ BRITE was extended in scope explictly addressing "European Research on Advanced Materials" (EURAM) and by a special section for aeronautics.

The areas of BRITE/EURAM are Advanced Materials Technologies, Design Methodologies for Products and Processes, Application of Manufacturing Technologies and Technologies for Manufacturing Processes.

For these subjects 374 projects were selected and initiated covering industrial applied research, focused on fundamental research and feasibility for small and medium sized enterprises. Current statistics show that approximately $56 \%$ of BRITE/EURAM participants come from industry (1/3 of these are SME's), $27 \%$ are Universities and $17 \%$ are research centres.

For the second phase of BRITE/EURAM a total budget of $\$ 639$ million was allocated.

In the third phase of BRITE/EURAM from 1990 - 1994, the focal points, defined in the second 
B.E. Hirsch et. al.: Western European R\&D for Manufacturing Systems

phase, are basically continued with a slight shift towards the integration of advanced technologies in user industries and technology transfer. Special emphasis is also placed here on materials, processes and technologies to reinforce the scope and effectiveness of recycling.

This current third phase is equipped with a budget of $\$ 858$ million.

\subsubsection{RACE}

RACE was launched in 1985 by a 18 -month definition phase for developing an Integrated Broadband Communication (IBC) reference model, to evaluate projects for technology options and to evaluate the techno-economic feasibility of the IBC reference model. For this work programme a budget of $\$ 28.3$ million was allocated, to implement the programme.

The first RACE programme phase from 1987-1992 was focused on the community wide introduction of Integrated Broadband Communication (IBC), in coordination with the European national introduction of the Integrated Services Digital Network (ISDN), starting in 1995. Covering all aspects of terrestrial networks, satellite and mobile telecommunications, it includes narrowband networks and distribution networks of all kinds as well as specific broadband networks. This first phase of RACE was equipped with a budget of $\$ 704$ million.

The second programme phase of RACE from 1990-1994 is basically a continuation of the activities defined in RACE I, but strengthening the research effort on optical communications and techniques of synchronic/asynchronic switching, intelligent networks and new value-added services that are both profitable and adapted to the developing needs of users. These actions include a community R\&D effort of the prenormative type in order to guarantee the interoperability of the systems on the basis of common standards and protocols. Particular attention will be given to the growing demand for mobile telephony services and the integration of these services into networks. This second phase has eight priority areas:

1. IBC (Integrated Broadband Communications)

2. Intelligence in networks/flexible communication resource management

3. Mobile and personal communications

4. Image and data communications

5. Integrated service technologies

6. Information security technologies

7. Advanced communication experiments 


\section{Test infrastructure and interworking}

The allocated budget for this current phase is $\$ 625.9$ million.

RACE is ultimately concerned with services, their definition and their exploitation by end users. This means a very general, multi-purpose and public infrastructure.

The impact of RACE for manufacturing is related to distributed manufacturing and multi-supplier situations. This is a very exciting field for future applications. For a long time the scope of CIM was limited to internal enterprise functions. So CIM systems were designed to integrate functions of one enterprise. The cross integration of functions from different enterprises into one consortium was beyond this view and not supported. But complementary networks, composed of different enterprises are an important business reality. Especially in europe a relevant proportion of business is organized by flexible consortia formed out of SME's. For this kind of manufacturing business open-systems and public IBC-networks have an important potential.

\subsubsection{Other relevant programmes}

Additionally to the above mentioned R\&D programmes aiming primarily at technology development, other programmes have been launched by the CEC to develop supportive structures. Examples of such programmes are COMETT, DELTA, DRIVE, SPRINT, STAR.

COMETT is the Community Action Programme for Education and Training for Technology. This programme was started in 1987 to promote European cooperation between universities and enterprises by fostering the joint development of training programmes and by improving the supply of training in the Community. The current COMETT phase from 1990 - 1994 has a budget of $\$ 256$ million.

DELTA is the acronym for "Developing European Learning through Technological Advance" and was started in 1988, to stimulate European cooperation in learning technologies by the development, testing and validation of Advanced Learning Technology concepts. The pilot-phase of this programme was equipped with a budget of $\$ 25$ million.

DRIVE is the acronym for Dedicated Road Infrastructure for Vehicle Safety in Europe. This programme aims for the introduction of an Integrated Road Transport Environment (IRTE) offering improved transport efficiency. DRIVE has a budget of $\$ 75$ millon. 
B.E. Hirsch et. al.: Western European R\&D for Manufacturing Systems

SPRINT (Strategic Programme for Innovation and Technology Transfer) is aiming to strengthen the assistance infrastructure for transnational technology transfer in Europe. The instruments of this programme are the creation of a cooperation network, conferences and the organisation of training activities to advise SME's on innovation. SPRUNT started in 1989 and has a budget of $\$ 115$ million.

STAR (Special Telecommunication Action for Regional development) is a general programme to support the development of less-favoured regions of the EC by access to advanced telecommunication services. This programme started in 1986 for a five year period and was equipped with a budget of $\$ 940$ million.

\subsubsection{National R\&D-programmes on Manufacturing Systems in Western Europe}

Subsequently a brief overview on publicly funded national R\&D-programmes for manufacturing systems will be given, followed by a short presentation of the coordinating bodies and organisations.

\subsubsection{Overview}

In figure 5 several national R\&D-programmes on Manufacturing systems in Western Europe are listed. This selection of current and recent programmes is probably not exhaustive, as there is no central institution or database, responsible for tracing and updating the actual programme-state in Western Europe.

\section{Fig. 4: $\quad$ National R\&D-Programmes in Western Europe}

This table shows that in most of the European countries complementary programmes are in effect. The total budget of these programmes even exceeds the budget available to the CEC for RTD. So the total publicly funded effort for industrial manufacturing systems was in $1988 \$ 6.2$ billion (see fig. 5), whereas the total budget of the current third Framework Programme of the CEC sums up to $\$ 7.3$ billion for five years! This stresses again the importance of the coordination principle, laid down in the Treaty of Maastricht and the potential for mutual synergy from that.

Fig. 5: National R\&D-Effort in AMT 
B.E. Hirsch et. al.: Western European R\&D for Manufacturing Systems

\subsubsection{Coordinating Bodies}

Subsequently the national coordinating bodies, mentioned in the table (see fig. 4) with their respective acronyms will be described in terms of the type of organisation, their responsibilities and objectives:

BMFT/Bundesministerium für Forschung und Technologie Heinemannstraße 2, D-5300 BONN 2

- The BMFT is the central R\&D National Ministry for Research and Technology, responsible for the preparation and execution of national programmes. Furthermore BMFT finances the major part of the scientific basic research in germany by providing funds for the "Max-Planck Gesellschaft zur Förderung der Wissenschaften (MPG)" and several other institutions like the "Fraunhofer Gesellschaft $(F h G) "$. The total annual budget of BMFT is $\$ 6.7$ billion.

CNR/Consiglio Nazionale delle Richerche

Piazza Aldo Moro 7, I-00100 ROMA

- $\quad C N R$ is the general italian governmental research organisation. It allocates the national budget for R\&D to different projects and institutes within and outside the universities. It also advises the Interministerial Commission for Economic Planning (CIPE). This commission is responsible for the development of national R\&D programmes.

CNRS/Centre National de la Recherche Scientifique

15, Quai Anatole France,F-75700 PARIS

- CNRS is a public institution for science and technology, reporting to the "Ministry of Research and Technology". The main task of CNRS is the management of national research programmes, the evaluation of programmes and projects and the dissemination of scientific results. CNRS has a budget to finance R\&D and as well own institutes and laboratories.

CSIC/Consejo Superior de Investigaciones Cientificas

Serano 117, E-MADRID

- $\quad$ CSIC was setup in 1981 and is one of the main bodies in spain to promote scientific and industrial R\&D. CSIC is directly reporting to the Ministry of Education an Sciences and manages about $23 \%$ of the total R\&D effort in spain. 
B.E. Hirsch et. al.: Western European R\&D for Manufacturing Systems

DFG/Deutsche Forschungsgemeinschaft

Kennedyallee 40, D-5300 BONN 2

- The DFG is the German national organisation for the support and management of scientific research over all disciplines. The DFG has an advisory function on various levels of governmental departments. The annual budget of the DFG in 1991 was $\$ 877$ Mio.

JNICT/Junta Nacional de Investigacao Cientifica e Tecnologica

Avenida Don Carlos I, 126, P-1200 LISBOA

- JNICT was founded in 1967 and is the governmental coordinating body to promote and finance scientific and technological research in Portugal.

KFWF/Kommission zur Förderung der Wissenschaftlichen Forschung

Wildhainweg 21, CH-3001 BERN

- THE KFWF is an public organisation for the administration of federal funds for R\&D in Switzerland. The main subjects of this R\&D are electronics, mechanical engineering and material science.

NBST/National Board for Science and Technology

Shelbourne House - Shelboume Road, EI-DUBLIN 4

- The NBST is an Irish organisation, reporting to the Ministry of Industry, Trade, Commerce and Tourism. The NBST is responsible for the development of a "viable national research competence in key technologies". The NBST conducts several R\&Dprogrammes on universities and research institutes. The annual budget of the NBST is 1,1 mio IRL (1988).

NTNF/Norges Teknisk-Naturvitenskapelige Forskningsrad

P.O. Box 70 Tasen, N-0801 OSLO 8

- NTNF's objective is to promote scientific, industrial and related research for the Norwegian industry. NTNF was founded 1946 as an independent institution. It advises the Norwegian government in trends and demands for R\&d and is widely autonomous in the management of the annual R\&D-budget granted by the govemment. NTNF's principal fields of interest are: industry and mining, energy supply and the continental shelf, building and civil engineering, shipping, transport and communication. 
SERC/Science and Engineering Research Council Garrick House, 3-5 Charing Cross Road, GB-LONDON

- The Science and Engineering Research council is the British national council supporting basic and applied research in natural sciences and engineering. SERC has close contacts to industry and provides grants for various R\&D-projects.

SPIN/Stimulerings Projectteam Informaticaonderzoek

P.O. Boc 316, NL-2600 AH DELFT

- $\quad$ SPIN is an organisation within the framework of the "Dutch Information Technology

Stimulation Programme (NL-INSP)". The function of SPIN is here to stimulate research in information technology, to administer the programme and to advise the Dutch Administration on strategic trends in technology markets.

STF/Statens Tekniskvidenkabelige Forkningsrad

Holmens Kanal 7, DK-1060 KOPENHAVN

- $\quad$ The STF is one of the six research organisations in Denmark, established in 1968, forming the so called "Central Danish Research Organisation". STF is responsible for technical sciences. Heading these research organisations is the "Council for Science Policy and Planning", established in 1973, which advises the government.

STU/Styrelsen for Teknisk Utveckling

Box 43200, S-10072 STOCKHOLM

- $\quad$ STU is the Swedish national board for technological development and supports various technical research projects, cooperative research and industrial developments. STU initiates, executes and monitors national R\&D-programmes.

TEKES/Technology Development Centre

Malminkatu 34, SF-00101 HELSINKI

- TEKES was founded in 1983 and charged with the task of raising and maintaining the level of technology in Finland. TEKES advises the Ministry of Trade and Industry (MT) in technology policy and is charged to implement national R\&D-programmes through the financing and R\&D-projects in cooperation with research units and other organisations which finance technological research. The funds of TEKES are intended to support corporate R\&D projects, as well as research performed in institutions of higher educations, and at research institutes. 
B.E. Hirsch et. al.: Western European R\&D for Manufacturing Systems

\section{EUROPEAN INSTITUTES IN THE FIELD OF R\&D FOR MANUFACTURING SYSTEMS}

The following section provides an overview of European institutes working in the field of advanced manufacturing systems development. Most of these institutes are publicly funded and located at technical universities. This is the result of a widespread policy in europe to combine the public educational functions at universities with technology transfer functions to industry by dedicated and related R\&D-centres at the same place.

The following list again does not claim to be complete or exhaustive. So it gives only a partial view and a brief characteristic of various institutes known by contacts, achieved in different European cooperation programmes. This list shows that there is a potential in all Western European countries to develop and adopt advanced manufacturing technology.

BLBA/Bremer Institut für Betriebstechnik und angewandte Arbeitswissenschaft an der Universität Bremen

Hochschulring 20, D-2800 BREMEN 33

- $\quad$ BIBA is an institute at the University of Bremen, working in the field of production techniques and the design of manufacturing systems. BIBA applies a broad multidisciplinary approach, covering mechanical engineering, electrical engineering, informatics, mathematics, economics and social sciences. One of the main functions of BIBA is technology transfer to industry. Moreover BIBA is involved in more than 200 projectcooperations with different European partners.

CIMRU/University College Galway

Nun's Bland, IRL-GALWAY

- CIMRU is one of the centres of excellence in Ireland in the field of factory automation, CIM architectures and control systems for CIM and CAD/CAM applications. CIMRU is one of four AMT Applied Research Units under the umbrella of the national AMT programme. CIMRU has close contact to industry and is here especially involved in the development of advanced production and inventory management systems. Moreover CIMRU is involved in various European programmes and projects. 
B.E. Hirsch et. al.: Western European R\&D for Manufacturing Systems

EPFL-LPG/Ecole Polytechnique Federale de Lausanne Laboratoire de Gestion de la Production ME-ECUBLENS, CH-1015 LUSANNE

- EPFL is one of the Swiss federal institutes of technology. CIM is one of the major areas of R\&D. In this field, several laboratories contribute to other European projects like the ESPRIT projects CIM-OSA, CNMA and FICIM. Furthermore a demonstration-centre is set up for information and training of SME's.

FhG/Fraunhofer Gesellschaft

\section{Leonrodstraße 54, D-800 MÜNCHEN 19}

- The "Fraunhofer Gesellschaft" is a german association, operating various institutes in applied R\&D in close cooperation with german technical universities. Fraunhofer institutes working in the field of Manufacturing Systems are the "Fraunhofer Institut für Arbeitswirtschaft und Organisation" and the "Fraunhofer Institut für Produktionstechnik und Automatisierung" in Stuttgart, the "Fraunhofer Institute für Produktionsanlagen und Konstruktionstechnik" in Berlin, the "Fraunhofer Institut für Produktionstechnologie" in Aachen, the "Fraunhofer Institut für Systemtechnik und Innovationsforschung" in Karlsruhe and the "Fraunhofer Institut für Transporttechnik and Warendistribution" in Dortmund. All these institutes work in close contact with industry and are involved in numerous national and international projects.

GPCIT/ Greek Productivity Centre IT

28 Kapodistrious Street, 10682 ATHENS

- $\quad$ GPICT is a greek R\&D centre of the greek ministery of National Economy in the fields of education and training, development of software application and standardisation in IT and $\mathrm{CAD} / \mathrm{CAM}$.

GRAI/Laboratoire GRAI - Universite de Bordeaux 1

Cours de la Liberation 351, F-33405 TALENCE Cedex

- GRAI is an institute at the University of Bordeaux working in the field of CIM and production techniques. The GRAI-institute is a specialist in modelling techniques for production systems. The GRAI-methodology is such a modelling technique designed for decision and information modelling. GRAI is involved in numerous European projects on advanced manufacturing technologies and production management systems.

HUT/IIA/Helsinki University of Technology, Institute of Industrial Automation 
B.E. Hirsch et. al.: Western European R\&D for Manufacturing Systems

Otakaari 1A, SF-02150 ESPOO

- The Institute of Industrial Automation is a research institute at the Technical University, working in the field of automation, mechanical engineering, industrial engineering and information technology. HUT/TAI works in close contact with national industry. Approximately $90 \%$ of the activities are based on industrial projects. HUT/TAI is also involved in various European R\&D-programmes like RACE, ESPRIT or BRITE/EURAM although Finland has to funf this participation with national money.

IIRS/Institute for Industrial Research and Standards Ballymun Road, IRL-DUBLIN 9

- IIRS is a technical service institute for industry, aiming at encouraging and assessing the use of science and technology in industry. The main working areas are electronics, engineering, information technology, textiles and timbers.

IKERLAN/Centro de Investigaciones Tecnologicas

E-20500 MONDRAGON

- IKERLAN is the spanish research centre for applied R\&D in advanced technologies for the basque machine tool industry. It offers $R \& D$ services on an contractual basis and as well training and consultancy services. The function of IKERLAN covers promotion of AMT and services to support regional development. IKERLAN is also involved in various European projects and programmes.

ITP-TNO/Instituut Informatie-Technologie voor Productieautomatisering P.O. Box 513, NL-5600 MB EINDHOVEN

- The ITP is one of the varous institutes of the dutch organization for applied research and development called TNO. Similar to the german "Fraunhofer Gesellschaft" TNO covers a wide spectrum of application oriented technical research. Within this framework ITP's one institute working in the development and application of computer science for discrete production, process industry, logistics and production management. ITP is located on the campus of the Technical University of Eindhoven.

LAAS/Laboratoire d'Automatique et d'Analyse des Systemes

7 Av. du Colonel Roche, F-31077 TOULOUSE Cedex

- LAAS is a french institute, working in the field of automation, computer science, microelectronics and production systems. The annual budget is about $\$ 15$ million. 
LNETI/Laboratorio Nacional de Engenharia e Tecnologia Industrial Estrada Paco do Lumiar 22, P-1600 LISBOA

- $\quad$ LNETI is a body with administrative and financial autonomy and has its own budget for disposal to R\&D. The function of LNETI is to promote and implement R\&D in industry and energy sectors. Furthermore LNETI performs training and consultancy projects for the portuguese industry. LNETI operates a technology institute called ITI and an energy institute. The ITI has 5 departments covering mechanical engineering, electronics and chemical R\&D.

NEL/National Engineering Laboratory

East Kilbride, G75 0QU GLASGOW

- NEL is a governmental organisation of the Department of Trade and Industry (DTT) in London and works on expert systems and computer integrated manufacturing within the national R\&D programmes. NEL is also involved in European projects to develop industrial oriented manufacturing systems.

RIT/Department of Manufacturing Systems and Computer Systems for Design and Manufacturing - The Royal Institute of Technology Brinnelvägen 81 , S-10044 STOCKHOLM

- The Institute of Technology is part of the Stockholm University and has about 7000 students in Engineering. The staff is 150 professors and about 2000 administrators and technicans. The Department of Manufacturing Systems works especially in the area of robotics and CAD/CAM. This work includes human, organisational and economic aspects.

SI/Senter for Industriforskning

Forskningsveien 1, N-0314 OSLO 3

- $\quad$ SI is a multidisciplinary research institute, providing professional development and market orientated R\&D for industry in the areas of automation, robotics, CAD/CAM and CAE. The application fields of SI are mechanical industry, offshore and marine industry. SI works mainly on a contractual basis.

\section{SINTEF/The SINTEF Group Norway}

Strindveien 2, N-7034 TRONDHEIM

- $\quad$ The SINTEF Group is an non-profit organisation with a total staff of nearly 2000 employees engaged in R\&D for industry, public services and governmental departments. SINTEF and the Norwegian Institute of Technology (NTH) in Trondheim, work together 
in close cooperation. The basic disciplines within SINTEF cover microelectronics, computer architectures, image processing and information management. The key application areas are: telecommunication, simulation of industrial processes, CIM, medical technology and the social impacts of IT.

\section{Teknologisk Institute (TI)/}

Gregensensvej, DK-2630 Tastrup

- $\quad$ The TI is a polytechnical industrial development centre providing resources and projects on mechanical engineering, automation, software engineering, industrial psychology, business administration and industrial engineering. The main function of the $\mathrm{TI}$ is to operate as a technology transfer centre for the danish industry. The TI has about 650 employees organized in 17 departments or groups.

UDIRL/University of Durham Industrial Research Laboratory

South Road, U-DH1 3LE DURHAM

- UDIRL is a public research laboratory at the university of Durham. The working areas of UDIRL are electronics, information technology, production technologies, robotics and aerospace technologies.

WTCM/CRIF/Wetenschappelijk en Technisch Centrum van de Metaalverwerkende Nijverheid, Campus Arenberg, Celestijenlaan 300 C, B-3030 HEVERLEE

- WTCM/CRIF is one of the industrial centres for technical research of the Belgian Metalworking Industry. WTCM has about 100 employees covering mechanical engineering, automation and surface technologies. Since 1987 WTCM has operated several R\&D-programmes in CAD/CAM and CIM applications. It is closely linked to the Catholic University of Leuven. Other CRIF-institutes are linked to the universities of Brussels and Liege.

3.

\section{RESEARCH AFTER MAASTRICHT: THE POLICY OF THE EUROPEAN COMMUNITY FOR EUROPEAN RTD}

Europe as it is in 1992 is considered by the CEC at a critical stage regarding integration, competitiveness and social needs. The process of moving into a common European market is extremely challenging and requires a wide scope of supportive actions. These challenges have to 
B.E. Hirscb et, al.: Western European R\&D for Manufacturing Systems

be reflected in the Fourth Framework Programme currently under preparation.

To achieve its goals - strengthening European cohesion and industrial competitiveness including volume products - the CEC has refined the programmatic approach as represented in figure 2 into a structure as shown in figure 6 . The left hand column represents the activities which are normally attributed to the public sector. The right hand column represents the activities which are the prerogative of industry itself - the actual activities would vary according the specific industrial sector.

Fig. 6: Integration Processes for EC Framework

Based on these general structure four types of activities has been selected by the CEC for the Fourth Framework Programme:

1. Implementation of research, technological development and demonstration programmes, by promoting cooperation with and between industry, research centres and universities;

2. Promotion of cooperation in the field of Community research, technological development and demonstration with third countries and international organizations;

3. Dissemination and optimization of the results of activities in Community research, technological development and demonstration;

4. Stimulation of the training and mobility of researchers in the Community.

In the preliminary proposal of the CEC from the 2 nd of October 1992, the group of activities is broken down into 35 individual activities covering Information and Communication Technologies, Industrial Technologies, Environment, Life Science and Technologies and Energy. The other groups of activities are also subdivided into 14 individual lines of action.

The total budget for this Forth Framework Programme (1994-1998) is calculated to a volume of $\$ 18.817$ billion. This is two and a half of the budget allocated to the current Third Framework Programme.

The allocation of this budget to the individual action lines is not yet completed. For the time 
being specific figures are not yet available. But it can be expected that the new high priority rule for "subsidiary" will cause a major change to the allocation rules. The current recommendation in this field is to support in the future those branches showing a high R\&D intensity, whereas branches with a low R\&D intensity should be neglected. A first proposal for a classification of branches, considering this principle, is shown in figure 7.

\section{Fig. 7: Technology Intensity Groups}

4.

\section{UNMET NEEDS AND OPPORTUNITIES IN WESTERN EUROPEAN R + D}

Research programmes normally originate from discussion between the financial sponsor and the various organizations being sponsored i.e. the industrial users and/or research institutes.

Through the cooperation of the partners, each considering his own interests, a more or/less wellbalanced programme comes into existance. At the same time the economic interests of all parties are in the foreground. This holds true not only for the research institutes but even more so for the industrial users.

In order to recognize the requirements and chances of future production systems, the superordinate global context has to be taken into account in addition to the technical, business management and economic needs and interests.

\section{Fig. 8: $\quad$ General Development Trends in Manufacturing}

Derived from the current development trends of industrial production various classes of needs can be distinguished:

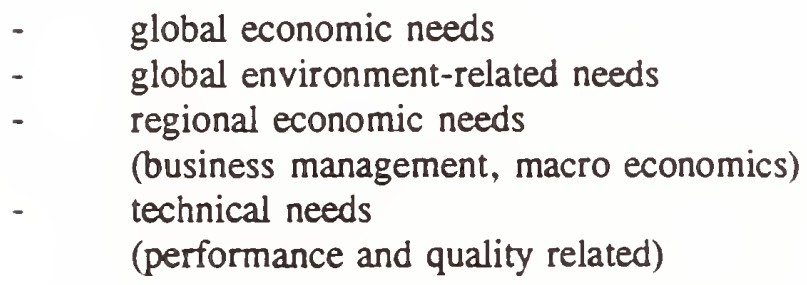

Unmet needs and opportunities are not to be derived from single or individual problems. On the 
contrary, the overall context shaping a future working together in this world has to be emphasized.

Beginning with the global needs it will be possible, following a top-down approach to derive the other requirements emphasizing their general relevance.

\subsection{Global Needs for Future Production Systems}

The future state of the world can be characterized by the following:

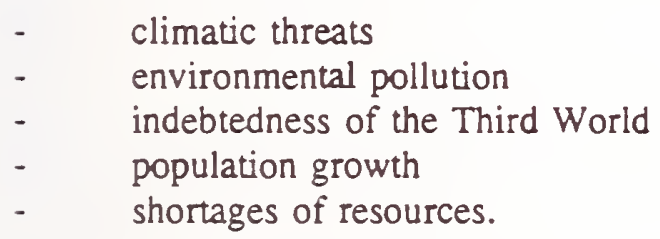

Fig. 9: World Population Growth

Fig. 10: Decreasing Quality of Copper Ore Mining in the USA $(1900-1990)$

Industrial production has a considerable impact on all these developments. Future production systems cannot shirk a global responsibility.

Through recent developments, such as the disintegration of the major military blocks, we are challenged to undergo a radical change. The necessity of a new orientation should be understood as a unique chance first time offered.

The fundamental rule of growth implies that when capital expands faster than the population, the standard of living rises.

Just the contrary is the case in the third world. Economic prosperity is declining and the population rate is climbing fast. This population increase hinders the growth of industrial capital, especially as an increased accumulation of capital is necessary in order to maintain life-essential services. The cause of the dilemma of the third world is the unequal spatial distribution of industrial growth. Economic growth is still concentrated in the already highly industrialized countries. 
B.E. Hirsch et. al.: Western European R\&D for Manufacturing Systems

\section{Fig. 11: Global Industrial Production}

\section{Fig. 12: Global Metal Consumption}

The flow of refugees from developing and over populated countries - as it can currently be observed in Europe and the USA - will not cease until these people see a chance of reasonable development and adequate prosperity in their own country. Only a suitable global distributed prosperity can reduce the population growth, which, in turn, will guarantee and improve the prosperity for everyone, including the industrial nations. What is the value of a product, if there are no solvent customers. However, the prerequisites for this are fair market conditions with inir product and raw material prices.

Independent of an active part by the industrialized countries in this context, the production resources will inevitably have to be reassessed in the future. Mass production will continue to shift to newly industrialized countries (NID) because of cheap labour and loose environmental regulations etc.. A trend which can hardly be stopped.

The problems of overdevelopment on one hand and underdevelopment on the other have to be overcome simultaneously. Only in this way can the earth's ecological capacity and balance be preserved and the survival of future generations be secured.

Industrial production may only be, but also has to be, increased on the basis of conservational activities and environmental technologies.

The industrial nations are being urged upon to think about a worldwide labour distribution in accordance with global political demands. A conscious and deliberate shaping of the global distribution of labour can be the basis for preventing national conflicts on the one hand and the worldwide introduction of environmental protective production methods and systems on the other hand.

The production challenges for the industrial nations resulting from a global labour distribution will be described in the following paragraph.

\subsection{Requirements for the Future Production Systems}

In order to develop business and economic requirements for future production systems we have to 
redefine our role in the context of an increased global distribution of labour. The time has come to develop and implement a new production paradigm for the industrialized countries.

The introduction of a new product both on domestic and foreign markets was usually performed according to the "product cycle theory".

Fig. 13: Market cycle

During the first stage, the innovation phase, the product is developed and produced for the domestic market. After sufficient production and marketing knowledge has been gathered, the product is introduced to foreign markets (export phase) where such relevant know-how isn't available. In the third phase the production has been improved and standardized. Afterwards it is adopted by foreign producers (imitation phase) who normally have the advantages of low labour costs and limited environmental regulations.

The innovator's technological advantage at this point decreases step by step until he ultimately starts importing the product in question himself (import phase). Sometimes a further stage, the repatriation phase, follows. This can happen when the country which initially designed the product manages to come up with advances in the production technology. In such cases domestic production is reinstated.

This generally acknowledged theory emphasizes the close relationship between international competitiveness and innovative capacities.

Fig. 14: Economical Influences on the Product-life-cycle

As highly industrialized countries can usually only be competitive in the early stages of production, it is especially important for them to keep coming up with so-called intelligent product or process innovations which cannot easily be imitated. These however generally depend on a high research and development input requiring extensive funding. This pressure is increased by the fact that the market cycles which reflect the market penetration and customer demand are continuously becoming shorter. Often only he who is first to introduce a product can count on making profits. "Time to market" is increasingly becoming a critical factor for success.

The development, maintainance and enlargement of the protoyping capability, i.e. the domination of a short "time-to-market" on the basis of the most up-to-date manufacturing technologies, will 
become the crucial challenge of a modern Industrial Community. In the future only the rapid transformation of a new product idea into a prototype and related manufacturing equipment will guarantee early profits in the field of serial and mass production.

To meet these challenges industrialized nations have to aggressively pursue advanced manufacturing processes for products as well as to take into account major technology breakthroughs driven by advances in information and communication technologies and manufacturing processes.

\section{One-of-a-Kind-Production Systems}

If the statements up to now have emphasized the "Time to Market" approach they depict only a form of the perfection of the former phases of the Mass Production Paradigm (MPP). The limits of the MPP will be reached by reducing lot sizes and increasing product variance.

Fig. 15: Product quantity vs. Product variety

Fig. 16: Variants in car manufacturing

One extreme example: Due to the numerous possible varieties of the Daimler Benz 190 model there are only two identical cars each year in the Bremen plant which produces over 500 cars daily and more than 120,000 annually [2].

Even though consumer goods are continued to be produced in large batches in the future, product individualization will take place in more and more areas. While in the area of investment goods constantly growing customer requirements for technical and usability functions are leading to an increase of product complexity and uniqueness, the same tendencies are shown in the area of luxury goods due to the increasing requirements for prestige functions.

\section{Fig. 17: Product oriented customer requirements}

The extreme case of infinite product variance is attained when the product is only manufactured once. With the tuming away from reproductive manufacturing the direct application and/or putting into operation of a uniquely developed product (a one-of-a-kind product) will be achieved. The following statements mainly focus on the single production of investment goods as is usual in shipbuilding, aircraft and aerospace technology, machine tools etc. 


\section{Fig. 18: One-of-a-Kind Production Characteristics}

Based on these peripheral characteristics and reflecting the general development trends of the international markets (see Fig. 19), future requirements for the prototyping capability of production systems can be derived.

Fig. 19: Future Requirements for the Prototyping Capabilities of Production Systems

Ongoing research and even standardization activities like STEP factory integration modelling, research for rapid prototyping techniques like Desktop manufacturing (DTM), etc. must be strengthened. The aim is the enforcement of the prototyping capabilities of future production systems.

Although a systematic reappraisal for a new production paradigm is beyond the scope of this contribution, some elements can be highlighted.

In order to be competitive in a global context, prototyping capability means the ability to offer and manufacture incomparably unique sophisticated products based on continuously changing customer demands.

Fig. 20: Customer Intervention in the Product Life Cycle

This will require a focus on the quality and productivity of intellectual workers; higher levels of creativity will be demanded.

Fig. 21: Mass Production versus One-of-a-Kind Production

In mass and serial production a decrease in the learning curve can be achieved by incremental investments in the automation level of the applied production systems. The greater the product quantity, the lower the price of the product. The lower the price, the greater the need for low production costs. The lower the approved costs, the greater the need for a high automation level.

Depending on the history and tradition of industrialized nations in production management there are different approaches (I, I, III) to manage the correlation between cost per part and the number of parts as characterized by the different learning curves. 
Fig. 22: $\quad$ Reconfigurability of Manufacturing Equipment

However all approaches are based on the idea of optimizing the production process and reducing the costs per part through reproduction strategies.

However, in the case of One-of-a-Kind production there is no possibility for optimizing the production process through reproduction strategies. The ultimate challenge will be: "Do it right the first time". In this context the reuse of experience will play a predominant role, in reducing the technical and economical risks.

Fig. 23: "To be" versus "As is" Information Level

Fig. 24: $\quad$ Experience-Centered Classification of Design and Planning Tasks

Fig. 25: Comparison of Production Programme Planning

Beside the reuse of data the use or reuse of experience is an important asset in the OKP business, but this experience must be acquired and maintained during the daily work. To obtain wholeness requires an involvement in a holistic loop to generate experience. The requirement for an experience generation loop is illustrated [1].

Fig. 26: Experience generation loop

With decreasing lot sizes and increasing customer interventions the basis of production systems is shifting from technical integration to human cooperation.

Due to the uniqueness and complexity of One-of-a-Kind products the human resource units as well as the machining resources should provide a high level of complexity in terms of capabilities. The one-task-one-employee principle in Adam Smith's pin fctory is not adequate here. Adam Smith's principle is based on standardization and specialization, but the OKP business implies nonstandard and fuzzy situations. This requires a complexity of capabilities a single employee cannot offer. This means that a high qualification level of the personnel, group work and the configuration of stable work teams are essential requirements. [1]

Fig. 27: Qualification of Personnel 
B.E. Hirsch et. al.: Western European R\&D for Manufacturing Systems

The generation and the use of human experience will become on essential subject of modern production systems if the competence of the worker will be requested and maintained by suitable decision and responsibility structures.

\section{4}

Enterprise Integration and Enterprise Cooperation

The above outlined demands have led to efforts being made to parallelize the product development process and to extend the just-in-time idea to the process of product development with regard to the information flow.

Due to the decrease in production depth (increase in team manufacturing) this development is not only confined to internal processes but increasingly also covers enterprise internal tasks as they occur between manufacturers and/or customers and suppliers. Accordingly advantages will only emerge from cooperation in the sense of an "extended" enterprise comprising all partners taking part in a particular task.

\section{Figure 28: Current and Future Enterprise Cooperation}

The resulting level of specialization and integration between designing, planning, and producing a product has therefore not only become increasingly important on an internal level but is also especially influential with regard to the cooperation between customer and supplier. "The supplier becomes (the customer's) external special department...".

Nets of independent, cooperating partners emerge. To ensure well functioning cooperation, appropriate information systems, communication technology, and compatible enterprise organization are required. Internal and external data exchange as well as the functional interdependencies between the various business activities therefore have to be coordinated and integrated, in order to enable the involved enterprises to deal with a project in a joint and integrated manner.

\section{Figure 29: Levels of Integration}

Enterprises will have to become customers, suppliers, partners, and competitors all at the same time.

If the industrialized nations acknowledge their global responsibility, we have to extend this 
B.E. Hirsch et. al.: Western European R\&D for Manufacturing Systems

interpretation of integration on the basis of a justified global distribution of production resources.

\subsection{Environmental Life-Cycle Analysis for Product and Production Systems}

In the past both product design and production systems design were, in principle, market and legislation oriented. New materials, manufacturing processes, etc. were used without considering the consequences for recycling or waste deposition.

Public pressure, extremely increasing costs for waste disposal and our own conviction to conserve natural resources and to recycle most kinds of materials make it necessary to develop new strategies for products and manufacturing processes for the future.

Corresponding to their global responsibilites and their high technological standards the industrial nations have to assume the leading position in the discussion on and in solving the production related environmental challenges.

\section{Fig. 30: Life-Cycle-Analysis}

Based on extensive knowledge of the interaction between economy, technology and ecology we have to analyze the whole life-cycle of our products, beginning with the generation of raw materials and ending up with the recycling and the waste management of used products.

The aim must be to get a much better coherence between economy, technology and ecology.

First analyses of different kinds of highly sophisticated machining processes show surprising results. The impact on the environment and accordingly the production costs are strongly influenced by using cutting fluids [3].

Fig. 31: Machining Process Input/Output

The consequent application of an overall life-cycle analysis can be seen as the most essential procedure to elucidate the energy and material flows which influence economy, technology and ecology.

\subsection{Performance Assessment on the Basis of Scenario Techniques}

Performance assessment of production systems is becoming a more and more complex task. As 
B.E. Hirsch et. al.: Western European R\&D for Manufacturing Systems

customers' decisions tend to be less determined by prices alone. Other features of production sytems, such as leadtime, product quality or the capability to customize products, are gaining importance. Altough difficult to quantify, these features have to be taken into account when evaluating performance of existing or designed production systems.

It is therefore not sufficient to describe the performance by a set of numbers alone. What we need is a holistic approach that not only looks at technical or economical criteria, but also at "soft factors" like social, organizational, cultural impact etc. Instead of comparing sets of indicators, we should rather compare scenarios showing us the production system as a whole, explaining its behaviour - which may well be driven by the soft factors - and its realisations to the world around it. Such scenarios will substantially improve our understanding of production systems and will open new design choices for the factories of the future.

Fig. 32: Levels of Analysis in CRIMP 


\subsection{Long Term Re-Assessment of Industrial Potential e.g. Maritime Industries}

According to the foregoing discussion on future requirements for production systems the industrial nations have to rearrange their areas of production activity. Non opportune alignments have to be identified; new chances have to be evaluated and developed. A strategic reassessment of the "value" of industrial potential with respect to production capabilities has to be carried out.

As an example we will derive the "value" of a Maritime Industry for Western Europe. Shipping, shipbuilding and equipment manufacturing are traditional industries in Western Europe. However the world market share of this european industry has decreased dramatically since the Sixties. Dus to high labour costs and the application of more or less conventional production systems these industries were forced to retire from traditional areas of shipbuilding activities. Accordingly there have been proposals within the EC to reduce or even stop the fundings for related industrial and R\&D activities. If this would come true Europe would loose its competitivness and influence over a nowadays as a "low-tech" rated potential which could be a major asset with respect to an important bussiness domain of the future. In the following this statement will be argued.

- Believing in serious predictions on the growth of populations we can imagine the future challenges in producing a suitable quantity and quality of food, but the potential of cultivateable ground is extremely restricted.

- An increasing shortage of nearly all kinds of raw materials including potable water and primary energy sources can be considered. Shedding the load of raw material and energy consumption can diminish but not solve this problem.

- The creation of the internal market leads to an increasing congestion in road traffic and a related increase of air pollution

- etc.

Facing these future challenges we should consider the following aspects:

- More than $70 \%$ of the surface of the earth is covered with water. 
- The sea and the sea-bed are composed of various kinds of resources (oil, gas, minerals, capabilities for aquaculture, etc.)

- Western Europe is more or less surrounded by the sea. Its coast - more than 10.000 miles long - is equipped with hundreds of small and medium sized ports, an excellent infrastructure for short sea shipping.

- etc.

Taking into account the long term industrial potential needed to meet this future challenge, a completely different approach for funding R\&D and industrial activities will be needed. Up to now the R\&D activities on production systems are more or less concentrated on terristrial approaches for production systems.

for future markets. The shipping, shipbuilding and equipment manufacturing activities need to be developed towards a cooperating Maritime Industry exploring the global and longterm opportunities and then to be transformed into a New Maritime Industry of the future. The requirements and potential supply of this new Maritime Industry are well known and crucial for the industrialized nations: High level R\&D activities combined with prototyping capabilities.

For modern, trade and production oriented nations, the complexity of the transport function is increasing. Not just the port-to-port carriage of goods but their movement from original source to ultimate destination is becoming a total logistic industry.

5. THE POTENTIAL FOR COLLABORATION FOR RTD IN THE
PERSPECTIVE OF INCREASING GLOBALIZATION

In order to recognize the potential for global collaborative R\&D projects, the superordinate global economic and environmental needs and responsibilities of industrial nations have to be taken into account in addition to the individual technical, business management and economic needs and interests of the different partners. A number of starting points are given to describe the actual state of the world:

- climatic threats

- environmental pollution 
- indebtedness of the Third World

- shortage of resources.

This contexts has already been discussed in chapter 4 . Global needs are only manageable with collective approaches. Recent developments give us the first chance to tackle these global challenges.

Within these collaborations the various nations should work on complementary aspects, related io their traditions and history. The greater the challenge the greater the need to integrate these specialised capabilities if we are to tackle these problems effectively.

Another potential area for global cooperation is represented by tasks which are characterized by minor economic interests of individual partners. One example: For the future there will be an increasing social and political demand for higher global safety and environmental standards. An ultimate basis for a successful cooperation within this field will be the exchange of different cultural backgrounds and an increasing knowledge about each other.

However a global collaboration will be successful if all partners can see their advantages even if their views are dominated by global or national interests.

In the following some first approaches for international cooperations are listed in which our institute is involved to some extent:

- Intelligent Manufacturing Systems (IMS)

Based on a japanese proposal from 1990 there is an ongoing discussion on a more or less global cooperation on Advanced Manufacturing System. During the IMS feasibility study which began in February 1992, approximately three test cases will be funded and launched internationally in order to test the emerging collaborative framework of IMS.

- $\quad$ EC - US cooperation on Enterprise Integration Modelling

(CIM OSA - MCC cooperation)

- $\quad$ EC - US "Collaborative Action" on Product Modelling

(NEUTRABAS - NIDDESC cooperation) Within this cooperation the funding is restricted to travel costs.

In addition there are several bilateral cooperation between many individual institutes and organisations. 
B.E. Hirsch et. al.: Western European R\&D for Manufacturing Systems

The growing spirit of global cooperation is shown by TINA, a joint industrial R\&D activity set up by BELLCORE, NTT and BT in the field of intelligent networking. This is the first time that development, rather than standardisation of a basic networking technology has taken place at a global level. TINA hopes to provide the communications building blocks necessary amongst others, for the development of fully integrated, globally distributed production. 
B.E. Hirsch et. al.: Western European R\&D for Manufacturing Systems

\section{LIST OF REFERENCES}

[1] Hirsch, B.E.; Hamacher, B.; Thoben, K.-D.

Human Aspects in Production Management; in: Computers in Industry; 19 (1992) 55-77

[2] Zeyfang, D.; Hesse, R.

New Organizational Structures for Automobile Assembly; in [4]

[3] Haepp, H. J.; Byrnes, G.

Life Cycle Analysis - A Strategic Element for Future Products and Manufacturing

Technologies; in: National Advanced Manufacturing Technology Programme; Sep. 1992, Galway, Ireland

[4] Hirsch, B. E.; Thoben, K.-D. (Editors)

"One-of-a-Kind" Production: New Approaches; Elsevier Science Publishers; B.V. (NorthHolland); IFIP Transactions, 1992

[5] Hirsch, B. E. (Editor)

CIM in der Unikatfertigung; Springer Verlag: Berlin, Heidelberg, New York, u.a.; 1992

[6] Ley, W.

Simultaneous Engineering in der variantenreichen kundenauftragsspezifischen

Anlagenproduktion; VDI-Berichte 758, 1989, S.43-64

[-] Meadows, D.H. and D.L.; Randers, J.

Beyond the Limits; Chelsea Green Publishing Co., Post Mills, Vermont, USA 1992

[-] Deutsches Übersee-Institut (Editor)

Jahrbuch Dritte Welt 1992; Verlag C.H. Beck, München 1992

[-] Information Technology Atlas - Europe; North-Holland; Amsterdam, New York, Oxford, Tokyo

[-] BRITE-EURAM Programme; Synopses of Current Projects 1990-1991; Office for Official Publications of the European Communities, Cataloque number: CD-NA-14042-EN-C; Luxemburg 1991 
B.E. Hirsch et. al.: Western European R\&D for Manufacturing Systems

[-] EC Research Funding; 3rd. Fully Revised Edition; A Quide for Applicants; Office for Official Publications of the European Communities, Cataloque number: CD-NA-14122EN-C; Luxemburg 1992

[-] ESPRIT: European Strategic Programme for Research and Development in Information Technology; Tätigkeits- und Ergebnisbericht; Office for Official Publications of the European Communities, Cataloque number: CD-NA-13583-EN-C; Luxemburg 1991 


\section{LIST OF FIGURES}

Fig. 1: The European Innovation Model

Fig. 2: $\quad$ European Needs and Opportunities for IT-Industry

Fig. 3: $\quad$ CEC Programmes Budget Development

Fig. 4: National R\&D-Programmes in Western Europe

Fig. 5: National R\&D-Effort in AMT

Fig. 6: Integration Processes for EC Framework

Fig. 7: Technology Intensity Groups

8ig. 8: $\quad$ General Development Trends in Manufacturing

Fig. 9: World Population Growth

Fig. 10: Decreasing Quality of Copper Ore Mining in the USA (1900 - 1990)

Fig. 11: Global Industrial Production

Fig. 12: Global Metal Consumption

Fig. 13: Market cycle

Fig. 14: Economical Influences on the Product-life-cycle

Fig. 15: $\quad$ Product quantity vs. Product variety

Fig. 16: Variants in car manufacturing

Fig. 17: Product oriented customer requirements

Fig. 18: One-of-a-Kind Production Characteristics

Fig. 19: Future Requirements for the Prototyping Capabilities of Production Systems

Fig. 20: $\quad$ Customer Intervention in the Product Life Cycle

Fig. 21: $\quad$ Mass Production versus One-of-a-Kind Production

Fig. 22: Reconfigurability of Manufacturing Equipment

Fig. 23: "To be" versus "As is" Information Level

Fig. 24: Experience-Centered Classification of Design and Planning Tasks

Fig. 25: Comparison of Production Programme Planning

Fig. 26: $\quad$ Experience generation loop

Fig. 27: Qualification of Personnel

Fig. 28: $\quad$ Current and Future Enterprise Cooperation

Fig. 29: Levels of Integration

Fig. 30: Life-Cycle-Analysis

Fig. 31: Machining Process Input/Output

Fig. 32: Levels of Analysis in CRIMP 


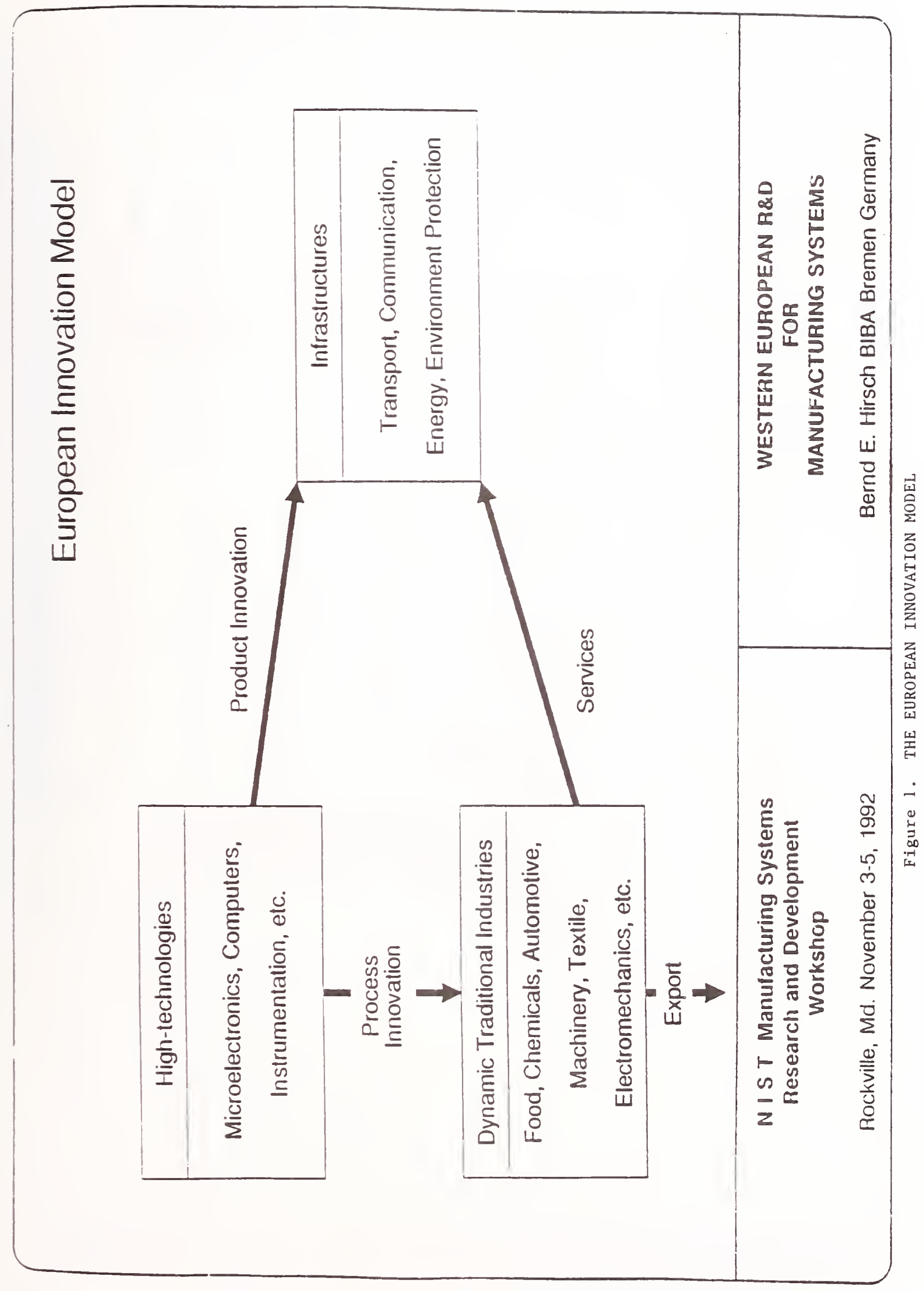




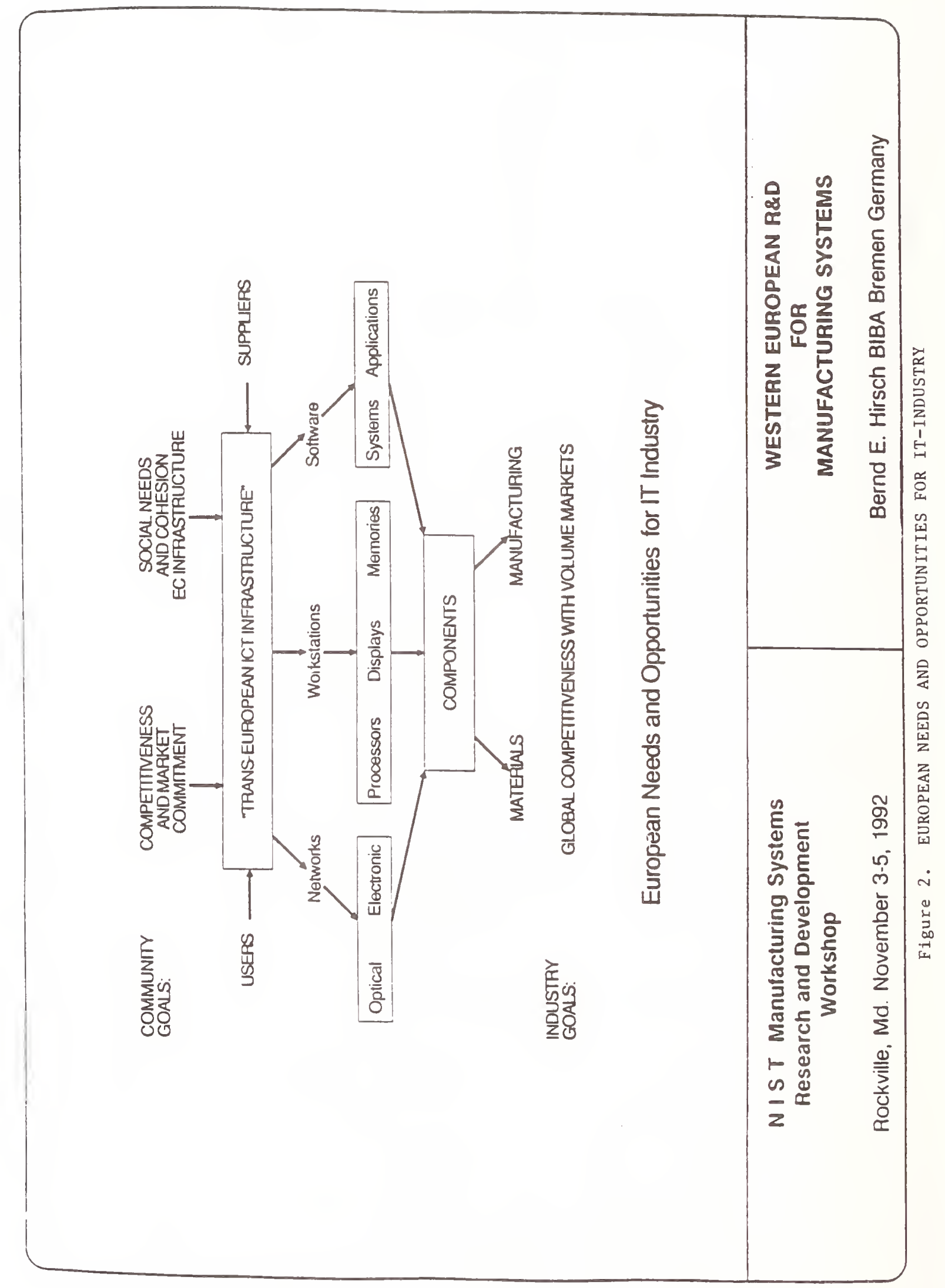




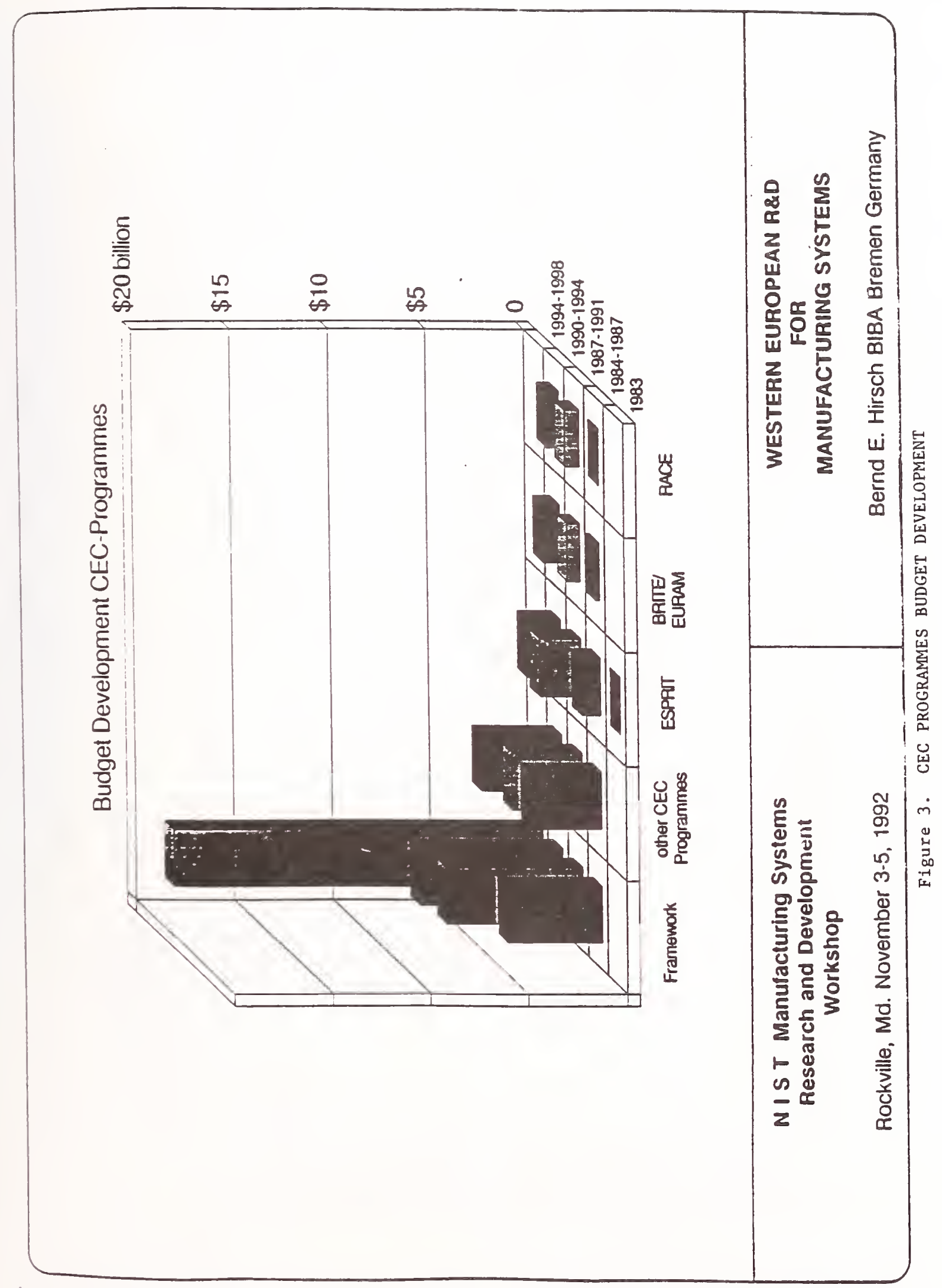




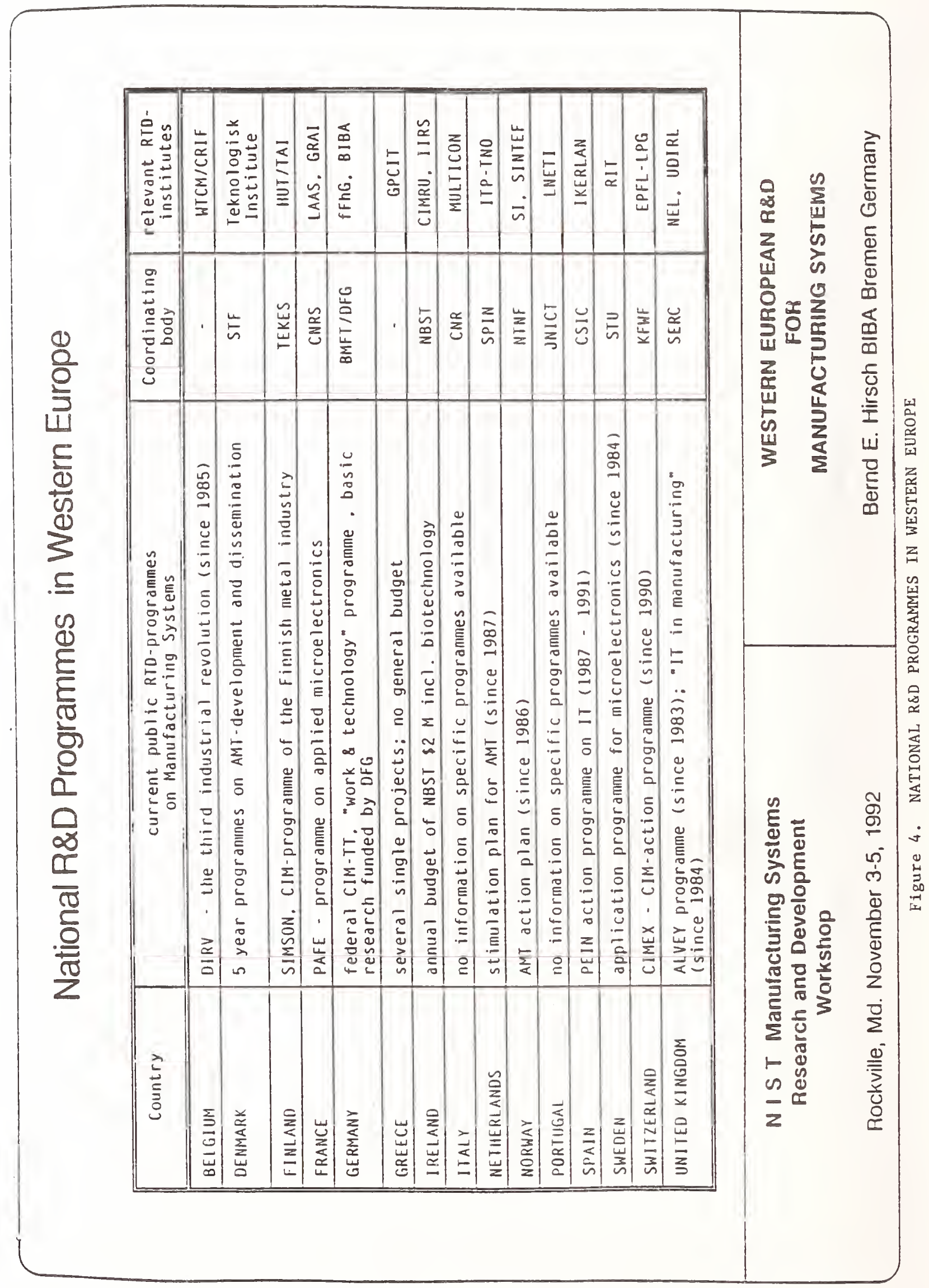




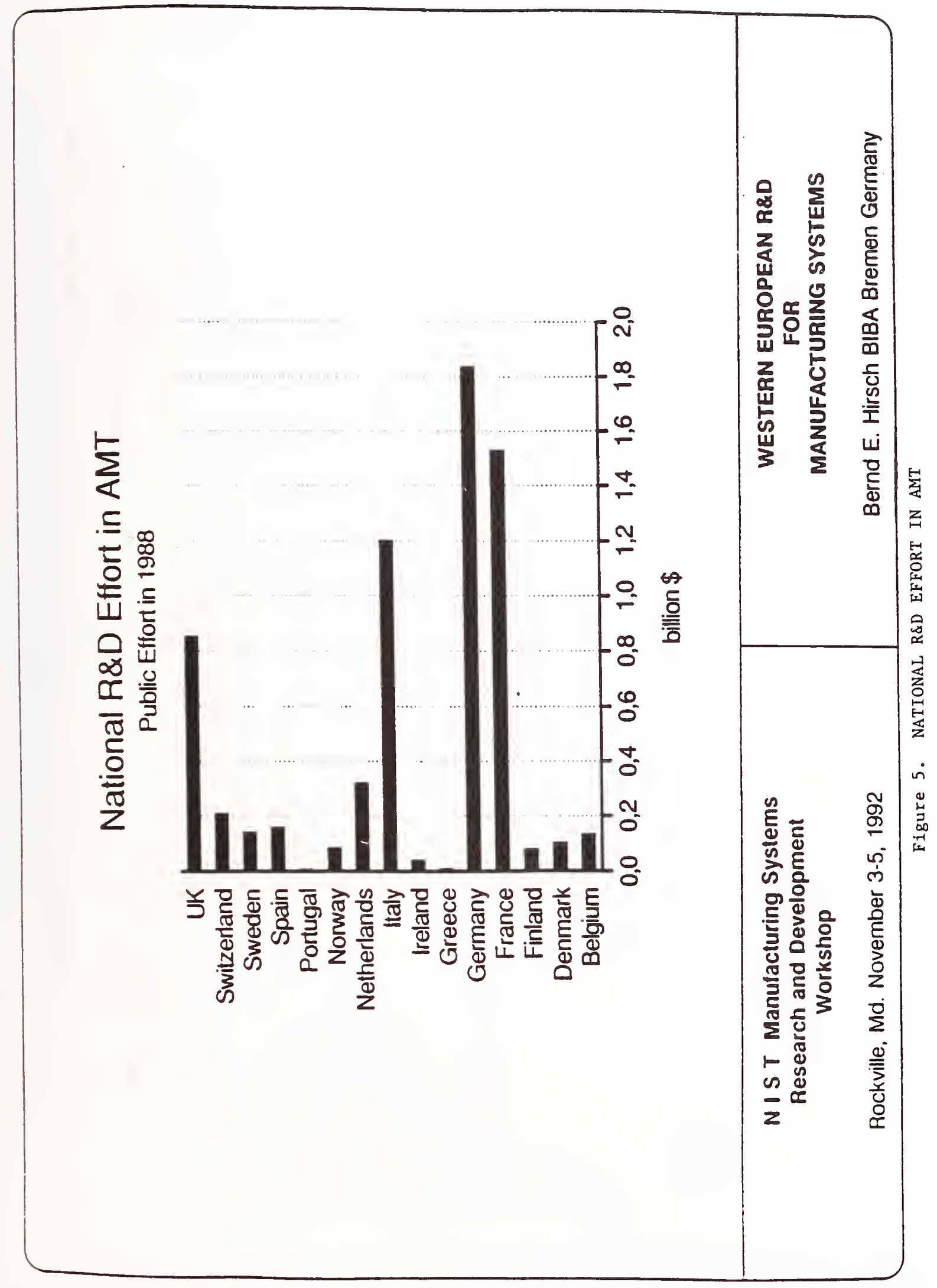




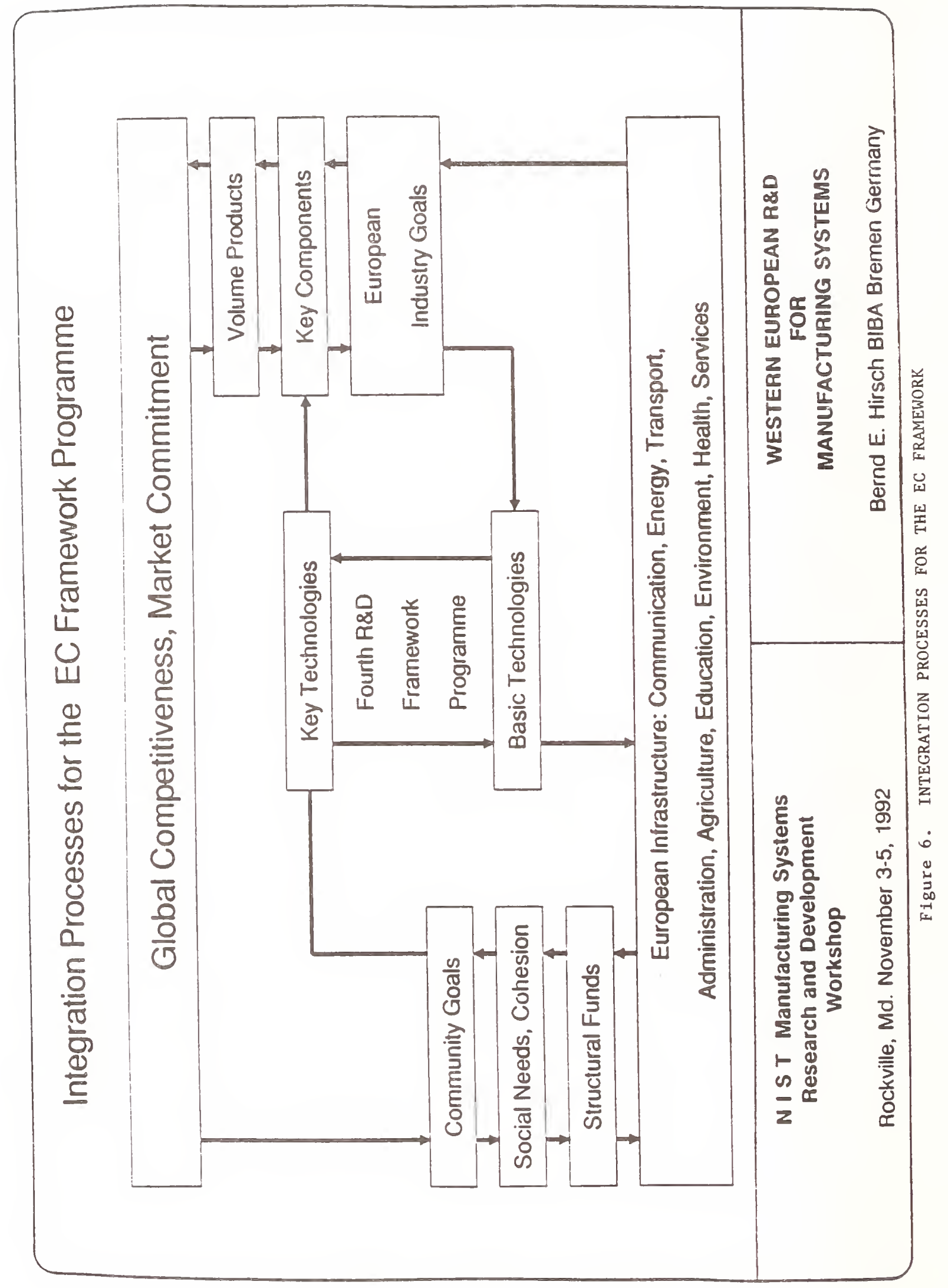




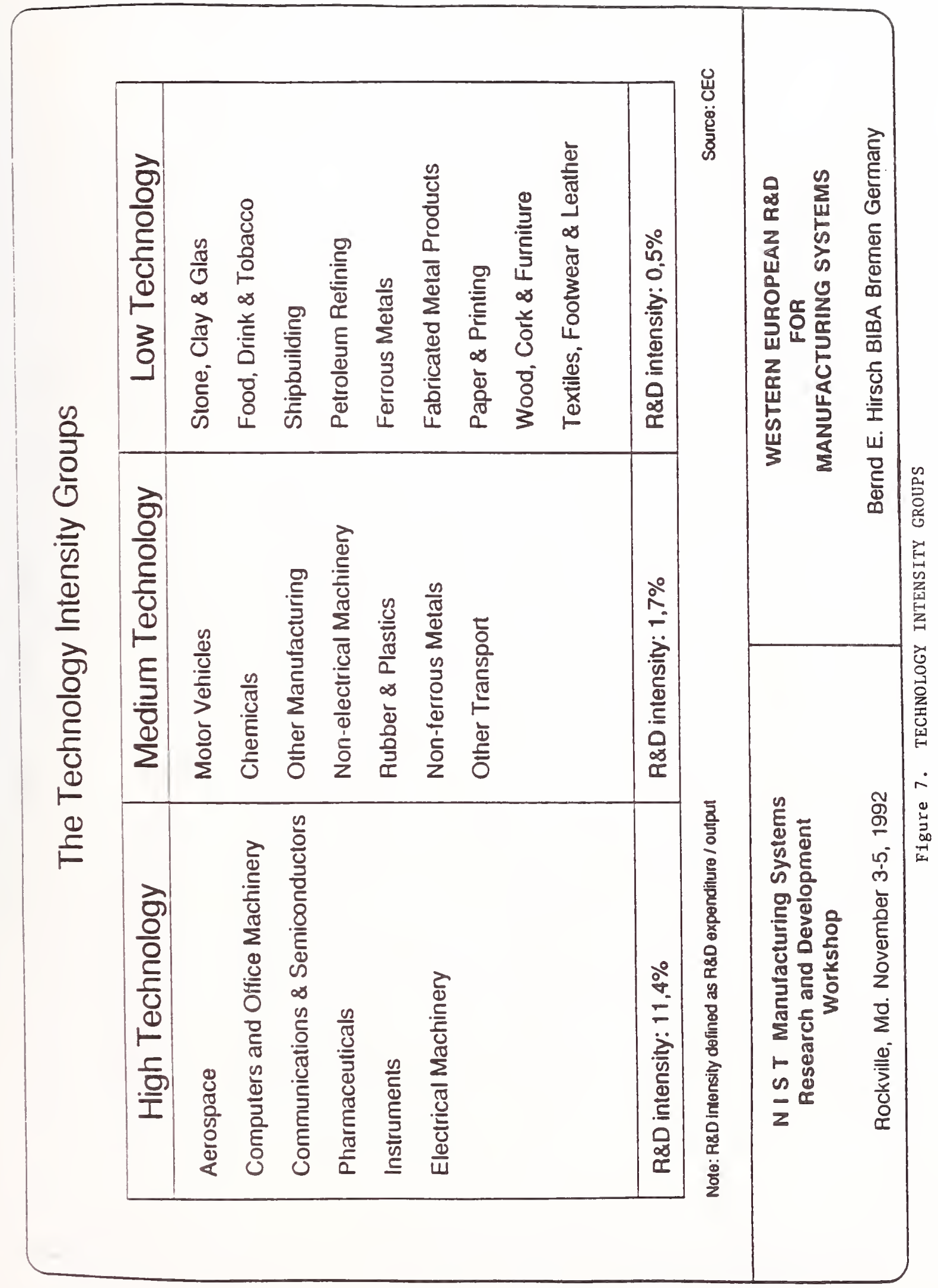




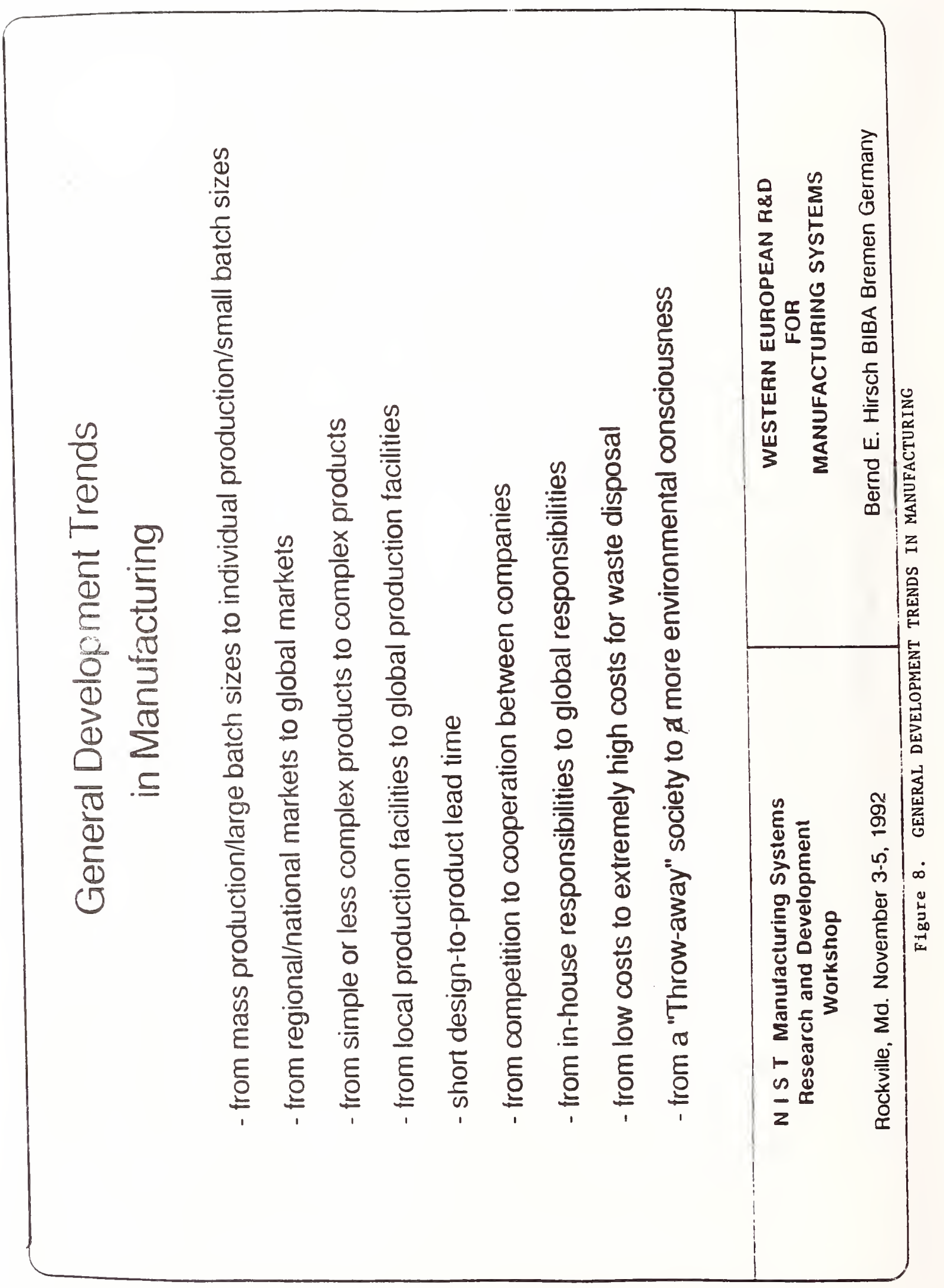



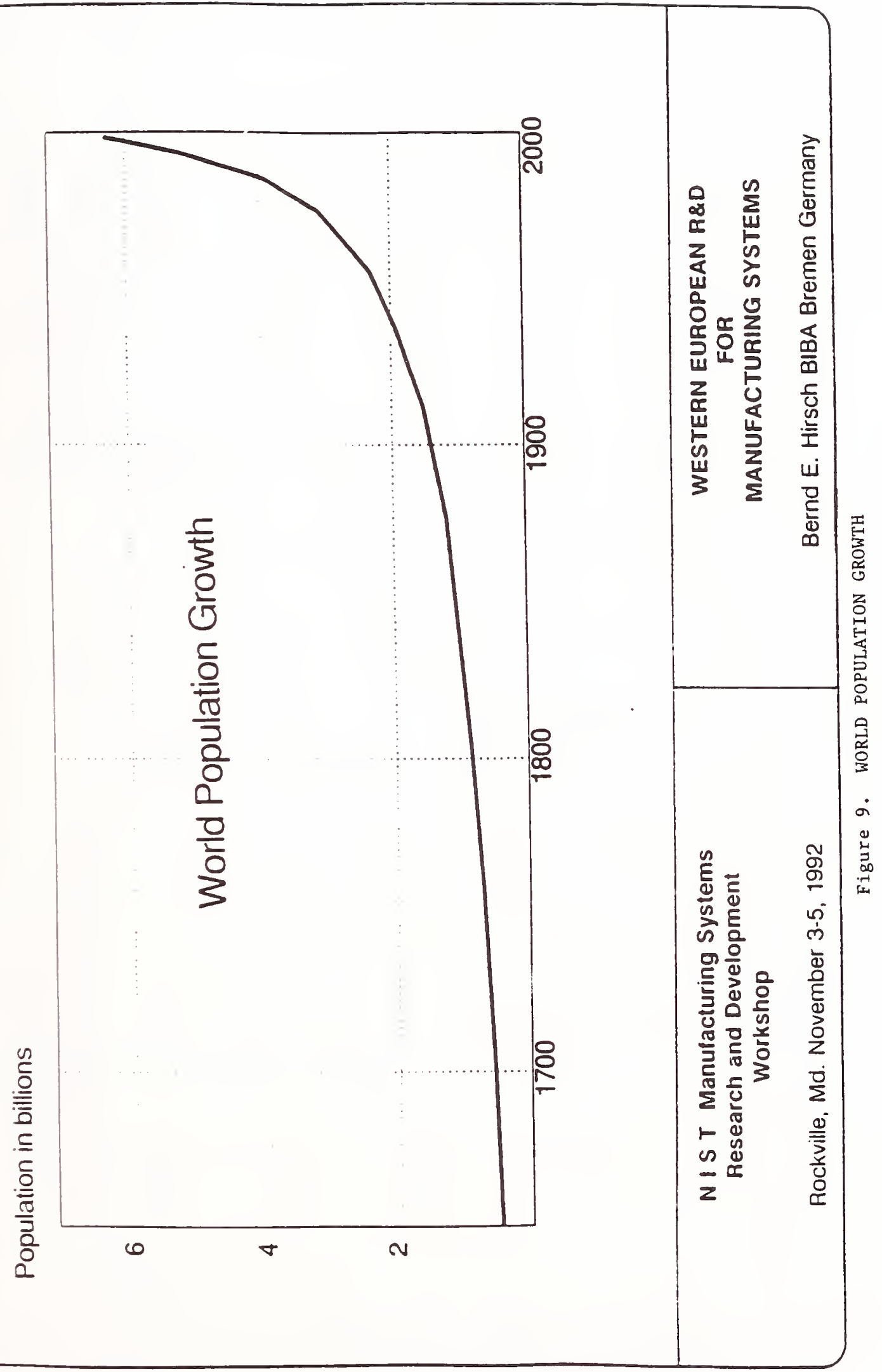


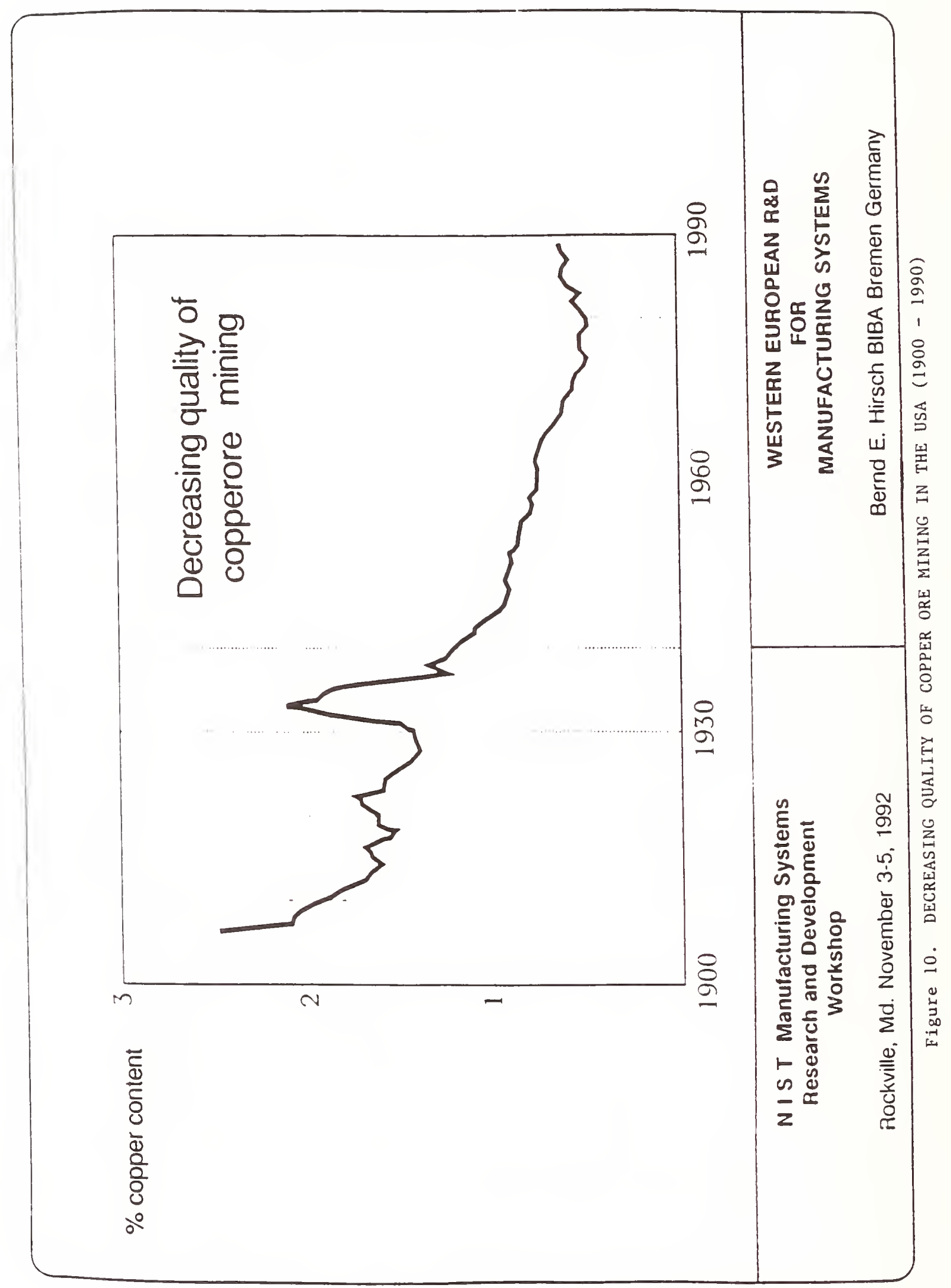




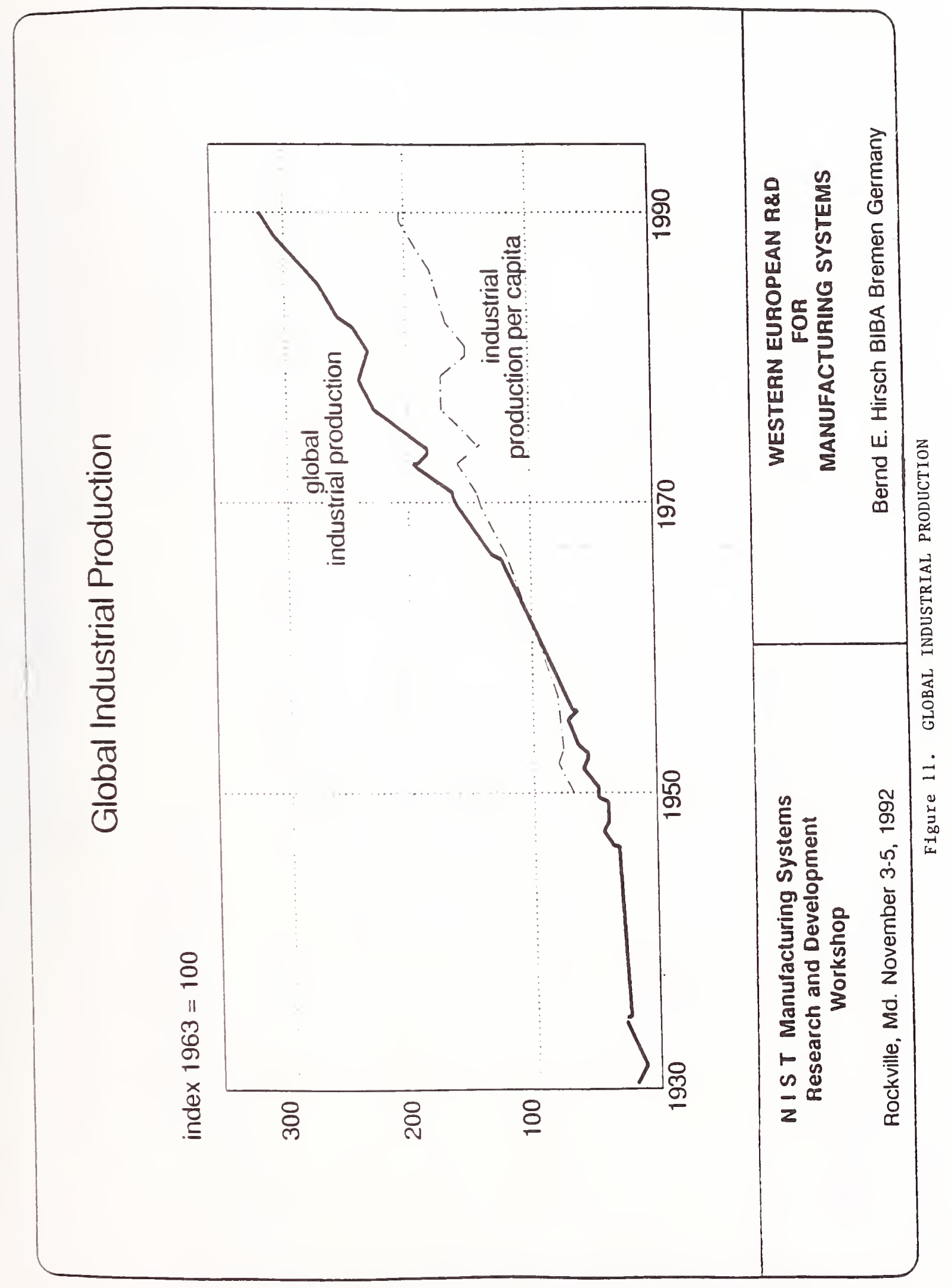




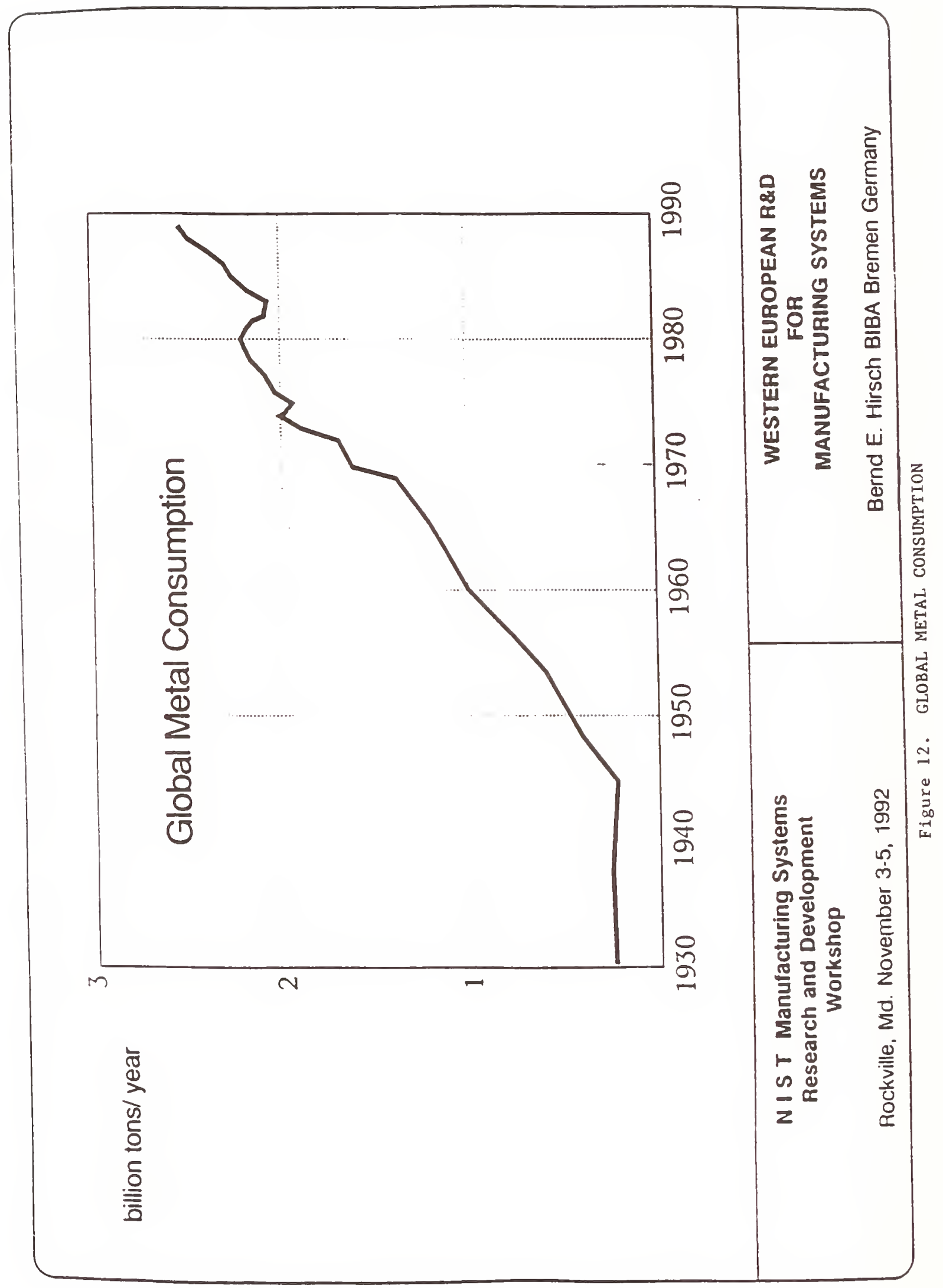




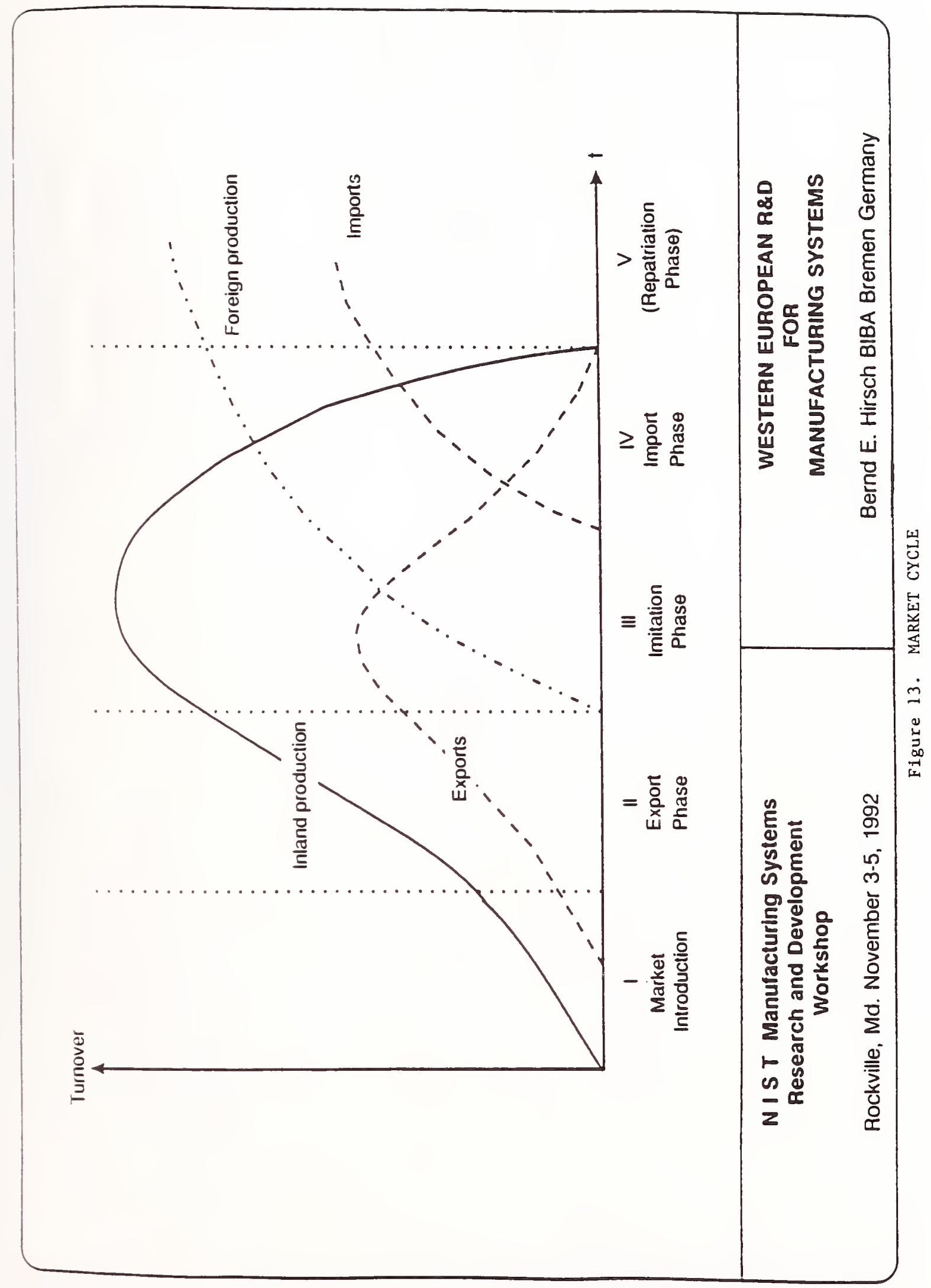




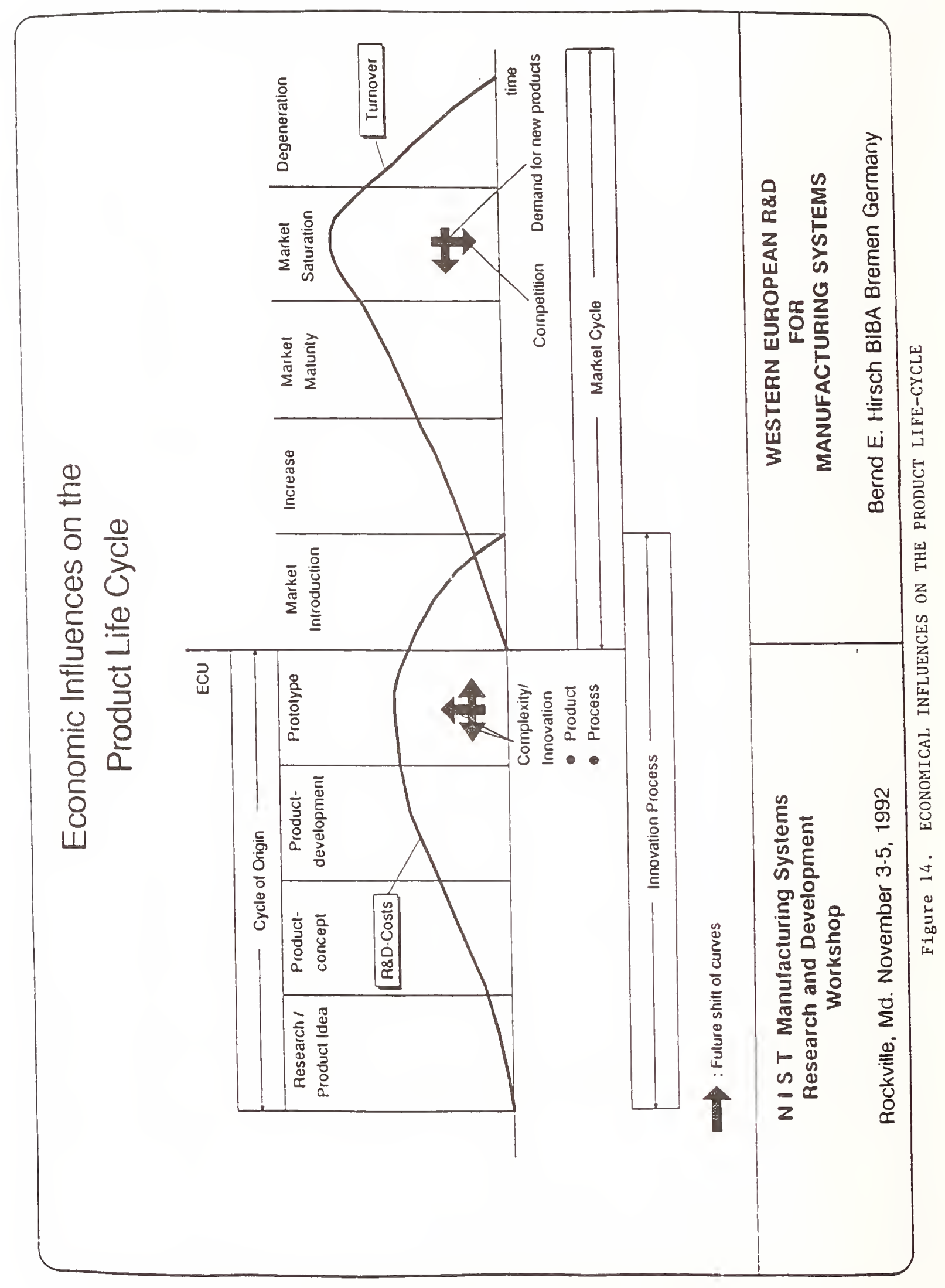




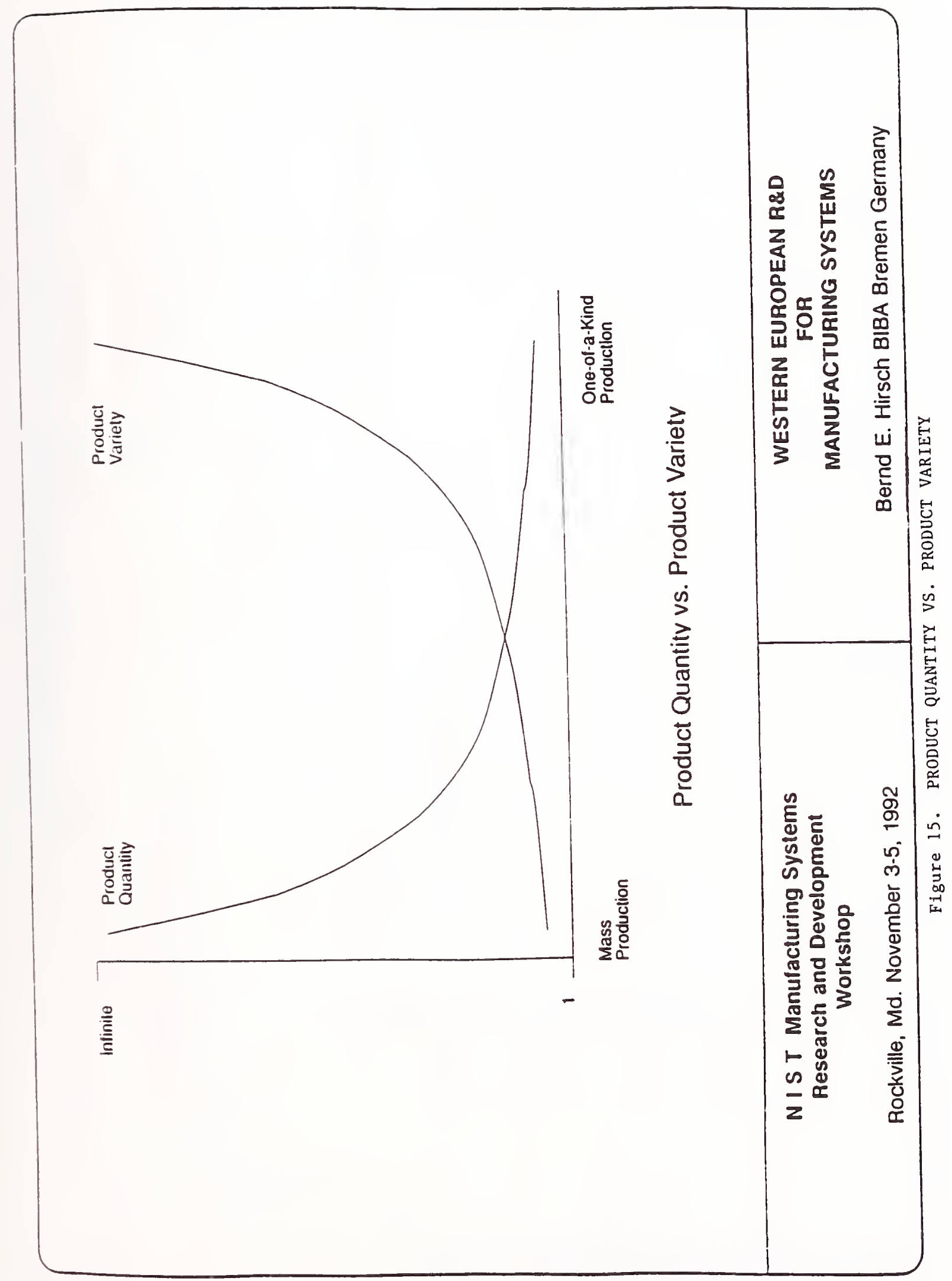




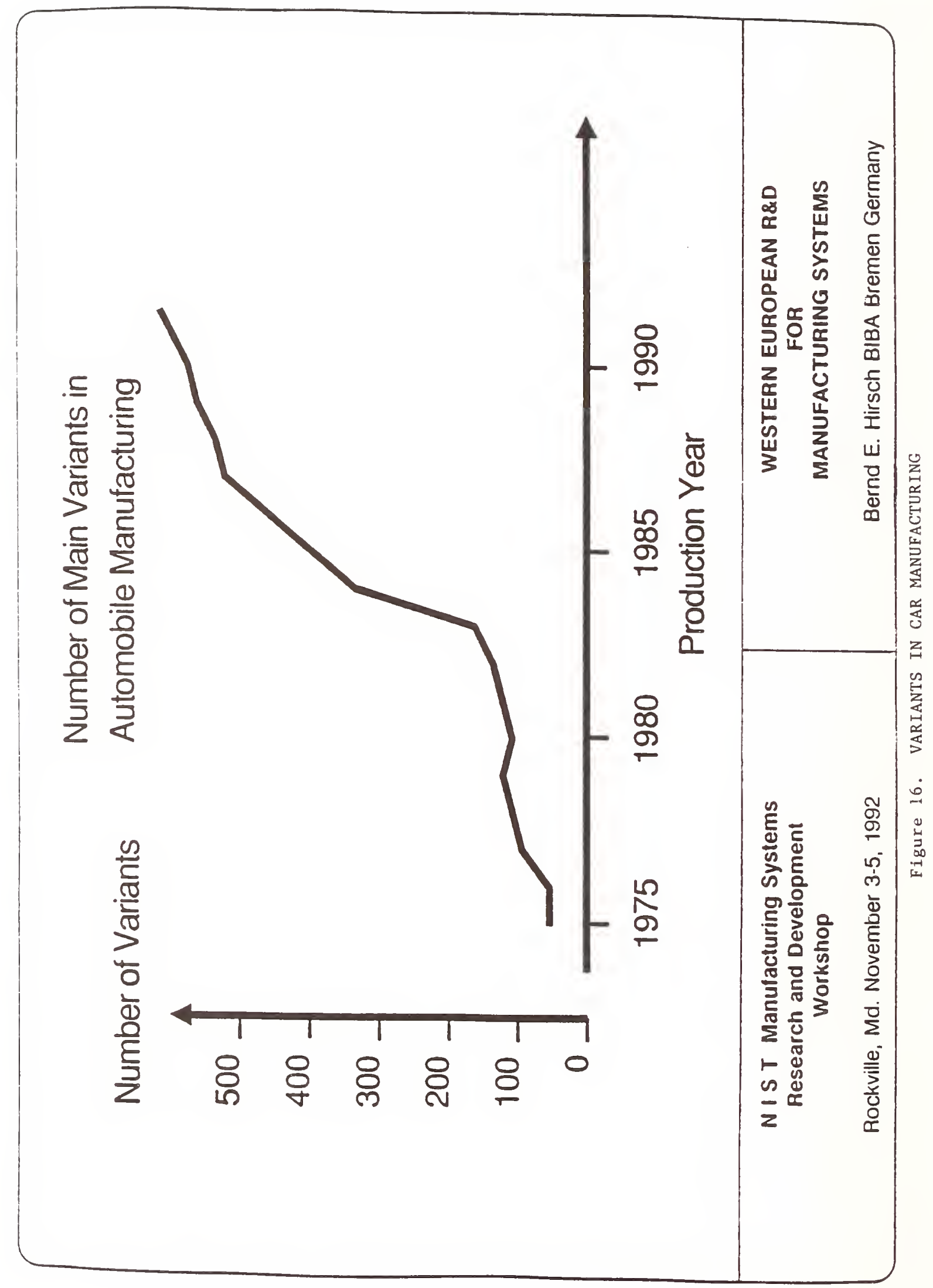




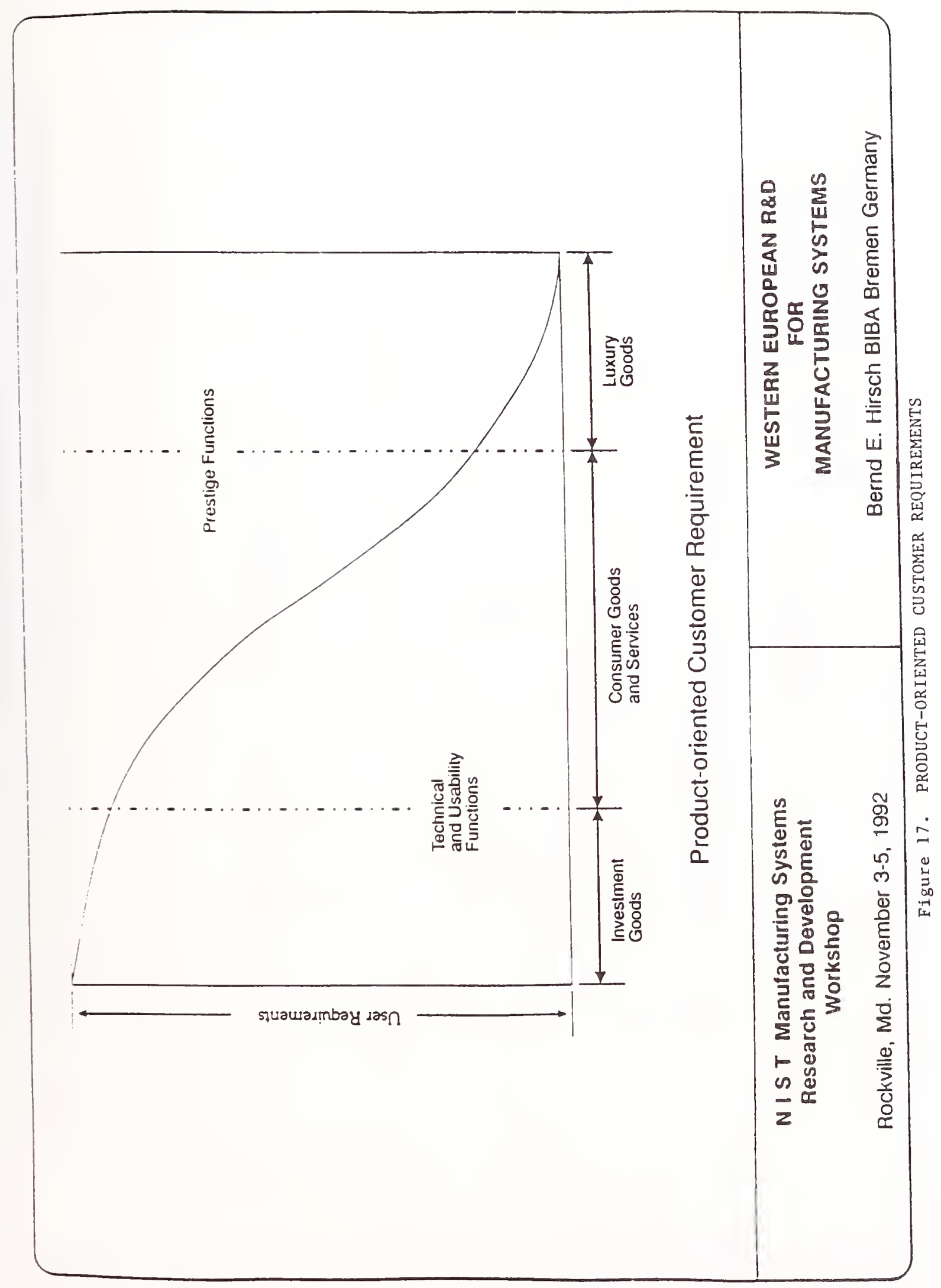




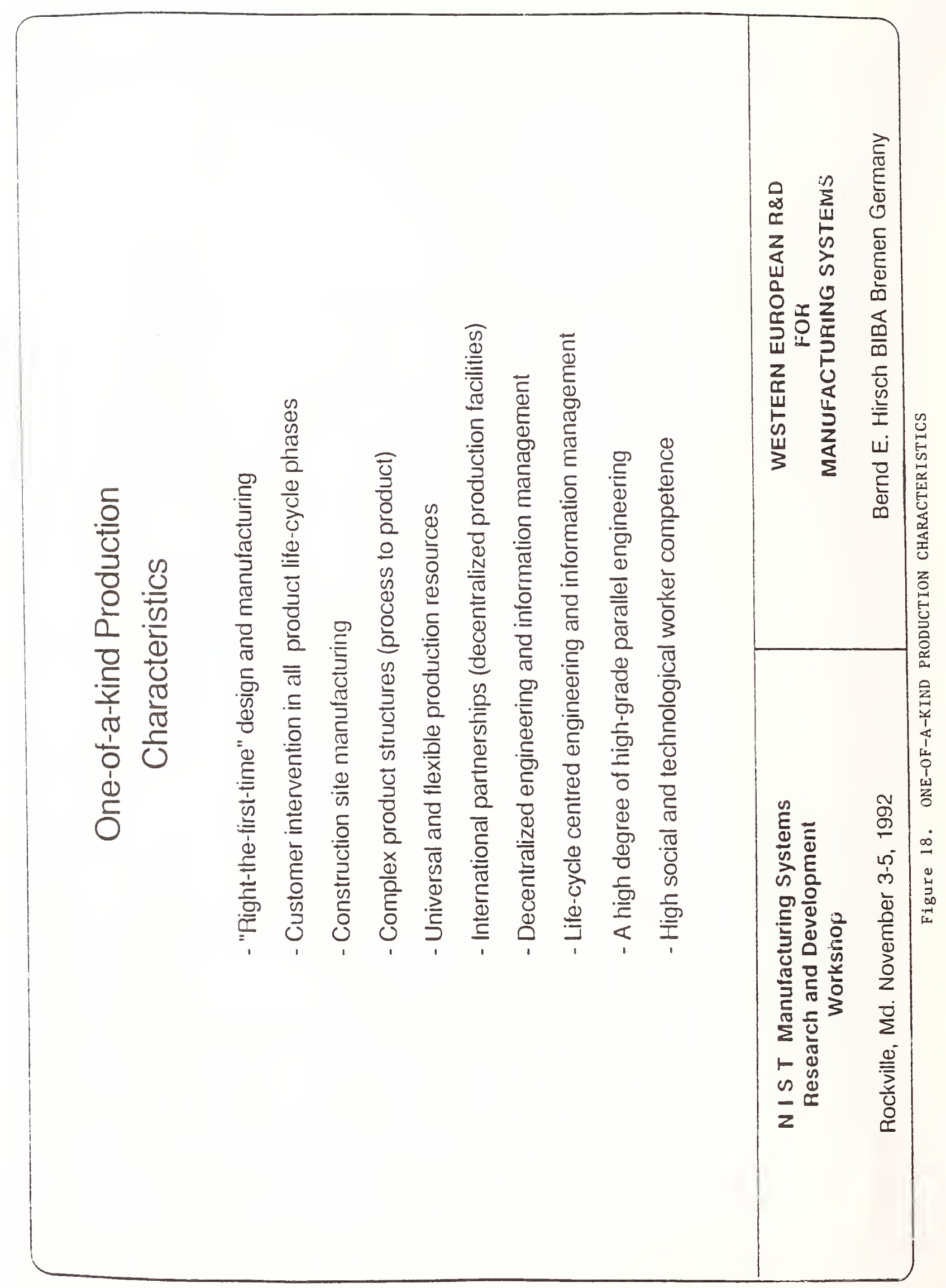




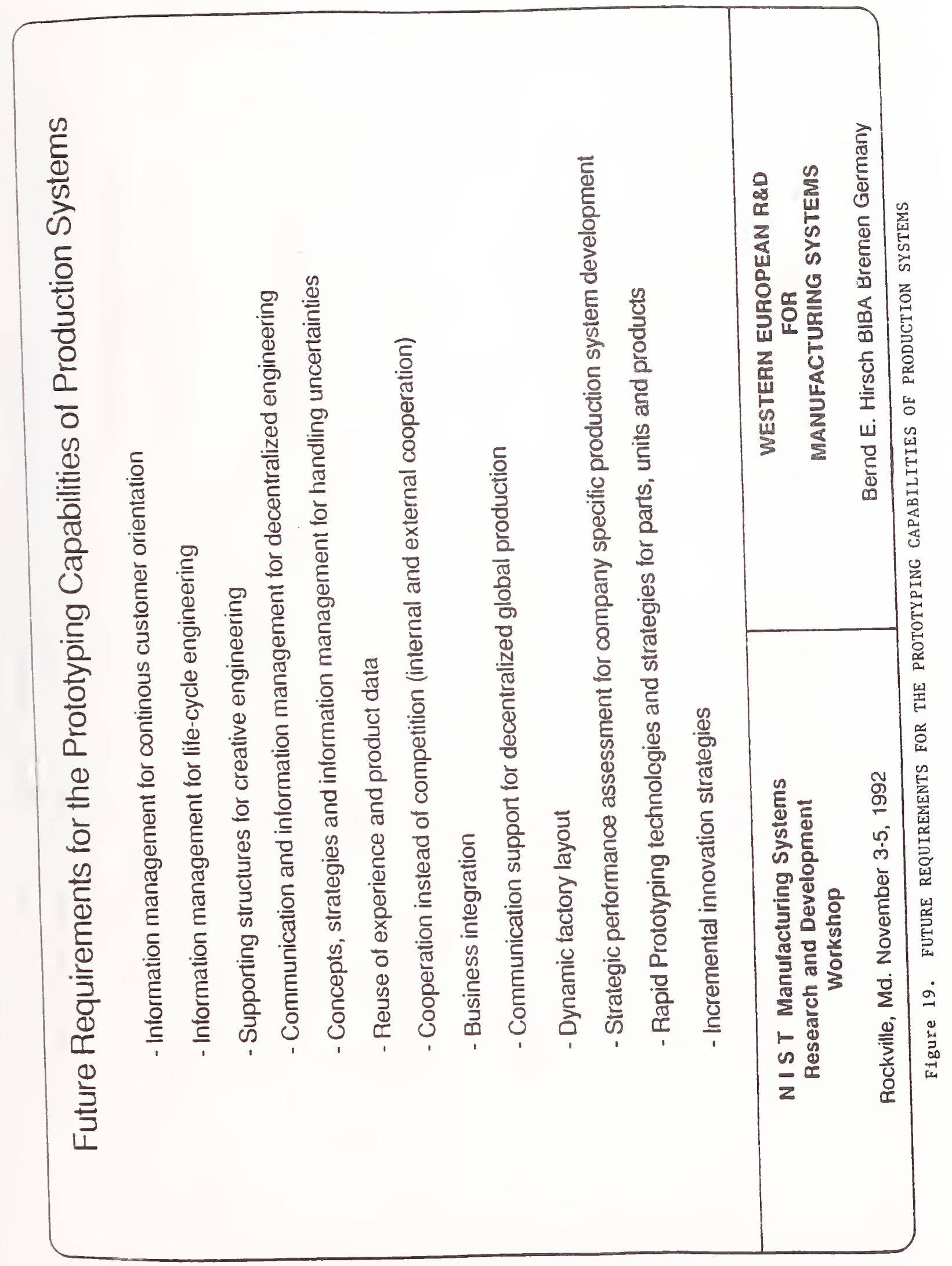




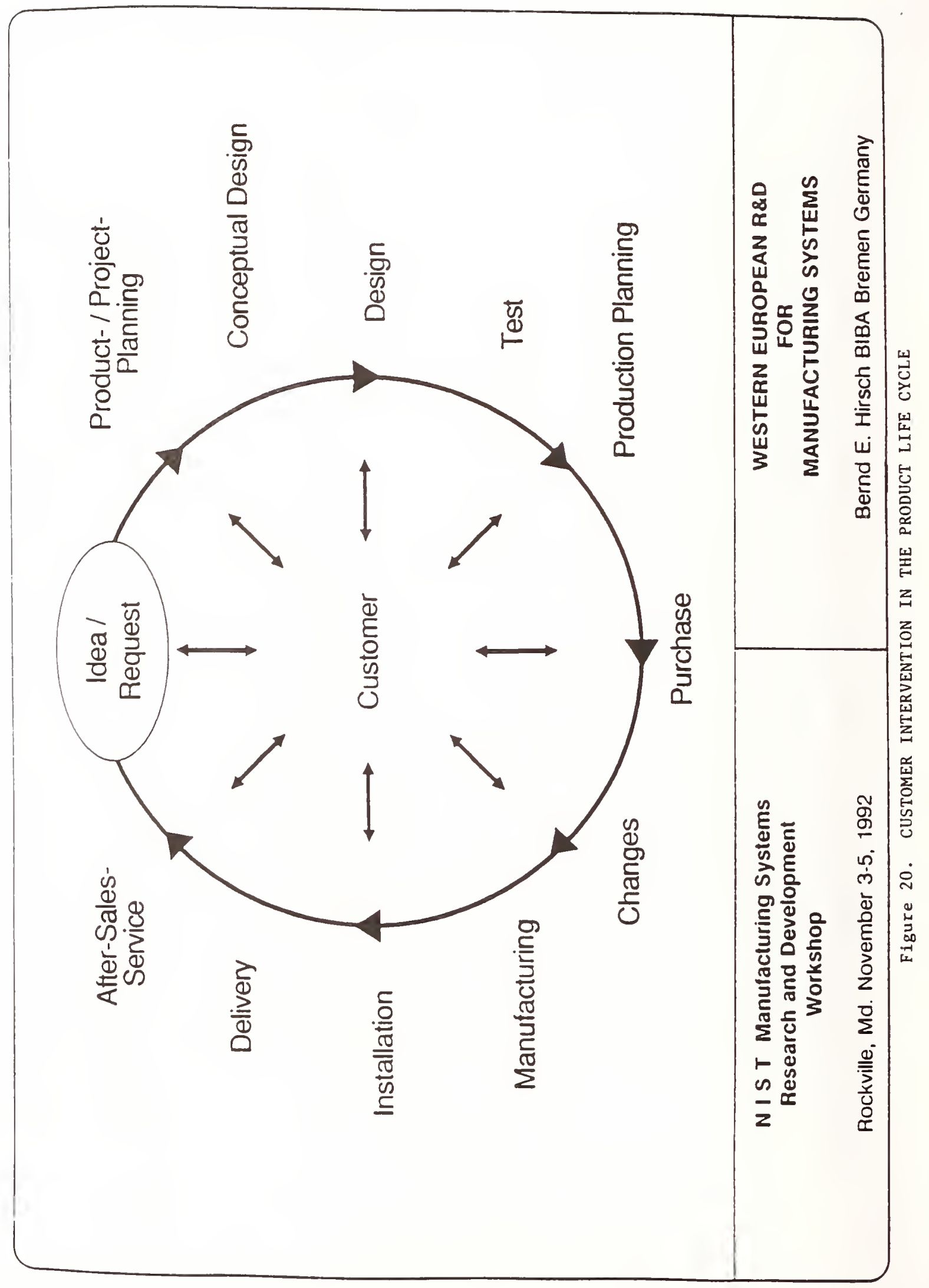




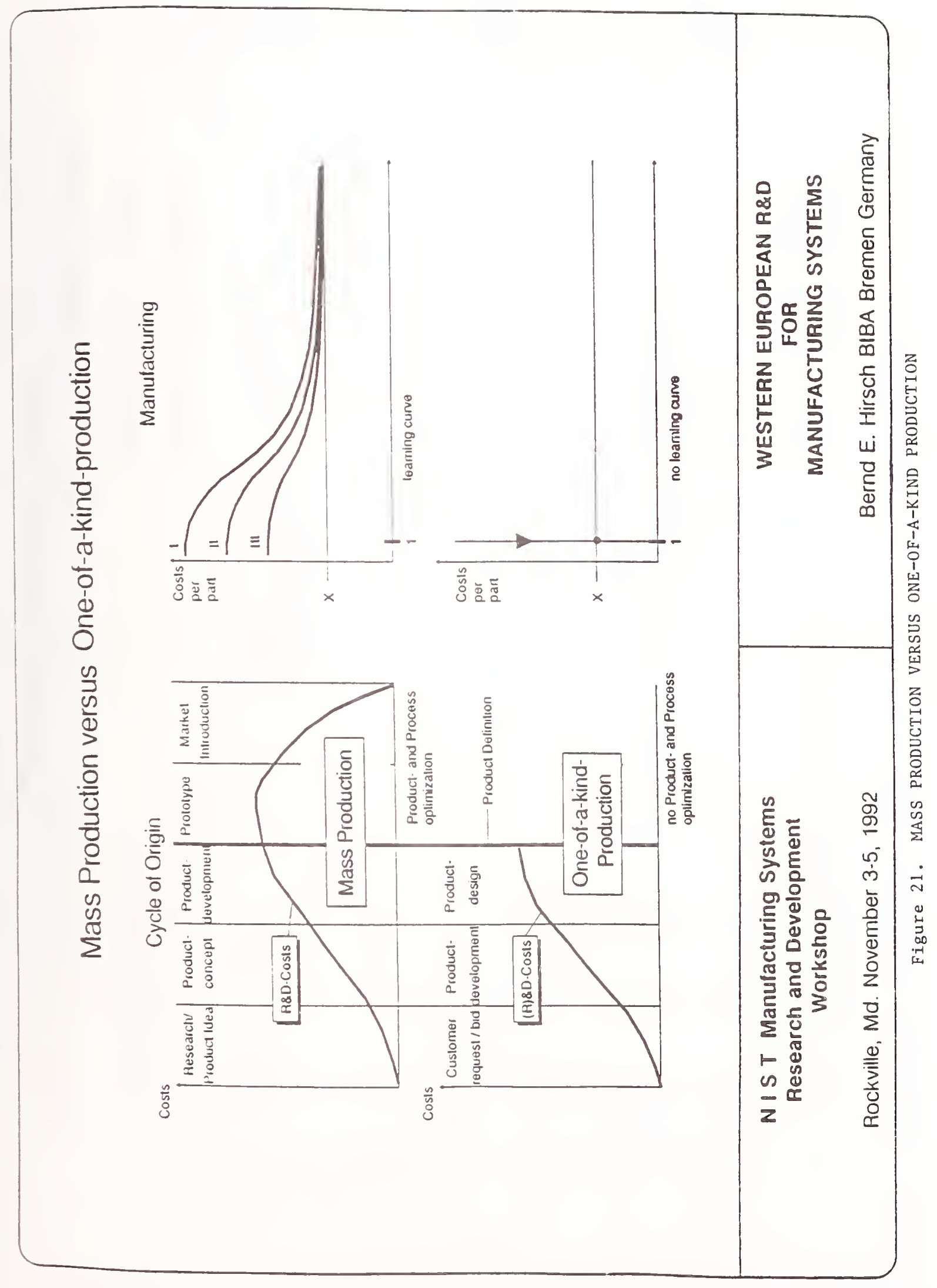




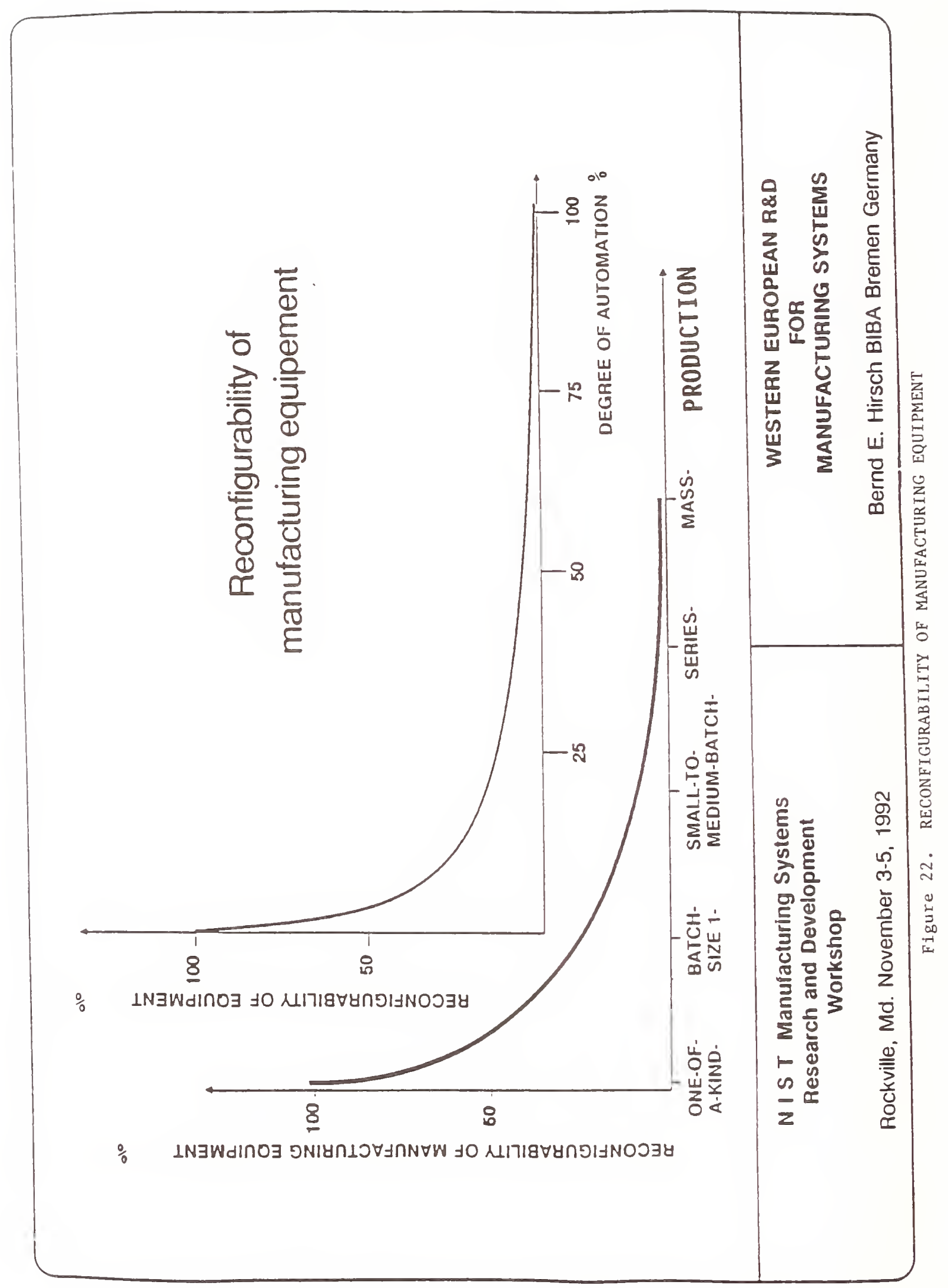




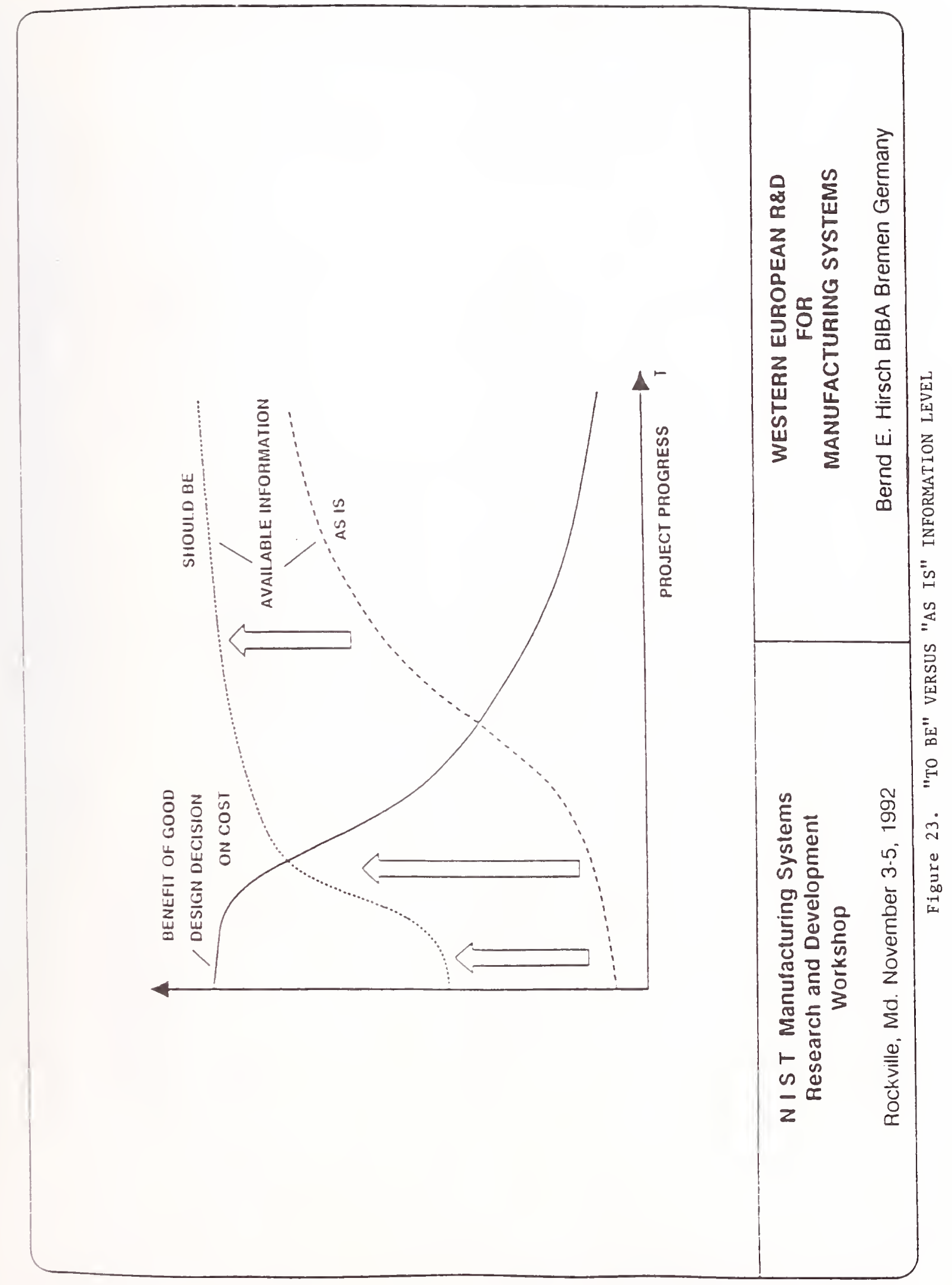




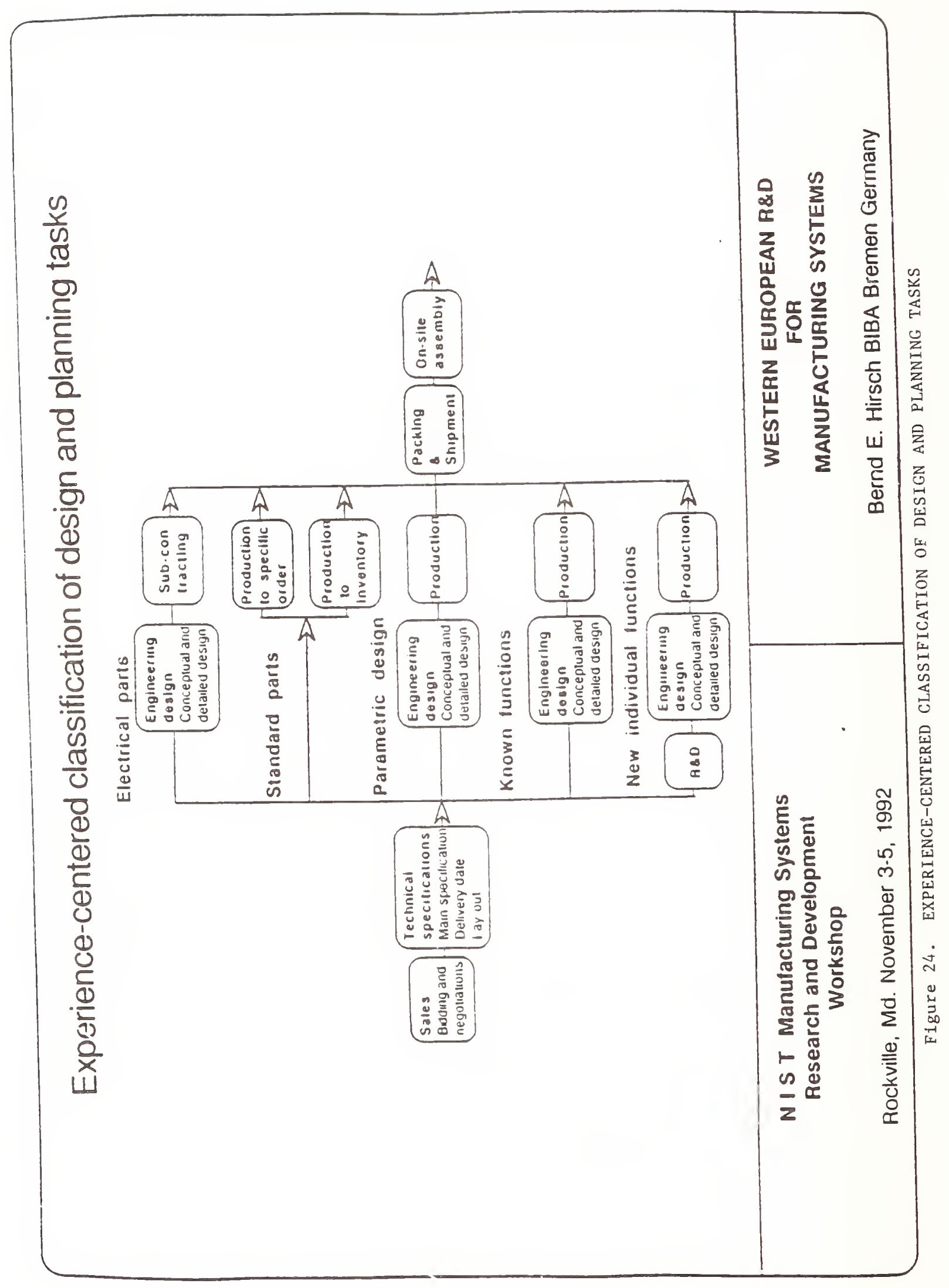




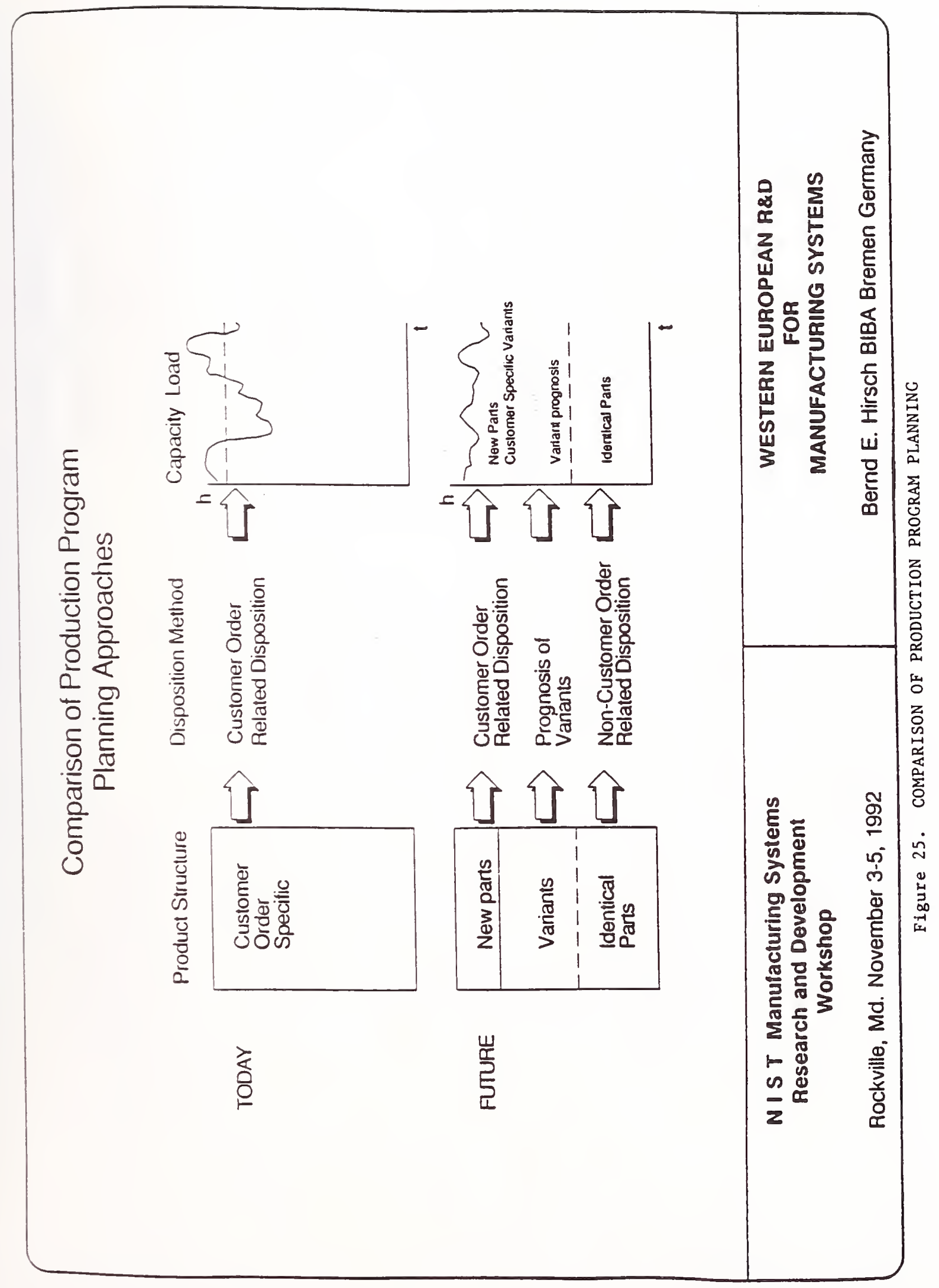




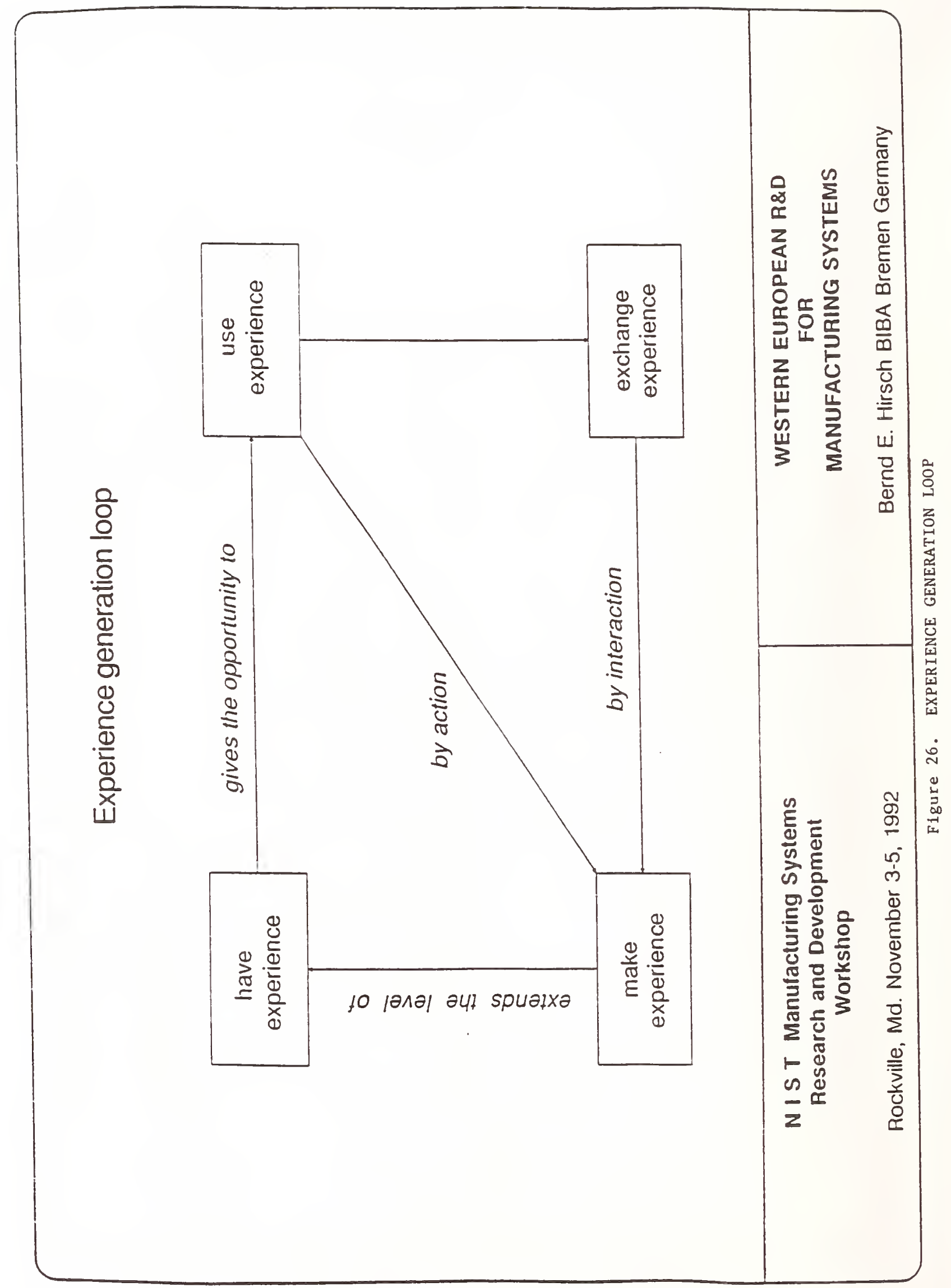




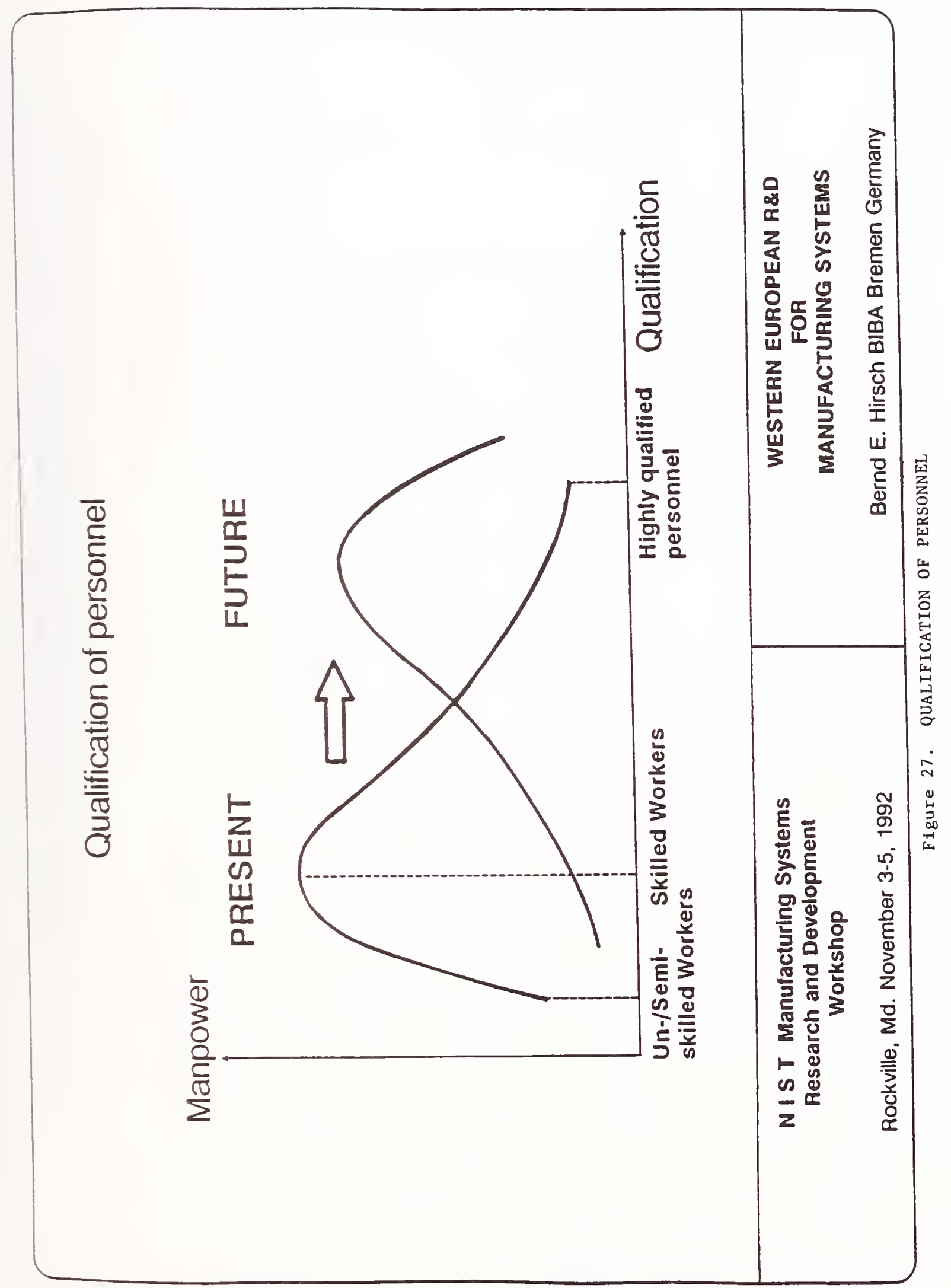




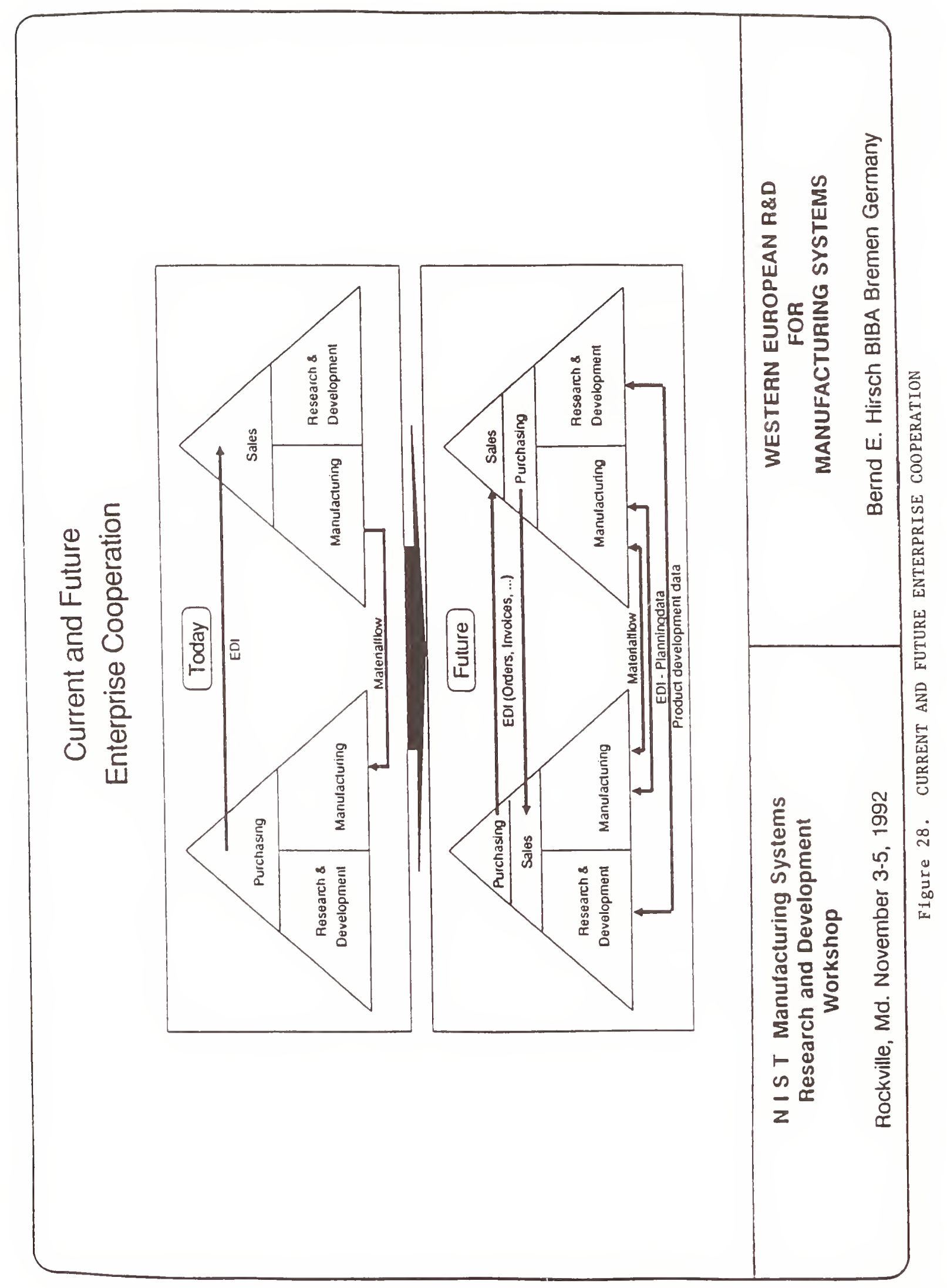




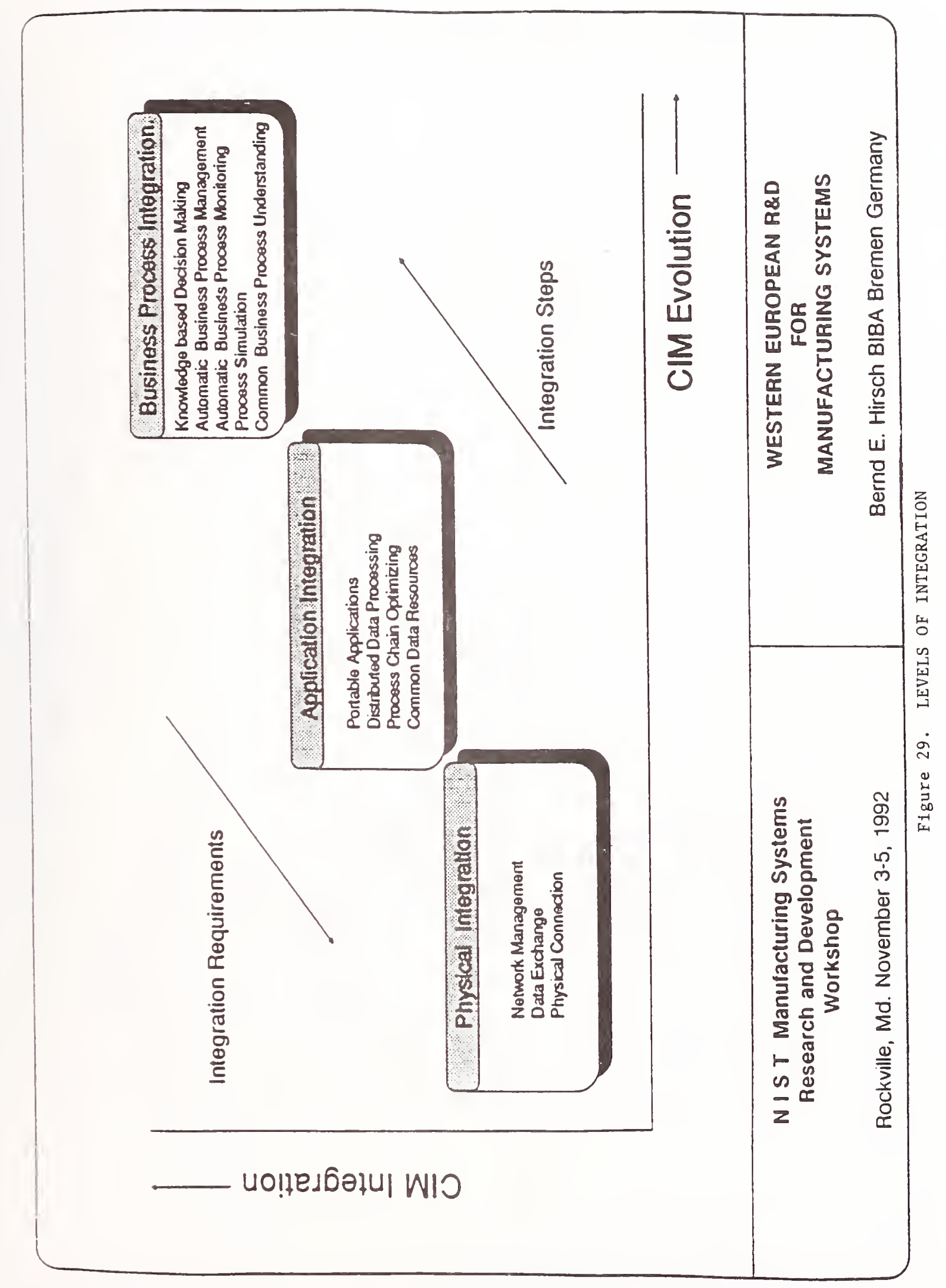




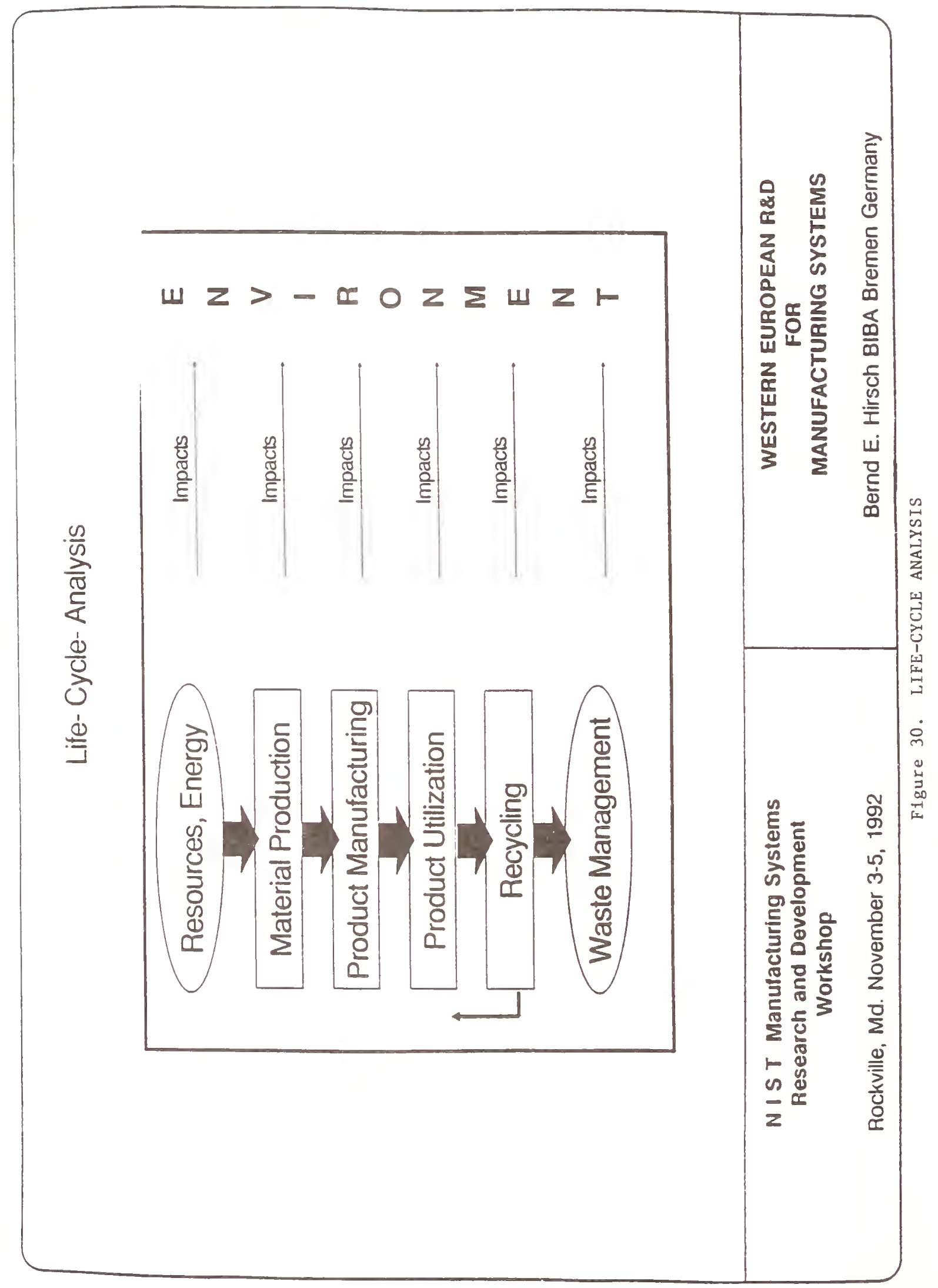




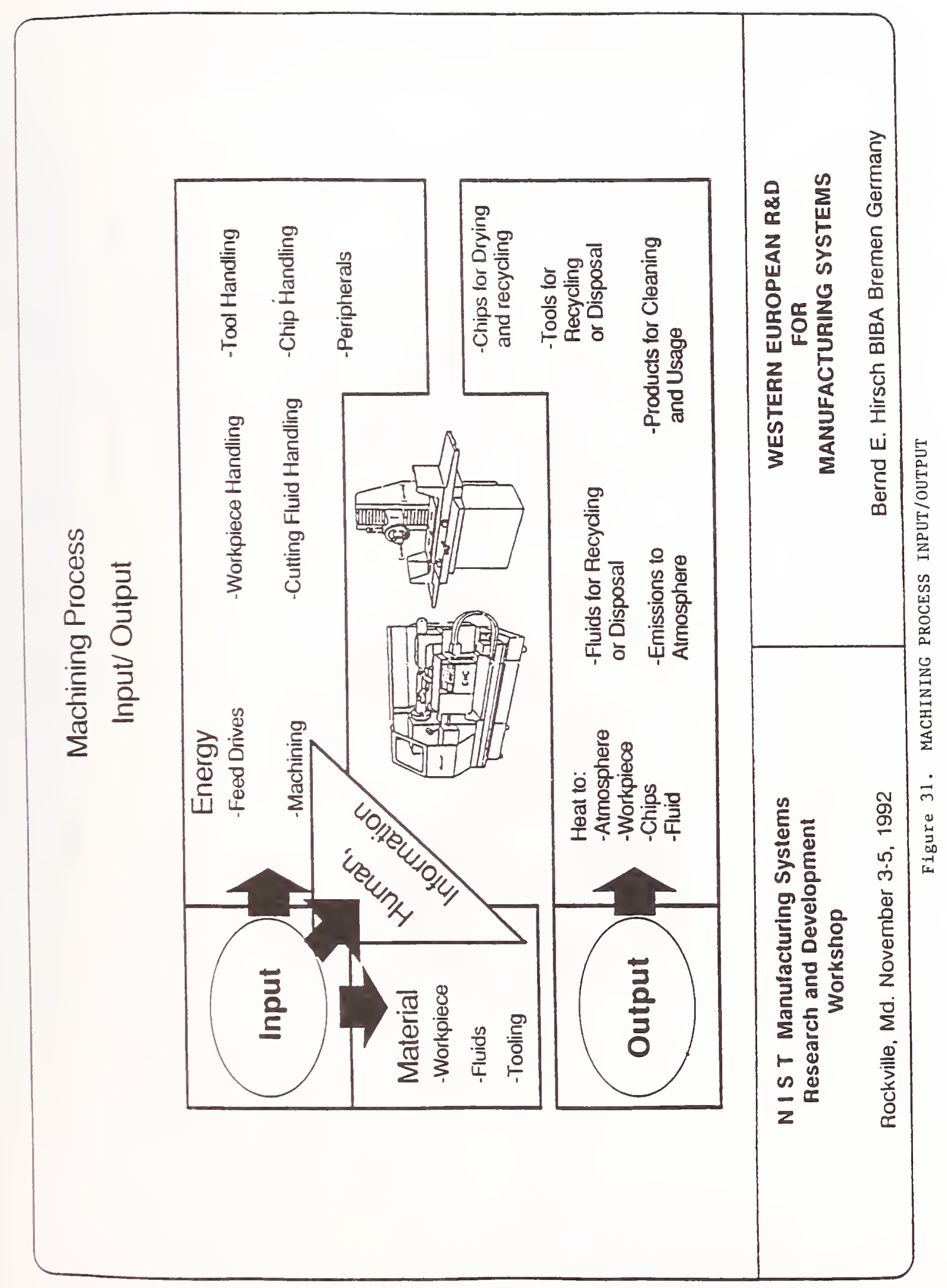




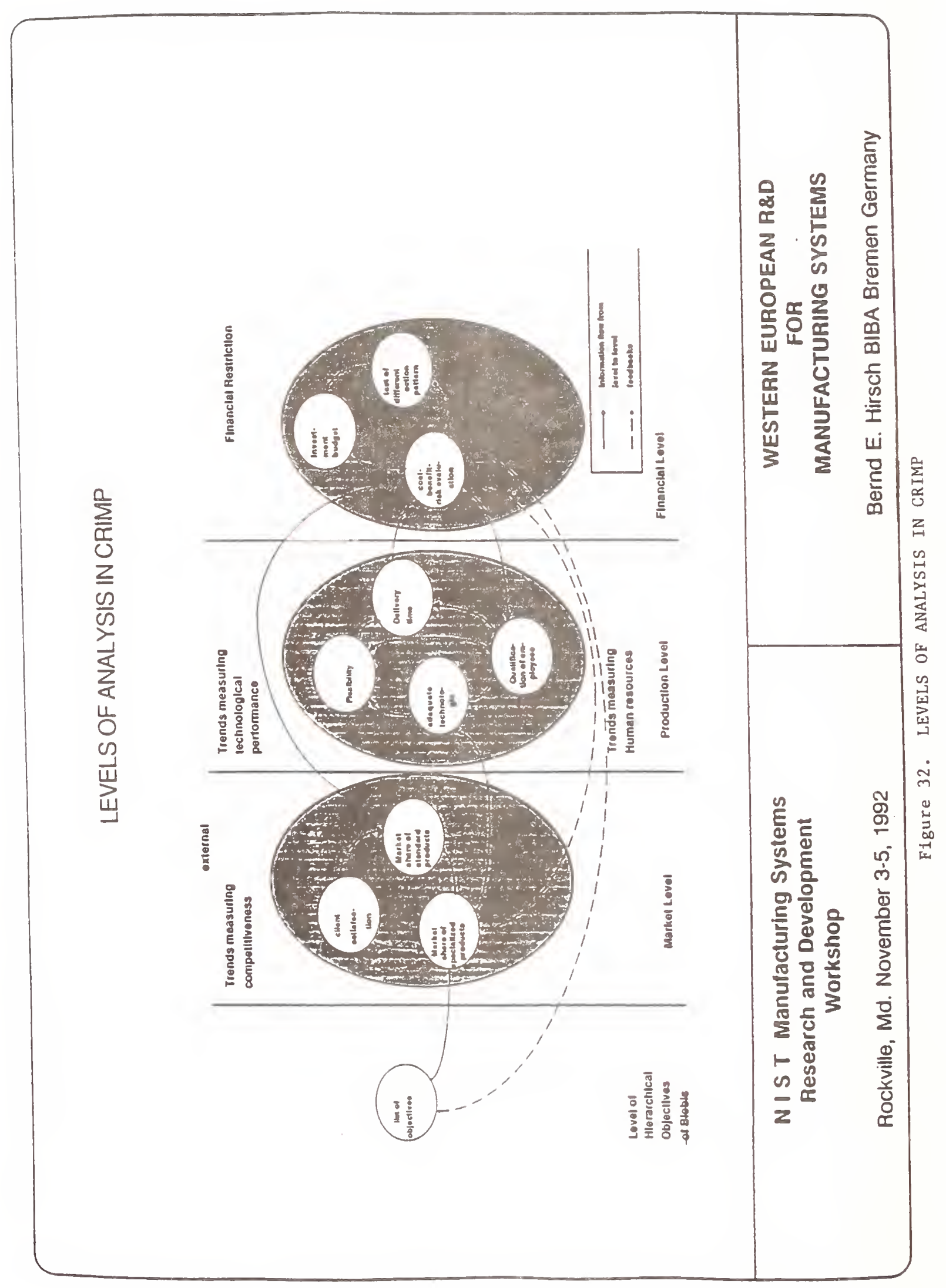


Russian Academy of Sciences

St. Petersburg Institute for Informatics and Automation

\section{Eastern European R\&D in Manufacturing}

\section{Main Tendencies in Research and Development of Advanced Manufacturing Systems in Russia and Eastern Europe}

St. Petersburg - 1992 


\section{Main Tendencies in Research and Development of Advanced Manufacturing Systems in Russia and Eastern Europe}

\section{Contents}

Introduction

State of Economics and Industry in Russia

Research Strategies and Motivations in Developing of Advanced Manufacturing Systems

Tendencies in the Field of Automation of Manufacturing Systems

Tendencies in the Field of Equipment Design and Industrial Engineering

Tendencies in the Field of Production Scheduling and Control

The Role of Information Management and Strategic Planning in Development of Manufacturing Systems

Potential for Collaboration

Appendix I. Russian Projects of Automated Plants

Appendix II. Organizations Working in the Field of Advanced Manufacturing Systems 
Abstract: Main tendencies are considered in the field of research and development of advanced manufacturing systems in Russia and Eastern Europe, caused by specific economic situation and engineering traditions in the countries.

\section{INTRODUCTION}

The title of the paper implies that the content is devoted to the situation in East-European countries. Unfortunately, in a short period of time, it was not possible to get exhaustive information about all former socialist republics of Europe and USSR.

Therefore, the main summary and conclusions are made on the basis of analysis of the situation in Russia. But to the strong belief of the expert group preparing the paper, the situation in the other countries is very similar because of adequate conditions in which they are now. The information which we have by means of international relations and post exchange proves that we are not mistaken. So the narration is organized around Russian events but it is possible to extend the main principles and conclusions to all countries mentioned above. In the table exhibiting research organizations working in the fields being examined, representatives of East-European countries can also be found.

\section{STATE OF ECONOMICS AND INDUSTRY IN RUSSIA}

The main distinguishing features of the economic state of Russia are as follows:

\section{In Economic Branch}

a. Recession in economy shows that the gross national product has reduced correspondingly: in 1990 - by $3 \%$, in 1991 - by $9 \%$, and in 1992 - by $12-15 \%$.

b. In essence, none are those production relations which are adequate to exchange economy. With $90 \%$ capital funds being state property, private enterprises do come into being.

c. Actually, the market relations are non-existent, forming in but only the commodity market; the capital and financial markets are none. The existing commodity market is deficient.

d. The government policy "profit-tax" is changing all the time and this, practically, excepts the possibility of strategic planning for the development of enterprises and their technical reconstruction. Add to this the perspective of privatizing the enterprises by the end of 1993 $35 \%$ federal and state property - to be privatized, total cost of the capital fund being about 1.5 billion roubles.

e. There is an inflation outbreak in the financial sphere. The average speed of money issued for the last 15 months makes up $37.4 \%$ a month; therefore there is no market basis, i.e., producer's competition for a consumer's rouble. In this case, increased are sharp rates of 
interest on credit - they amount to 50-100\% annual ones, this exceeding the world standards 5 times and more.

f. In energy and transport infrastructure, for the last 5 months, more expensive have become power-carriers and transportation services (more than 10 times). However, considering the existing rate of the Russian rouble converting, this is considerably lower than world prices (the price of oil is $10 \%$ of the world price).

g. As to the sphere of labor resources, wages have grown 10-20 times (mainly in the raw materials and extractive industry), in the science-consuming branches, those do not exceed 2-3 times, the living standard of the population has fallen 3-5 times. All of the above indications lead to the loss of qualified personnel draining off from the production and scientific sphere.

h. Because of political reasons, there takes place breaking off of the economic connections among the enterprises, substituting of the civilized character of the commercial agreements "commodity-money-commodity" for the form "commodity-commodity".

i. The level of inflation in 1992 will amount to $2100 \%$, comparing with the developed countries where it is $3.3 \%$.

\section{In Industry Branch}

a. In the industry of Russia, predominant is the proportion of "non-market" branches: extractive and raw material industry and military industry (the latter in St. Petersburg makes up 70\%); necessary is structural reconstruction of the industry which leads, as it is known, to the decline of the traditional branches.

b. Giving up the militarization of the economy has resulted in essential reduction of the state order for the enterprises of the military industry complex (in 1992 - by 30\%, for St. Petersburg - by $75 \%$ ). These conditions bring the necessity of carrying out their civil conversion.

c. By force of historic reasons which have dictated the existence of the Russian enterprises within the bounds of the tough centralized state systems of planning, the life cyclical phases such as - "marketing" and "follow up" - are, practically, in embryo at present time.

d. On the threshold of privatizing, the large-scale enterprises begin to disintegrate and form mobile small enterprises with their own subject-closed specialization of production.

e. In connection with raw materials and materials becoming more expensive, the expenses of the enterprises for the first months of 1992 has exceeded their incomes 3-4 times. That has brought, for example, over $20 \%$ of the enterprises of St. Petersburg to the verge of ruin.

f.. Under the conditions of existence of the deficient domestic market, in fact, there fallen away are the requirements to be satisfied by the products' quality. 
g. Simplification of the foreign economic activities has required from some developed branches as avia-, motor-, and power-plant industry to increase competitiveness of products. This being expressed, among other things, for example, in increasing the proportion of individual orders up to $30-50 \%$ of the production volume.

h. The processing equipment of most parts of the enterprises is worn out (17\%). This has resulted in reduction of industrial production rate, for example, in May of 1992 - by $15 \%$.

i. Most of the enterprises have practically no present-day information technology, as the Russian computer science has lagged behind the world level for no less than 10 years. Acquiring the up-to-date equipment and programs requires hard currency, but this, under the existing conditions of forming the state currency equalization fund (about $50 \%$ of hard currency income is withdrawn from the enterprises), is significantly difficult. This is the cause of isolation from the information recourse of the civilized world, and among other things, from the wold bases of data and knowledge.

j. The level of capital investments in the industry has abruptly been reduced. Compared with the 1 st quarter of 1991, it has reduced by $43 \%$ with the largest drop being observed in machine-building; it making up $60 \%$.

k. During the last two years, the volume of financing of research and development in the field of advanced manufacturing systems has reduced no less than 3-4 times.

Nowadays in the frame of the newly established Ministry of Industry of Russia, special funds for research and development of advanced manufacturing systems are being founded:

- The fund for tool and equipment design,

- The fund for support of industrial engineering works.

But up to this moment, the volume of these funds has not yet been defined.

\section{RESEARCH STRATEGIES AND MOTIVATIONS IN DEVELOPING OF ADVANCED MANUFACTURING SYSTEMS}

In order to organize designing and development of the manufacturing systems within the ministries and departments, in former days, leading designing institutes were created specializing in development and design of new plans and specifications for erecting the enterprises engaged in production of articles in conformity with the type of the ministry. These designing institutes formed scientific research programs, worked out the plans of financing the creation of new productive capacities, and developed the existing ones of these ministries. Uncoordinated and closed designing works resulted in their duplicating, choosing the subjective decisions connected with using the processing equipment from that for machining, preparing processes, and for the specialized machines intended for performing the unique processing operations. This tendency was maintained and at transition to ordering and purchasing the processing equipment abroad. The leading institutes dictated not only the 
technical policy aimed at working out the projects but at the reconstruction and technical requirement of the enterprises as well.

At present, such a tendency has weakened significantly due to decentralization of planning and financing of the enterprises. If finances, in particular, relating to long-term programs, have been reserved by the state structures (committees and commissions), the enterprises have consolidated their initiatives to define the directions of the scientific-technical development and their realization, and the administrators (mainly chief engineers) of the existing enterprises have to become chief designers of programs for technical reconstruction being responsible fully for the strategy and realization of chosen direction.

For the last ten years, observed are several periods concerning strategy of creating and developing the enterprises peculiar to the tendencies in the society. At the beginning of the 1980s, the extensive way of development of the productive capacities at their high specific amount of metal per structure as well as high power consumption has resulted in exhaustion of most natural resources. The direction adopted in reconstruction of the society has influenced the strategy of development of the enterprises and caused the changes in it. Aiming at intensification of the production has led to creating the all-union and regional programs for reconstruction of the enterprises. The base of this being introduction of automated or "substantially" automated production systems based on using the flexible manufacturing systems. Investments of considerable capital of the centralized use into the processing equipment (indices, as a rule, has let down from the top, at least, relative to automation level of processing operations) have led, most commonly, to the fact that the general production process has not been developed as required. Thus, introduction of highefficient equipment for the local processes increasing production 2-3 times, has led to general growth of productivity $2-3 \%$ maximum.

Such an insignificant general effect of automation level change has been caused by lagging in other types of provision, for example, in information servicing means (technical preparation of production, managing the materials' flow was mainly carried out only on paper base). Even there, where the introduction of flexible modules (FM) into production process was successful, the production preparation was not in time for their requirements. The effect from their introduction corresponding to the amount of financing was obtained only in large-scale production, but this requiring considerable cooperation of customers of the given products.

The experience of five-seven year introduction of the automated modules, sections, and shops, as well as considerable reduction of centralized financing have led to the necessity changing the strategy of development and reconstruction of the enterprises. In 1989, the decision was taken to concentrate financing for special purposes in the form of the projects for creating the plants of the future which are a testing ground of integration of the automated systems for different purposes (see Appendix 1).

Such testing grounds of the state budget financing for special purposes are meant to solve the problems of creating the integrated automated systems based on the typical designs for different-purpose automated systems followed by their circulation. 
At present, the concentration of financing does not give the due effect, although it reduces the level of duplicating the developments being financed by the state. To our mind, this is connected with the following shortcomings of organizing these works:

- insufficient experience of creating the industrial software: the USSR had no market of the programs of domestic production and, as a rule, each software product had singleintroducing equal to (93\%), two-or-three times introducing - $(5 \%)$, and the rest - $(2 \%)$ for the circulated software product (data of 1991). This tendency (ordering by myself-using by myself) has led to the deep-rooted technology of carrying the program product to completion in the shortest time in order to pass it to the electronic computers of the customers considering their remarks and by no means satisfying the requirements of the technology of the software being circulated (though operation was not services by the development engineer);

- not strict enough discipline of executing the specifications for each subsystem (long terms of development and introduction - lead to the changes improving each component, but the characteristics of their integration are growing worse);

- insufficient, to our mind, financing for purchasing the computer facilities results in orientation to personal computers (both - in developing organizations and in computing centers of the plants under design). These are effective for solving test problems in designing institutes, but as far as real volumes of information are concerned, their field changes are lengthening out for long terms (half a year - year);

- high barrier of currency rate in respect to a rouble on the domestic market has not allowed wide use of western software and this leading to complete and, rarely to partial lack of the discipline of standardization of data exchange on specialized developments. The level of user interface has made no provision for strict control of the data being introduced.

Widely used were own database management systems without deeply analyzing the requirements to the typical ones, and in these cases any transition to the up-to-date software led to partial and, sometimes, complete loss of information (this being a deterrent for their introduction), or to parallel accompaniment of several versions of program systems for onetwo years.

\section{TENDENCIES IN THE FIELD OF AUTOMATION OF MANUFACTURING SYSTEMS}

The problems which are stated today in the field of production automation can be classified conditionally into two groups:

- the first group is brought to mass covering with partial automation of some machines, units, and processing operations as part of their reconstruction and modernization;

- the second group is brought to radical changes in the processes and to putting into operation of integrated production processes. 
As the domestic experience shows, $50-70 \%$ of the defects found in the ready machinebuilding products are caused by errors in the design, $20-30 \%$ are due to the limitations of the production processes, $5-15 \%$ are through the workers' fault. Therefore, throughout the processing requirement of our country, of great importance are automated integrated processes. The integrated processes are developing in two directions:

- integration of processing operations through concentrations of the operations when a number of operations are being tied together on one machine or on the complex of machines;

- computer-integrated processes realized by means of integrated production complex (IPC). This direction is considered defining in development of the production processes now.

Integration of the processing operations is realized by two ways:

1. Creating the multi-zone processing centers (complexes), including several operating zones, for example, St. Petersburg State Technical University has created the complex with the zones of plasma jet hard facing and machining by cutting and grinding. The use of such complexes, to the experts' mind, will provide the possibility of increasing the time of proper machining with the use of equipment from $5 \%$ to $28 \%$ of the operating time fund.

2. The units with several machining heads, for example, centers of $A \Gamma \prod-400$ and AГ I-300 type (with four and three capstans) developed by Research Institute for Technology and Organization of Production (in Moscow).

The development of automation goes in parallel with development and usage of information processes. Today the production is characterized by complication and complexity, this requiring the creation of new management approaches. Thus, the decisive role of success of the production processes belongs to such information processes by which completed are the production processes.

The basis of these facts (in principle, making provision for the status of IPC at our time) becomes apparent in the tendency making provision for development in two directions. This tendency is oriented to real and wide introduction into the industry of the fully automated complex system of production. The first of these two directions is a "management" one, and it stimulates development and usage of new management methods of production systems. Both directions are important when mastering the new and high-efficient method of the production organization which is assumed as the basis of IPC.

Within the technological direction outlined are two development tendencies. The first is a clearly defined tendency aimed at creating the powerful potential for simultaneous designing the articles, planning and realization of their production as well as servicing. The second important technological tendency is directed at development of artificial intelligence for the production systems. Within the management direction defined may be four types of important development tendencies regarding correspondingly, organizational, professional, educational, and financial aspects of the enterprise activity. 
In Russia, these important strategical directions of the production systems development are not widely spread enough for now. The main reasons are as follows:

- the manufacture of modern qualitative and safe complexes of the processing program-controlled equipment with numerical control realizing ecologically-pure "breakingthrough" resources and power saving technologies have not been corrected;

- enough qualitative and safe computer facilities of all the classes necessary for IPC have not been manufactured;

- there is no qualitative and safe equipment and software for creating the computing networks;

- the manufacture of the peripheral equipment necessary for recording and primary processing the information is not organized. The question is remote collection of data, operating control of the manufacture processes, information representation, commutation and data transfer;

- cheap and reliable supply stabilization units for computing means, including built-in control systems of the processing equipment with numerical control are not manufactured;

- there is no series production of system, problem, and application software for flexible manufacturing systems.

\section{TENDENCIES IN THE FIELD OF TOOL DESIGN AND INDUSTRIAL ENGINEERING}

The analysis of the methods and means used in the process of designing the equipment and tools shows that their development depends on the technical possibilities of computing means. At the beginning of the 1980 s, computers were mainly used for engineering calculations of the parameters based on physical models of the objects under design. Among these methods are, for example, strength analysis carried out with the use of the method of finite differences for constructions, gear-boxes of processing equipment, fastening elements of cutting tools, temperature distribution in stamps and so on.

The next stage was the creation of data bases for design decisions. This allowing:

- to reduce labor-consuming search of scientific and technical information and specification and standards to pass to designing with the use of prototypes; this resulting in considerable effect when using the borrowed and most successful designs;

- to carry out realization of most functions of the technical systems with the use of one physical phenomena;

- to form a considerable number of versions to realize one physical function choosing the effective designs. 
In the middle of the 1980 s, started was the active use of computing means for automating the solution of the problems connected with turning out the design plans and specifications, drawings, sketches, and text. The first successful attempts in graphic documenting or of typical machine-building drawings have changed into difficulties connected with the organization of automated files (data bases). Limited volumes and low safety of data storage facilities of search of parameterized drawings, lack of full volume of technical means for preparation of documents - all this has led to existence of a double standard. Left was the technology of turning out the paper documents by hand in conformity with the old standards; designations, code classifiers, and so forth. At the same time, it was the new system of simplified requirements that was developing actively. The latter allowing to formalize the process of graphic and text documenting. Naturally, the double standard of documents has not allowed to introduce full volumes of data-retrieval, reference, and other automated data processing systems for information service of the production.

Another important problem for creating CAD/CAM systems is predominance in using personal computers. During the first stage-wide use, personal computers gave the possibility at the end of the 1980s to increase sharply the number of automated working places in design offices and in production. Convenient "friendly" interfaces for the users have stimulated to a great degree their use on a mass scale. Their spreading was greatly connected with lack of legal protection for software in the USSR. Availability of western automation facilities has given the possibility to include them into the production cycles within the shortest terms. In many cases, the software on a personal computer has not required money investments, at least, on the stage of its mastering and introducing. But this had also a negative effect. For medium-scale and large scale computers such a method of getting software was not realized. Such a situation has led to an abrupt disproportion of using the computers of different classes - main orientation is directed to personal computers. They are used for multi-hour engineering computations, for creating the production data base and so forth, i.e., solved are the problems with the specifications unsuitable to them. Usage of local computer networks based on the personal computers of IBM PC-type does not solve the principle difficulties of using the computers of this class.

The mentioned problems hold back the development of CAD/CAM systems in the states of the former USSR. However, great scientific potential allows us to make optimistic prognosis for developing these systems. To our mind, creating the financing mechanisms on the basis of the requirements for creating the industrial software will give the possibility to raise their technical level.

The main tendencies of creating CAD/CAM systems in Russia as well as in the former USSR can be presented by the following directions:

- creation of interactive designing medium that makes provision for multi-functional graphic user's interface in order to operate it with multi-media information;

- actively including into the designing process the knowledge bases with different reasoning mechanisms by means of creating the expert systems, decision-support systems, intellectual CAD/CAM; 
- development of the means for geometric modeling of the complicated details and space constructions;

- creation of the distributed data bases (deduction, object-oriented, semantic, weak type-designed ones, and so forth;

- development of parallel process decision-support in CAD/CAM systems.

\section{TENDENCIES IN THE FIELD OF PRODUCTION SCHEDULING AND CONTROL}

One of the key directions of the large-scale automation which was started at the beginning of the 1970s is automation of production scheduling and planning tasks. In this case, the main tendency of solving these problems is connected with their position in the hierarchy of the production tasks.

The automatic control systems was designed by tradition as a multi-level storage system. The top level (of the formation) is intended for solving the tasks of computations of volume and cost indices, for analysis of technical indices, redistribution of materials and labor resources, and for information servicing the administration. At the level of the plant solved are the tasks of operative-calendar management, engineering calculations, and designing and technological tasks. The next level is intended for solving the planning management tasks of separate shops and sections.

The first advance in this direction is connected with solving the tasks of automating the control of the technological conditions of separate production links (machines, production units, transport). The main means of formalization for such systems were finite-automation models. The subsequent stages were the works aimed at automation of dispatching control level of management and planning tasks (tasks in on-line moment mode of the technological complex members' activity in conformity with the schedule of actuation/release of details). In this case, the most effective are: situation analysis, recognition, classification, and elaboration of the decisions under the strict limits for the time of taking the decisions. At least, the present stage being considered is connected with complex decision of control and planning tasks as lower levels, so the top ones, including the tasks of operating control and planning the production. The methods and models used at this level are based, to a large extent, in simulation, combinatorial optimization, and artificial intelligence.

In spite of substantial simplicity and traditional character of general consideration of control processes and planning the production, the particular development of these systems runs against a number of problems of the principle character. Primarily, it is a high structural and functional complication of the technological objects under control. Besides, control does grow substantially considering the alternative equipment, processing operations and routes of processing the details. The control processes of production are characterized by the main features of the complicated technical systems, such as distributiveness, asynchronous, dynamic, and parallel character. Control of production systems is connected with processing 
the large volumes of information (about 100 Mbytes), the substantial part of which has, in principle, an illegible and heuristic character.

This has resulted in the following main demerits of control systems existing in most enterprises of Russia:

- excessive overloading by control and recording functions;

- planning the range and series of products based on the results obtained by studying the consumer's demand not being carried out. In fact, it is determined to a large extent by the consumer's requests and is not investigated by the enterprise itself;

- excessively low level of automation of the working places of the management subdivisions;

- deficient interrelations of the services when solving through control tasks requiring the unique information base and complex economic calculations;

-duplicating the work by the subdivisions;

- prevalence of the current (for a day) planning;

- most part of the working time is spent for the works out of plan (the main reasons of that are as follows: deficient operativeness of getting the necessary information; waiting for business meetings; necessity of frequent travel and long terms of their routes; shortage of personnel specializing in calculation of typists, messengers, and so forth);

- weak discipline of fulfilling the duties, high labor-consuming control of executing orders and directions;

- unsatisfactory organization of operative registering of the motion of material, blanks, semi-products, completing details, and assembly units.

\section{THE ROLE OF INFORMATION MANAGEMENT AND STRATEGIC PLANNING IN DEVELOPMENT OF MANUFACTURING SYSTEMS}

Now some words about Information Management (IM) and Strategic Planning (SP), one can say that in former socialist countries, these methodologies have been developed only during the last few years. That is true if we speak about them in western meaning. Namely we mean economically-oriented accumulation and systematic analysis of information for the purposes of development of the enterprise. It is very important that this kind of analysis is oriented mainly to support business activities of the company.

First about strategy, in the conditions of command system, there was no need to formulate the objectives of enterprise development based on philosophy of the firm and consideration of the 
market situation. In that, goals of each enterprise were defined rather strictly, at least for the last five years, by Ministry. Therefore, not so many top-managers were thinking about long term development of the enterprise. The main task was to fulfill the already defined five year plan. Of course, inside this plan there were special parts devoted to application of new equipment and technologies but in the majority of cases, the main directions were also determined by the Ministry or sometimes even by the Government. A good example is a case of universal recommendations for Automatic Control Systems (ACS) in the 1970s. In such conditions, the only task of the development group was to confirm on paper the possible efficiency of new equipment which was already recommended. From this came the fact that methods for evaluating the costs and benefits of new technologies were poorly developed. No methods of work analysis, very rare comparison of different innovation variants, and no topdown decomposition of enterprise structure were used.

One simple formula was applied for each unit of new technique, usually not in good connection with the other parts of the enterprise.

There was a kind of methodology of pre-design investigations for computer systems applications, publicated by the Ministry of Instrumentation. But it was formulated in an arbitrary way, fixing only the consequence of steps in the investigation. As a result, the generated documents couldn't be used as a base for project management, realizing systematic approach for the purpose of enterprise development.

The described activities did not bring to the situation when methodologies, devoted to development of the enterprises and organizations, were based on scientific achievements of systematic analysis and other branches of science.

We stress here that there was no need in usage of symbolic languages for description of activities, special methods of top-down decomposition, analysis/synthesis procedures, software packages, supporting the methodology and special CASE tools for production, adaptation, and follow-up of these packages.

As a conclusion, one can say that methods, connected with IM and SP were poorly developed. Automation tools for systematic analysis did not exist at all.

One of the reasons of the workshop is to identify unmet needs or gaps in our current R\&D. We can state here that one of the tasks of specialists working in the field of Information Management is to adapt and develop the above mentioned methodologies for the needs of East-European countries. Only with this condition, the economy of East-European countries can be successfully integrated with the others.

Moreover, we can say that these methods should be developed further, representing a better link with such areas as strategic marketing and organization planning.

These additional needs are connected with specificity of the economical situation in EastEuropean countries. It was said previously that many large enterprises, which were under the 
control of the government, have the tendency to be decentralized and are trying to find their place in the market.

For this purpose, they need an instrument for modeling new organizational structures and decision support systems for marketing.

Beginning in 1985 in former socialist countries, research in this direction was made separately by groups mainly organized inside universities and high schools. Appendix II shows the facilities of these research groups. It is visible that they are small. Maybe it is worth it to organize some type of common project to concentrate the efforts of the researcher.

\section{POTENTIAL FOR COLLABORATION}

Here we come to the most important point: Potential for Collaboration. In the opinion of the expert group who had prepared this report, it would be very useful to concentrate the efforts of international teams in solving the technological problems of conversion for military enterprises. We think this task is of common interest for many countries. We mean elaboration of a special methodology and decision support system which can help to convert the former military enterprises in the direction of civil production, keeping as much as possible of its property. In this paper we imply under term "conversion" mainly a technological not a social problem as it was understood before. In that case, the solution was simple: only buildings were kept, all other things belonging to the former enterprise were changed, including people. If we look at this task from the side of technological problems to be solved, we can find it much more attractive. As the result of application of such kind of methodology, you don't need to make any sharp decisions, such as lock-outs, etc. Instead, you have the opportunity to keep the most valuable parts of the enterprise and make a rather soft turn from production with centralized finance support to a market-oriented profitable factory.

In our opinion, this problem is closely connected to the topics which we discuss today because they are a part of reconstruction and development of the enterprise. Moreover, the main achievements in these topics, in principle, may be used as a basis for new advanced methodology. Let's try to describe it.

The most important thought is to determine new goals of the enterprise for civil purposes and to formulate a long-term strategy and actions for the immediate future. For this reason, it is thought that we will need a better link of "above-the-shop-floor" activities with marketing and general management. Such a support system has to be highly computerized because we need to examine plenty of variants.

After the strategy is formulated, we shall need a special tool for evaluation of facilities of existing equipment and one which is going to be purchased by the firm. At this stage, the main task is to keep the most suitable for new goal units and find the best new equipment to accomplish the whole system. 
This procedure is going to be repeated many times from the very beginning until we can find a good solution. Each iteration has to include cost/benefit analysis evaluating plenty of technical and economic parameters of every unit.

One of the features of new methodology is a possibility of top-down decomposition of the problem area by way of modeling the area in the graphical language. As a basis for such an approach, already existing methods may be used such as Information Systems and Analysis of Changes (ISAC) elaborated in Sweden or Structured Analysis and Design Technique (SADT) used in the USA.

A number of different models may be used in the development of such a system: functional models to define what the system must do, implementation models to tell how, and so on.

In many aspects, the application of expert systems, knowledge bases, and other tools might also be very efficient.

We think international research in this direction might be very fruitful. Many countries now need such an approach and special methodology. 


\section{APPENDIX I}

\section{RUSSIAN PROJECTS OF AUTOMATED PLANTS}

Creation of automated plants (AP) in Russia is financed now by the Ministry of Science, high school and technical policy based on the program "Technologies, Machines, and Production of the Future". In 1992, the volume of financing for scientific research to the experts evaluation, made up no less than 100 million roubles.

The leading organizations and the main executors of this program are: Experimental Research Institute of Metal Cutting Machine Tools, Research Institute for Technology and Organization of Production, Institute of Management Sciences (in Moscow), and St. Petersburg State Technical University.

The main principle for the organization of this program is financing the typical projects. Here are two examples of such in the machine-building field. Both projects are financed from 1989, expenses for the projects for the last two years amounting to:

1991

$\begin{array}{rr}15 \mathrm{mln} & 25 \mathrm{mln} \\ 4 \mathrm{mln} & 11 \mathrm{mln}\end{array}$

1992
MPO "Krasny Proletary" (machine-tool plant):

Tushinsky machine-building plant (stamps and moulds):
The terms of creating the base automated plants (AP): $4-5$ years

As does show the analysis of a number of the projects of the automated plants being realized in Russia, the cost of scientific-research and research and development works, if considering as the expenditures is comparable with the cost of the equipment of an automated plant. The expenditures for $S \& R$ and $R \& D$ works are distributed, in their turn, among the directions as follows:

Development of new technologies - 19\%

Development of tools providing system - $2 \%$

Development of CAD for product - $2 \%$

Development of CAD for tools - $2.5 \%$

System of automated programming for numerical control system $-7.6 \%$

Designing an automated plant $-32.5 \%$

Designing the quality assurance system - $19.2 \%$

Development of new information technologies:

hardware $-8.9 \%$

software $-4.7 \%$ 
The characteristics of the production as expected for the automated plants in comparison with the existing productions are as follows:

Labor productivity growth - 9 times

Reduction in the number of staff -4.5 times

Capital productivity increase $\cdot 1.5$ times

Increase of production output per unit of production area - 2.3 times

Level of CAD works and technological preparation of the production (TP) - up to $90 \%$

Level of automating the manufacture, control, and tests - up to $70-90 \%$

In connection with the high labor-consuming process of automation of control and designing tasks at an automated plant, they will be realized in the following turn (in brackets indicated is a relative cost):

The first turn (20\%):

- Forming a portfolio of orders,

- Considering the plan of finished products supply,

- Designing the control programs for the machines with numerical control (NC),

- Unification of products and technological processes,

- Information retrieval systems for the technological purposes.

The second turn $(25 \%)$ :

- Designing the operational technological processes,

- Grouping the details and designing the group technological processes,

- Unification of technological equipping,

- Technical and economic planning,

- Volume and calendar planning,

- Taking account of material resources on warehouses and in storerooms.

The third turn $(50 \%)$ :

- Production scheduling,

- Construction and modeling the lines, sections, shops (the task is carried out after detail and/or subject-closed areas in the shops being organized),

- Primary accounting,

- Personnel registering,

- Designing the articles (stamps and moulds),

- Designing the technological equipment.

The fourth turn $(5 \%)$ :

- Informant of director and chief engineer,

- Control of the production technological preparation, informants of chief product engineer and chief designer, 
- Control of the financial activity of an enterprise.

Main statements laid in the indicated projects are as follows:

In the field of Production Organization:

- subject specialization of the areas, creation of closed productions which permit to carry out TP in whole (from a blank to a finished detail);

- creation of a buffer production zone, "an automated plant-environment", aimed at localization of external sources of breaking down the operation keeping a steady pace;

- the possibility of change-over from the transport scheme "machine-machine" to the scheme "machine-storage-machine";

- realization of the block-module structure of the production processes, including one for their wide circulation;

- creation electronic system for coding and identifying of the material objects of an automated plant.

In the field of Technologies and Equipment:

- economy of expensive materials when passing over to the more progressive methods of production of blanks with the utilization factor of material $0.65-0.75$ (precision steel casting in combination with gas staticizing process, laser and jet water-abrasive cutting-out of blanks, repeated usage of rejects);

- creation of integral machine stations to perform all the operations in conformity with the single controlled program on one field. The question is sized processing, strengthening, and control of stamp and mould details. It is expected that performing this integrated equipment will permit to reduce abrupt time losses for intermediate operations, to achieve reduction of labor consumption by 2-10 times, production defects by 3-5 times, production areas by 2-3 times, production cycle by $1.5-2$ times, transport expenses by $50-60 \%$, and to increase reliability by $1.5-2$ times;

- utilization of rejects (briquetting and packaging);

- electrodeposition with separation for processing the slurry;

- manufacture of combined tools permitting to perform several transition of processing in one setting;

- creation of complex equipment realizing electrophysical and chemical technology of the new level for finishing the complicated space (shared) surfaces of stamps and moulds;

- usage of surface strengthening methods for strengthening the surfaces of stamps, moulds, and cutting tools;

- introduction of independent technology for manufacture and assembly of stamp and mould details being tied up on the basis of using the experience of the automated production of heat-protective coating of multiple spacecraft "Buran". 
In the field of Designing:

- computerization of forecasting and considering the demand, creation of the perspective design-and-processing decisions' bank, prediction of the required production arrangement;

- usage of the block-mould principle for building up the article (ganging up) based on design-and-processing unification of the product details and assemblies;

- classification of the product components according to their resistance against time for invariable ones (terms of renewal-10-15 years), changing for 3-5 years and quickly changing;

- creation of standard-sized series of the product unified components on the similarity base;

- usage of the new easily-processed materials, (for example, organic concrete, posessing high dumping ability and low susceptibility to short-term environmental fluctuations).

In the field of Planning and Control:

Creation of the problem-oriented automated work stations containing the following functional software components;

- facilities for introduction, representation, and editing of the primary information, which are oriented to the sets of the documents entered for a particular working place. The facilities for diagnosis of the information being entered permits essential lowering of the labor-consumption for preparation of the primary data.

- data base of norms and standards (All-Russian state standards, branch standards, directions and methodical documents, and so forth);

- computation-and-logic facilities (computation, analysis of the decisions having been taken, visualization and archiving the designs) oriented to the particular list of tasks.

- the facilities for interacting with the other work stations (network facilities, multi -machine complexes);

- the facilities for text and graphic documentation (forming the output text and graphic documents) as well as the facilities for generation of new output forms at introduction of changes in the made up documents' turn-over.

In the field of Quality Control:

- with the aim of increasing the quality of stamps and mould, usage of nondestructive tests (controlling the structure and residual stresses in the surface layers of tool working surfaces) based on metallographic and physical methods.

- high resistance of product (about 100 thousand working cycles and over) is obtained by means of "breaking-through" processing methods for coating (plasma coat under the conditions of vacuum and microexplosion);

- obtaining the required quality of products by means of active automated operational 
control and of using "breaking-through" strengthening technologies based on heat treatment in vacuum furnaces with the use of induction and gas heating, as well as multi-layer titanium carbides and nitrites vacuum evaporation, plasma-mechanical treatment, and so on);

- creation of quality control systems for details and assemblies; sy stems of control, prediction and failure diagnosis of treatment equipment. 

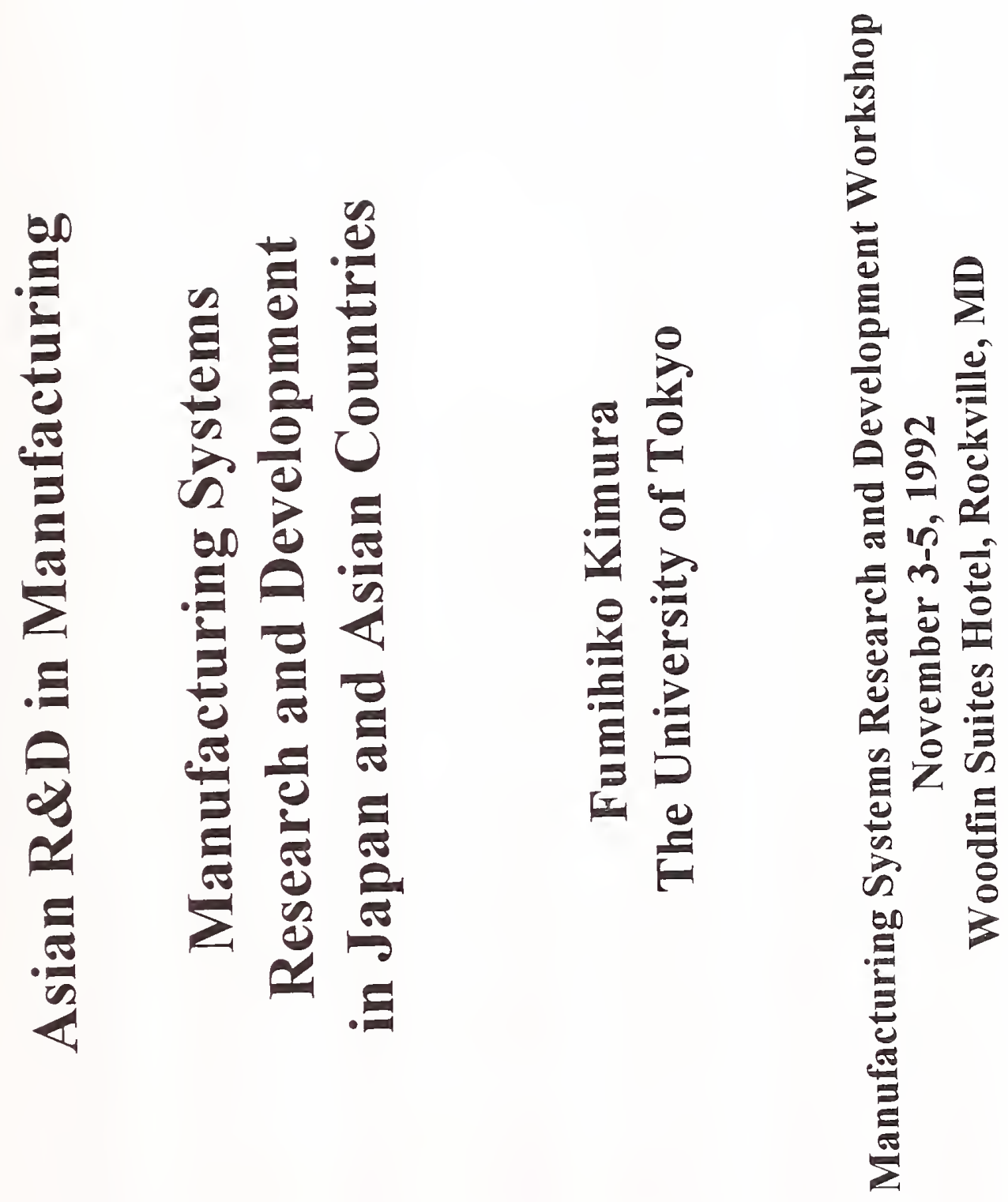


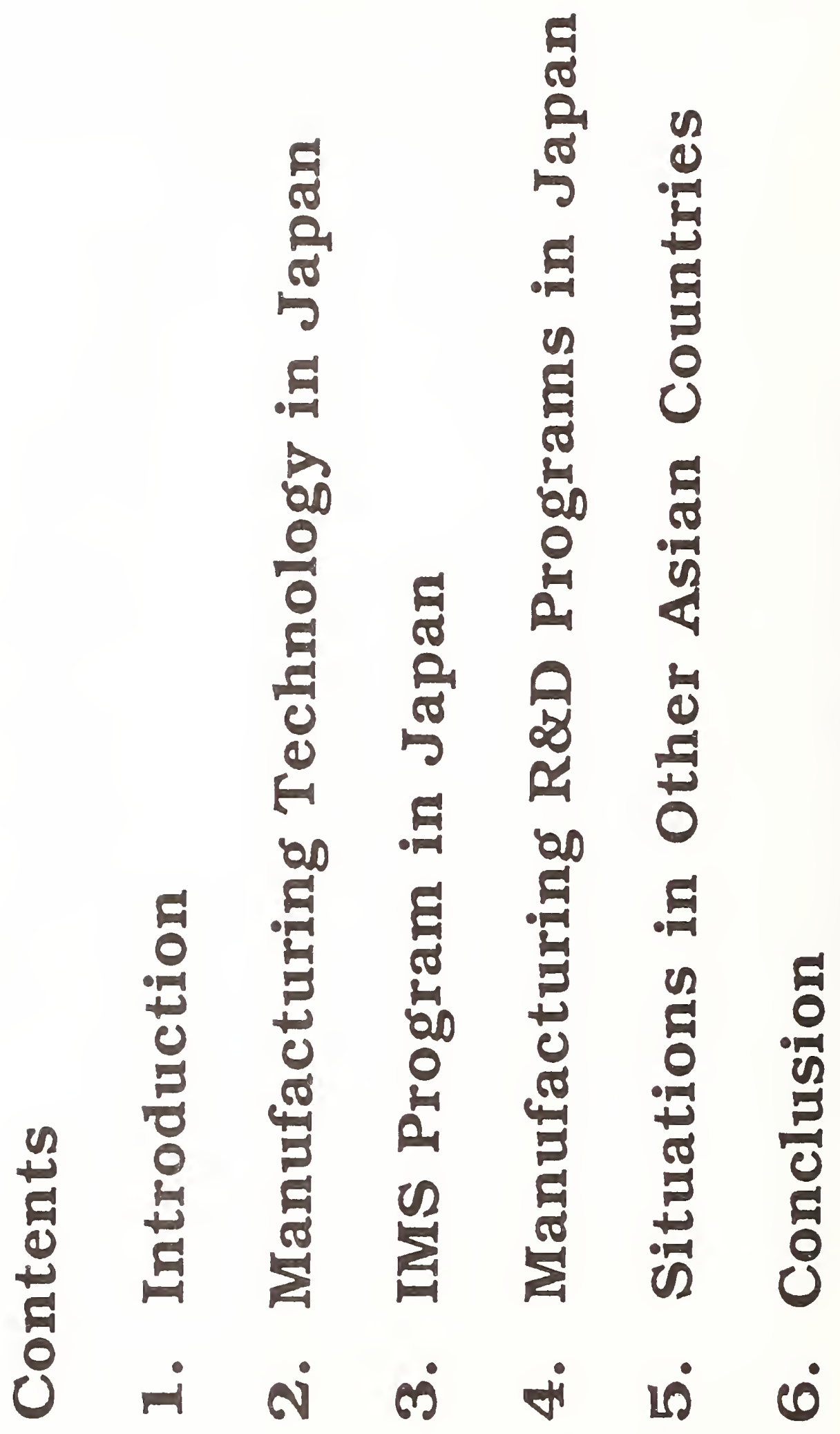




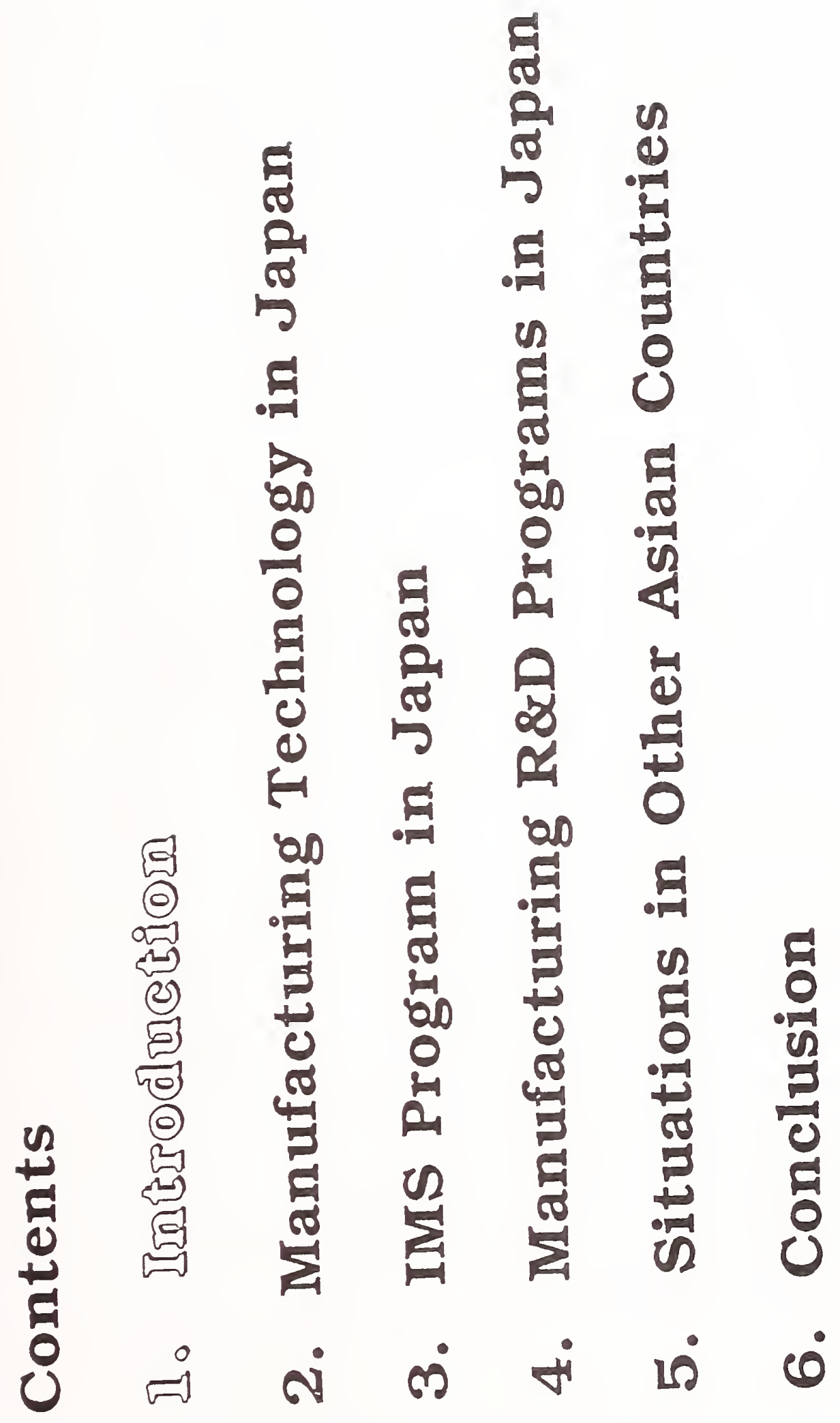




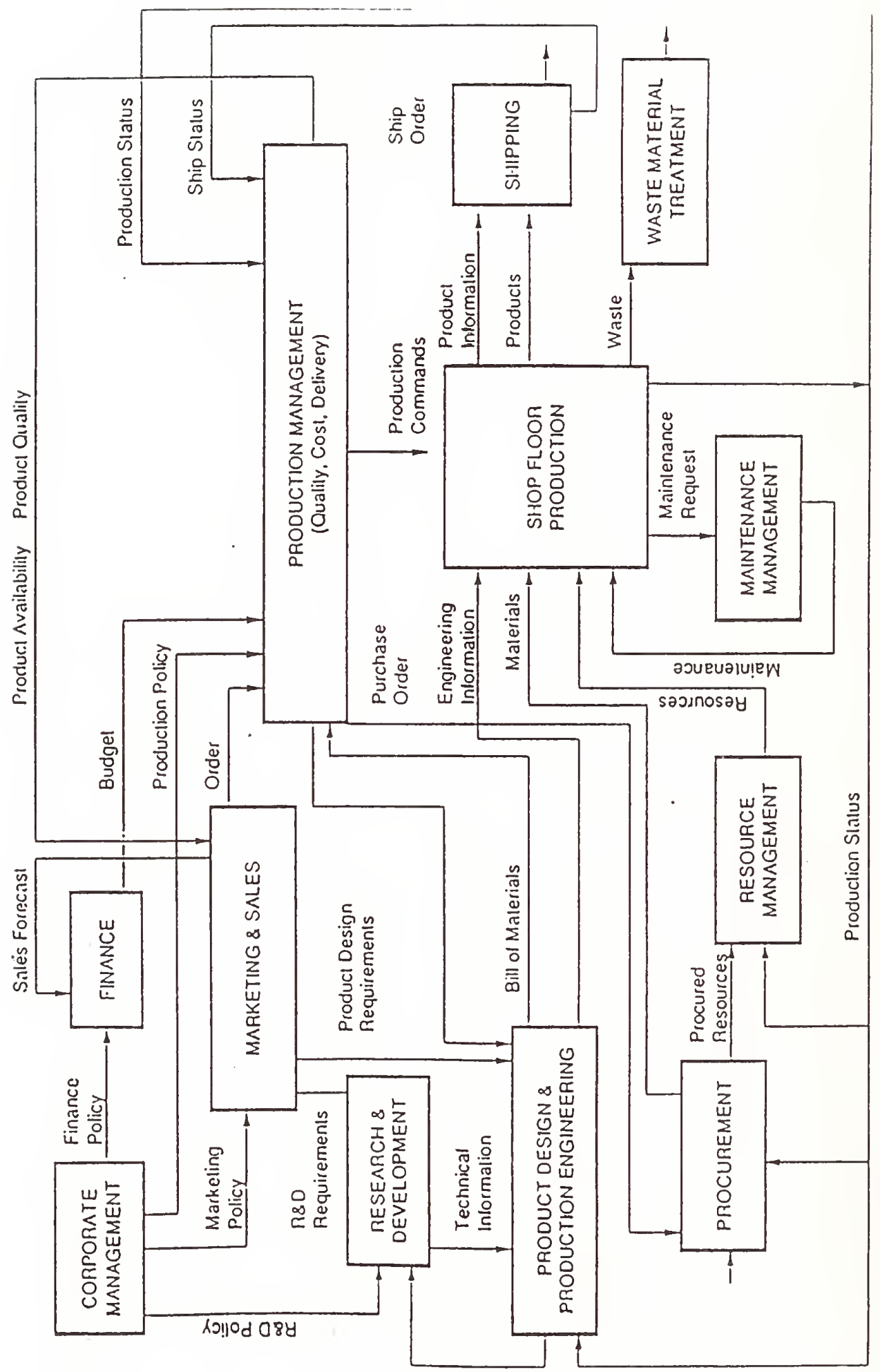

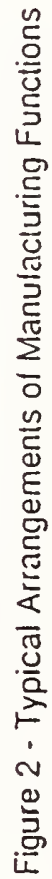




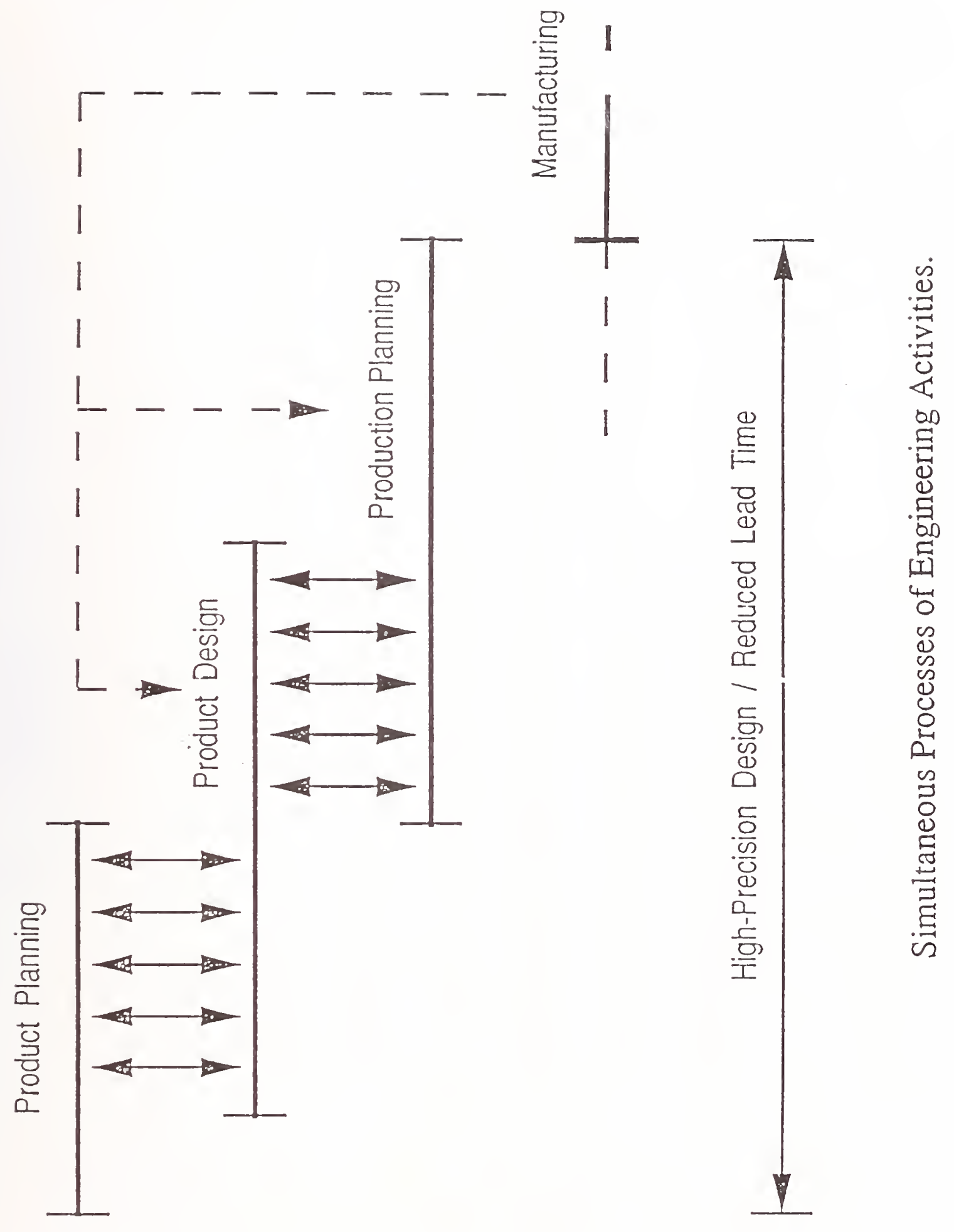




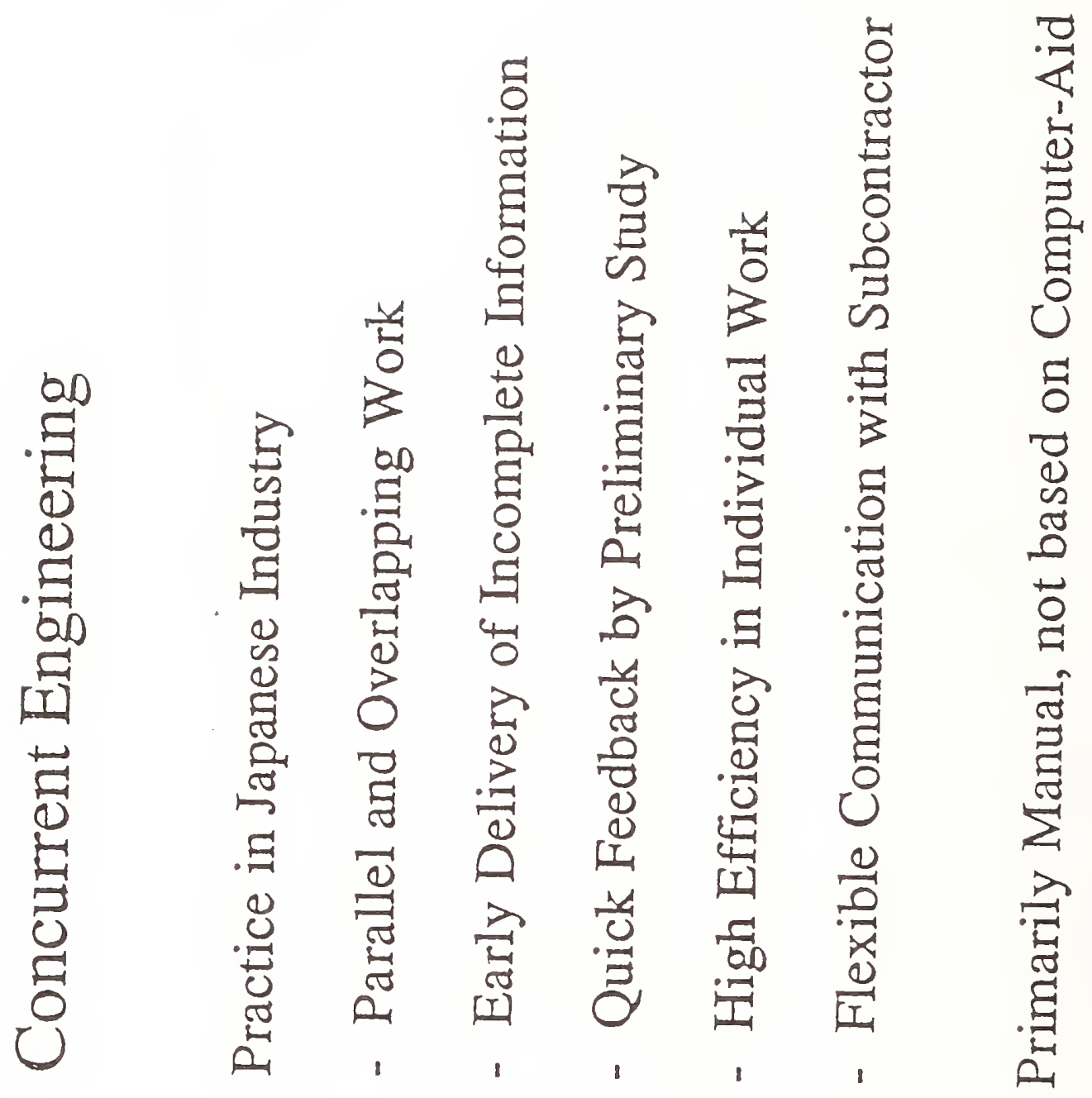




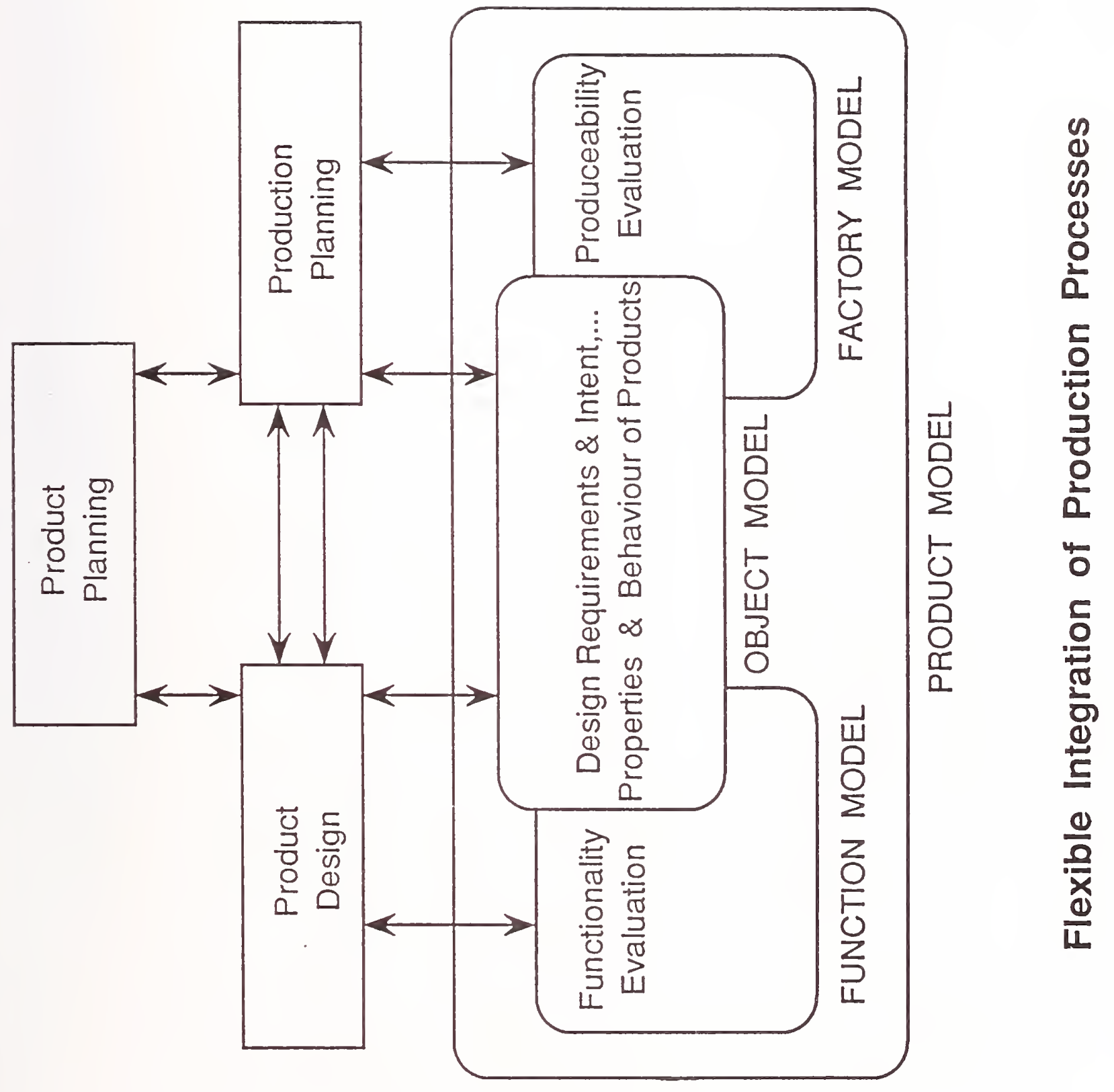




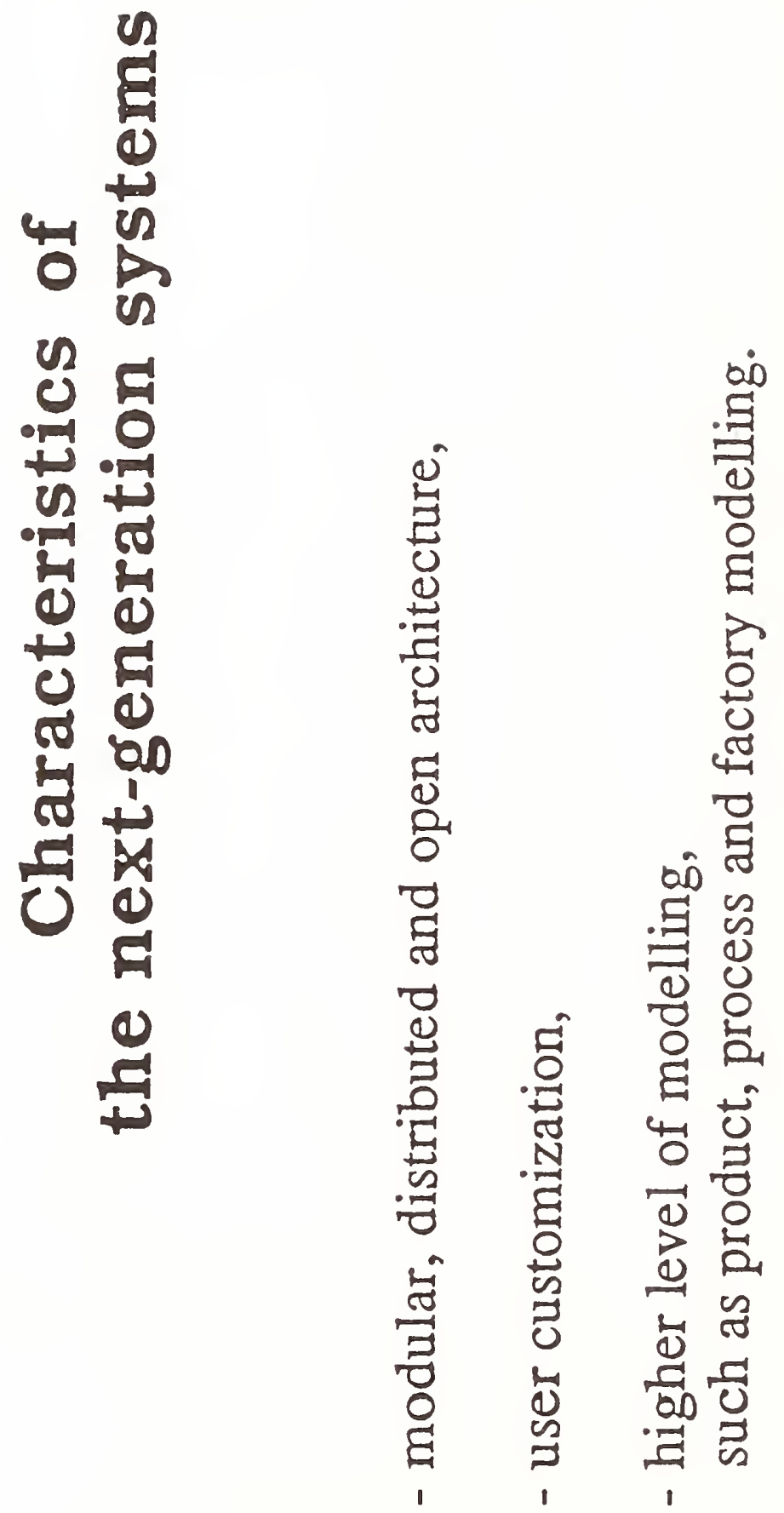




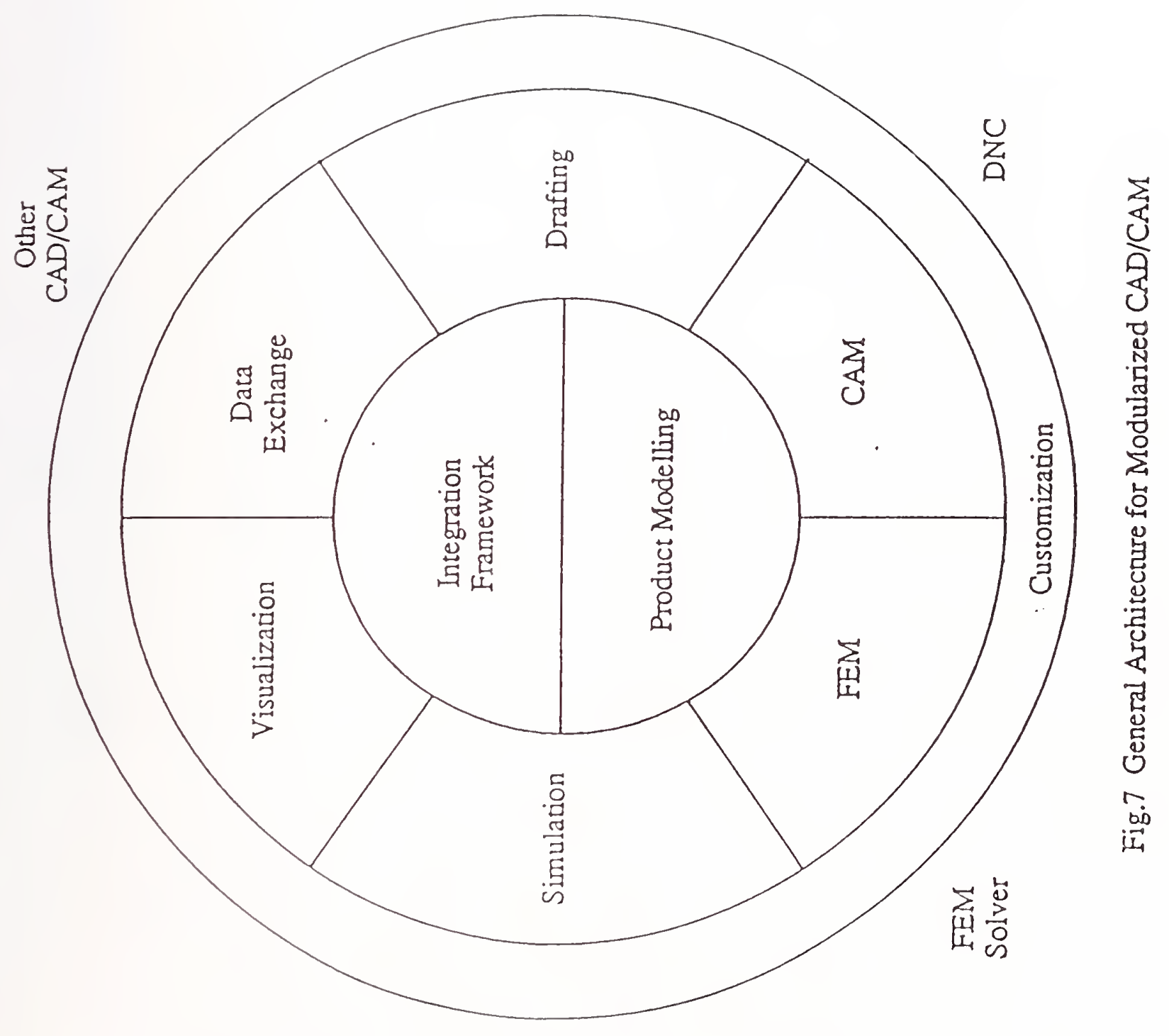




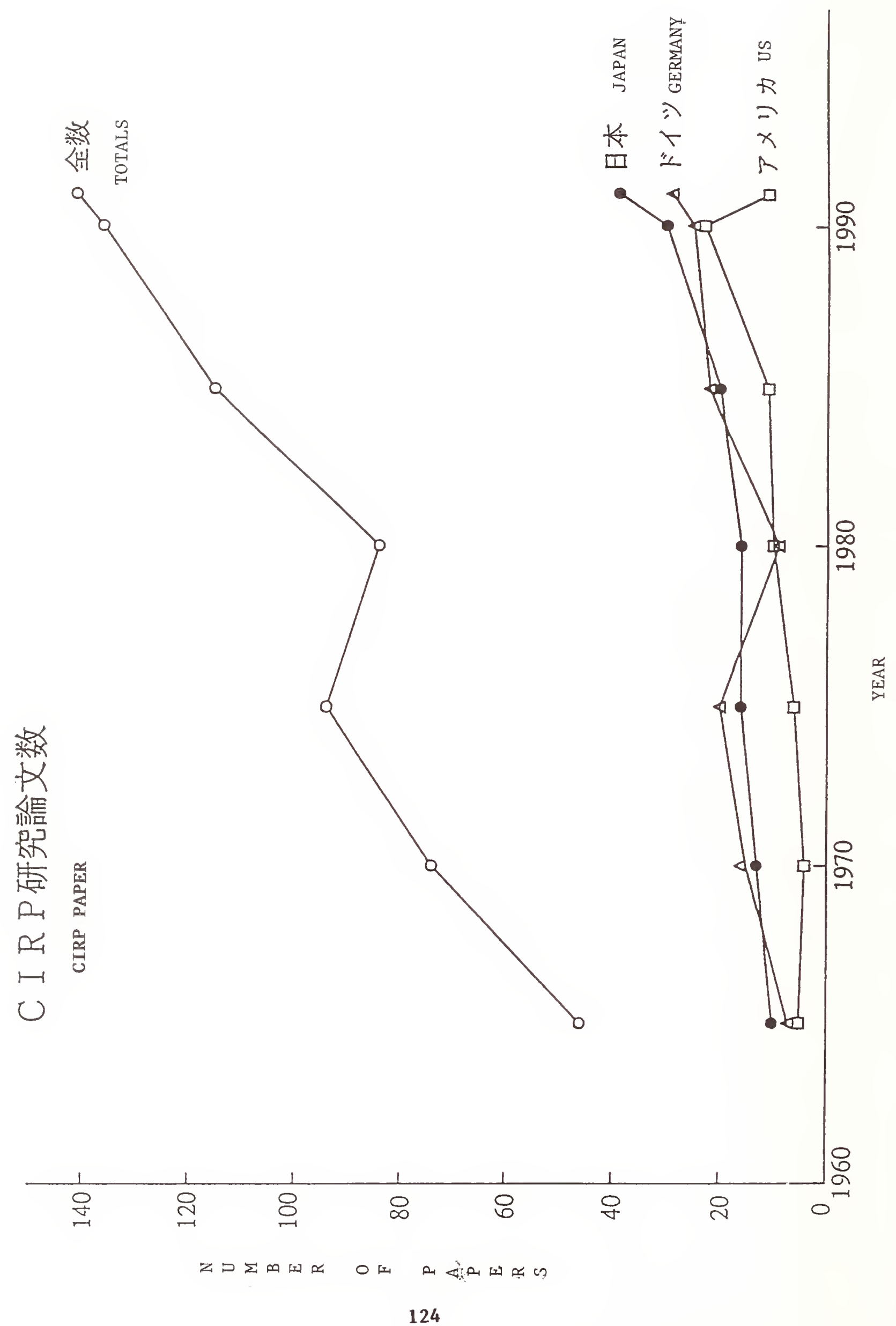




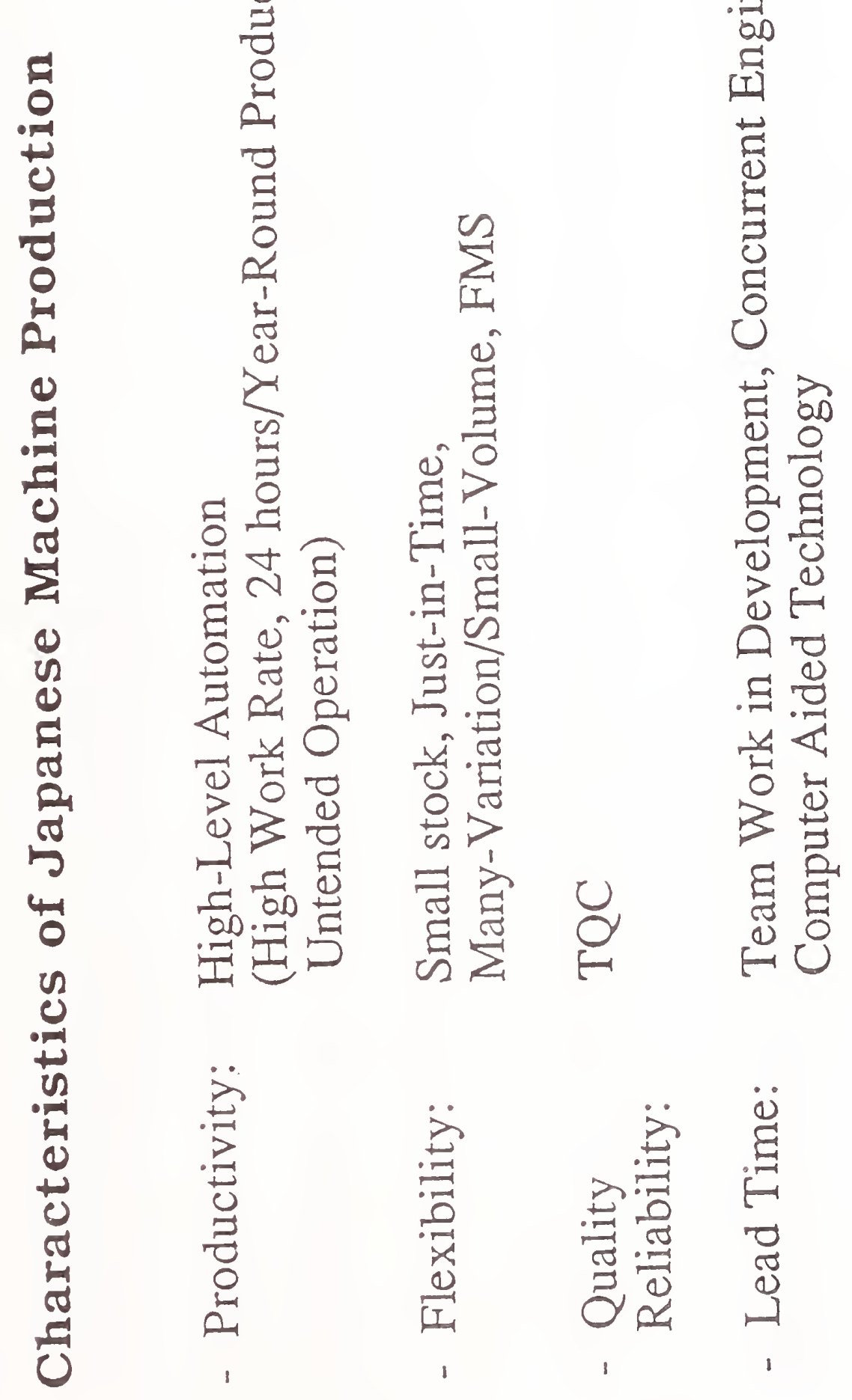



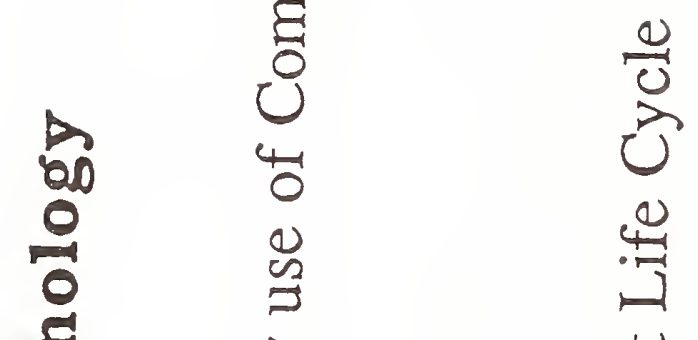

눙

bo

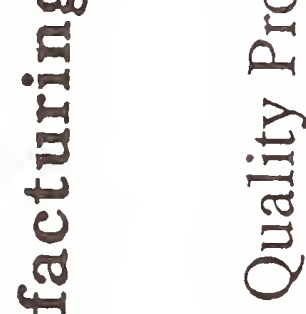

ลิ

热

ב

8

0

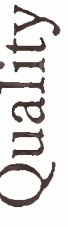

달

(1)

บ

()

등

2

5

4

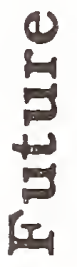

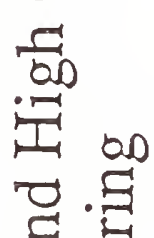

허

동. ્ㅗㅁ

-음

已

¿

के

의

तु

Uै

芯

沓

4 op

$\frac{0}{0}$

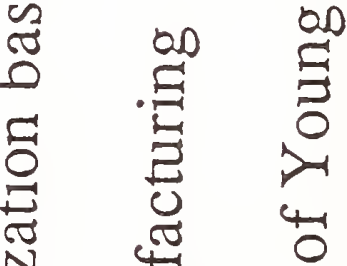

忌

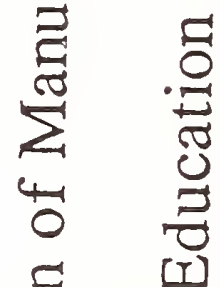

豆

공

$\frac{0}{0}$

芑

I

I 


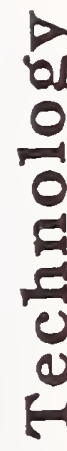

on

草

$\Xi$

is

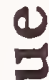

is

$\mathscr{n}$

药
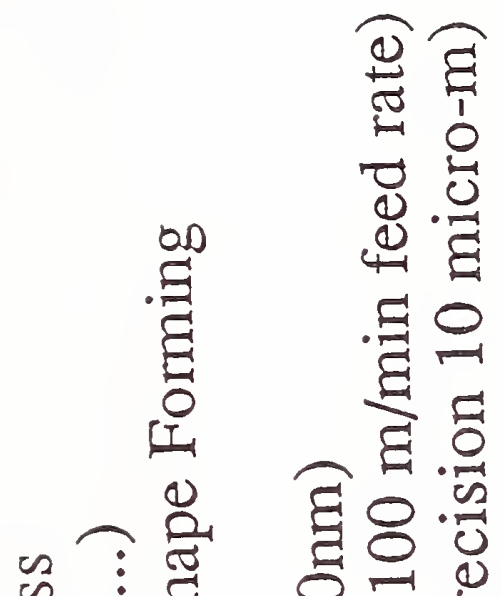

论谣

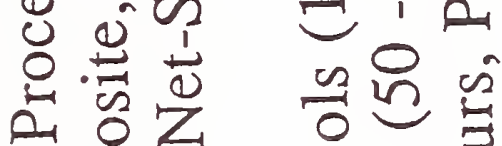

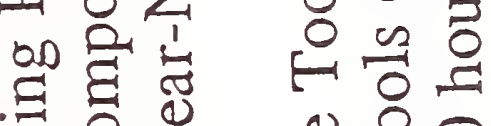

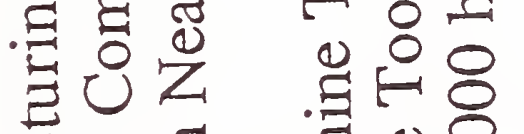

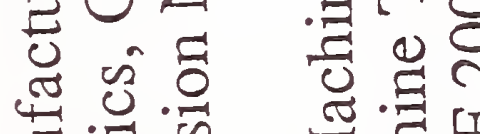

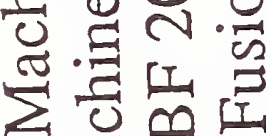

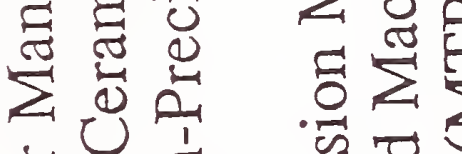

s

里 o \&

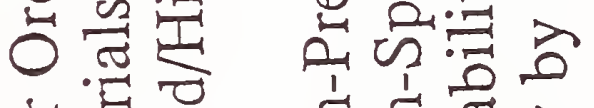

牙它

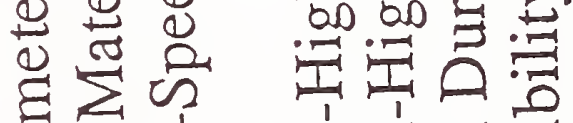

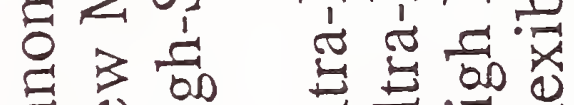

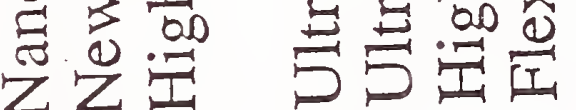

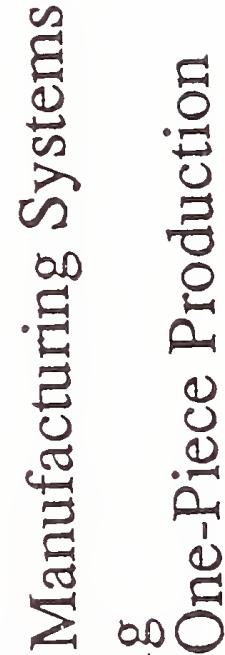

으. 들

D 50

晃

on

诸红

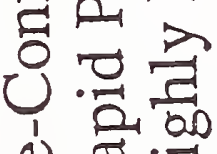

岃 $\tilde{I}$

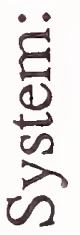

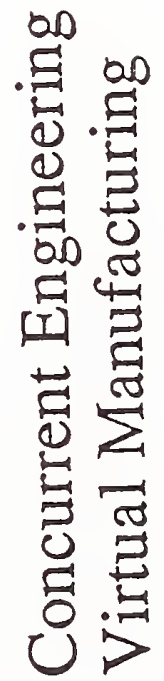

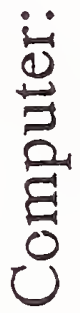




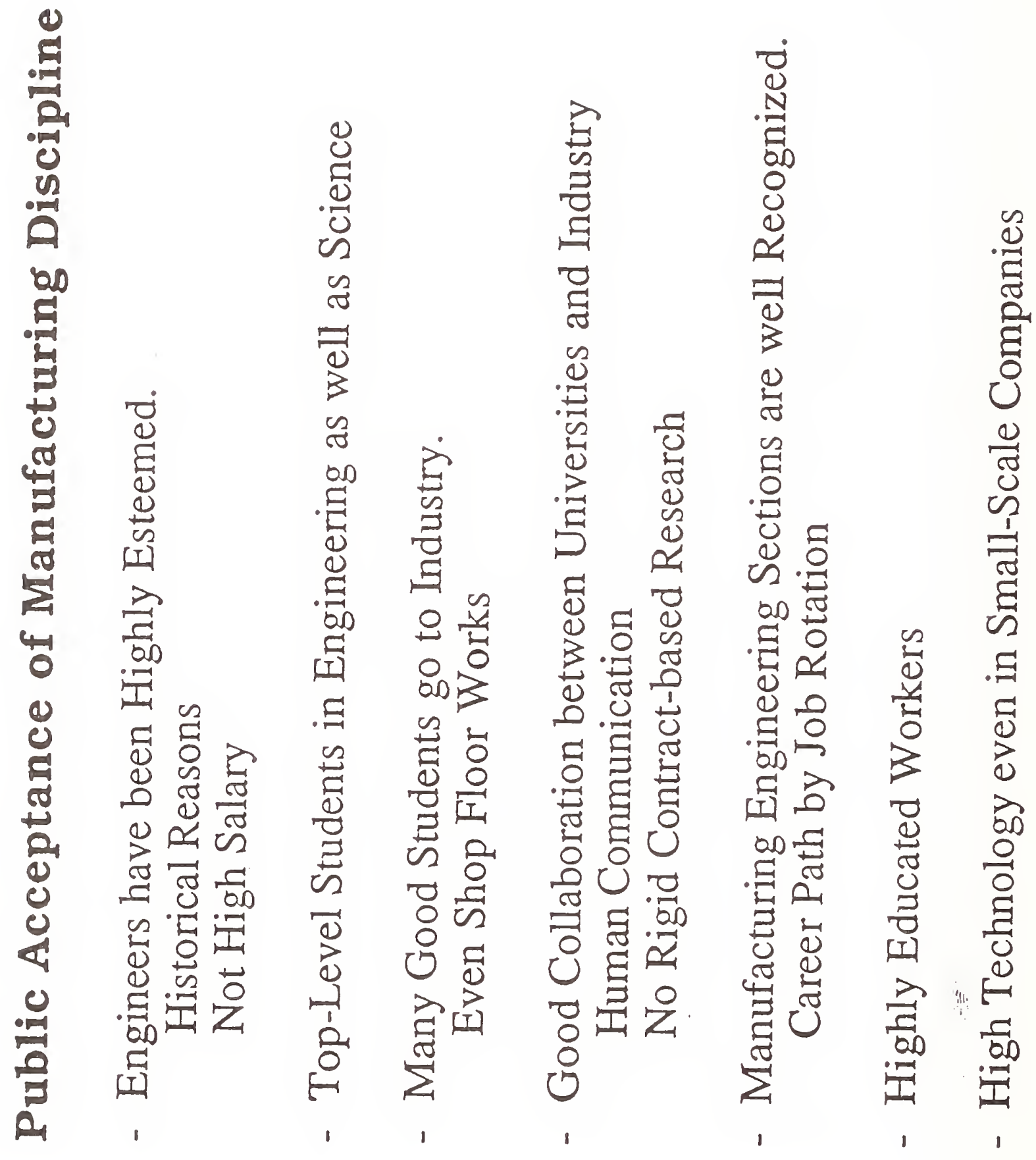




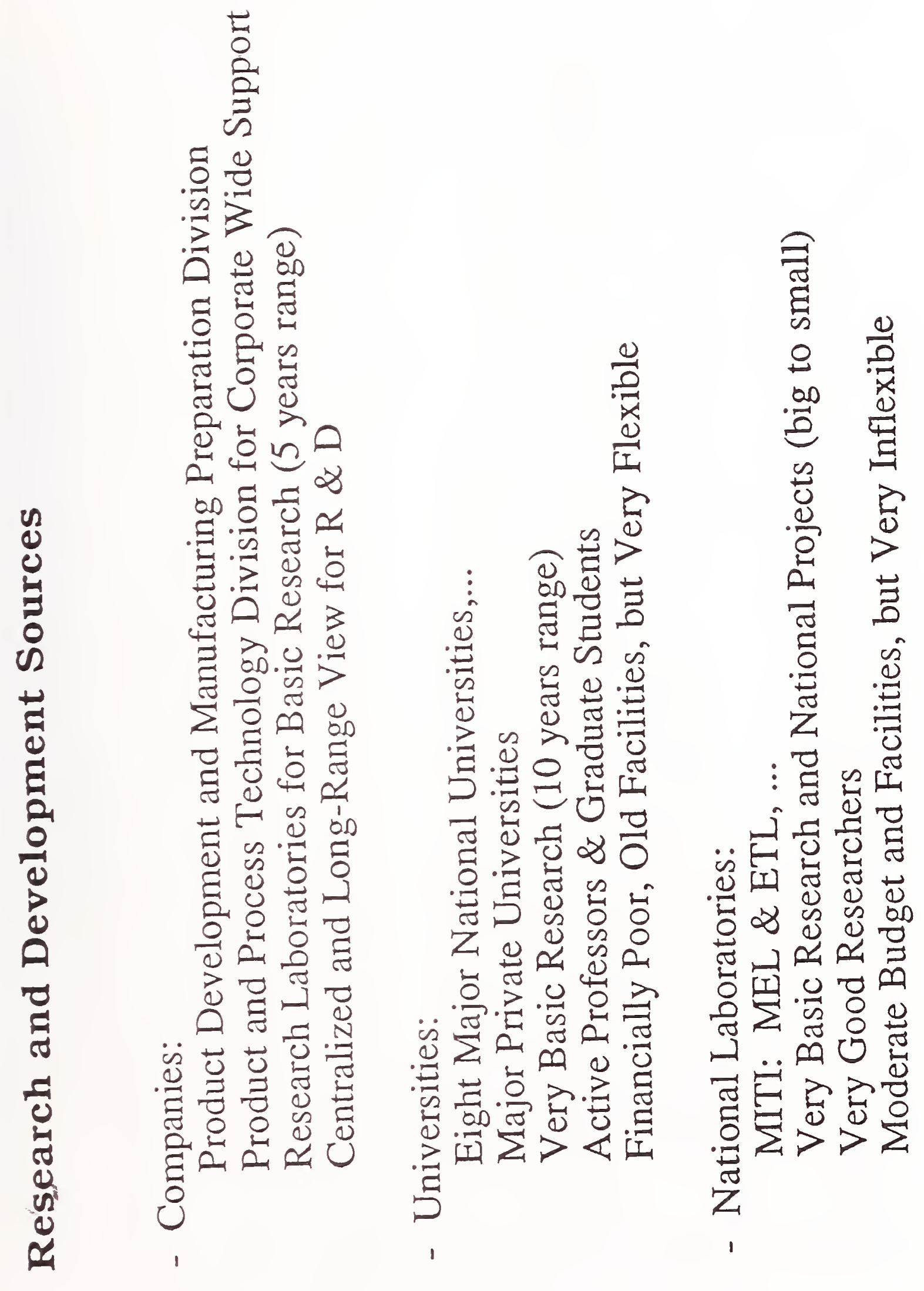



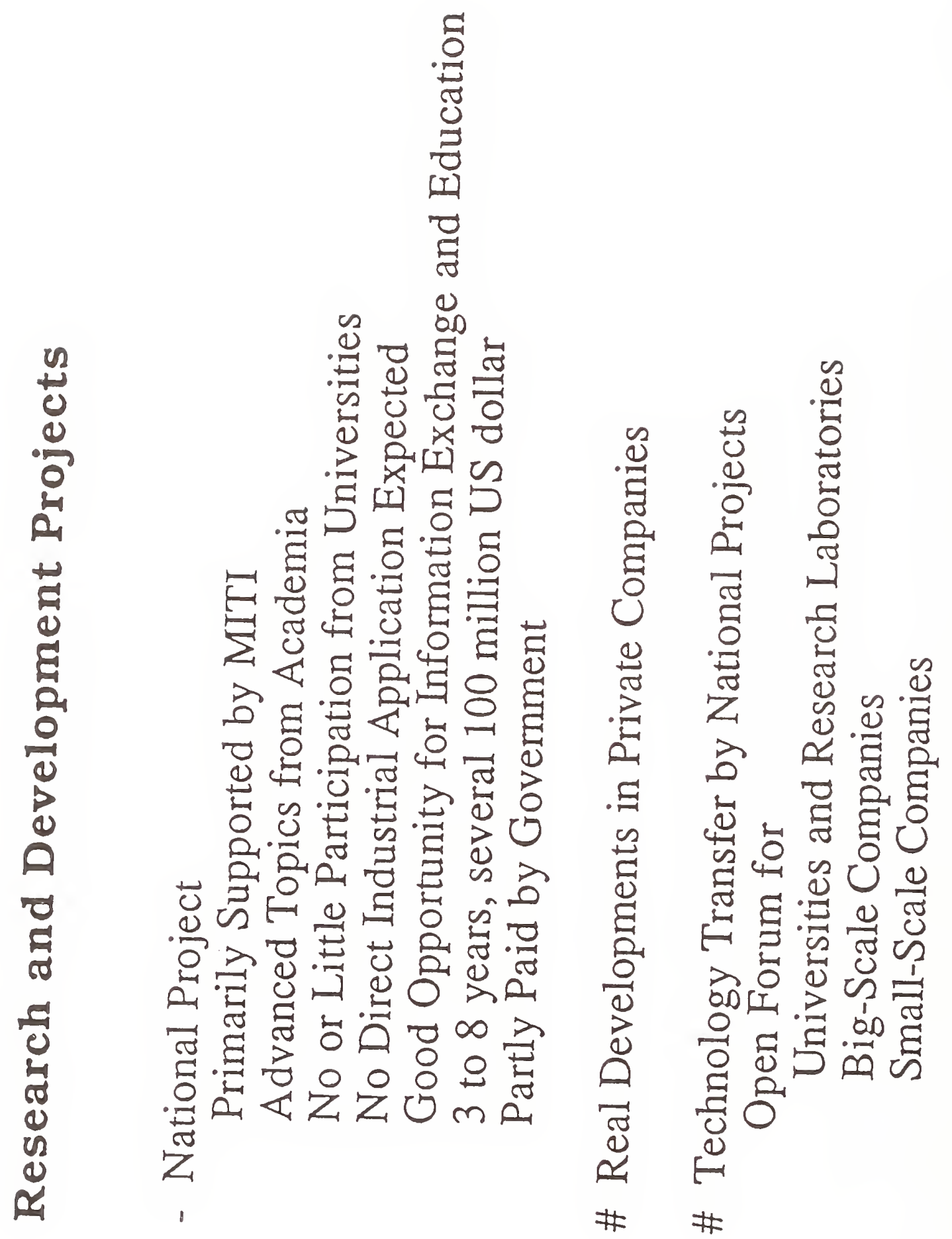


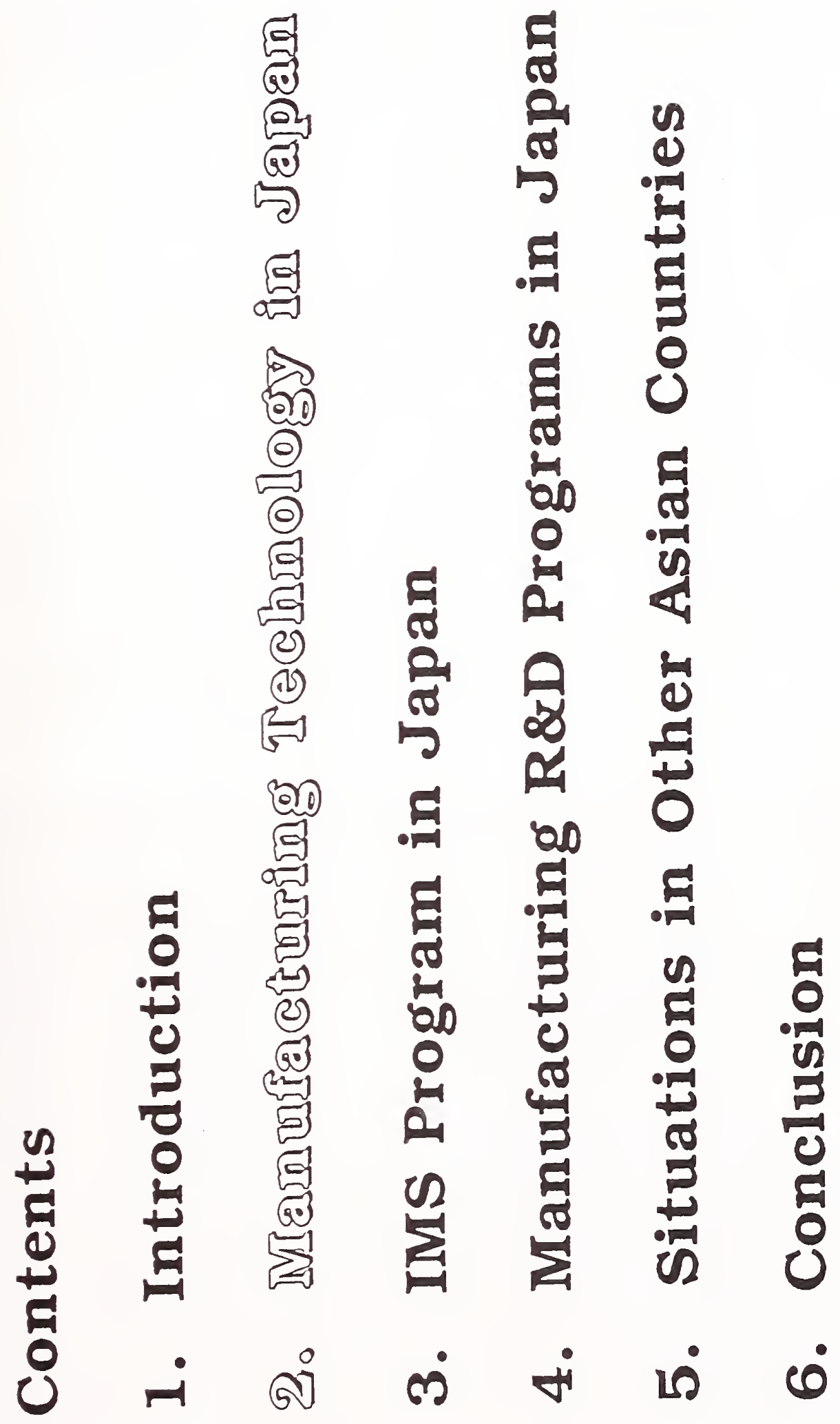




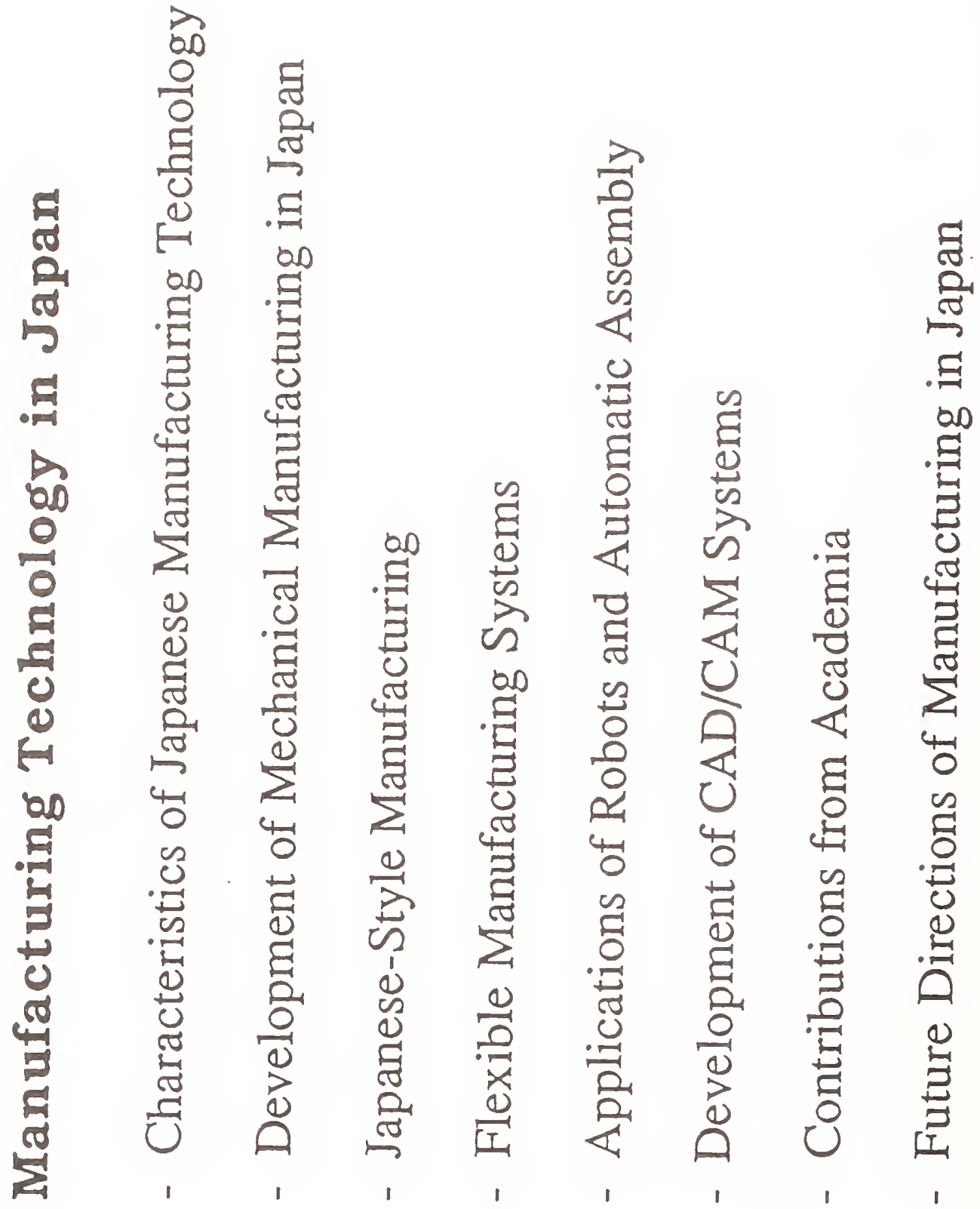




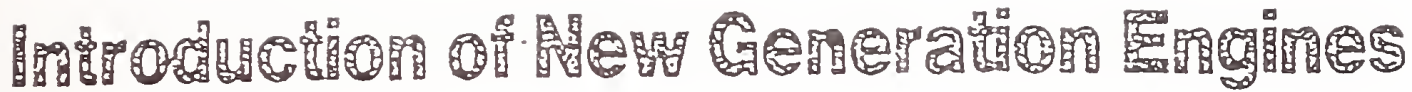
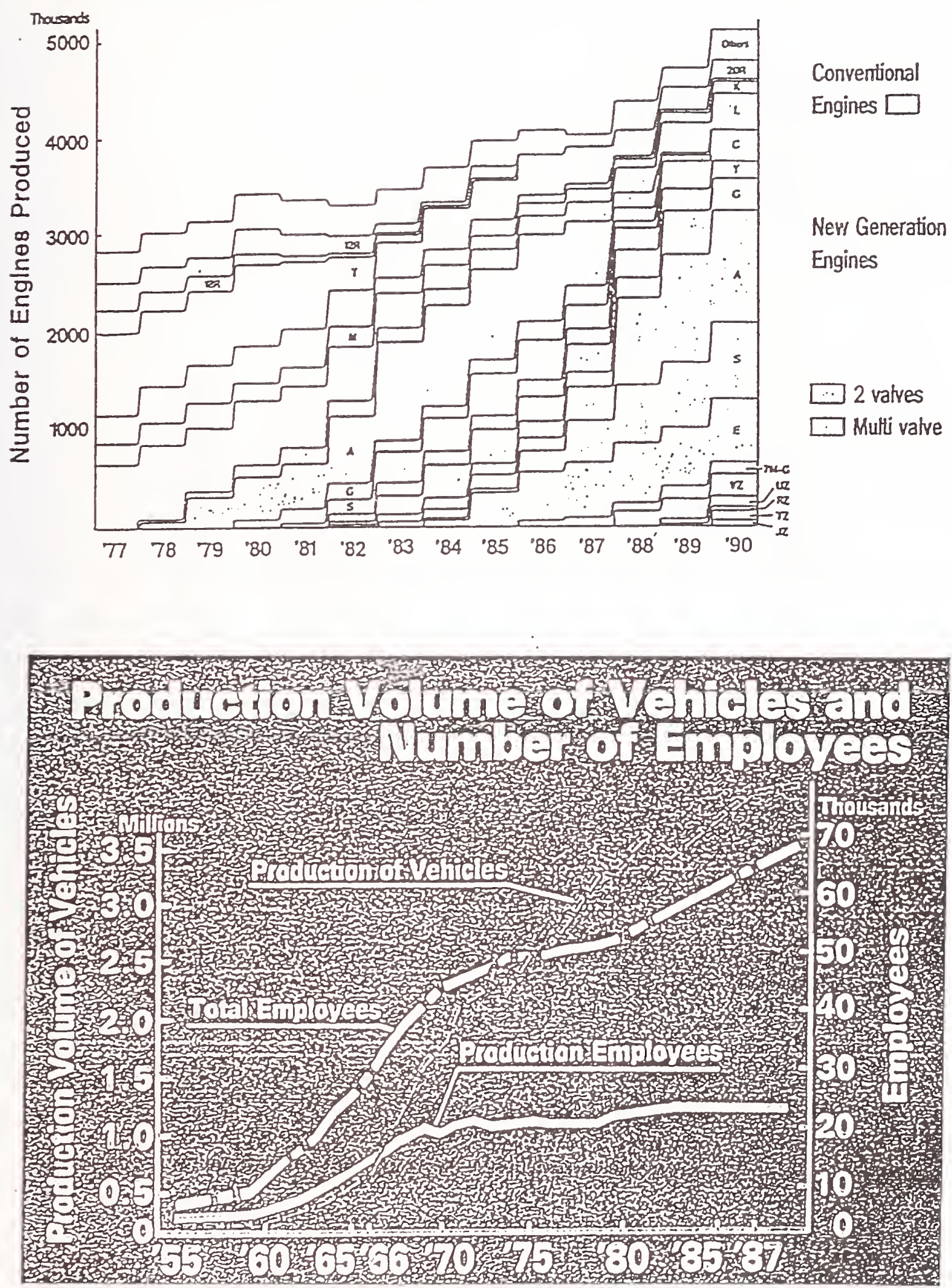


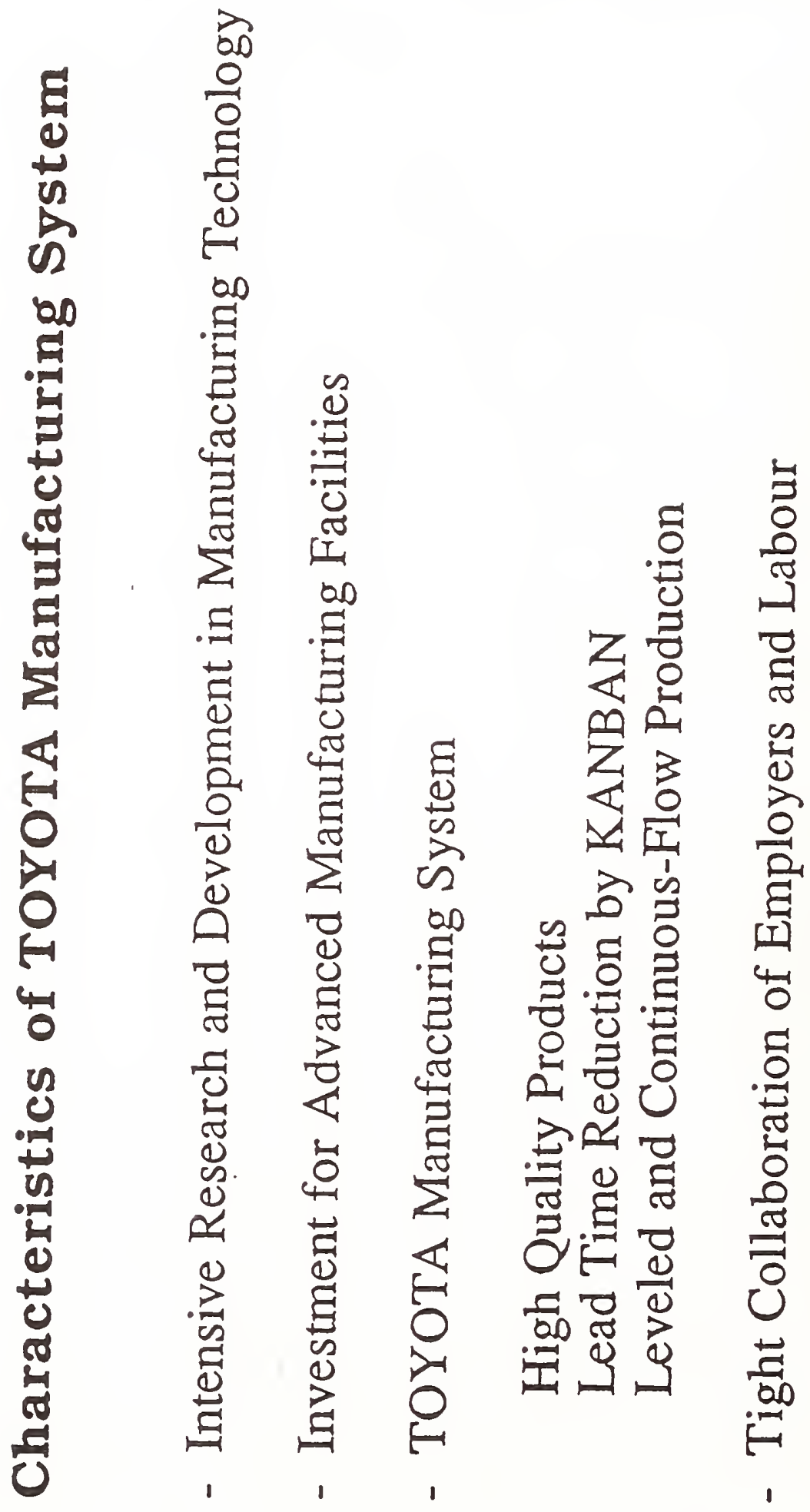




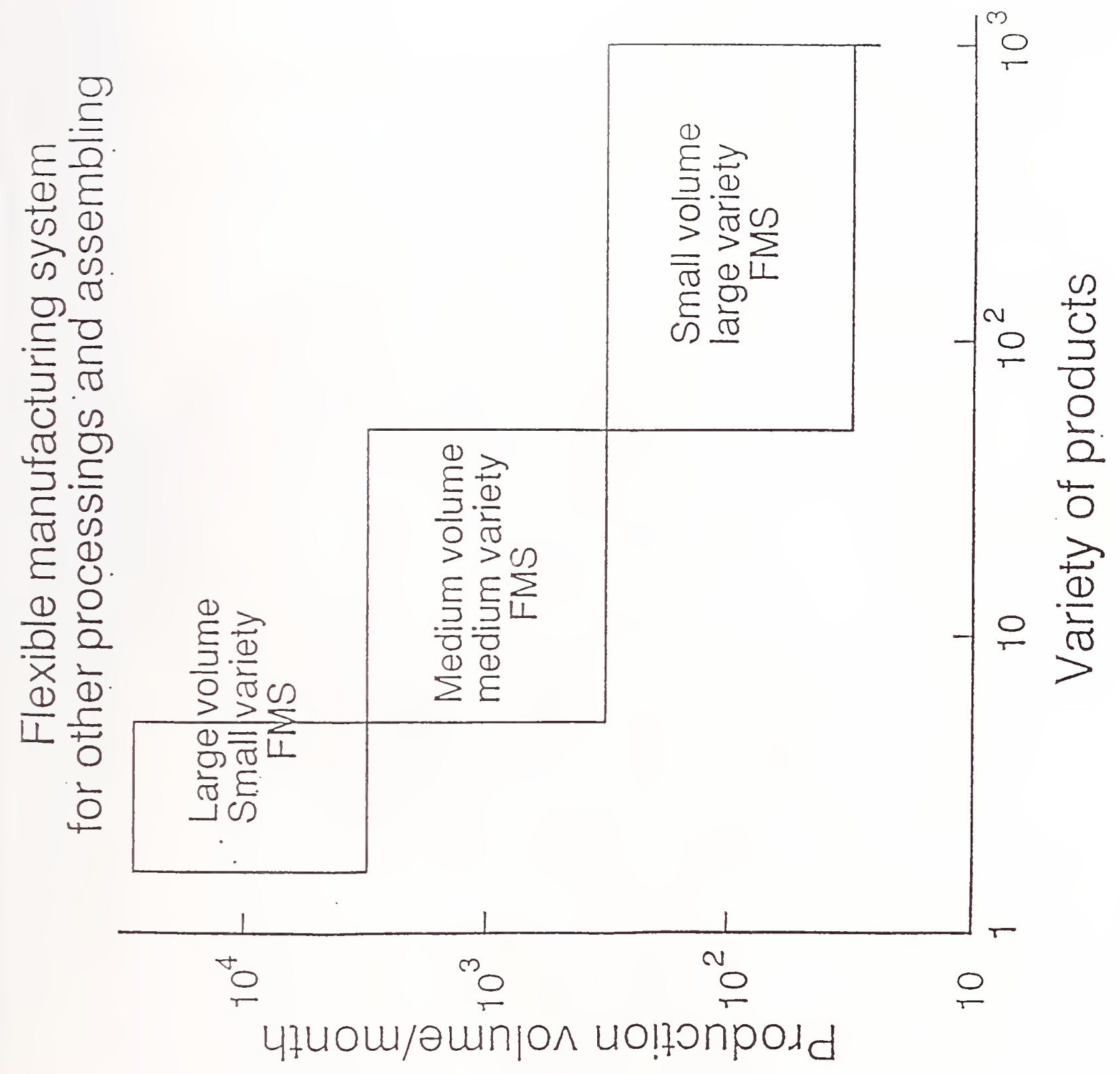




\section{ANNUAL OPERATION HOURS}

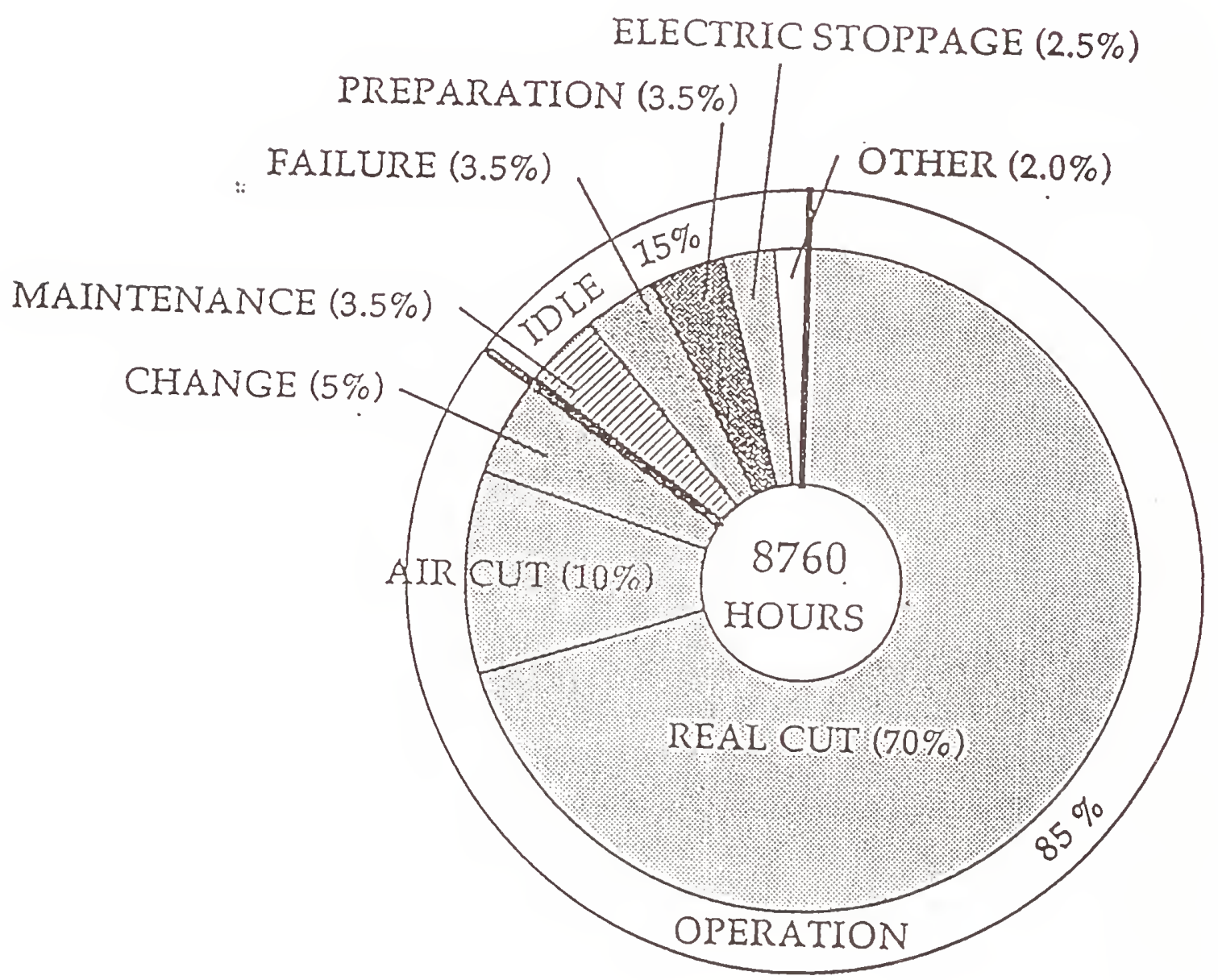




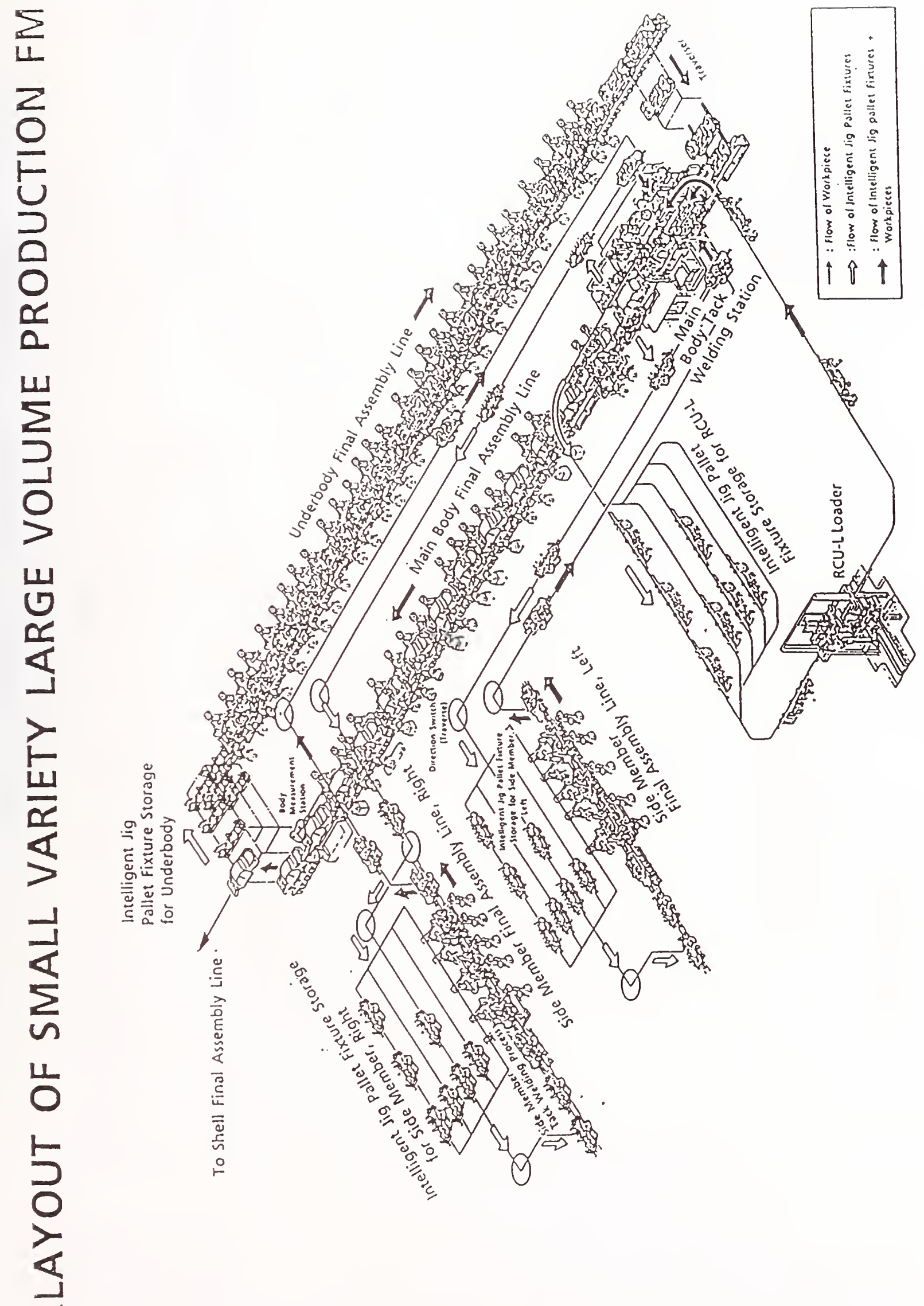




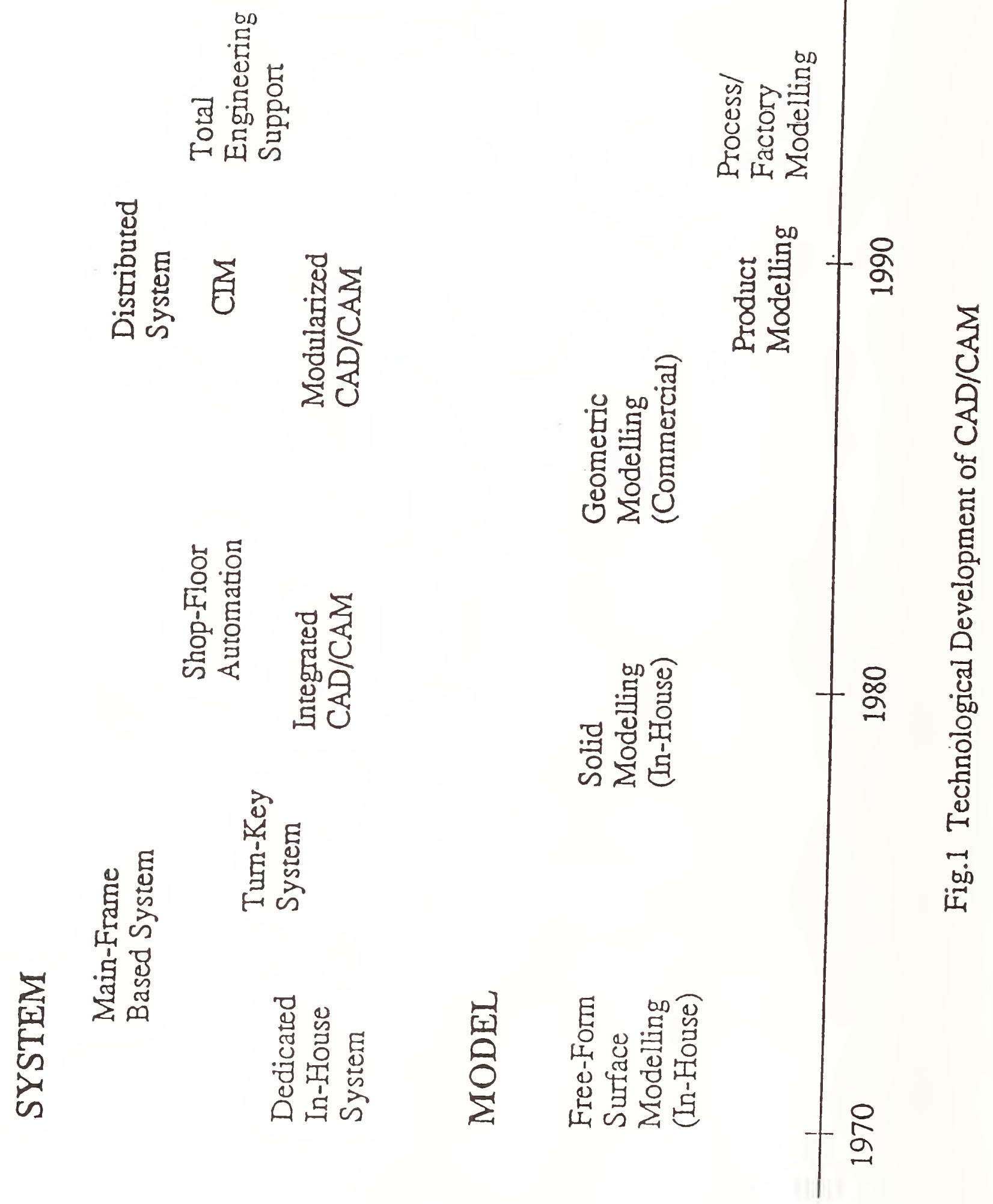




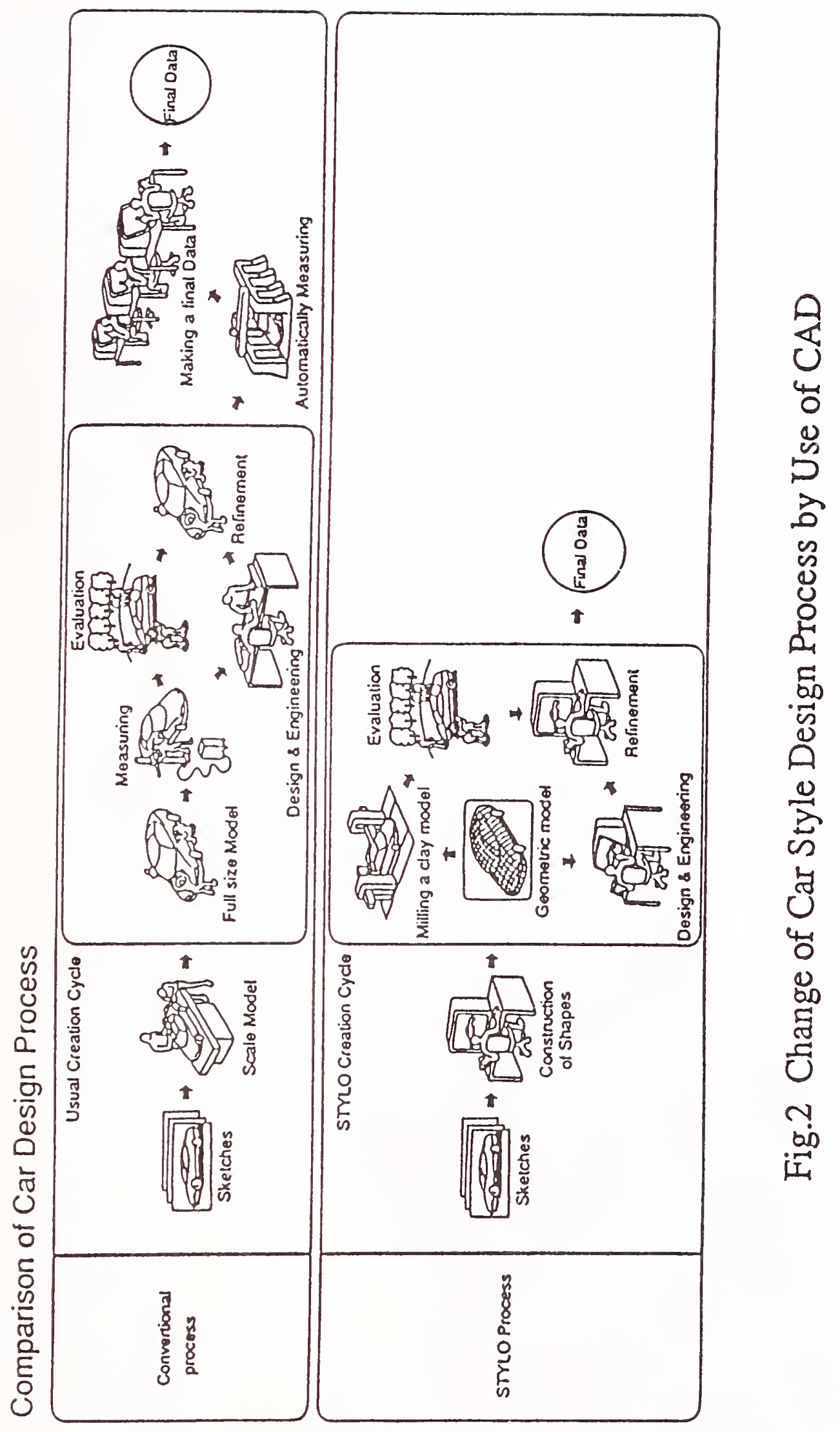




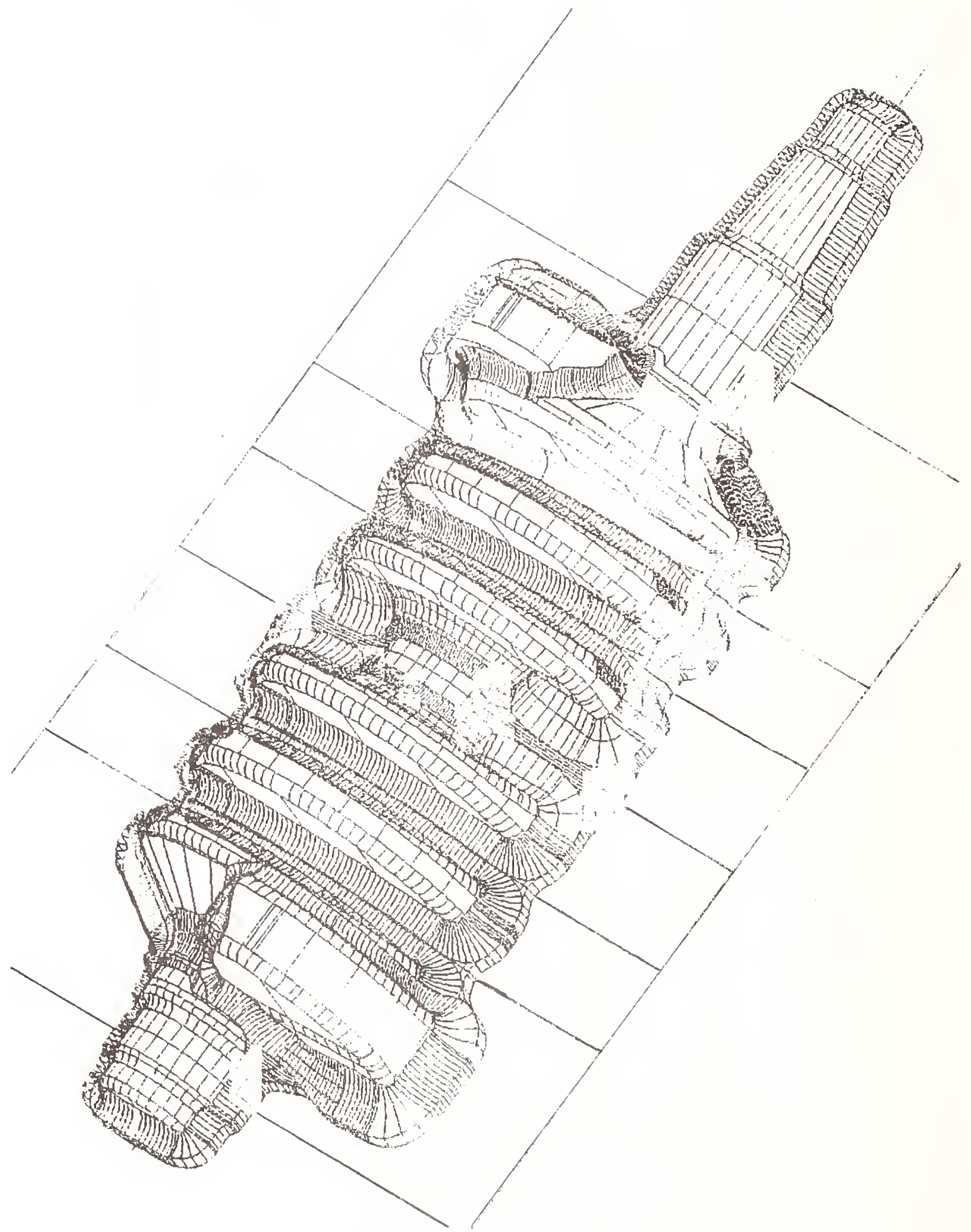




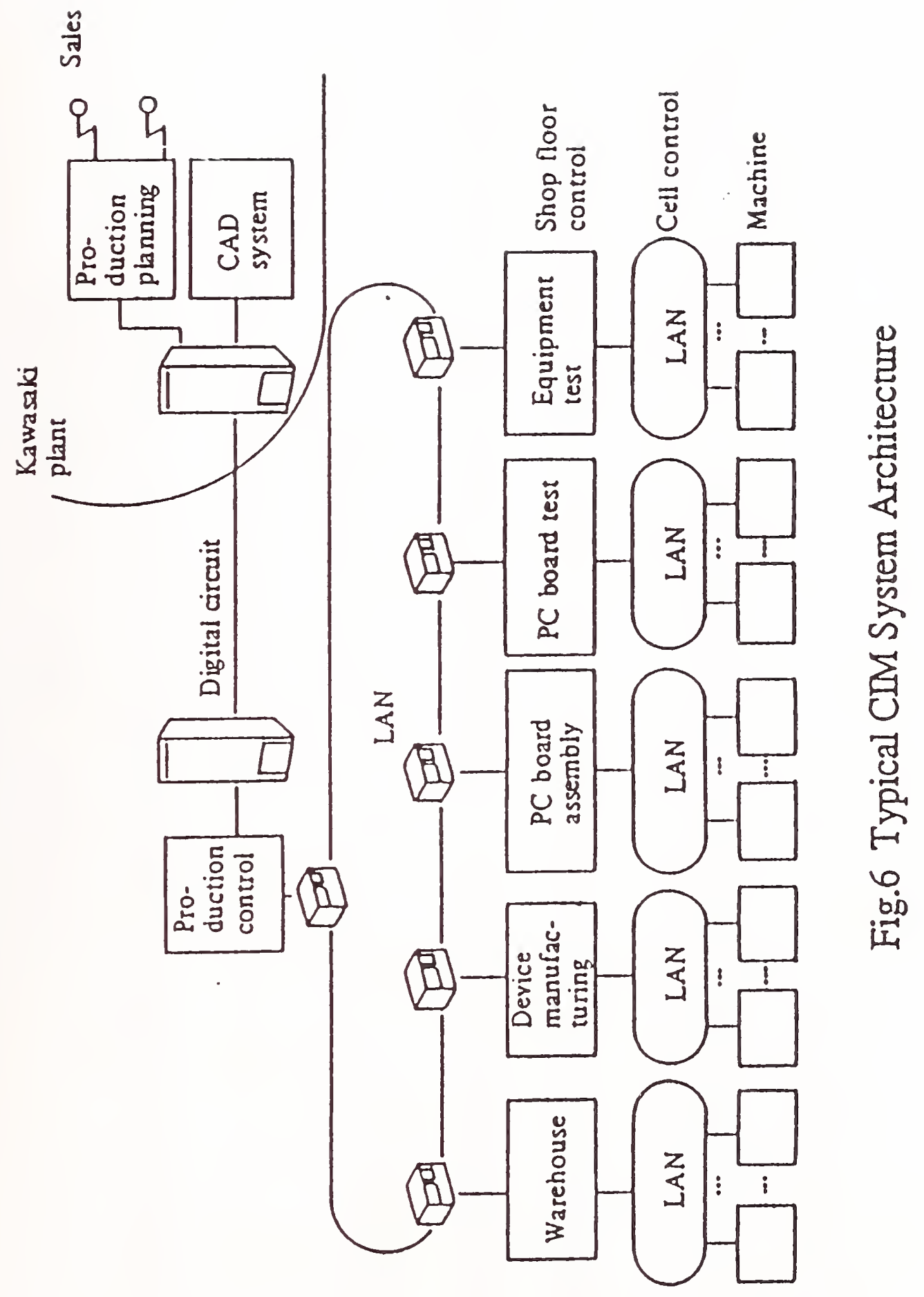




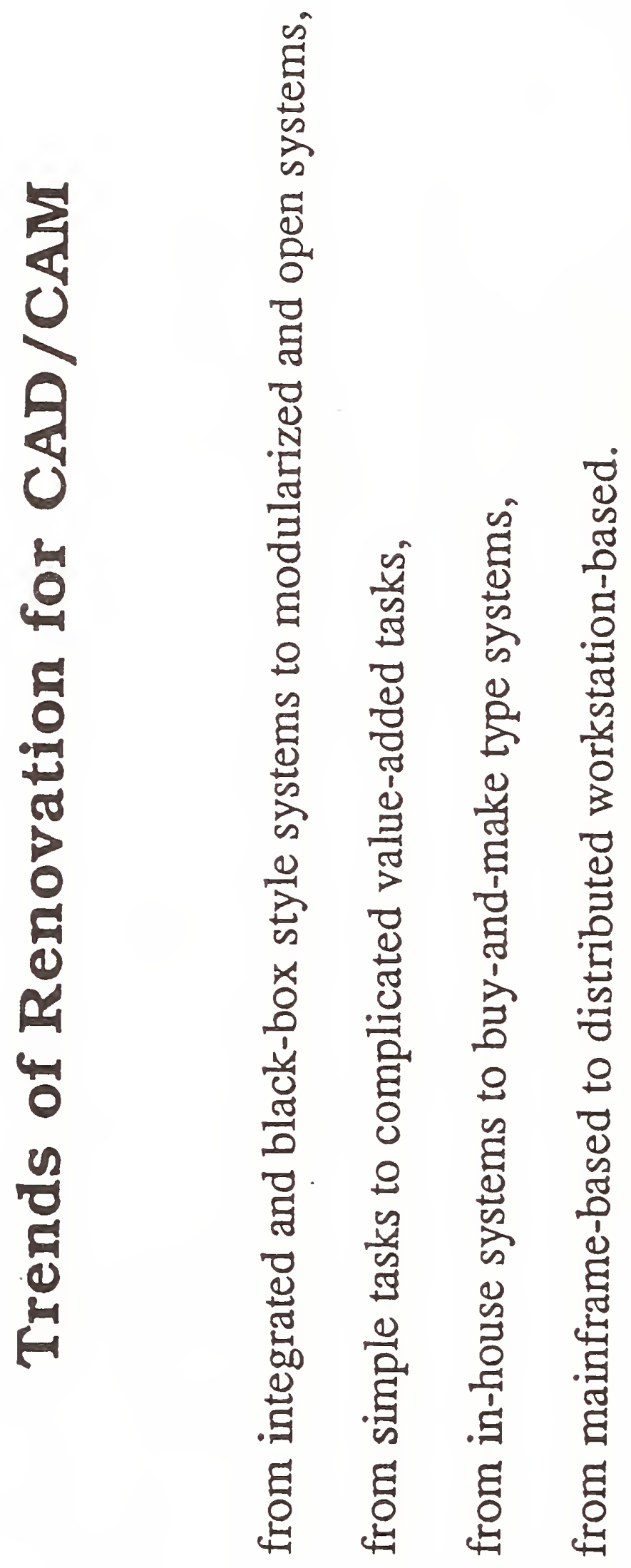




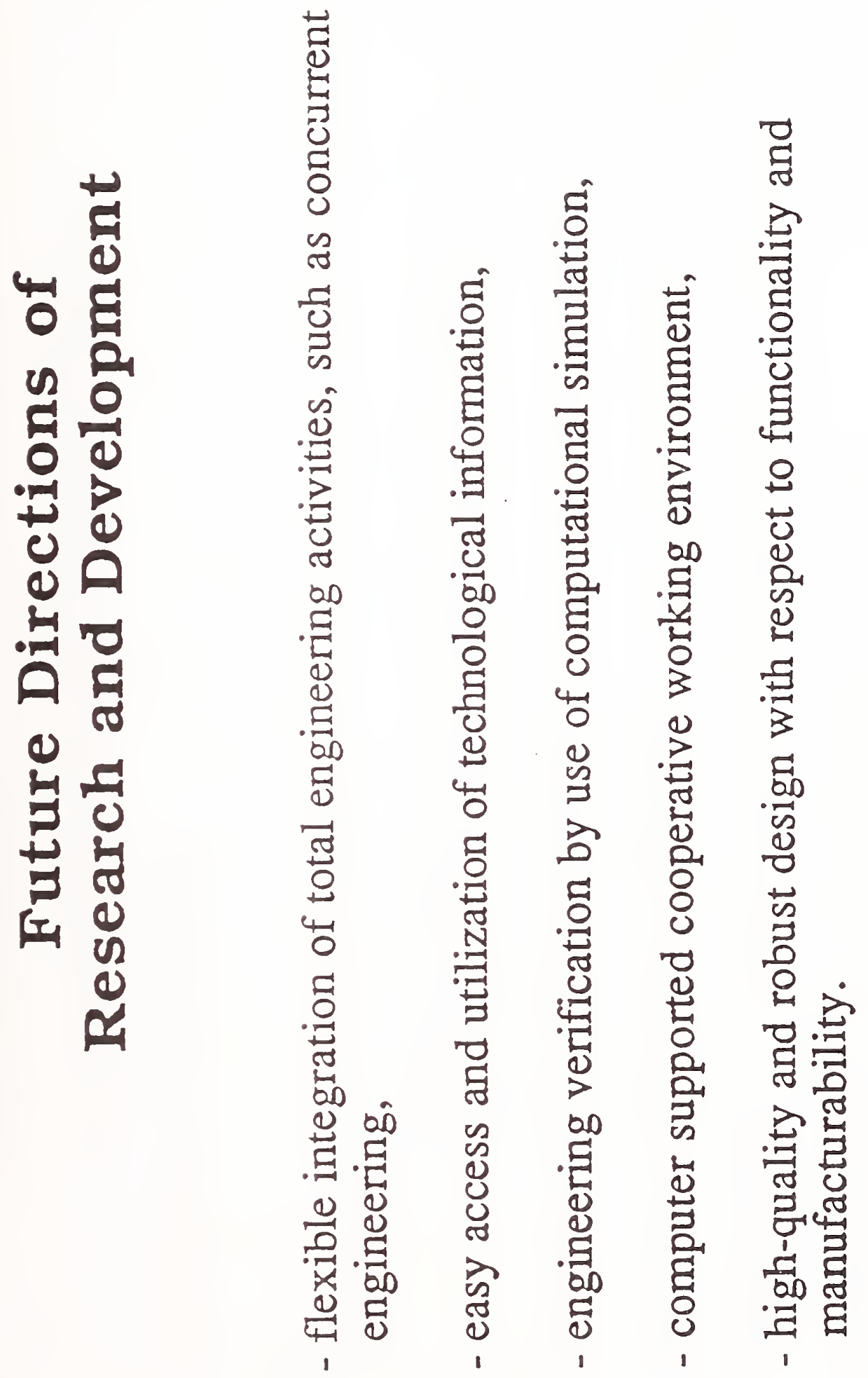




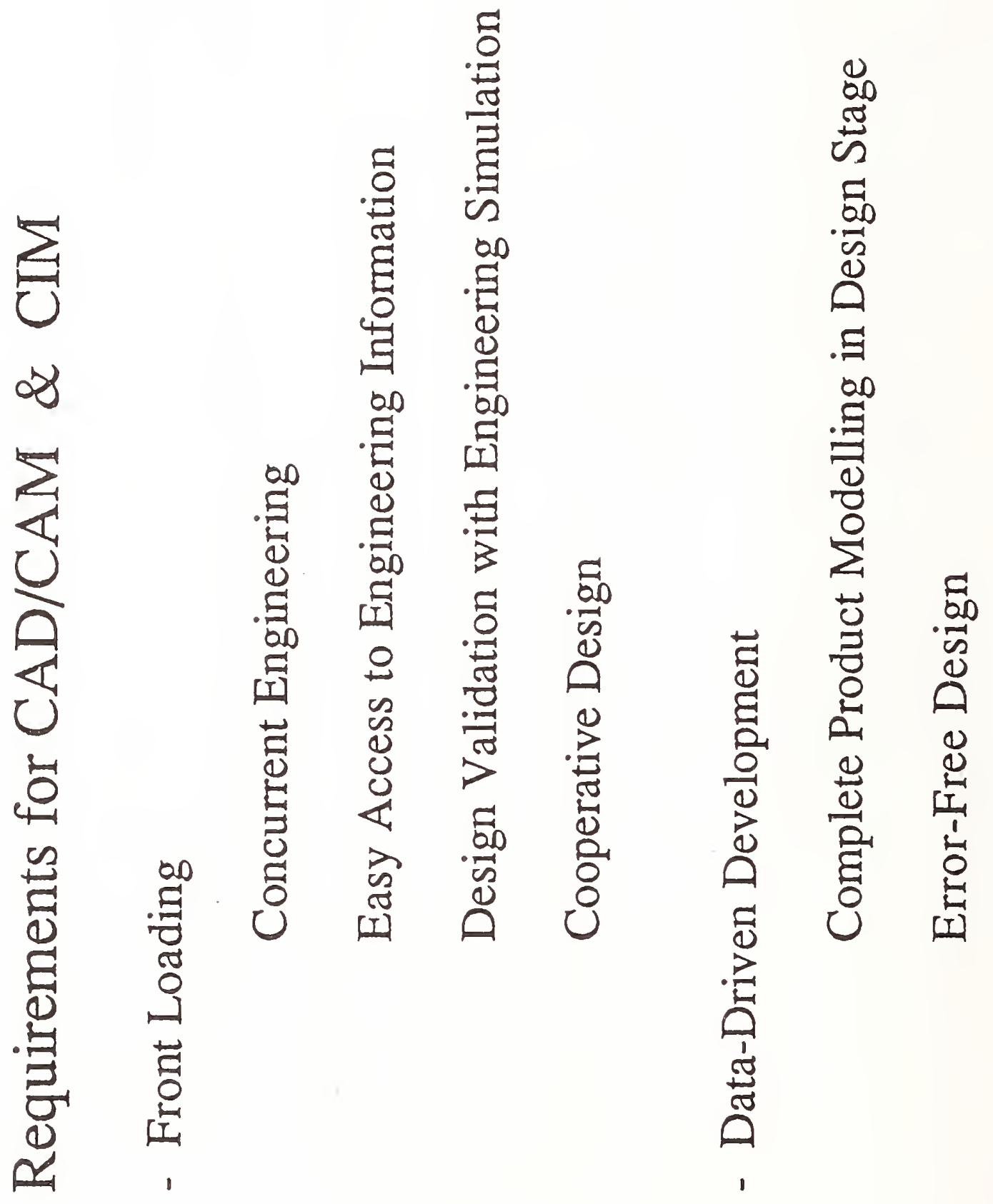




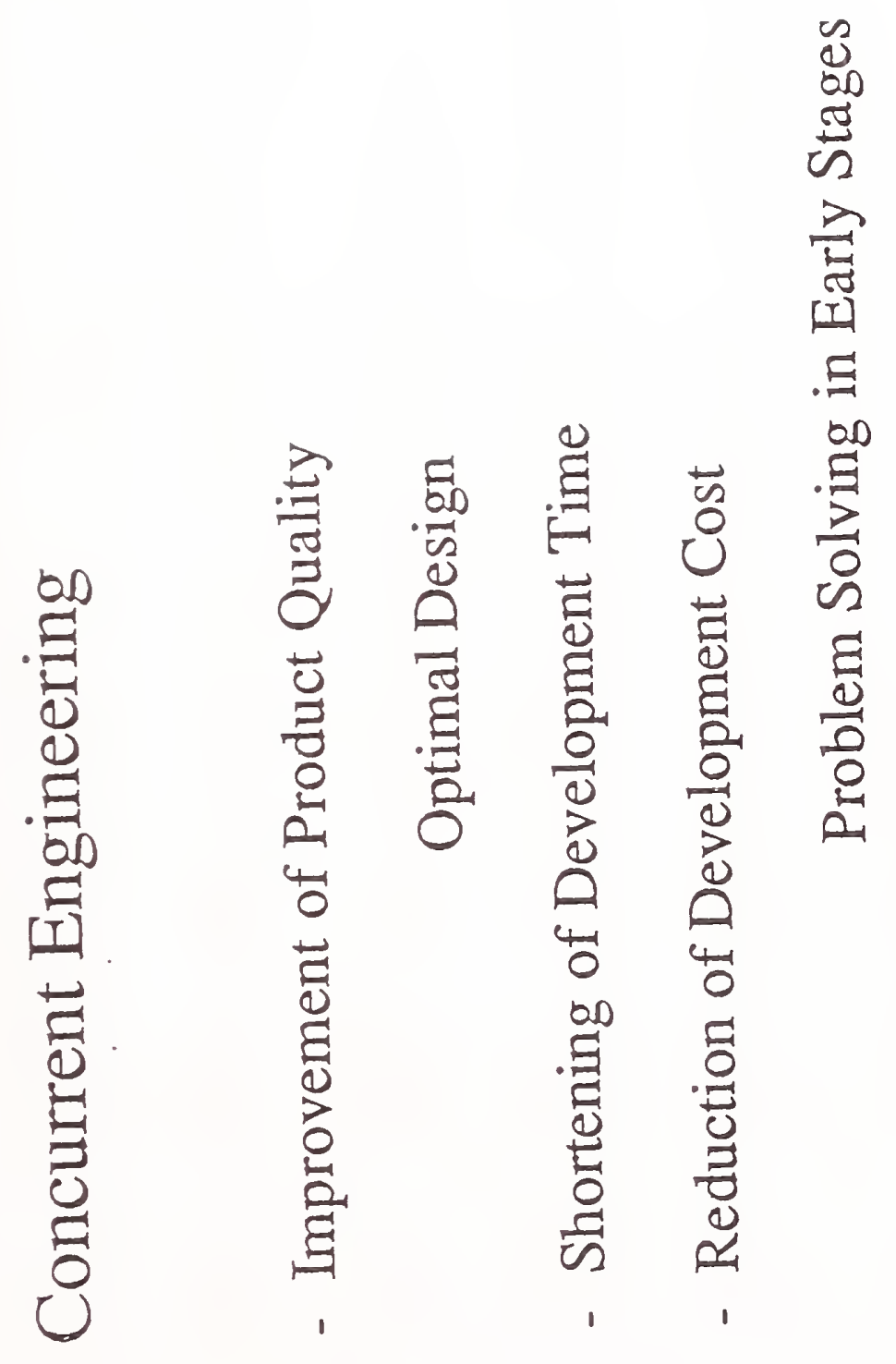




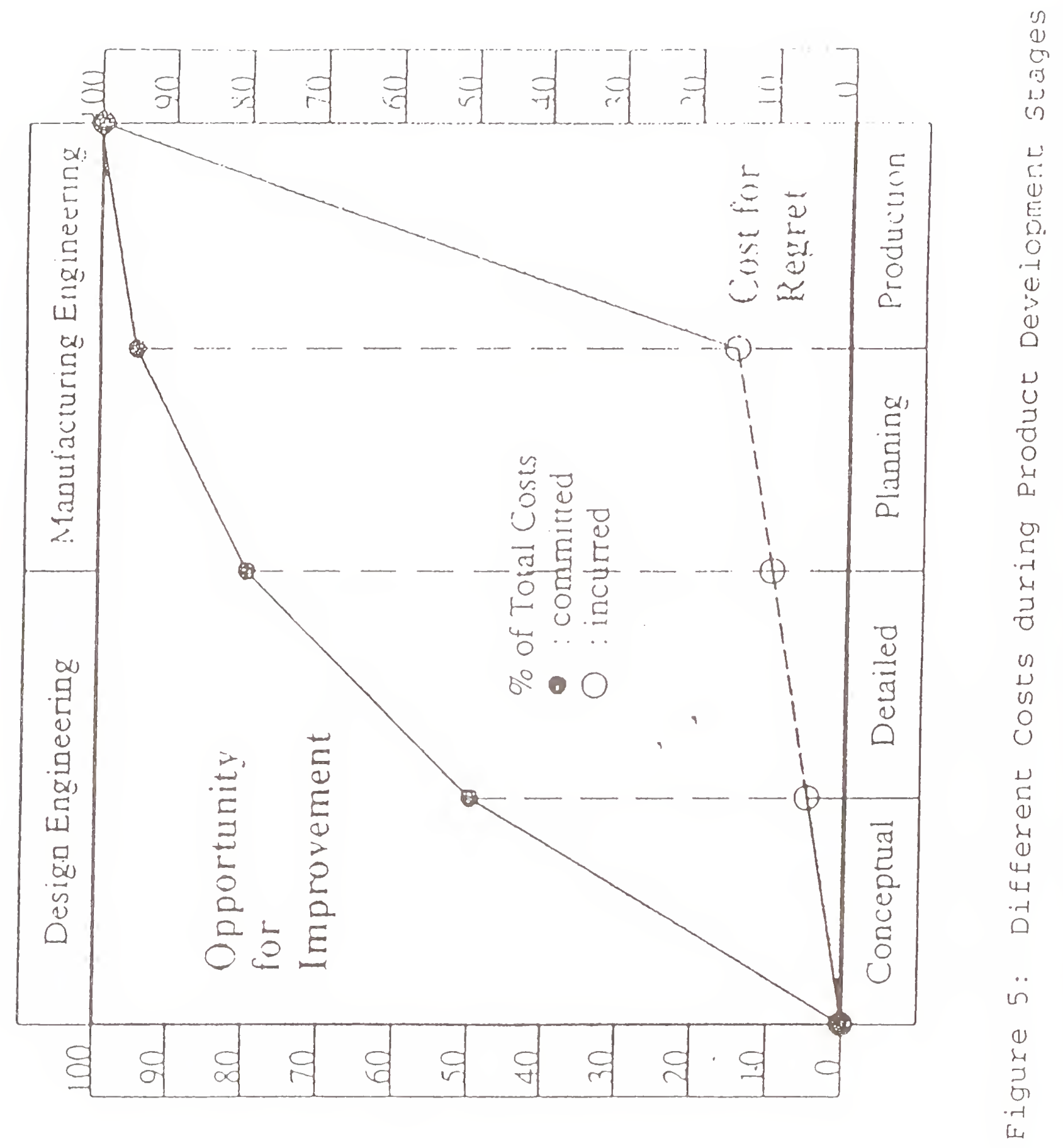




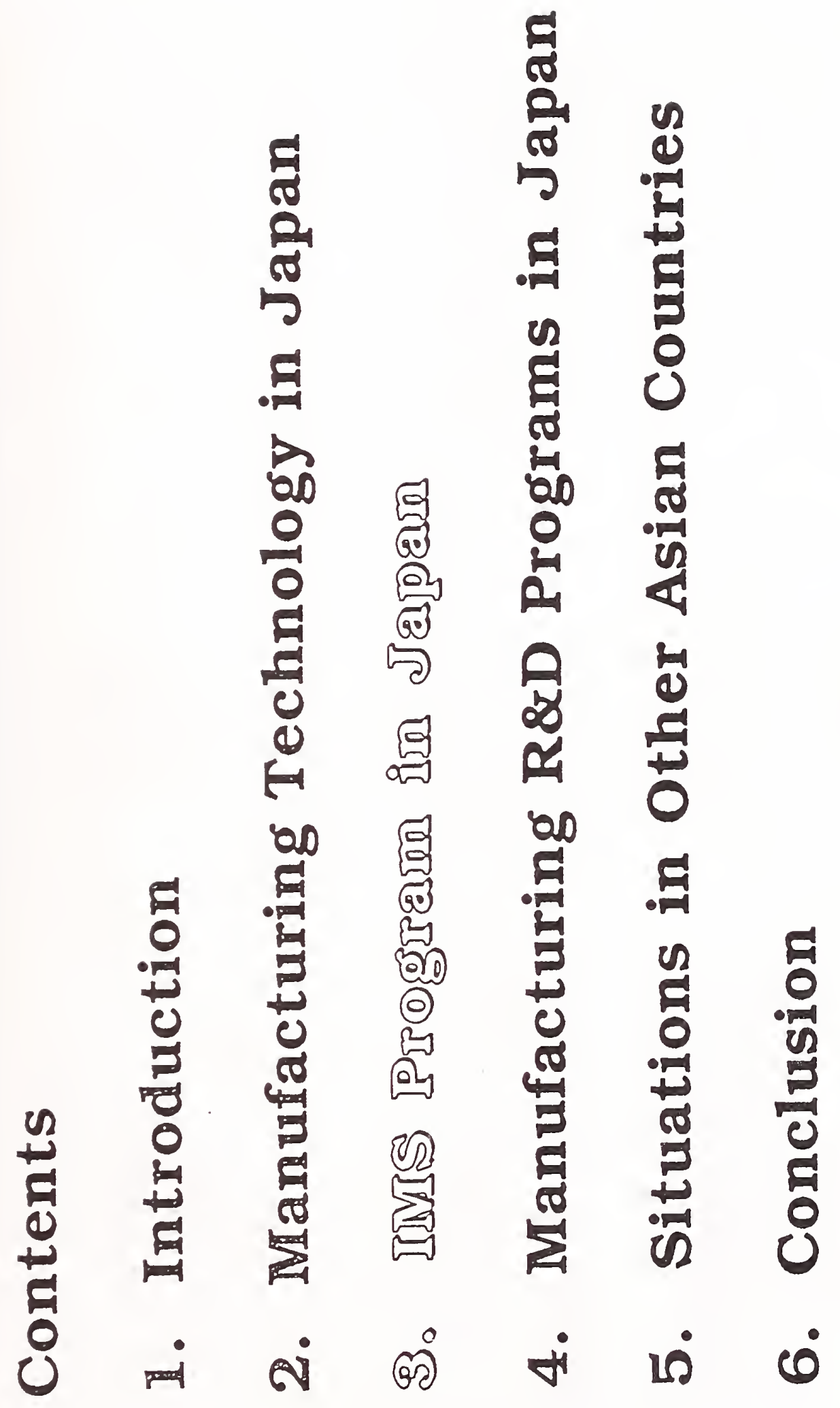




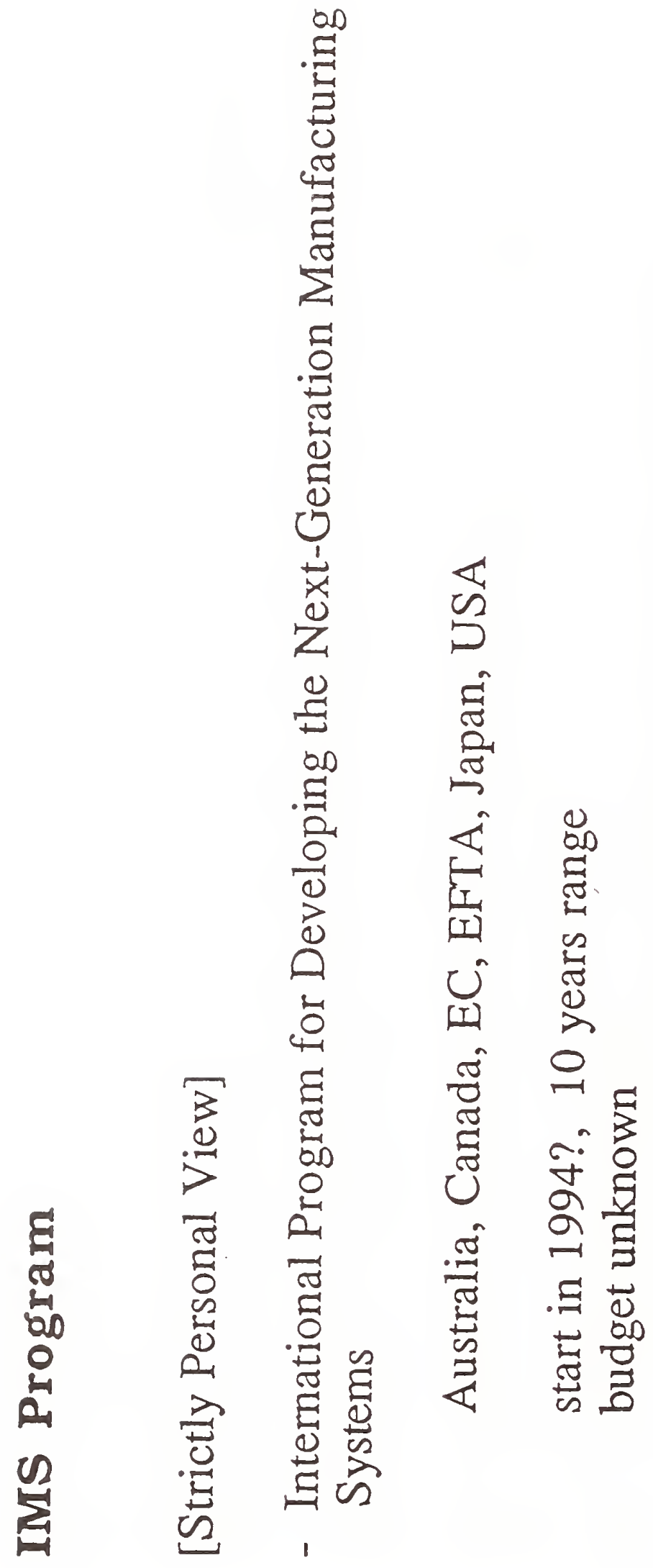




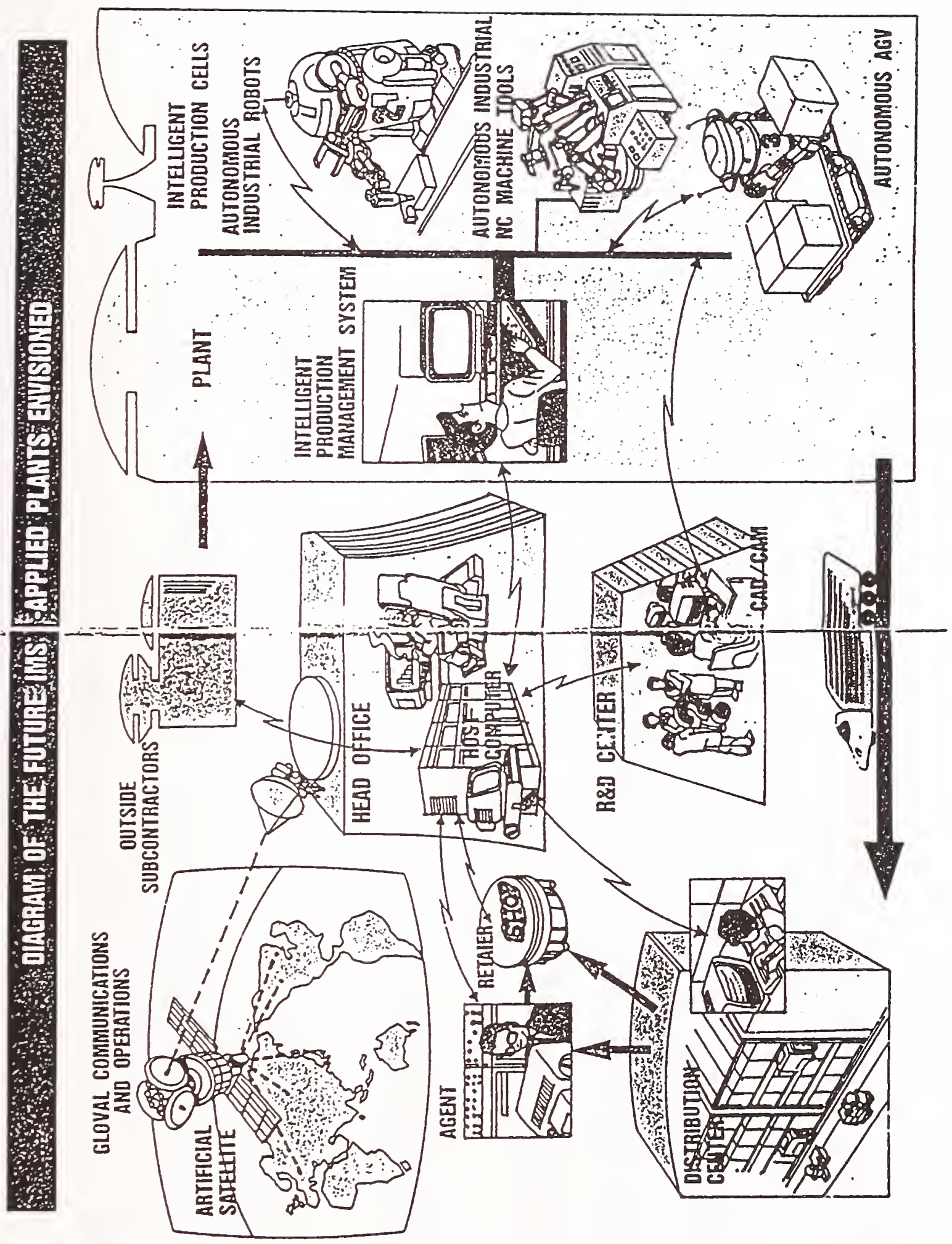



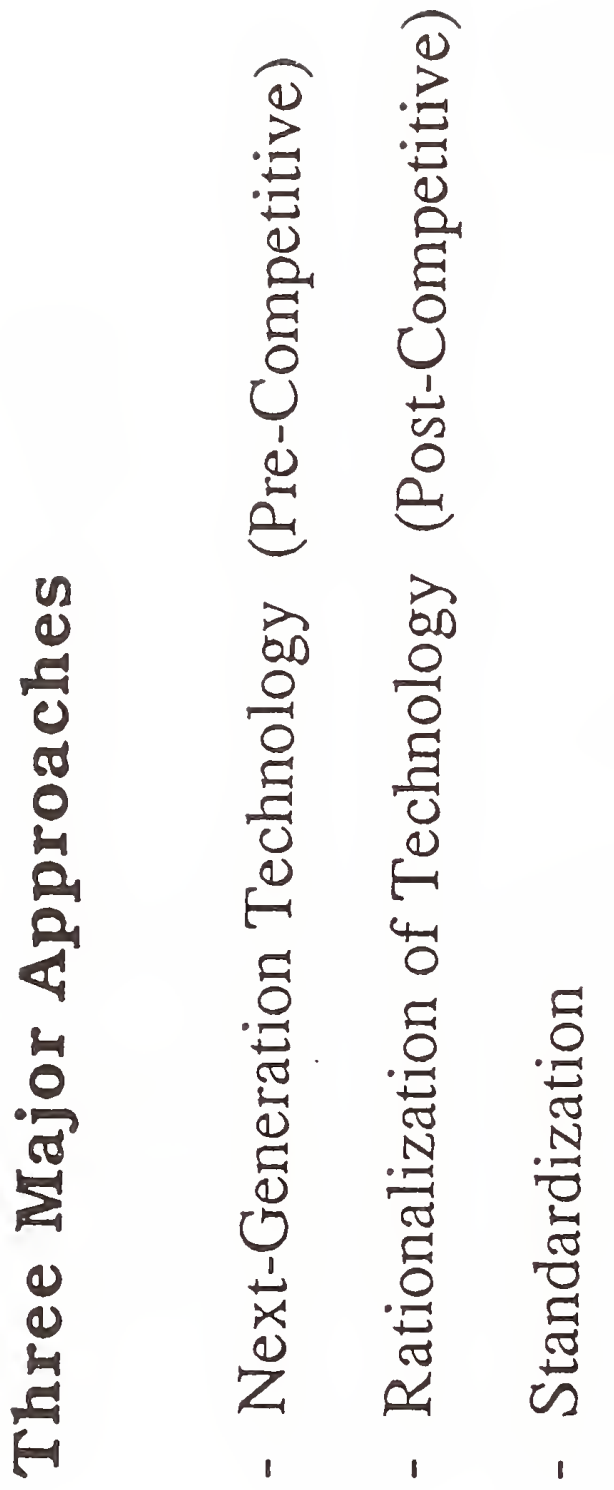

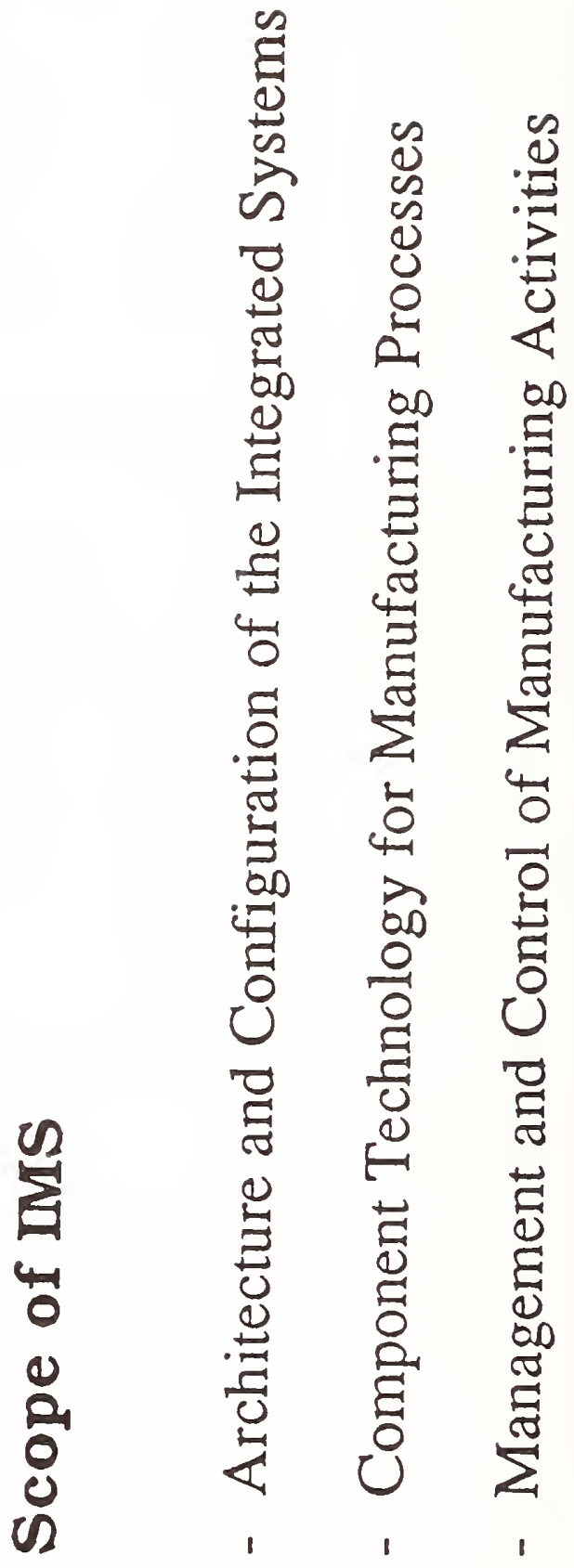




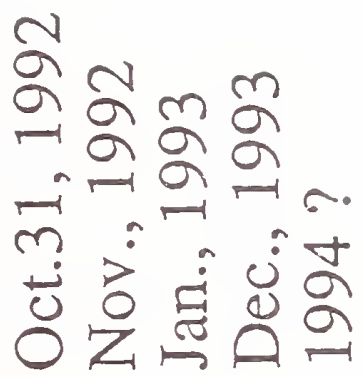

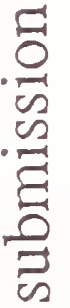

$\sum_{i=1}^{\infty}$

च थ $थ$ थ थ

0
0
0
0
0
0

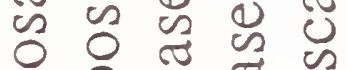

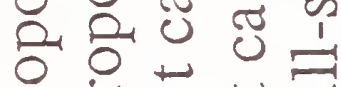

:

40000

()

0

U

co

$+2$

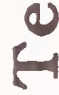

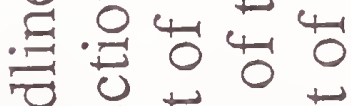

(1) 它 峁光

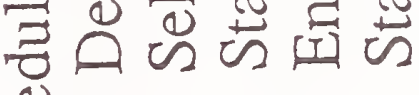

$\frac{1}{0}$

용 के की

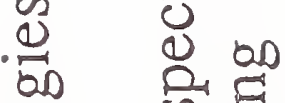

0 के थ

() Ш

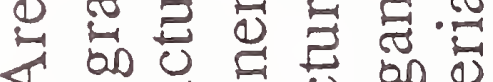

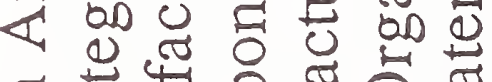

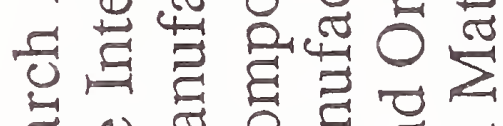

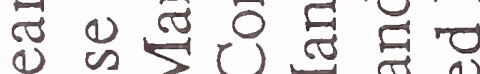

() $\approx \sum \sum$ क

\&

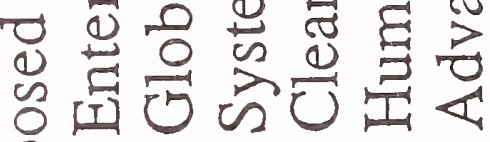

en 


\begin{tabular}{|c|c|c|c|c|c|}
\hline 谠地貝 & IKEGAI IROH WORK LTO. & \multicolumn{2}{|c|}{ 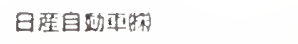 } & \multicolumn{2}{|c|}{ HISSAN MOTOR CORPORAIIOH } \\
\hline NKK & HKK CORPORATIOH & \multicolumn{2}{|c|}{ 日ホアイ・ピー・エム物 } & \multicolumn{2}{|c|}{ IBM JAPAY. LTD. } \\
\hline NTNOA & HTH CORPORATIOH & \multicolumn{2}{|c|}{ 日本板硙子物 } & \multicolumn{2}{|c|}{ HIPPOH SHEET GLASS CO.. LTO. } \\
\hline オークマ时 & OKUMHA MACHIHERY HORKS LTD. & \multicolumn{2}{|c|}{ 日本有工睁 } & \multicolumn{2}{|c|}{ HIPPOH SEIKO K.K. } \\
\hline 政大栋細 & OBAYASHI CORPORATIOH & \multicolumn{2}{|c|}{ 日本就気蜊 } & \multicolumn{2}{|c|}{ HEC CORPORATIOH } \\
\hline 沖管気工栄䧊 & OXI ELECTRIC IMOUSTRY CO.. LTO. & \multicolumn{2}{|c|}{ 日本正装物 } & \multicolumn{2}{|c|}{ HIPPOH OEHSO CO.. LTD. } \\
\hline オムロン踩 & OMPOH CORPORATIOH & \multicolumn{2}{|c|}{ 9积阳組 } & \multicolumn{2}{|c|}{ HAZAMA CORPORATIOH } \\
\hline 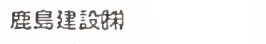 & KAJIMA CORPORATIOH & \multicolumn{2}{|c|}{ 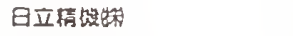 } & \multicolumn{2}{|c|}{ HITACHI SEIKI CO., LTD. } \\
\hline カルピー和 & CALBEE FOOOS CO.. LTD. & \multicolumn{2}{|c|}{ 日立再工晽 } & \multicolumn{2}{|c|}{ HITACHI SEIKO. LTD. } \\
\hline 川畸重工栄煳 & KAWASAKI HEAVY IMOUSTRIES. LTD. & \multicolumn{2}{|c|}{ 铩日立裂作所 } & \multicolumn{2}{|c|}{ HITACHI, LTD. } \\
\hline 神㱦梨紙踝 & KS SYSTEMS IHC. & \multicolumn{2}{|c|}{ 日立造船稆 } & \multicolumn{2}{|c|}{ HITACHI ZOSEY CORPORATIOH } \\
\hline キヤノン瞅 & CAMOH IHC. & ファナ & ク锈 & FAHUC & LTD. \\
\hline 踈クポタ & KUBOTA CORPORATIOH & 物不三 & & MACHI- & FUIKOSHI CORPORATIOH \\
\hline 光洋辕工眯 & KOYO SEIKO CO.. LTD. & 畐士せ & ックス的 & FU, 2 & IEROX CO.. LTD. \\
\hline 䗗小昖顽作所 & KOMAISU LTD. & 制富士 & 合明㠰所 & FUI $R$ & IESEARCH IHSTITUTE CORPORATIOH \\
\hline 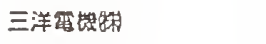 & SAHYO ELECTRIC CO., LTD. & 畐土通 & & FWITS & SU LTD. \\
\hline 消水建設踝 & SHIMIZU CORPORATIOH & 富士跑 & & Fl E & IECTRIC CO., LTO. \\
\hline シャープ跐 & SHARP CORPORATIOH & 古河出 & 工荣期 & THE $\mathrm{R}$ & URUKAWA ELECTRIC CO., LTD. \\
\hline 住友西気工菜珠 & SUMITOMO ELECTRIC IHOUSTRIES LTD. & ホンタ & ンジニアリング蹐 | & HOHOA & ENGIHEERIHG CO.. LTD. \\
\hline ソニー路 & SOHY CORPORATIOH & 路致野 & ライス琵作肪 | & MAKIH & OO MILLIHG MACHIHE CO., LTD. \\
\hline ダイキン工攀瞅 & DAIKIH IHOUSTRIES LTD. & 松下亚 & 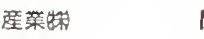 & MATSU & JSHITA ELECTRIC INDUSTRIAL CO., LTD. \\
\hline 大成建铅时 & TAISEI CORPORATIOH & マッダ & & MAZOA & М МОTOR CORPORATIOH \\
\hline 大日本スクリーン裂造䅨 & OAIHIPPOH SCREEN M.F.G. CO., LTD. & 三井造 & & MITSU & II EHGIHEERIHG \& SHIPBUILDIHG CO.. LTD. \\
\hline 萪タイフフク & OAIFUKU CO.. LTD. & 三整政 & 栄㦹 & MITSU & IBISHI HEAVY IHOUSTRIES, LTD. \\
\hline 瞔竹中工拐后 & TAKEHAKA CORPORATIOH & 三基最 & & MITSU & I8ISHI ELECTRIC CORPORATIOH \\
\hline 千代田化工建殷胡 & CHIYOOA CORPORATIOH & 三琵マ & リアル㩆 & MITSU & IBISHI MATERIALS CORPORATIOH \\
\hline 蜊東芝 & TOSHIBA CORPORATIOH & ミネベ & & MIHEB & IEA CO., LTD. \\
\hline 曹洋エンジニアリング踢 & TOYO EMGIHERIHG CORPORATIOH & 村田接 & & MURAT & TA MACHIHERY, LTD. \\
\hline 東洋轺荣踿 & TOYO SHIGYO PRINTING CO.. LTD. & 蝶安 114 & & YASUK & AHA ELECTRIC MFG CO., LTD. \\
\hline 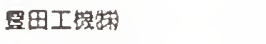 & TOYOTA MACHIHE WORKS LTT. & ヤマザ & マザック踝 & YAMAZ & EAKI MAZAK CORPORATIOH \\
\hline トヨ夕自跏車物 & TOYOTA MOTOR CORPORATIOH & 山炡八 & ウエル蚮 & YAMAT & TAKE-HOHEYWEU CO., LTD. \\
\hline 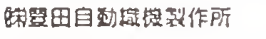 & TOYOTA AUTOMATIC LOOM WORKS LTD. & 拱菏对 & & YOKOG & AWA ELECTRIC CORPORATIOH \\
\hline 踈新晹鉄工所 & HIIGATA ENGIHEERIHG CO.. LTD. & 踿リコー & & RICOH & COMPANY \\
\hline 日挥物 & JGC CORPORATIOH & & & & 平成 4 年3月 5 日現在 \\
\hline 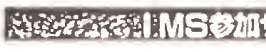 & ings? & & हाना & NEM: & Biscomi: \\
\hline アマダ & AMAOA CO.. LTD. & & セイリーエプソン & ン铩 & SEKKO EPSOH COAPORATIOH \\
\hline アッフルオベレーションオ & スアンド APPLE OPERATIOAS AMO & & 戸田建锊践 & & TOOA CORPORATIOH \\
\hline テクノロシースシャハン & TECHHOLOGIES JAPAH. IHC. & & トムソン シャハン & 「ン称 & THOMSOH JAPAH KK \\
\hline 梱イーセル & EZEL INC. & & 日本ユニシス踝 & & HIHOK UHISYS. LTD. \\
\hline 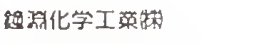 & KAMEBUCHI CHEMICAL IHOUSTRY CO. & .. LTD. & 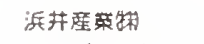 & & HAMAI CO., LTD. \\
\hline 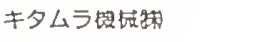 & KITAMURA MACHIHERY CO.. LTD. & & 日立ブラント建設 & 站时林 & HITACHI PLANT ENGIHEERIHG \& \\
\hline 䊏三和㩆行 & SANWA BAKK, LTD & & & & CORPORATIOH CO.. LTD. \\
\hline 锹昷建琵作所 & SHIMAZU CORPORATIOH & & 晽フジキン & & FWIKIH IHCORPORATED \\
\hline 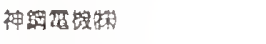 & SHIHKO ELECTRIC CO., LTD. & & 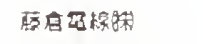 & & FWIKURA LTD. \\
\hline 特准友頯行 & THE SUMITOMO BAHK. LTD. & & 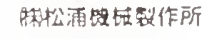 & & MATSUURA MACHIHERY CORPORATIOH \\
\hline 住友陑需踈 & SUMATOMO CORPORATIOH & & 三抹物程物 & & MITSUI \& CO.. LTD. \\
\hline ススキ补 & SUZUKI MOTOR CORPORATIOH & & 物ミツトヨ & & PMIISUTOYO CORPORATION \\
\hline & & & & & 平成 4 年 3 月 5 日現在 \\
\hline
\end{tabular}

\section{Wy}

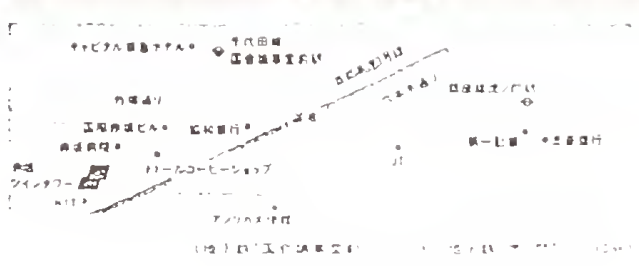

斯団法人国際ロボット・FA技街センター IMSセンター

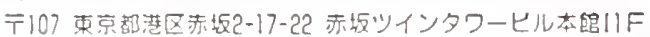
TEL. (03)5562-0331 FAX. (03)5562-0310

Ihis Promotion Center International Robotics and Factory Automation Center $11:$ FI. Akasakd Twin: oner Bldo 2-17.22 Átasana.

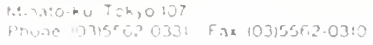




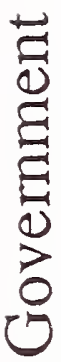

$\stackrel{U}{\rightleftarrows}$

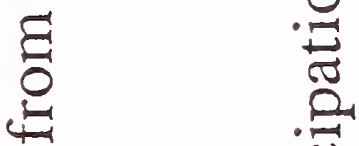

है

$\rightleftarrows \quad$ म

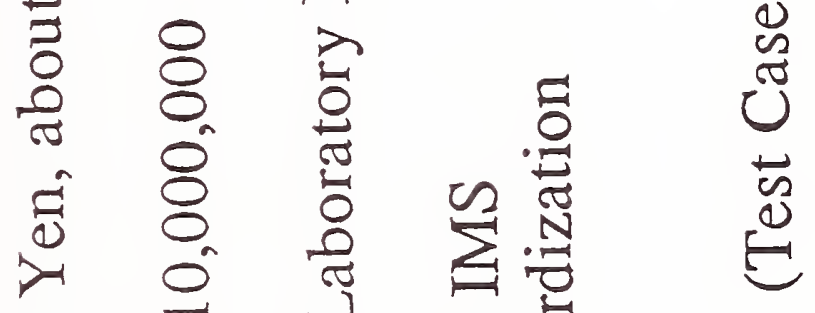

0

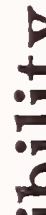

(2)

(1)

G.

5

몽

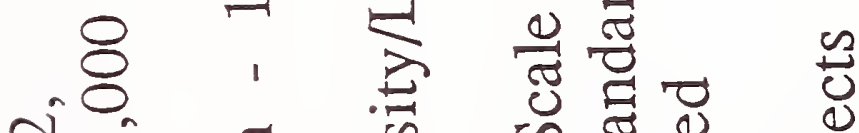

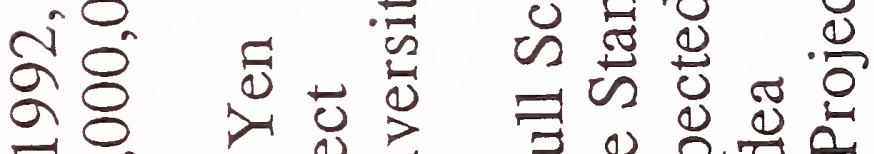

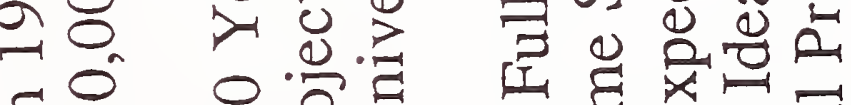

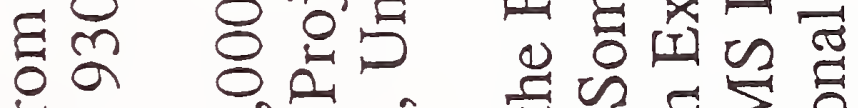
\# क 0 ठ .

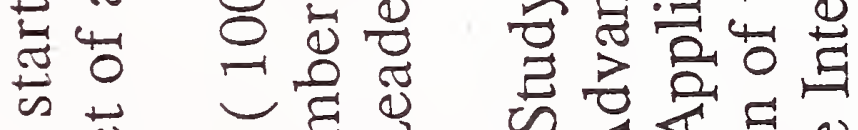

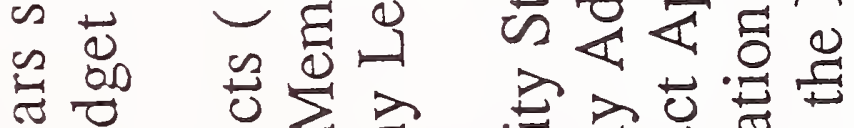

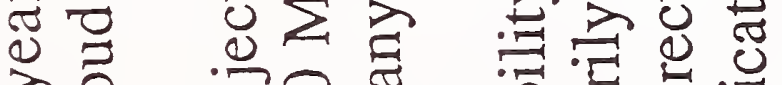
ᄀo 00 宁

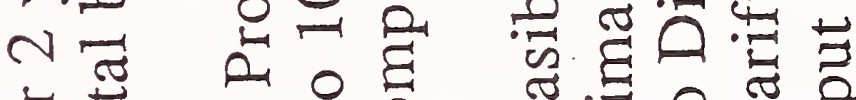

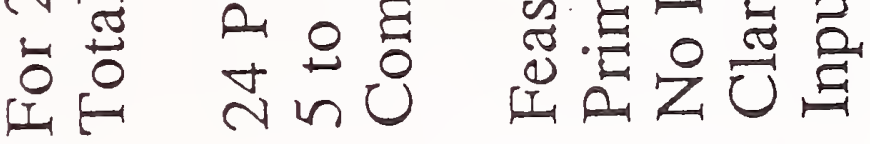




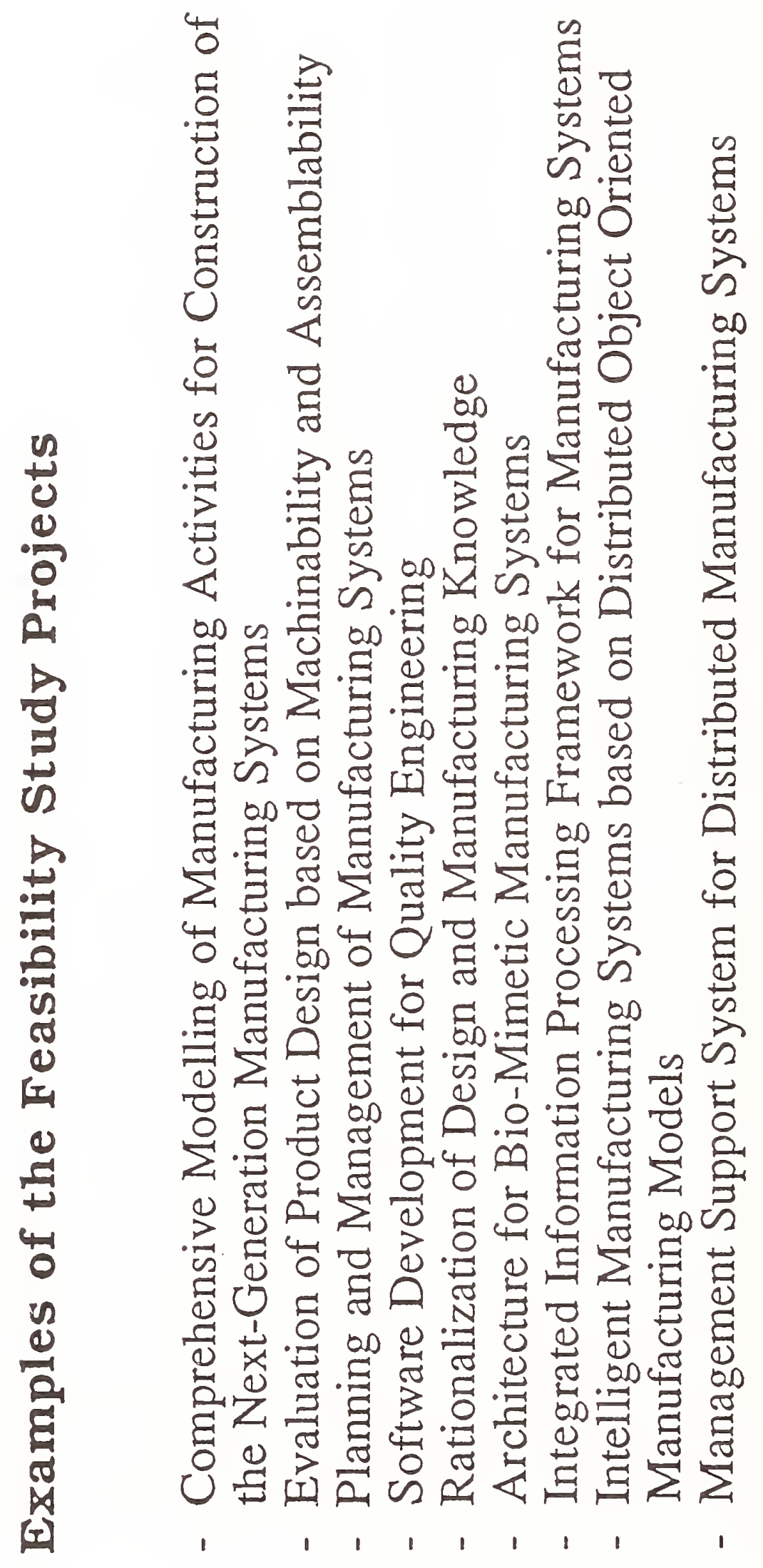


.

2

究

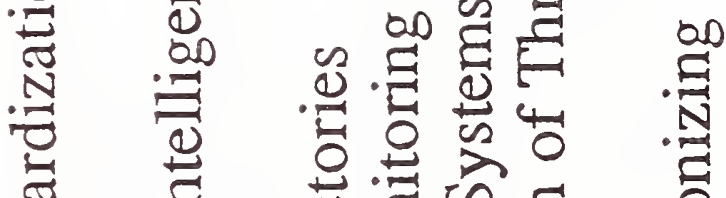

$\rightleftarrows$

\&

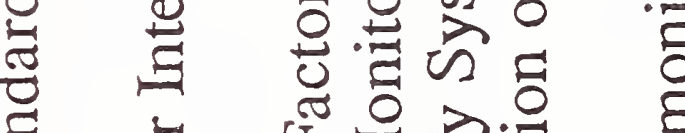

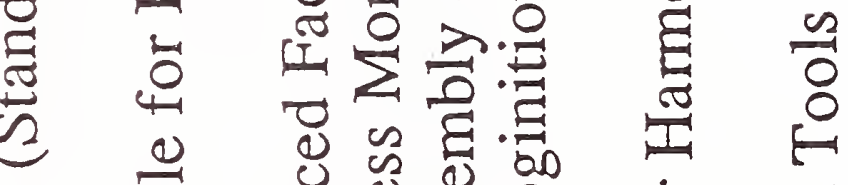

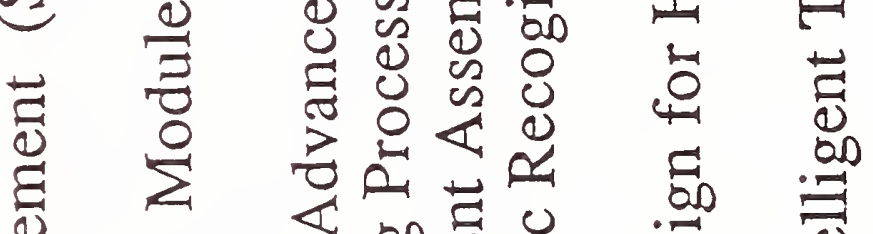

D $\sum_{0 \rightarrow 0} \ll$ on

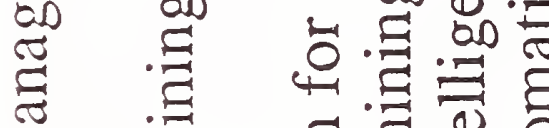

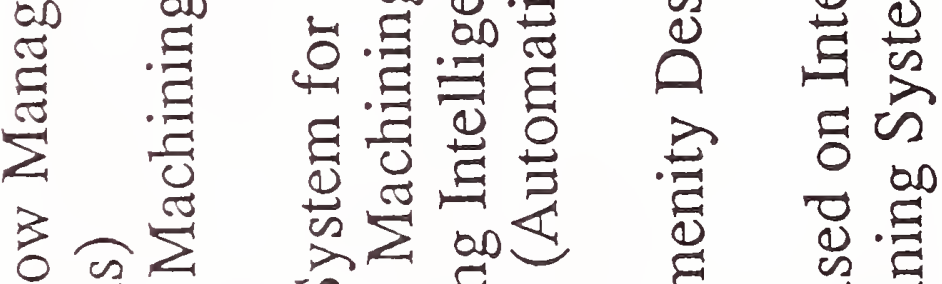

朐

일.

届

उ. $\Xi$ E

:

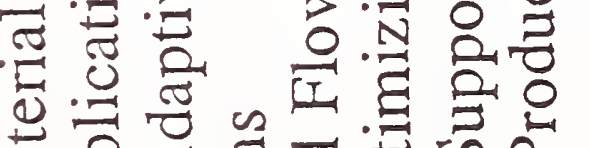

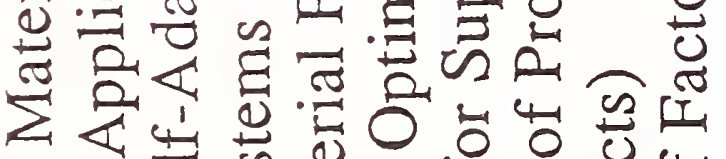

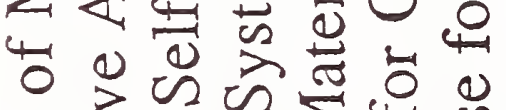

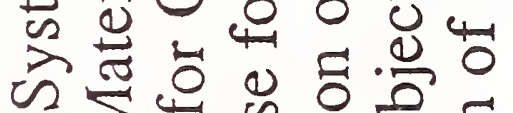

길

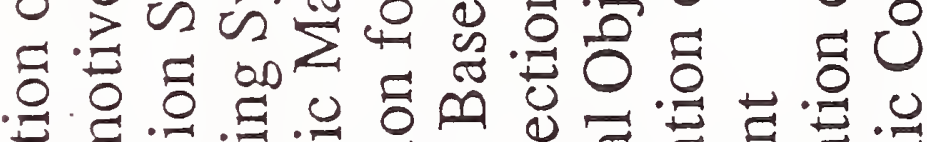

章

的.

글

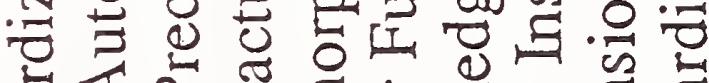

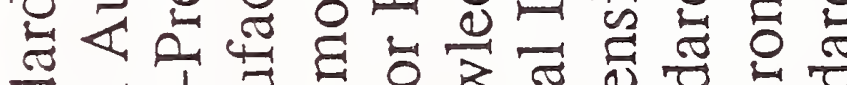

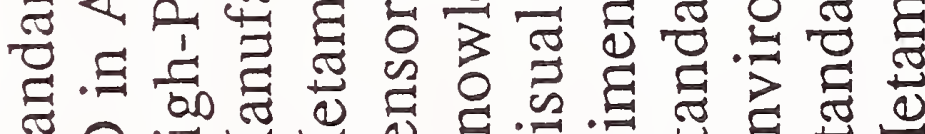

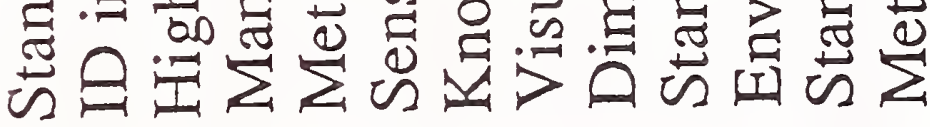




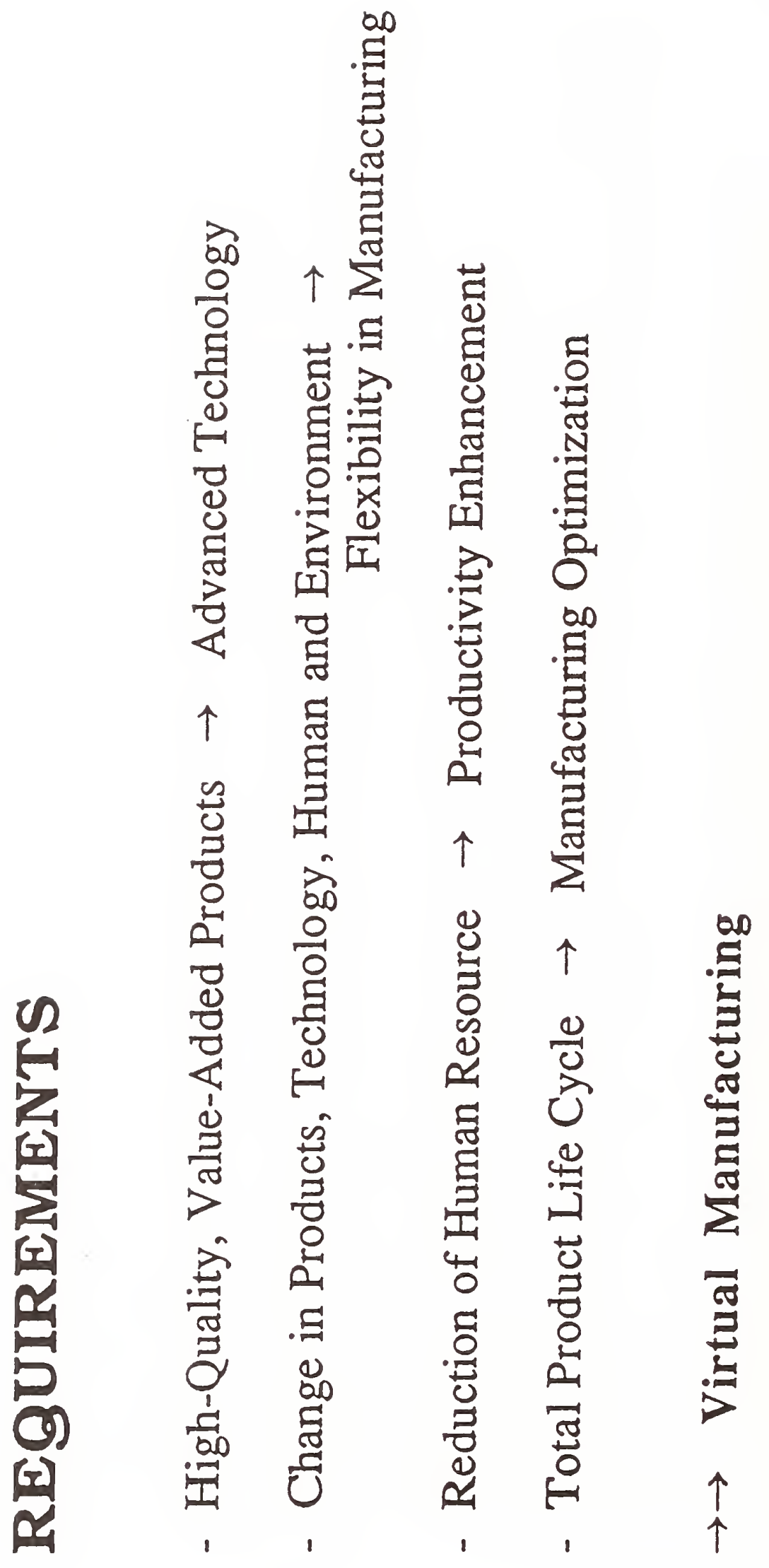




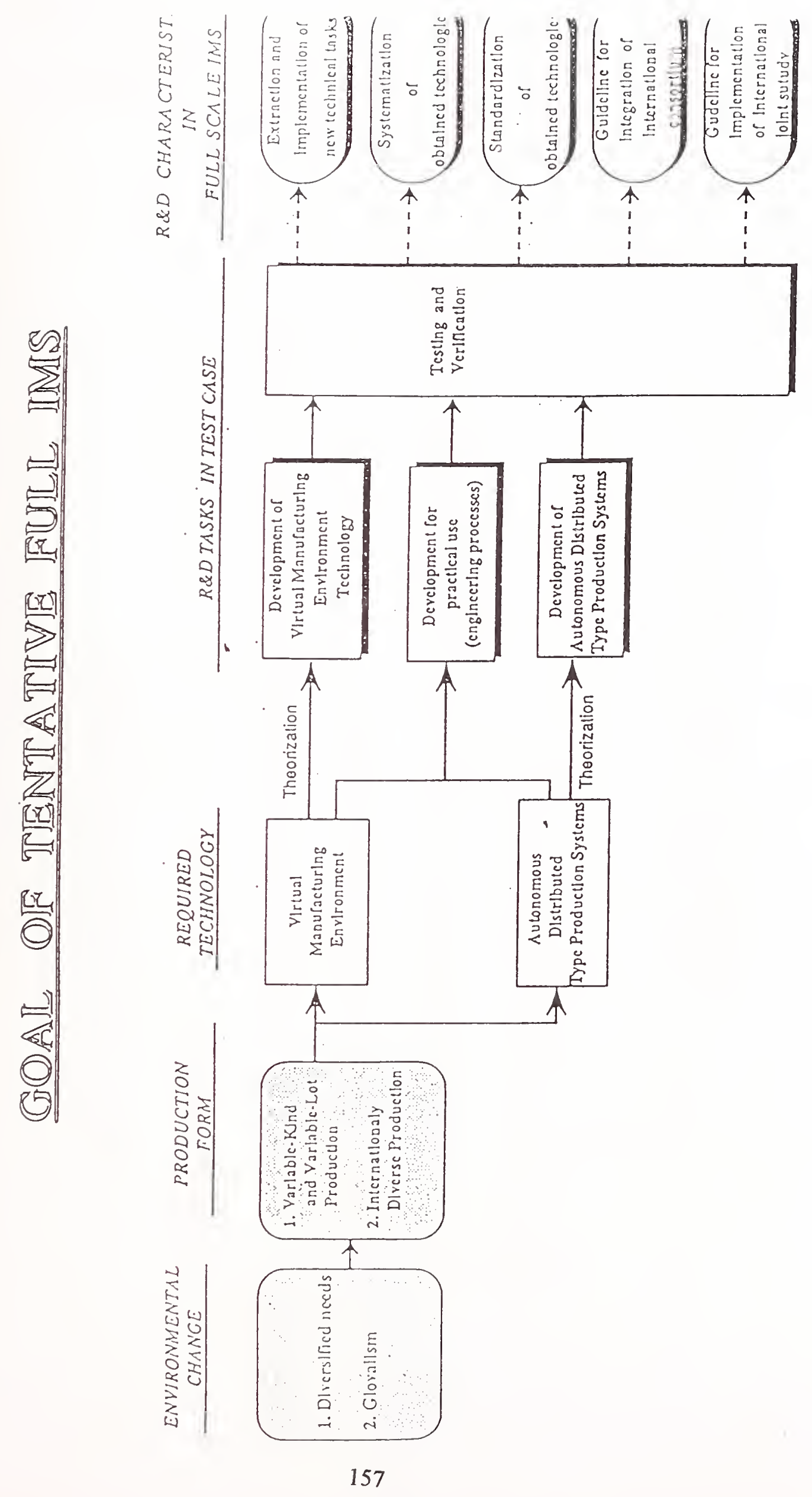



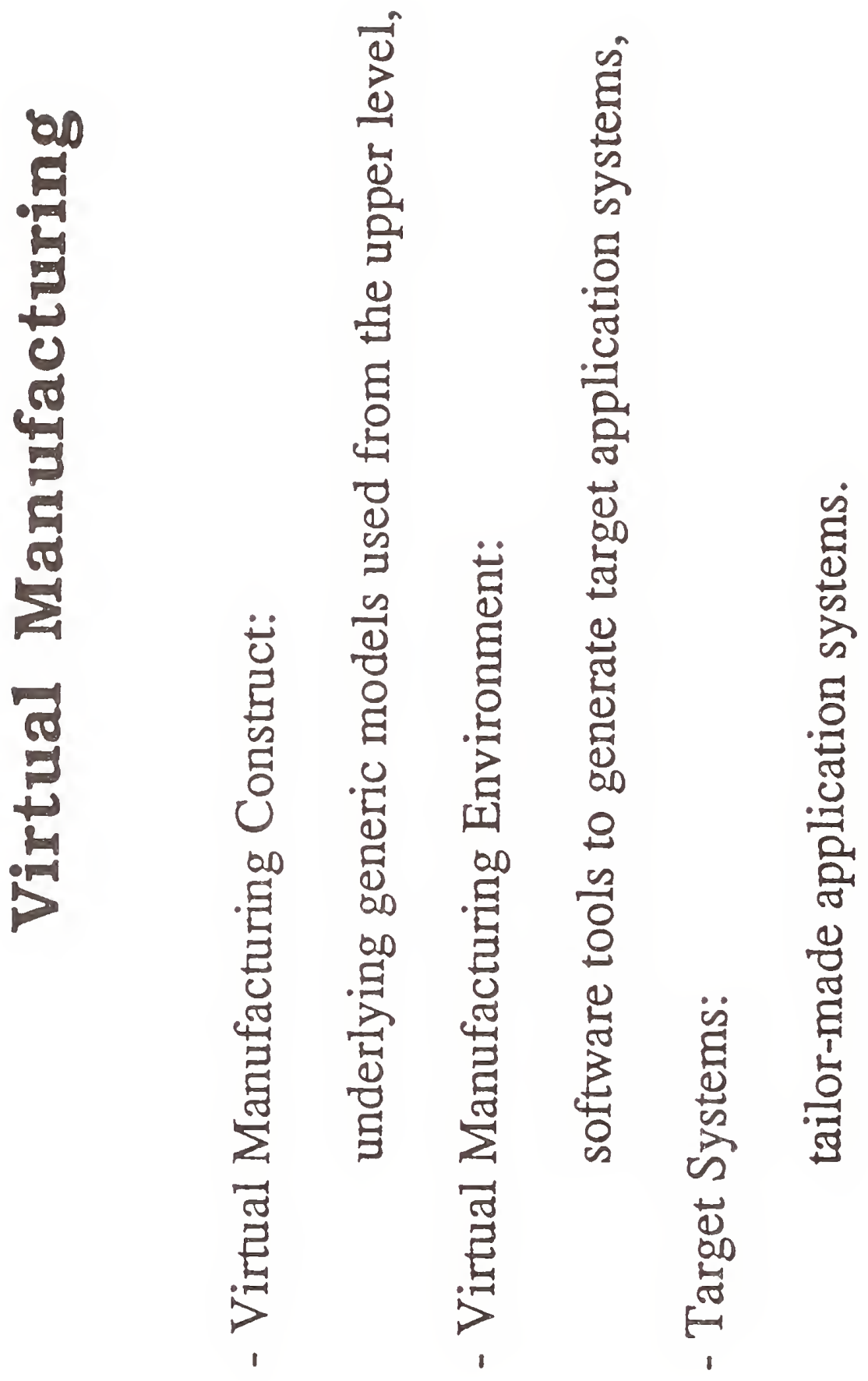
Target Systems

CIM System

CAD System

CAM Systcm

Factory Automation

System

Virtual Manufacturing Environment
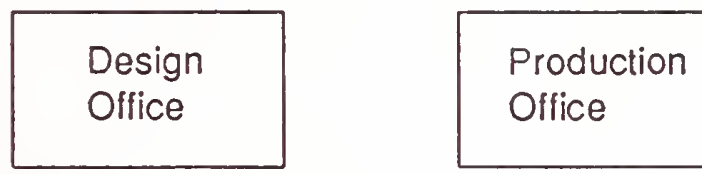

Factory
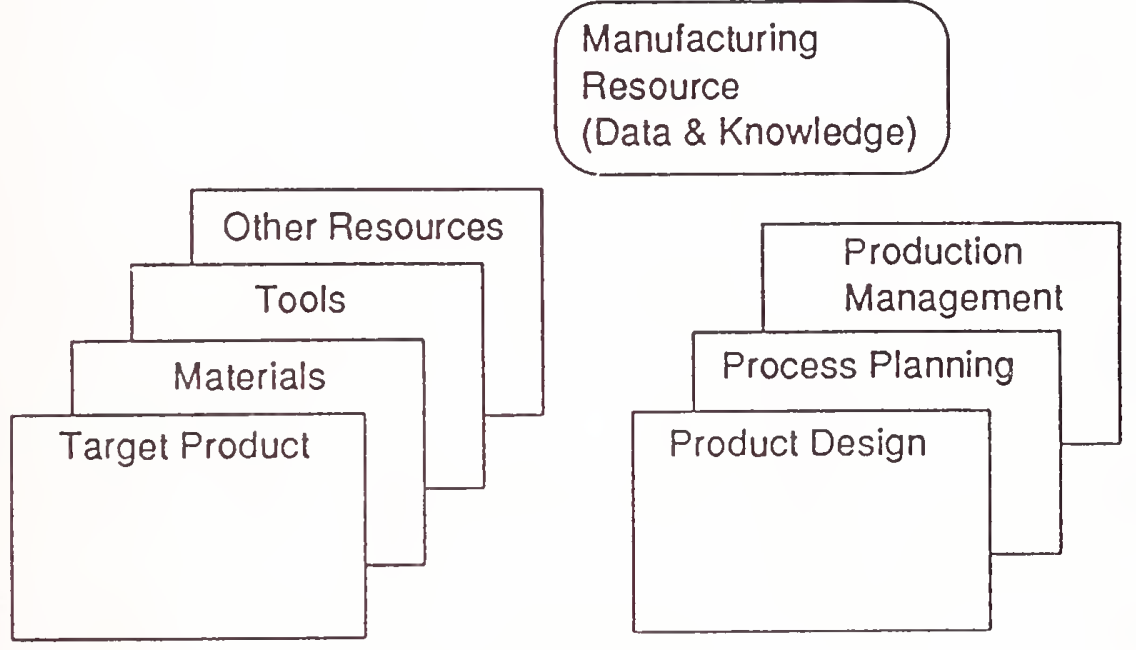

Virtual Manufacturing Construct

\begin{tabular}{|l|}
\hline Object Model \\
- Structure \\
- Dependency \\
- Consistency \\
- Fcalurc \\
- Shapc \\
- clc.
\end{tabular}

Activity Model

- Backtracking

- Multi-World

- Cooperative Work

- Uscr-Model

- clc.

Physical/Computational Process Model

- Dynamics

- FEM/BEM

- cic.

Virtual Manufacturing Environment 

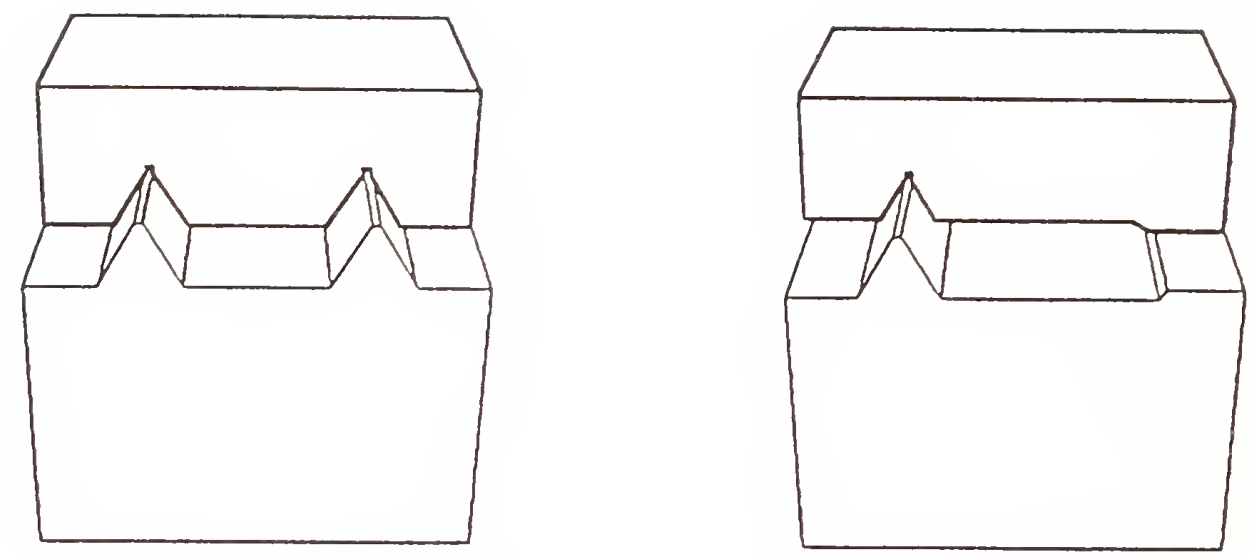

Figure 1: Two types of linear motion guide mechanisms.

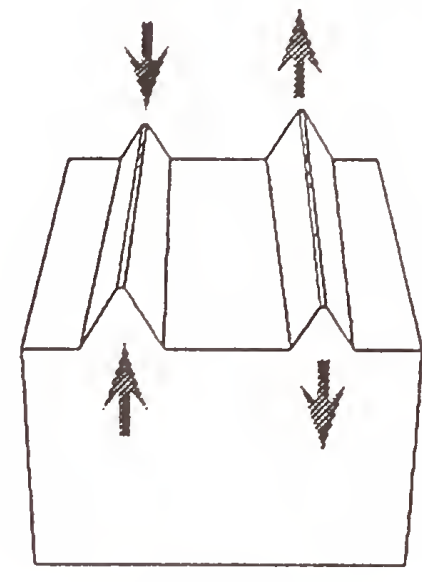

(a)

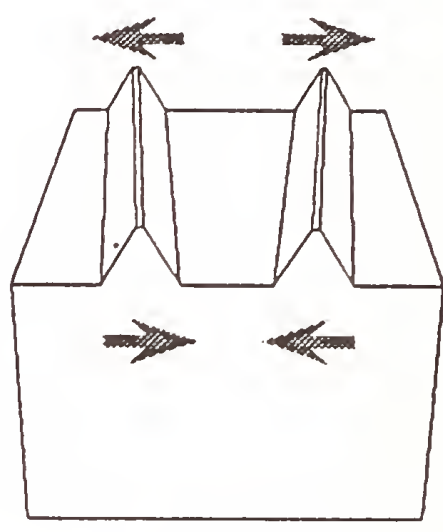

(b)

Figure 2: Two types of shape errors: (a) Twisted error (b) Horizontal inclination error.
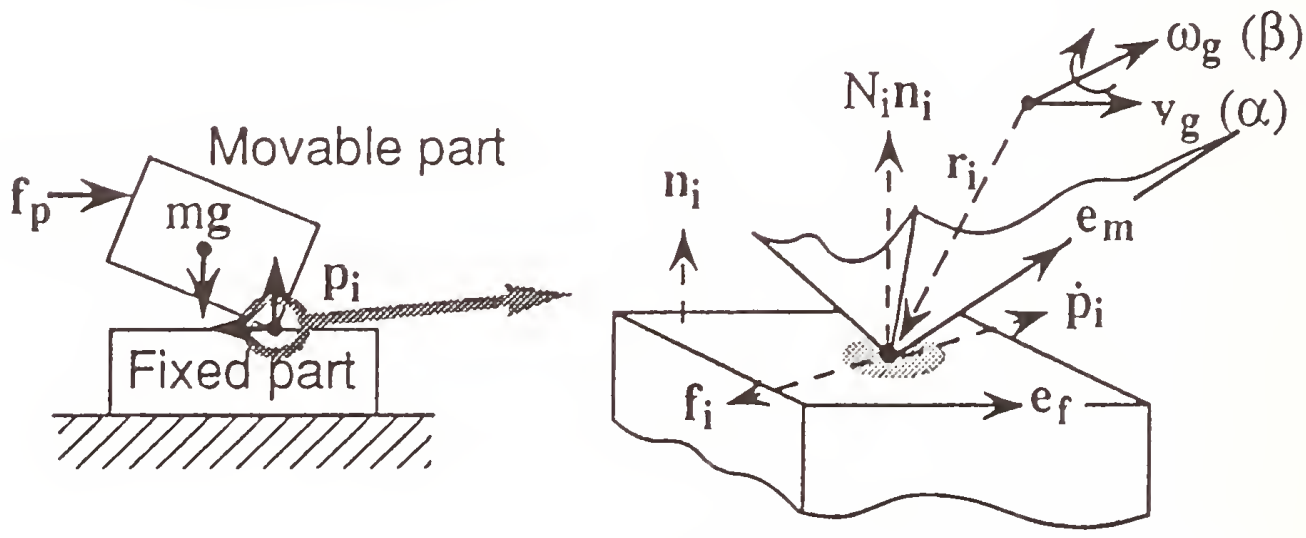

Figure 3: Terminology; a contact of a vertex and a face. 


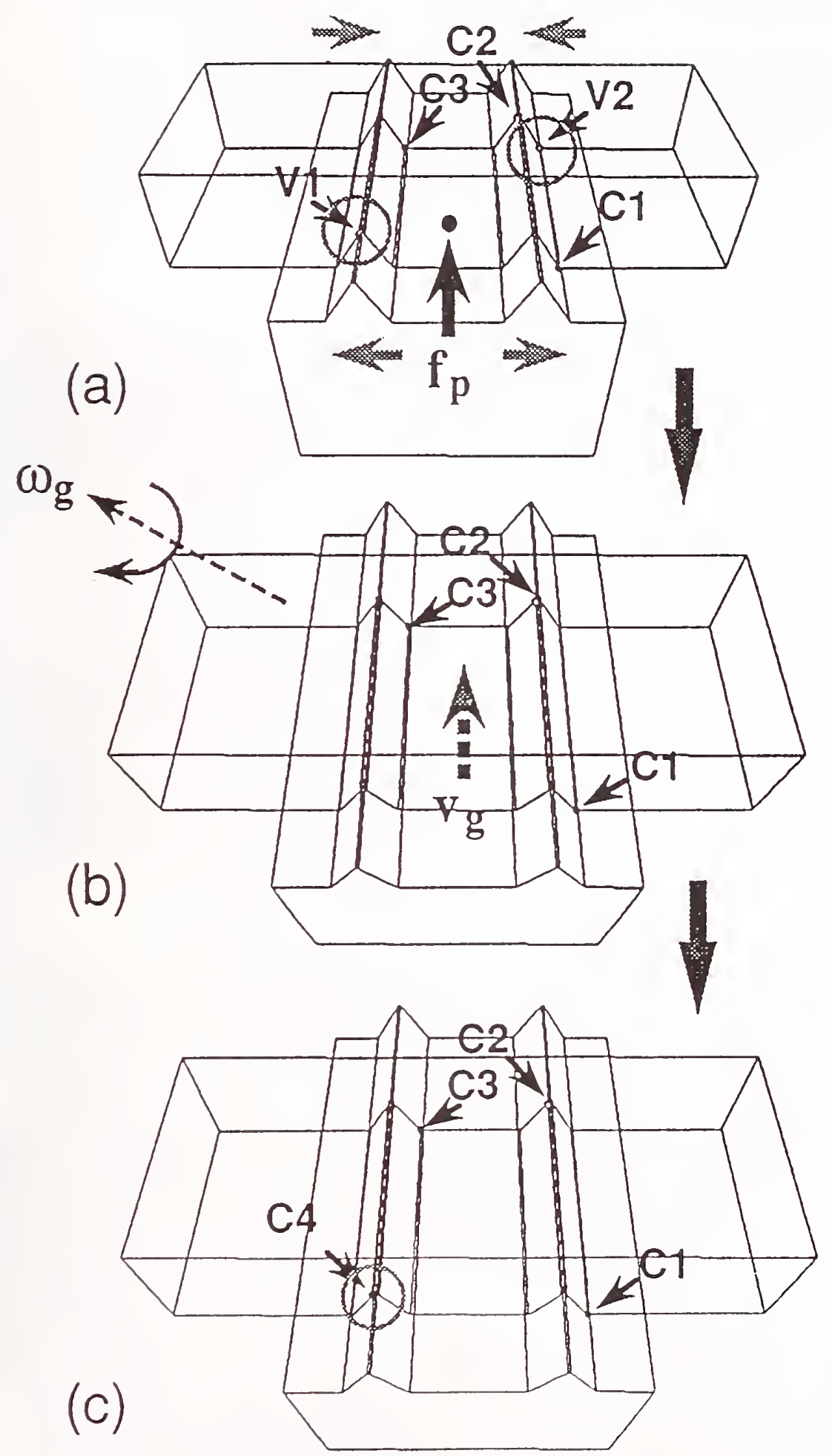

Figure 5: Example of the effect of horizontal inclination error: (a) Initial contact state (b) Intermediate state (c) New contact state. 


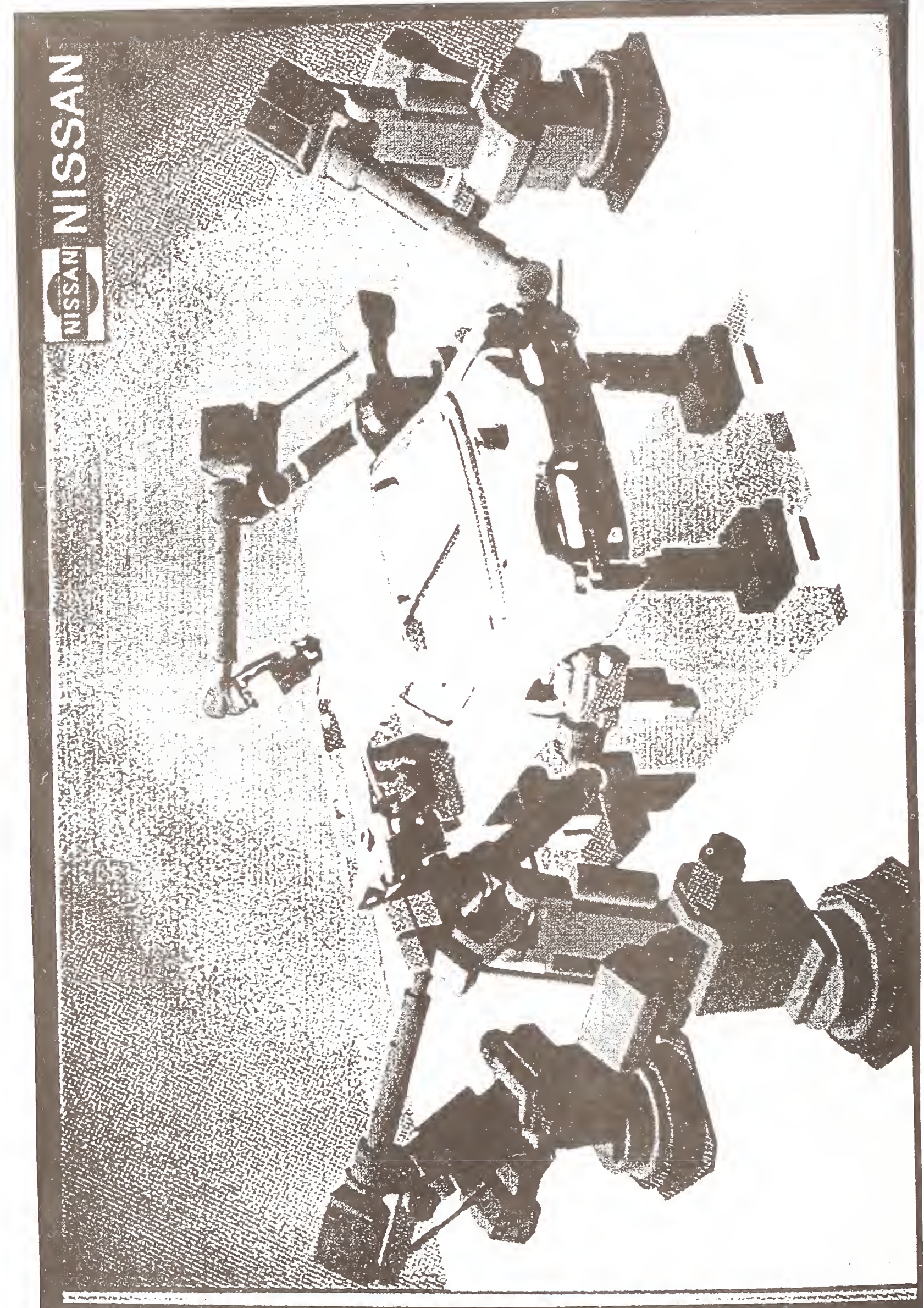




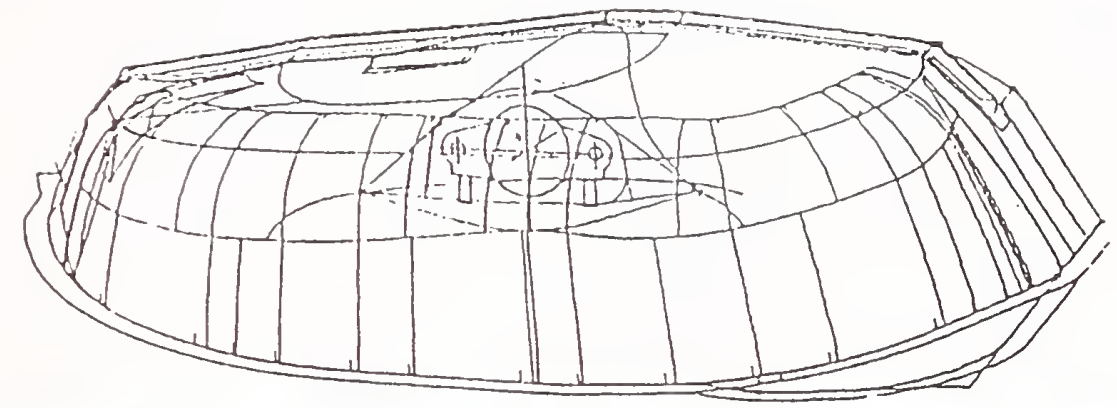

Tool geometry

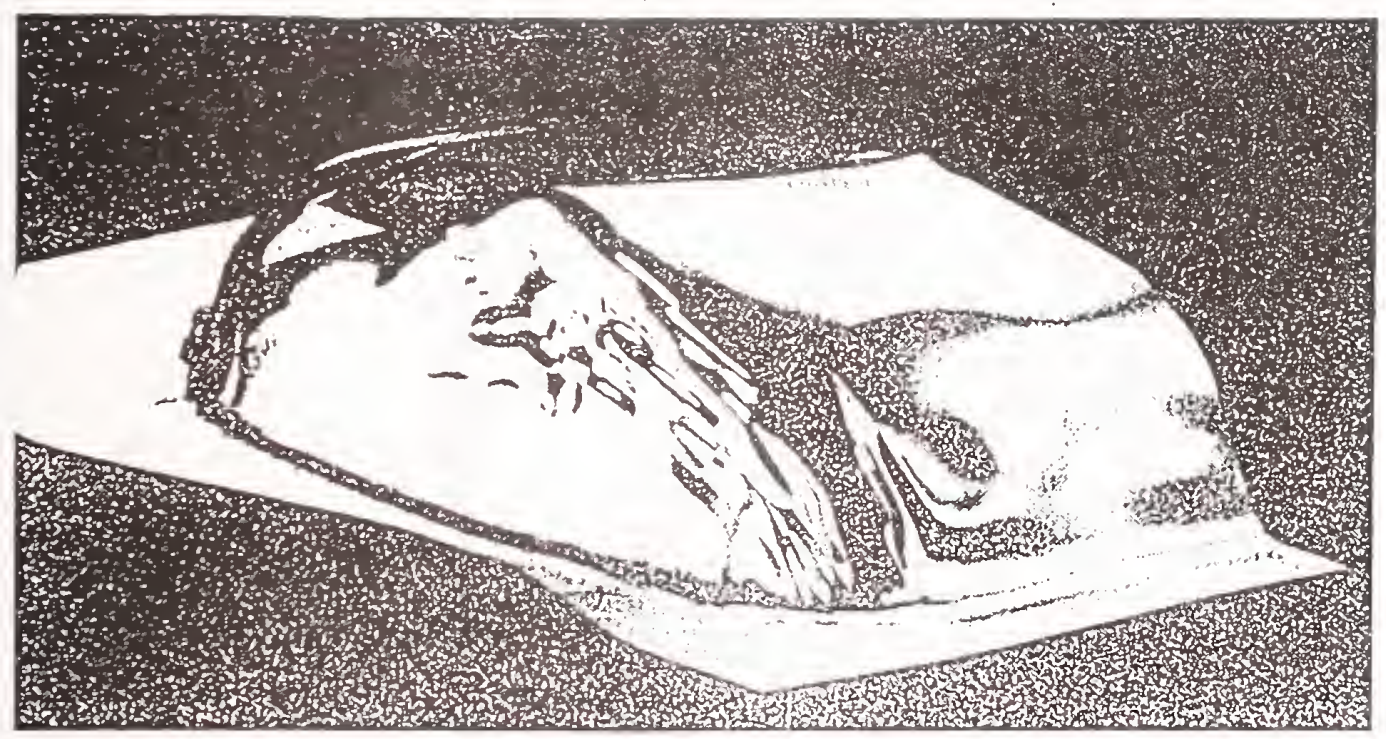

(a) Blank holding load $=689 \mathrm{kN}$

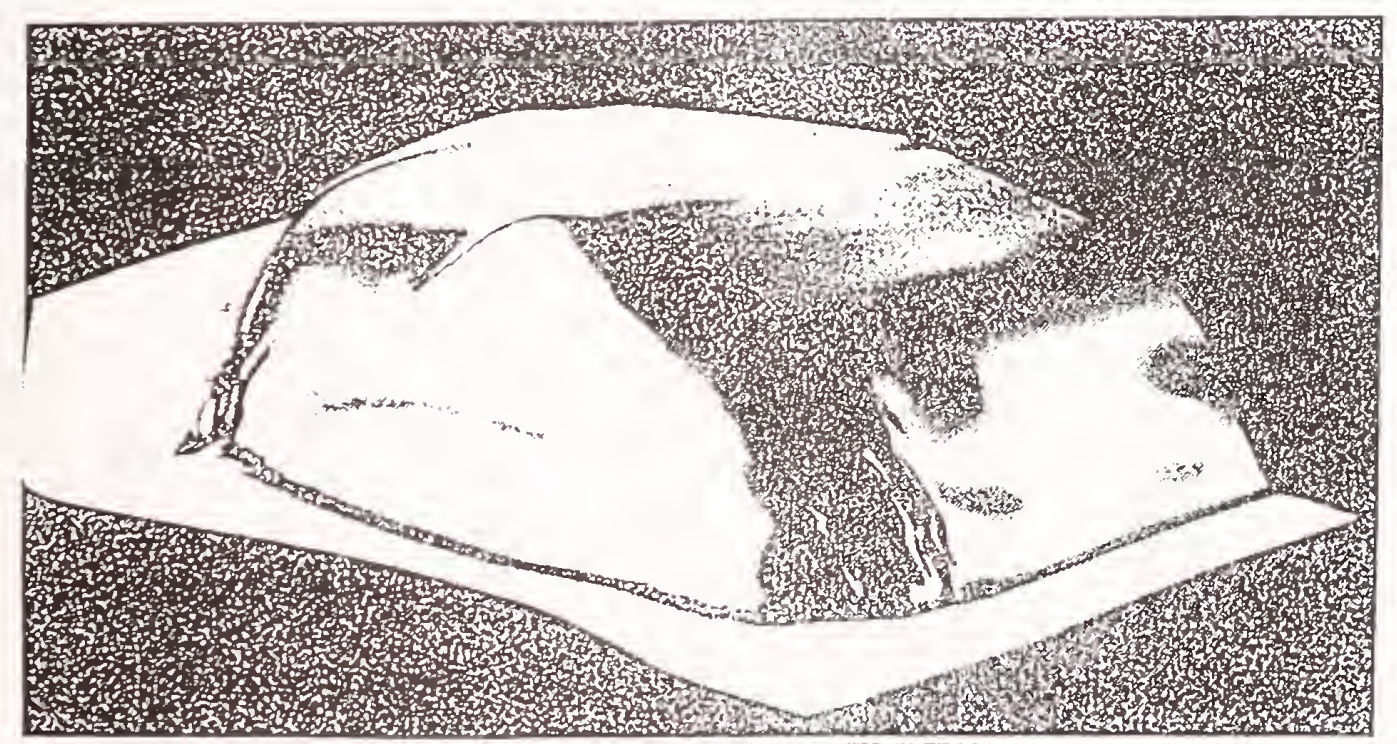

(b) $\overline{B l a n k}$ holding load $=\overline{9} \overline{80 \mathrm{kN}}$

Fig. 4 Prediction of wrinkles in drawing process of a wheel house by ROBUST. A post-process graphic software visualize wrinkles clearly. Effect of blank holding pressure is demonstrated. 


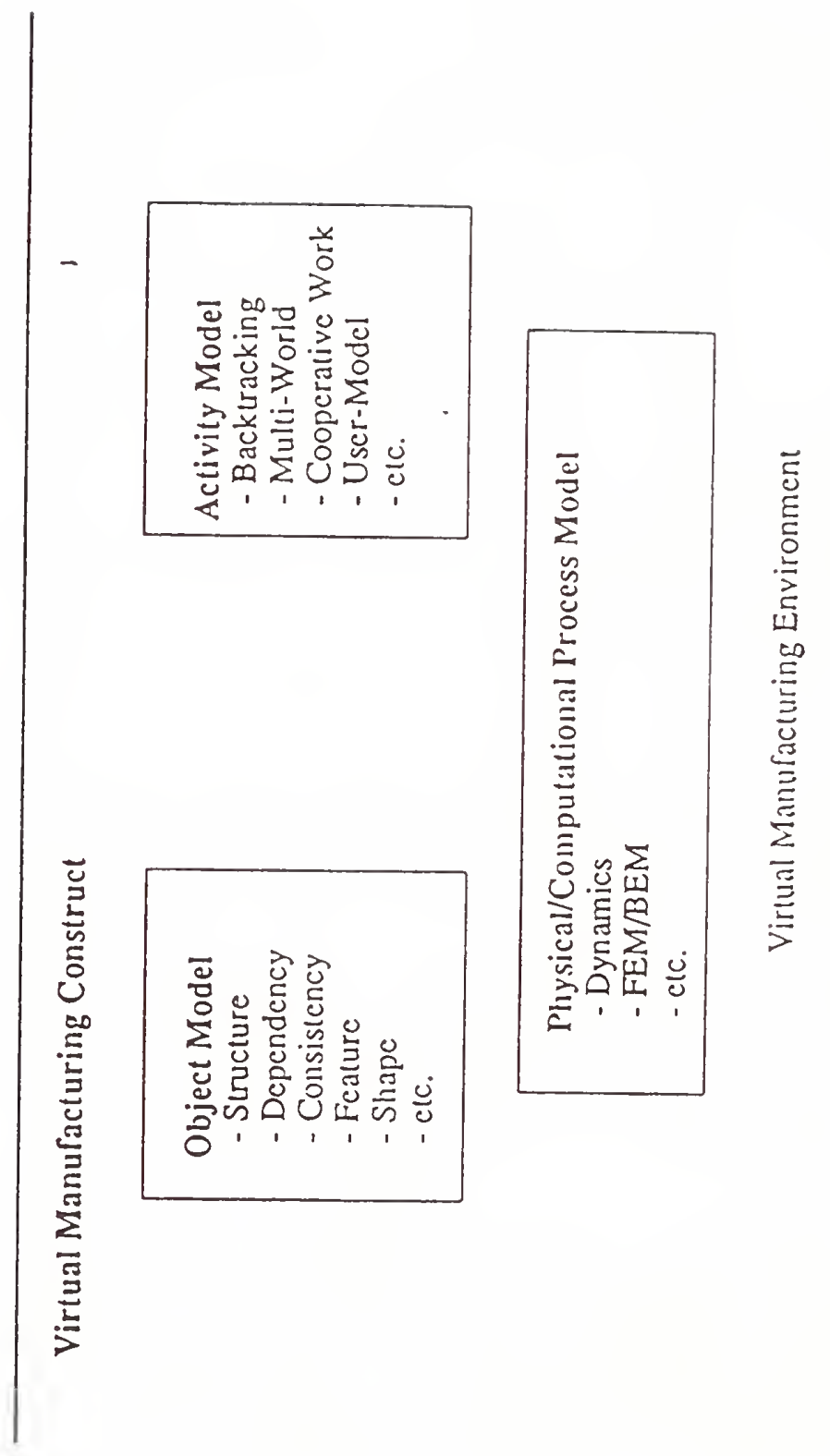




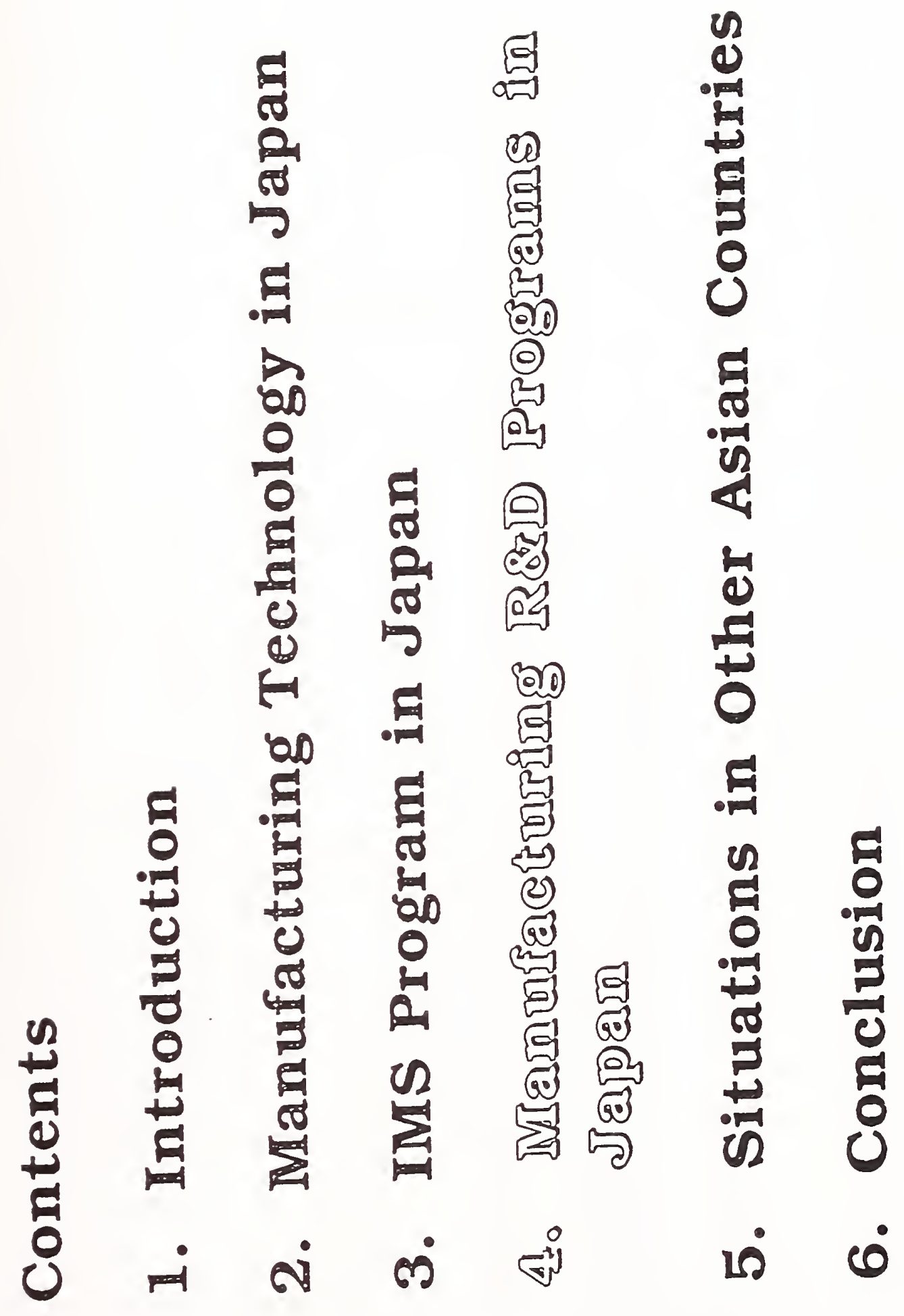




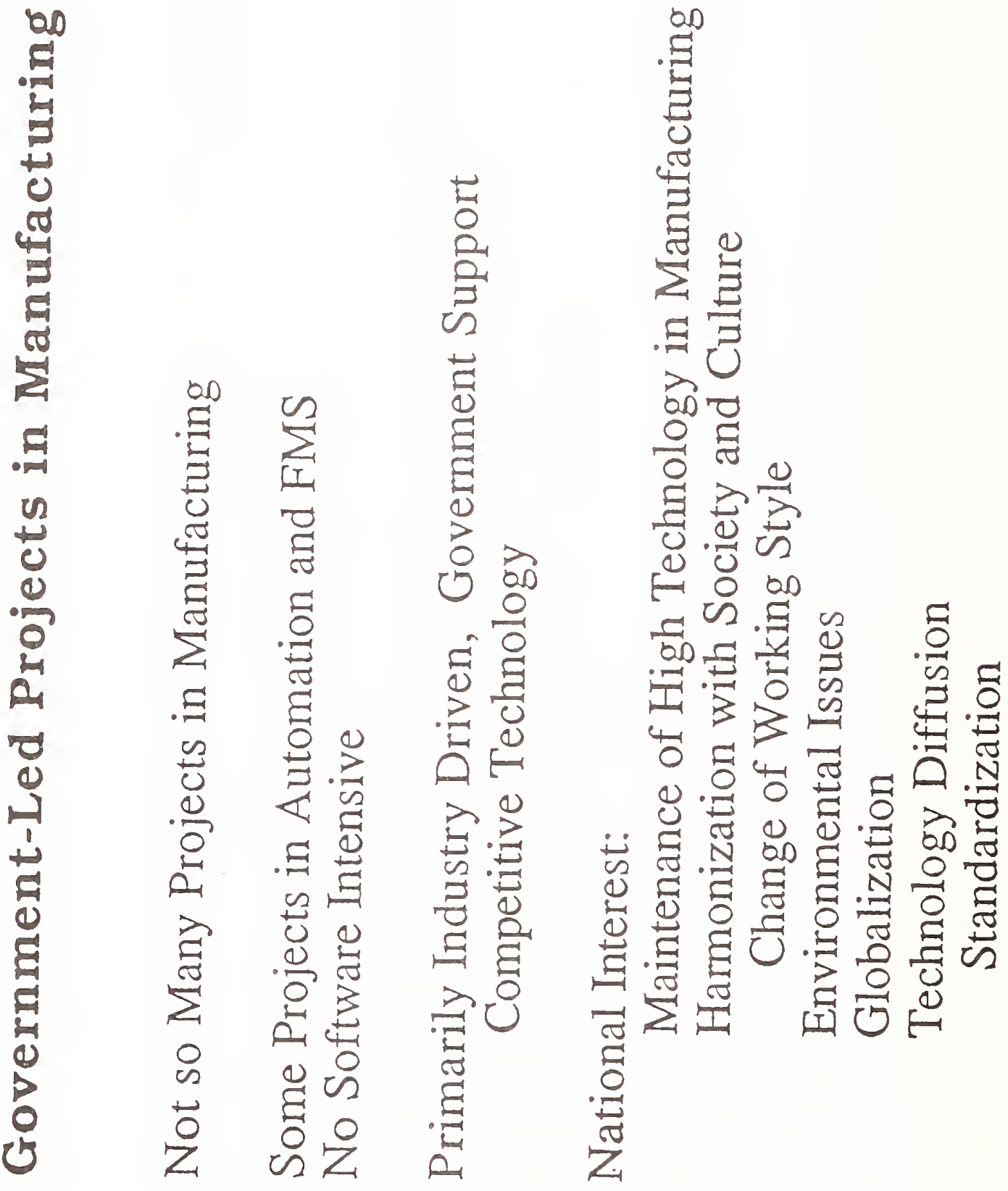




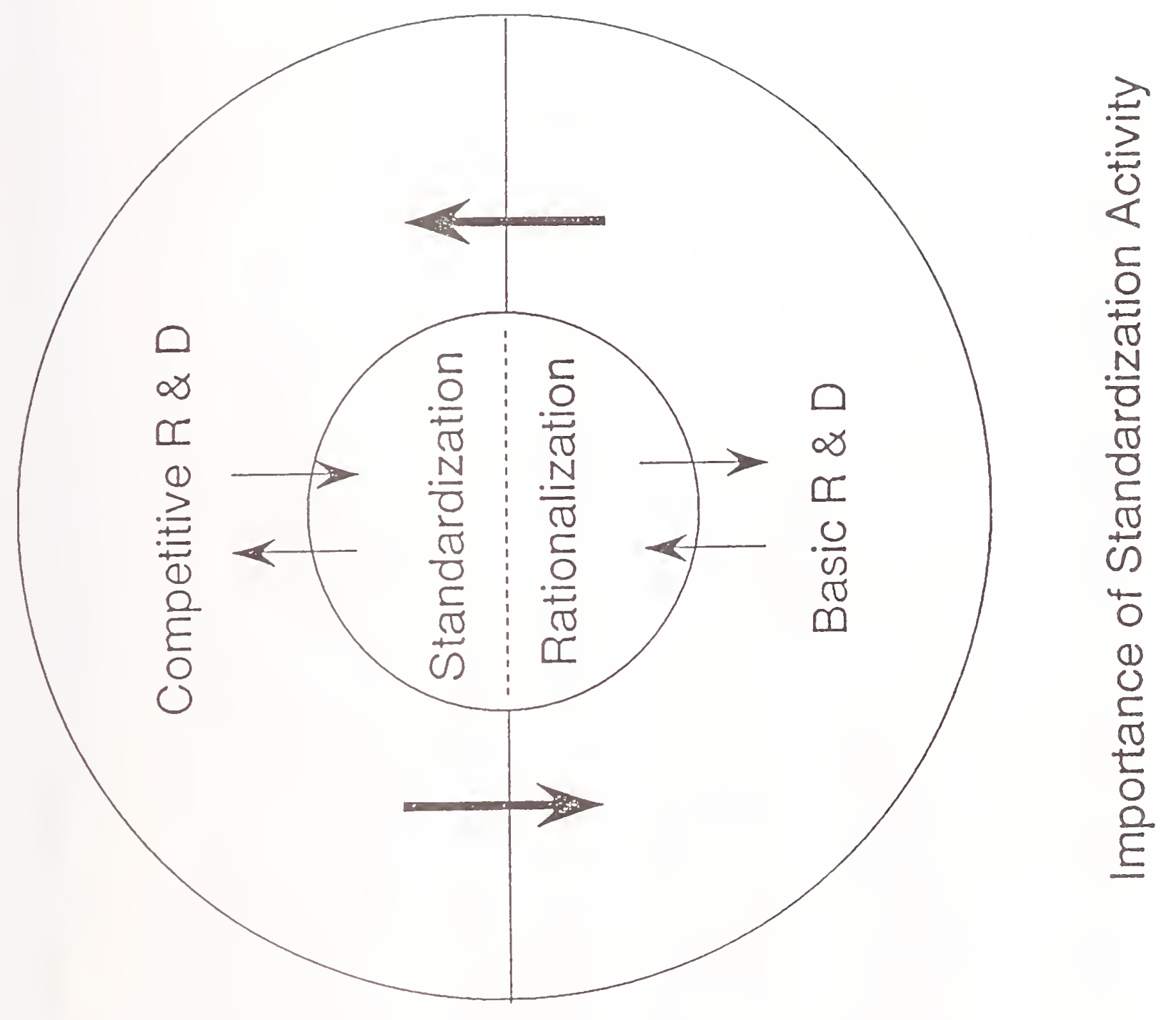




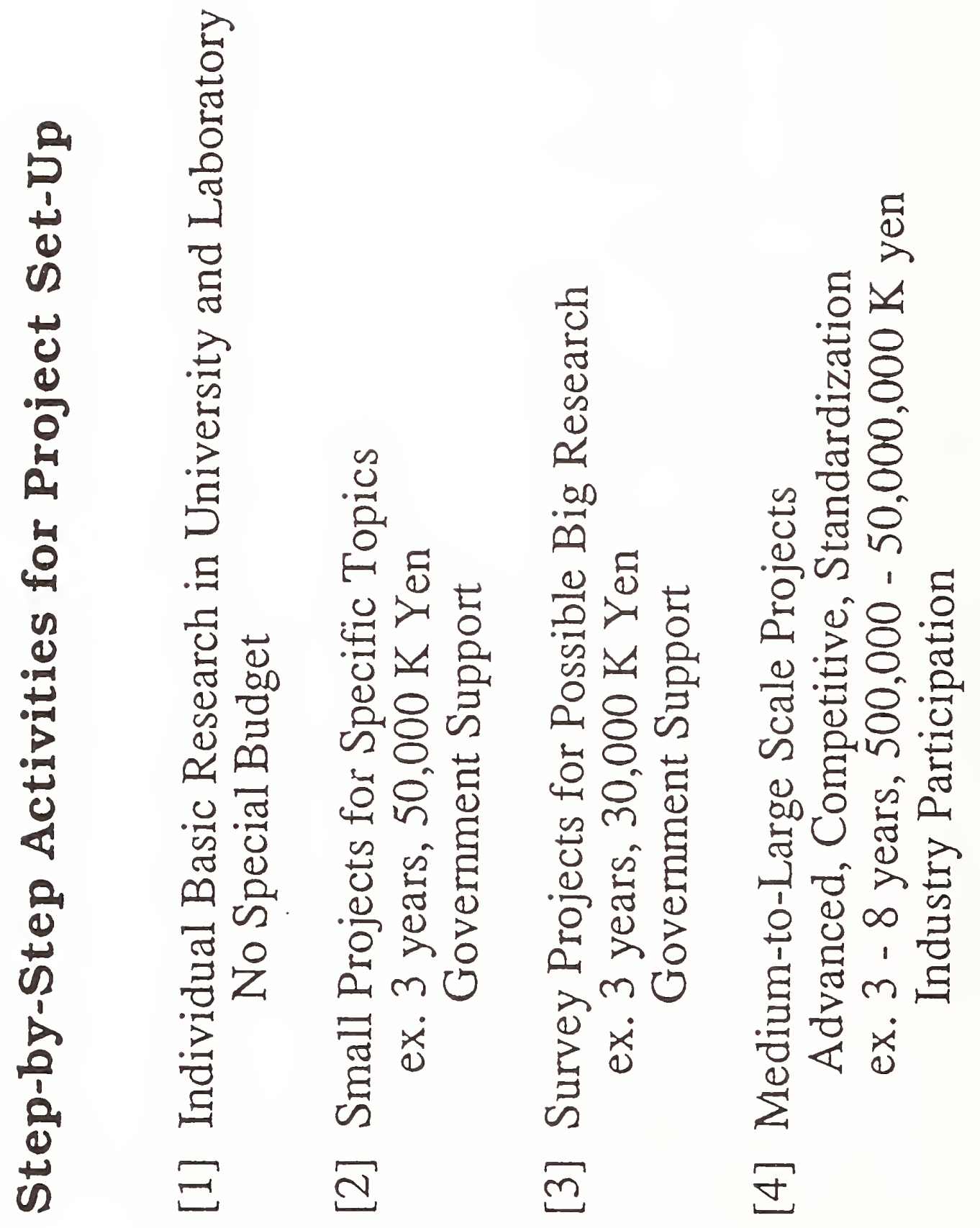

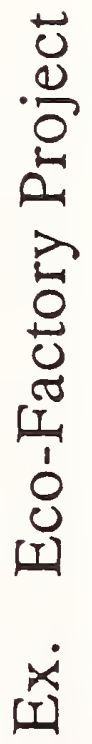




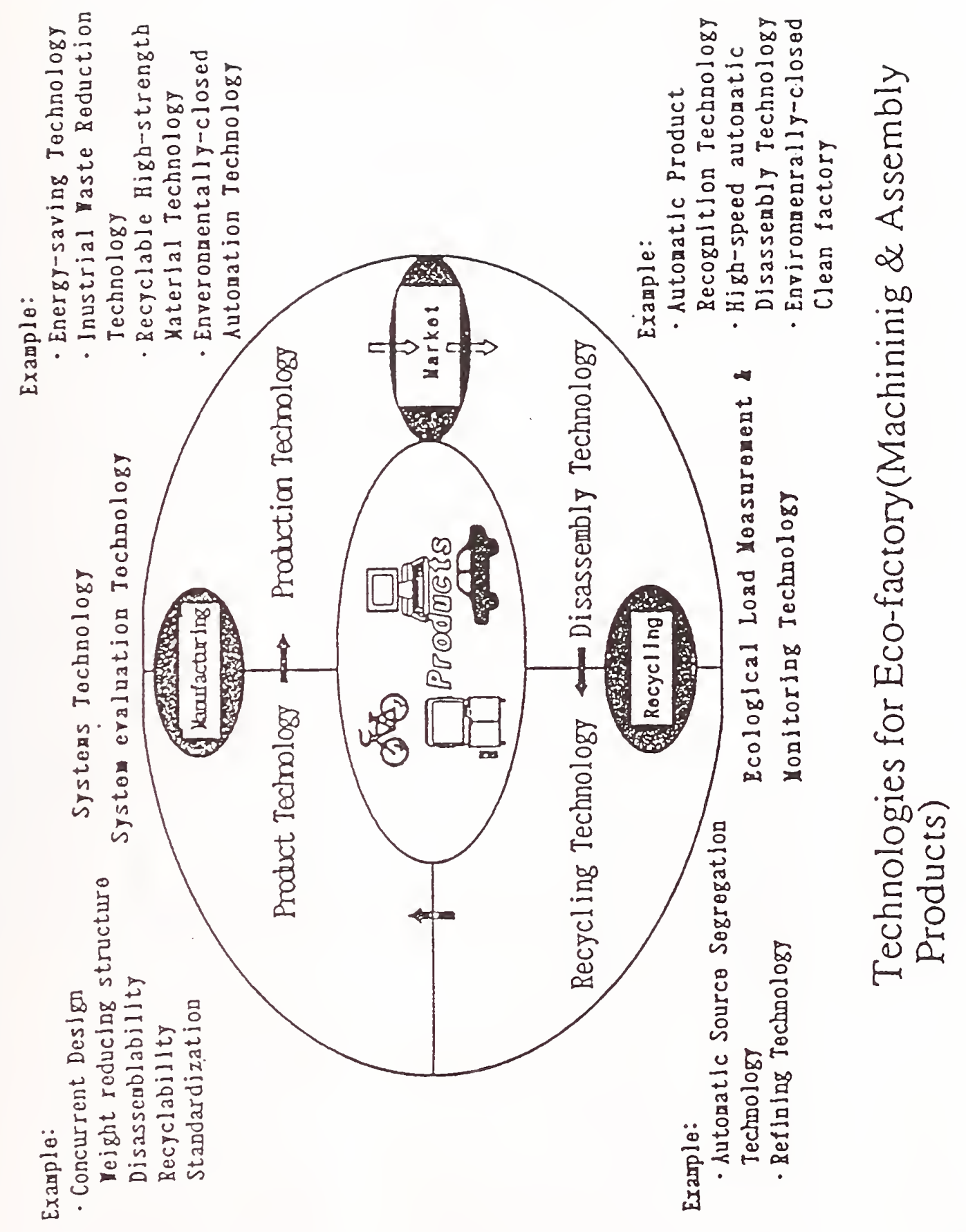




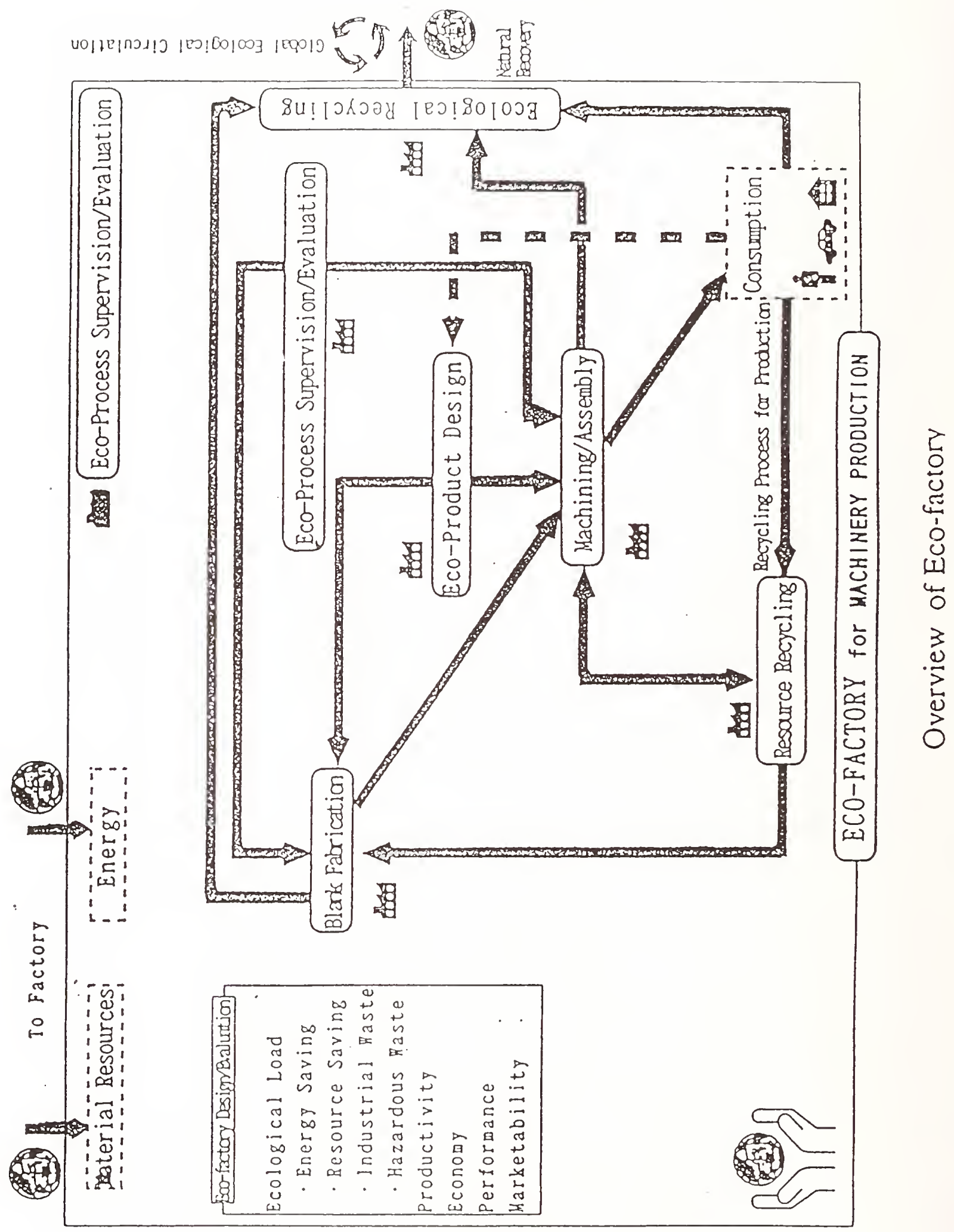




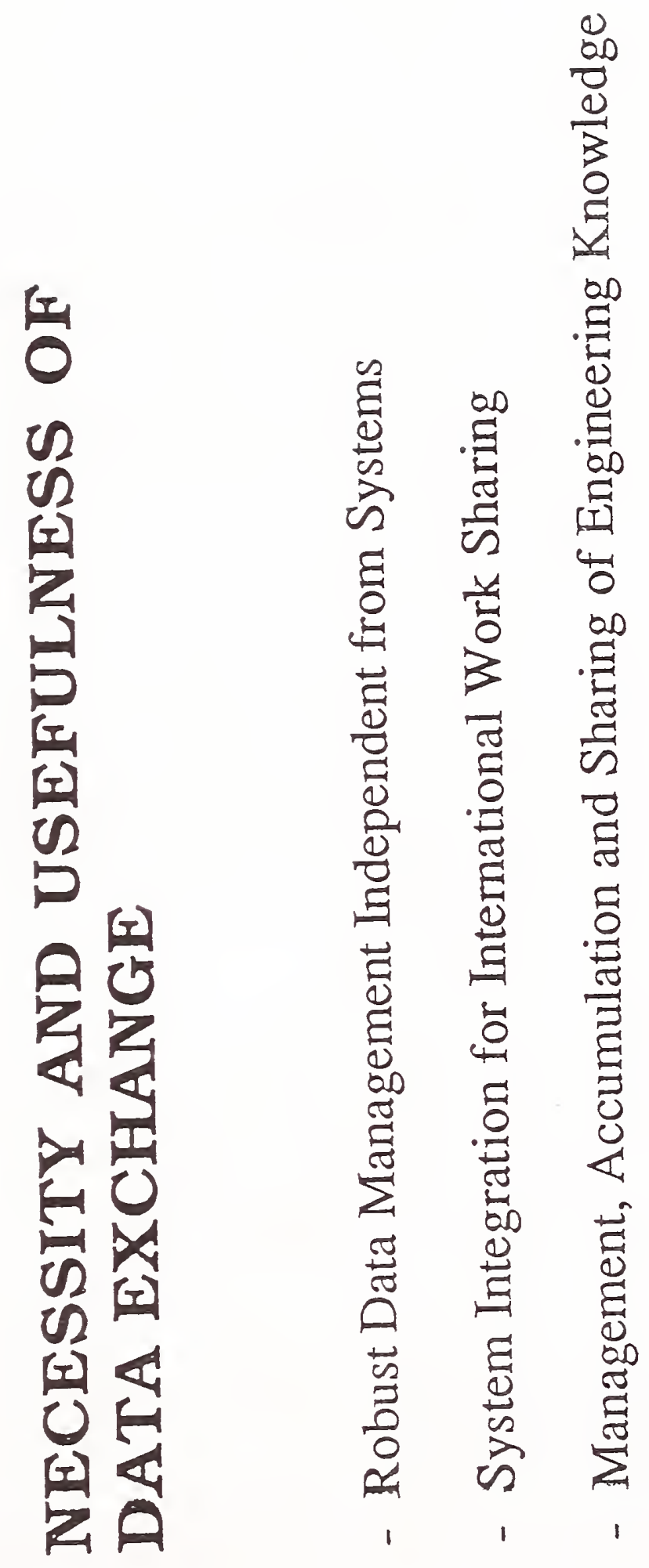


$\mathrm{I} \mathrm{S} \mathrm{O} \quad \mathrm{TC} 184 / \mathrm{S} \mathrm{C} 4$

TC184:

SC1: Physical Device Control

SC2: Robots for Manufacturing

Environment

SC4: Manufacturing Data and

Languages

SC5: Architecture and Communication

Title:

Industrial Data and Global

Manufacturing Programming Languages

Scope:

Standardization in the field of

data and languages for

manufacturing applications

- New Work I tem:

Standard for the Neutral

Representation of Standard Parts 
STEP :

HEADER; FILE_NAME ('tel2 $\left.2^{\circ}, \ldots\right)$ ) ...; ENDSEC;

DATA:

$\# 845=\operatorname{LINE}(\# 299, \# 592) ; \# 846=\operatorname{LINE}(\# 301, \# 595): \ldots$ $\# 1006=$ YERTEX (

$\# 1162=E D G E(\# 1003, \# 984, \# 848)$;

$\# 1163=$ EDGE_LOGICAL_STRUCTURE (\#1007，.F.); . .

\#1545=EDGE_LOOP ((\#1459, \#1460, \#1461,\#1462)); . .

$\# 1696=$ SURFACE_LOGICAL_STRUCTURE (\#922, .T.);

\#1697=CLOSED_SHEL,L ( $\# 1519, \# 1550, \# 1551 ， \ldots$

$\# 1615, \# 1617, \# 1618, \# 1619, \# 1620, \# 1621, \# 1622))$;

\#1698=MANIFOLD_SOLID_BREP $(\# 1697)$ :

ENDSEC:

ENDSTEP :

Fig. 5 STEP Exchange File (total 1,708 lines)

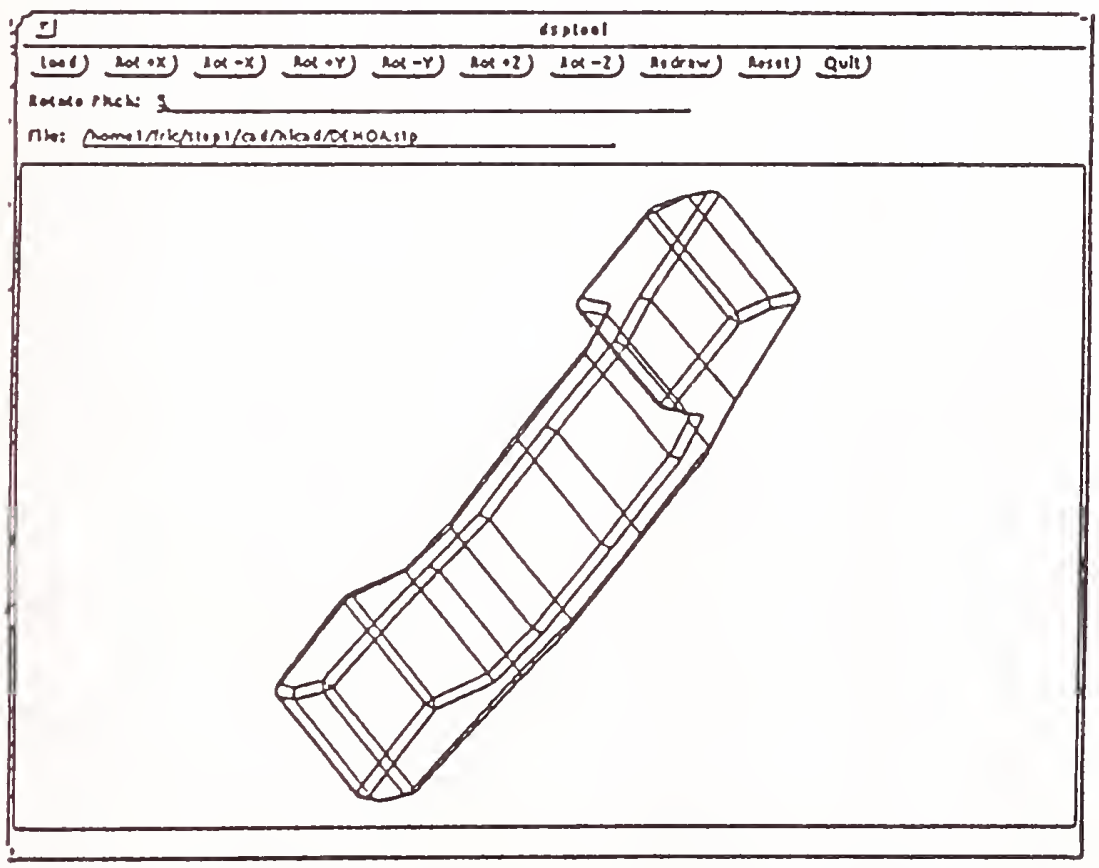

Fig. 6 Telephone Handset (STEP data) on the CRT 


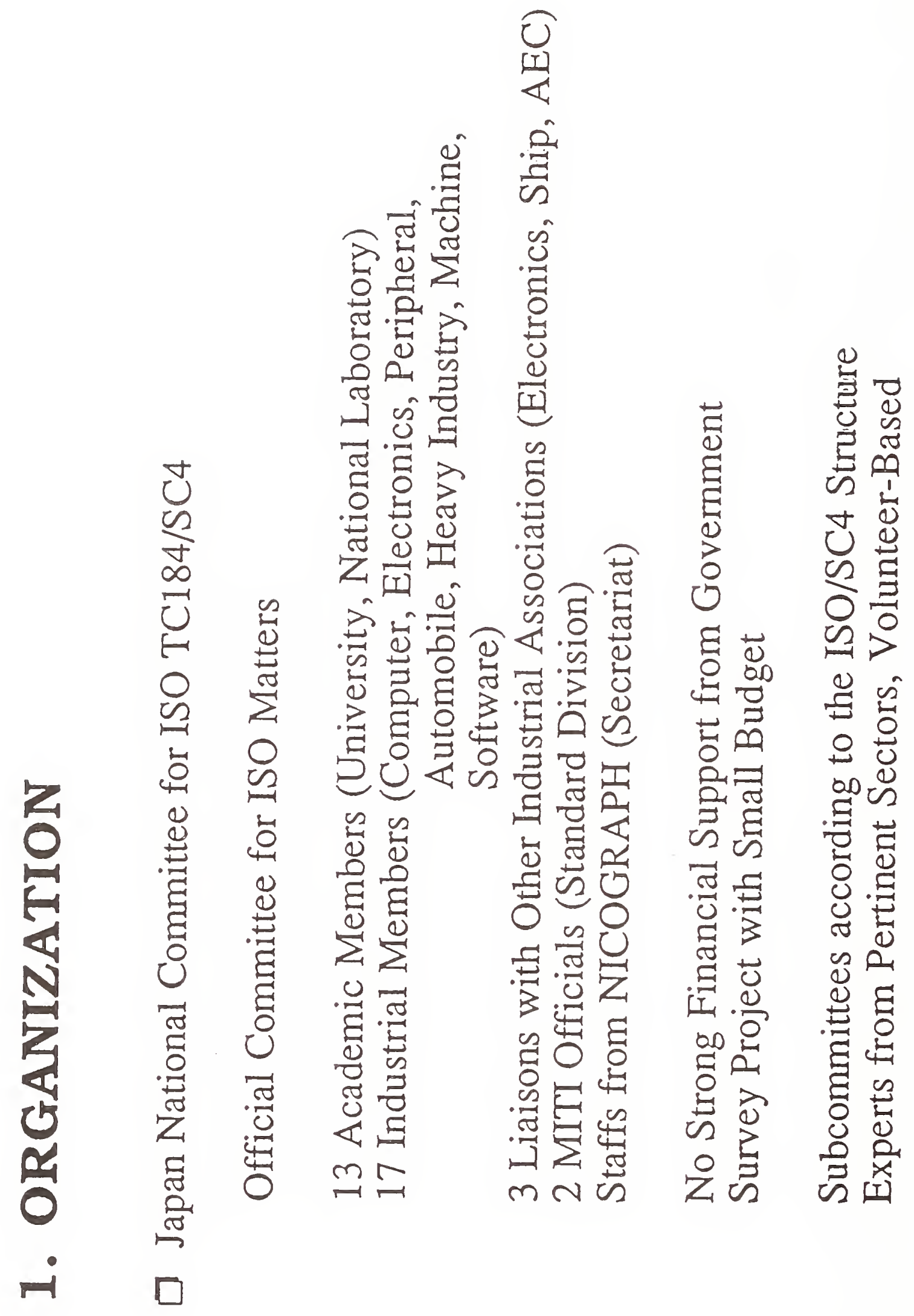




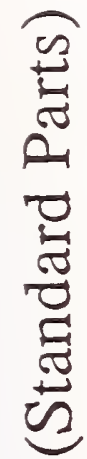

¿

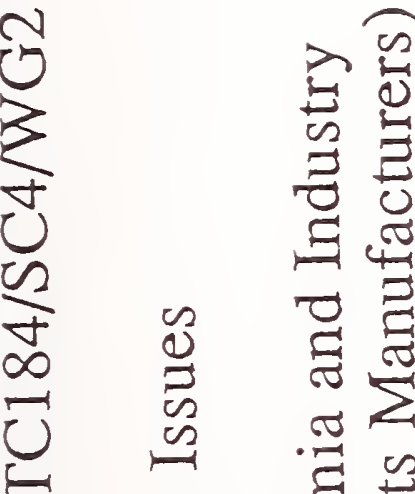

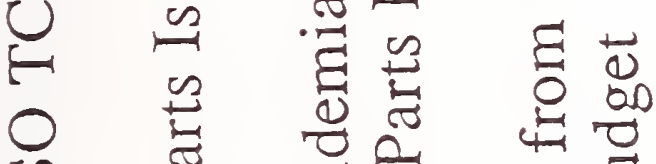

吕

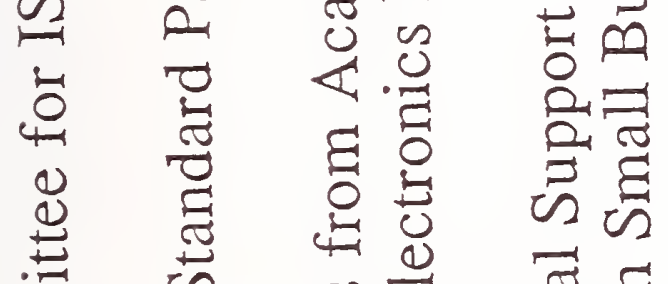

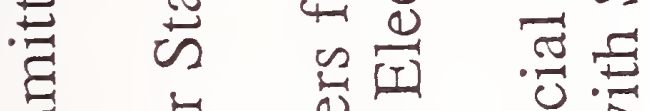

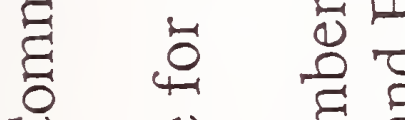

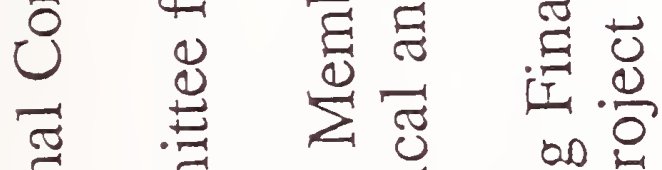

.

Z ठ

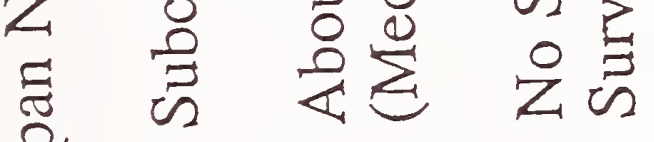

这

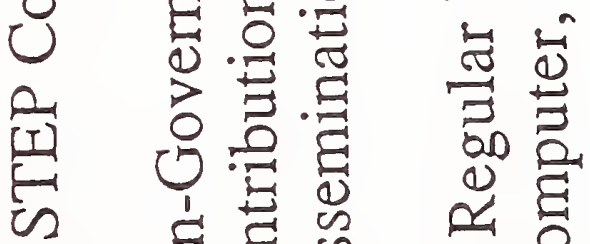

专

总

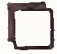

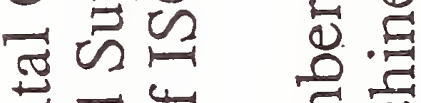

: छ

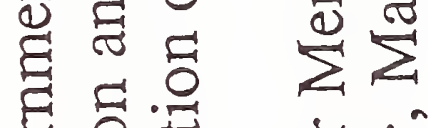

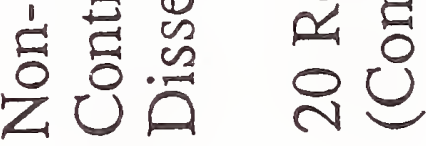

त苍 क

总嵒点

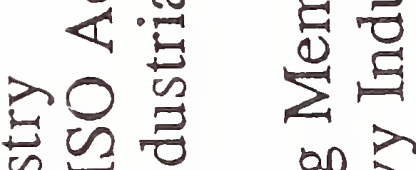

焉

토월

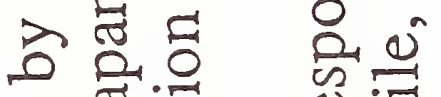

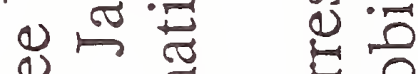

它药

世 00

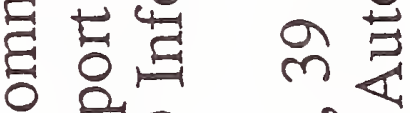

U

is

$\square$ 


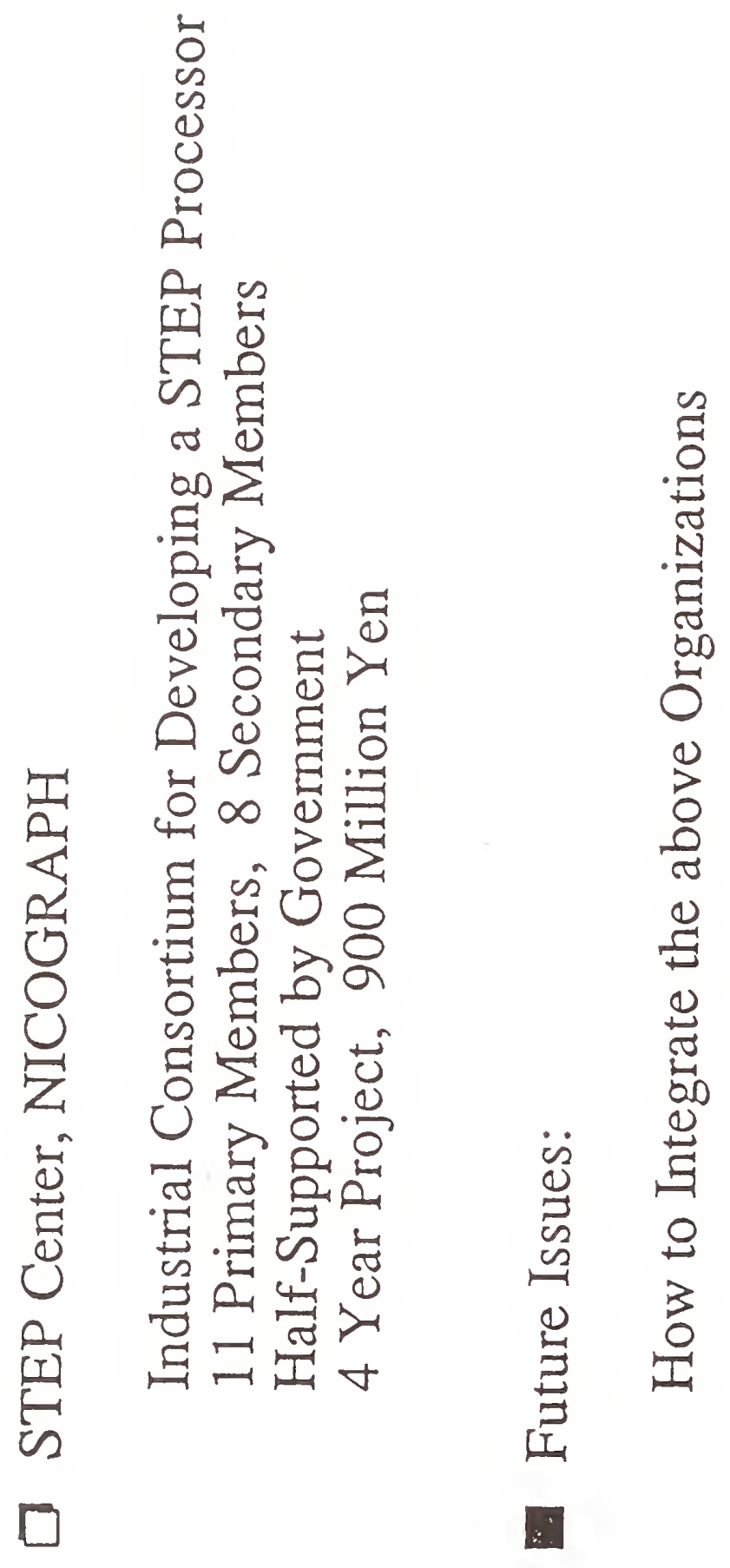




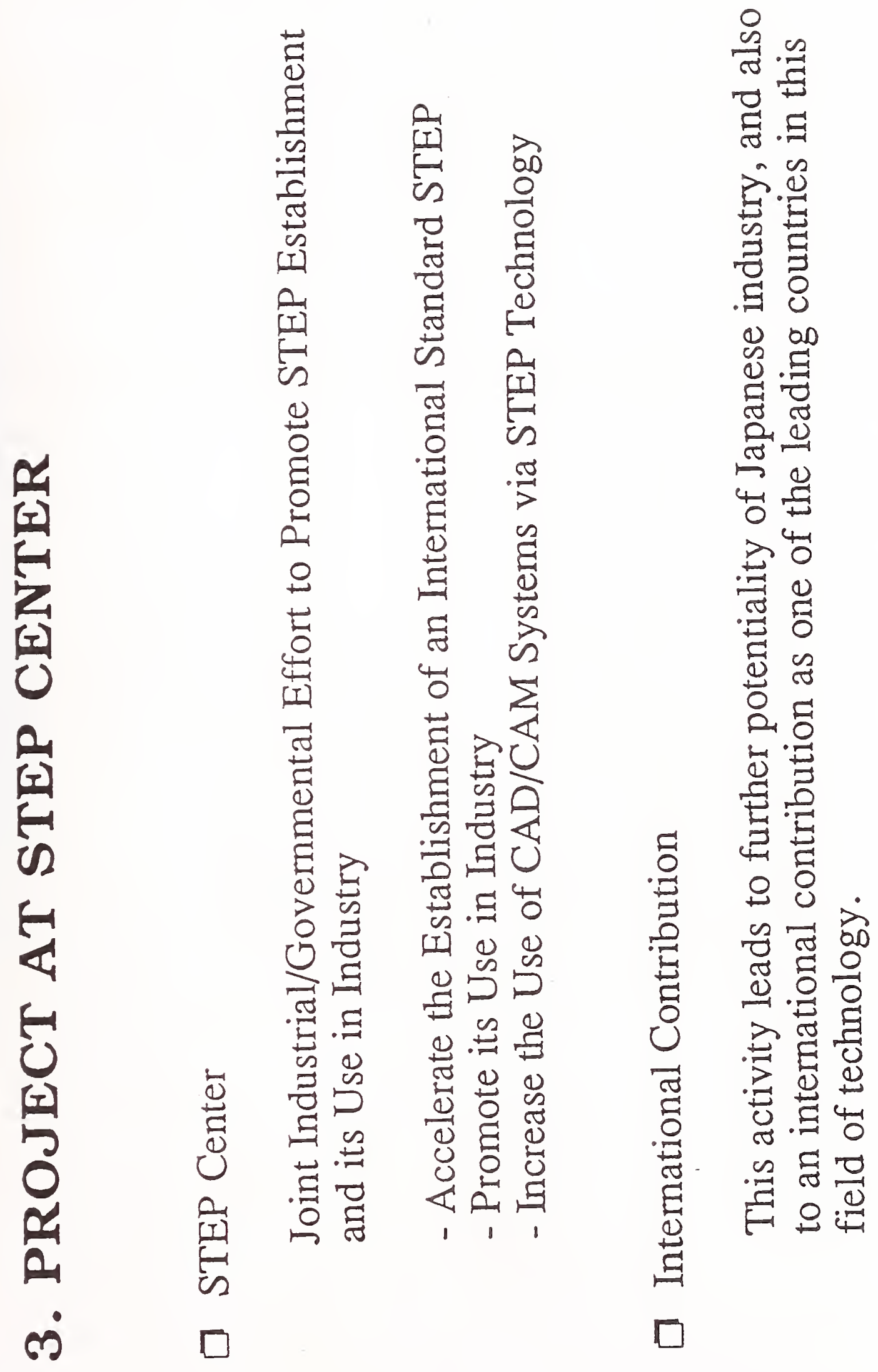




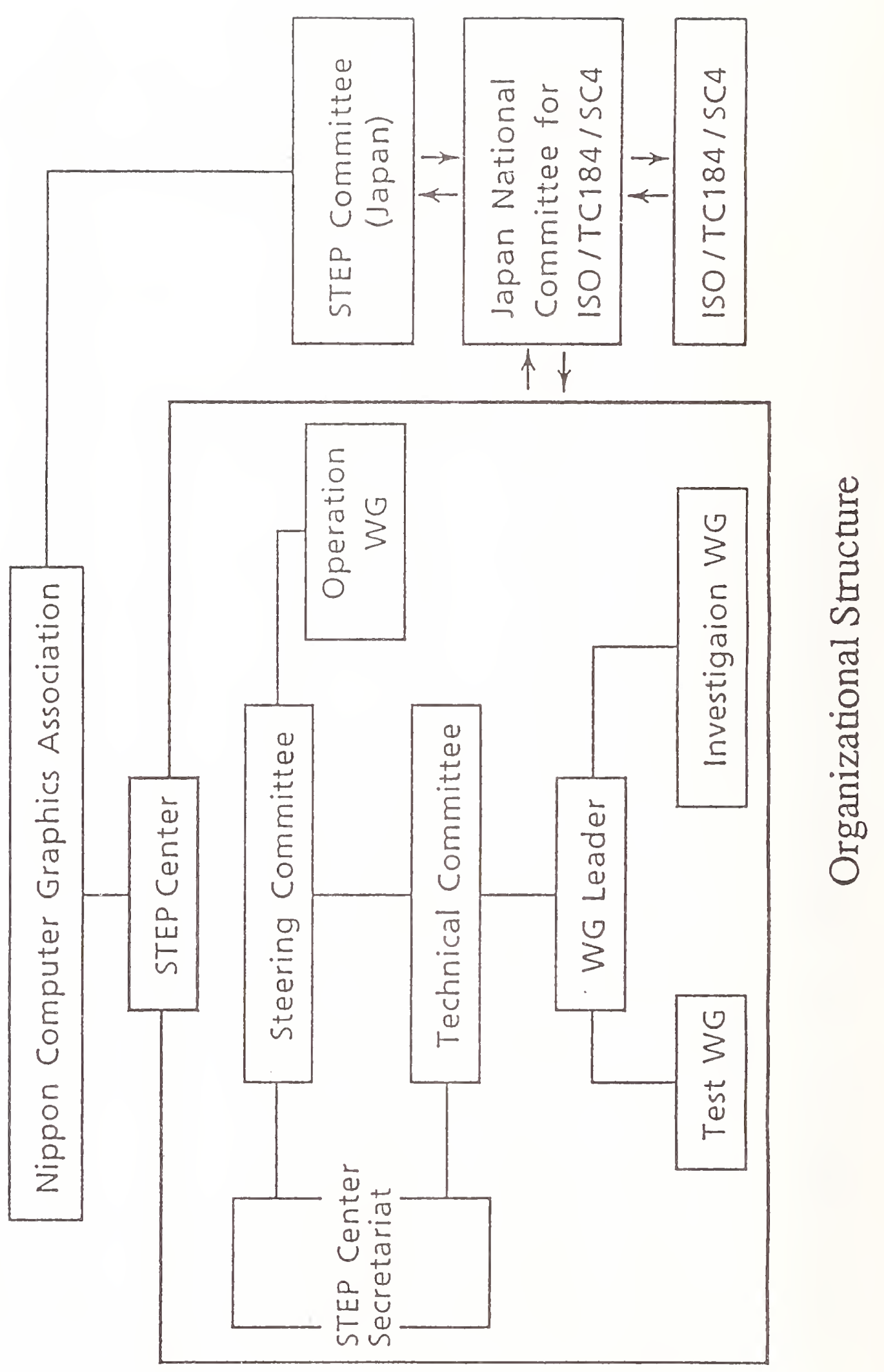




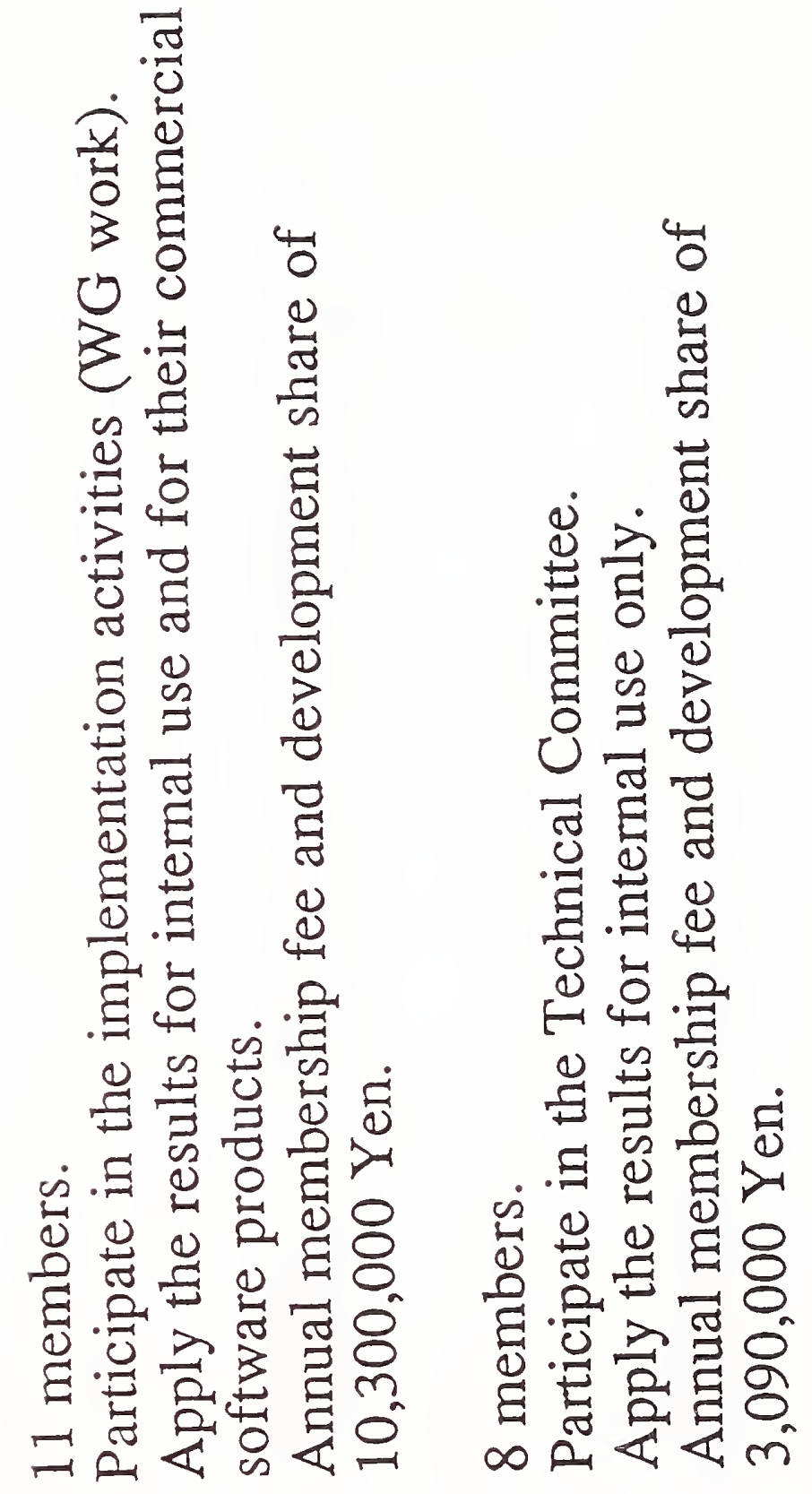

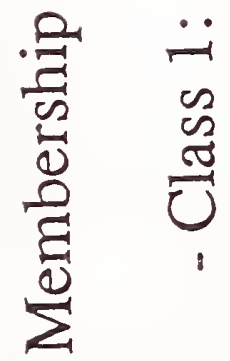

$\ddot{i}$

0

ㅁ 


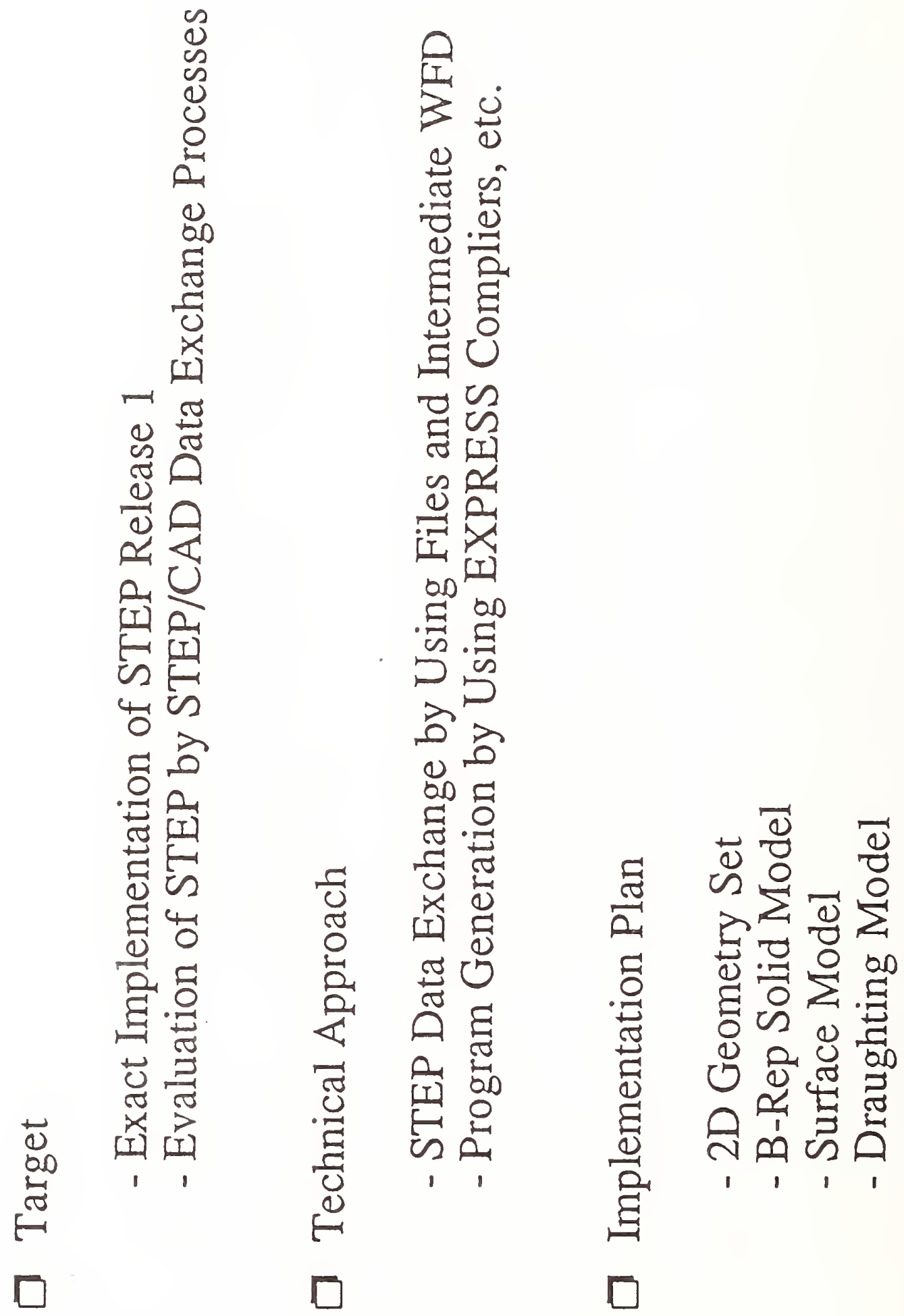




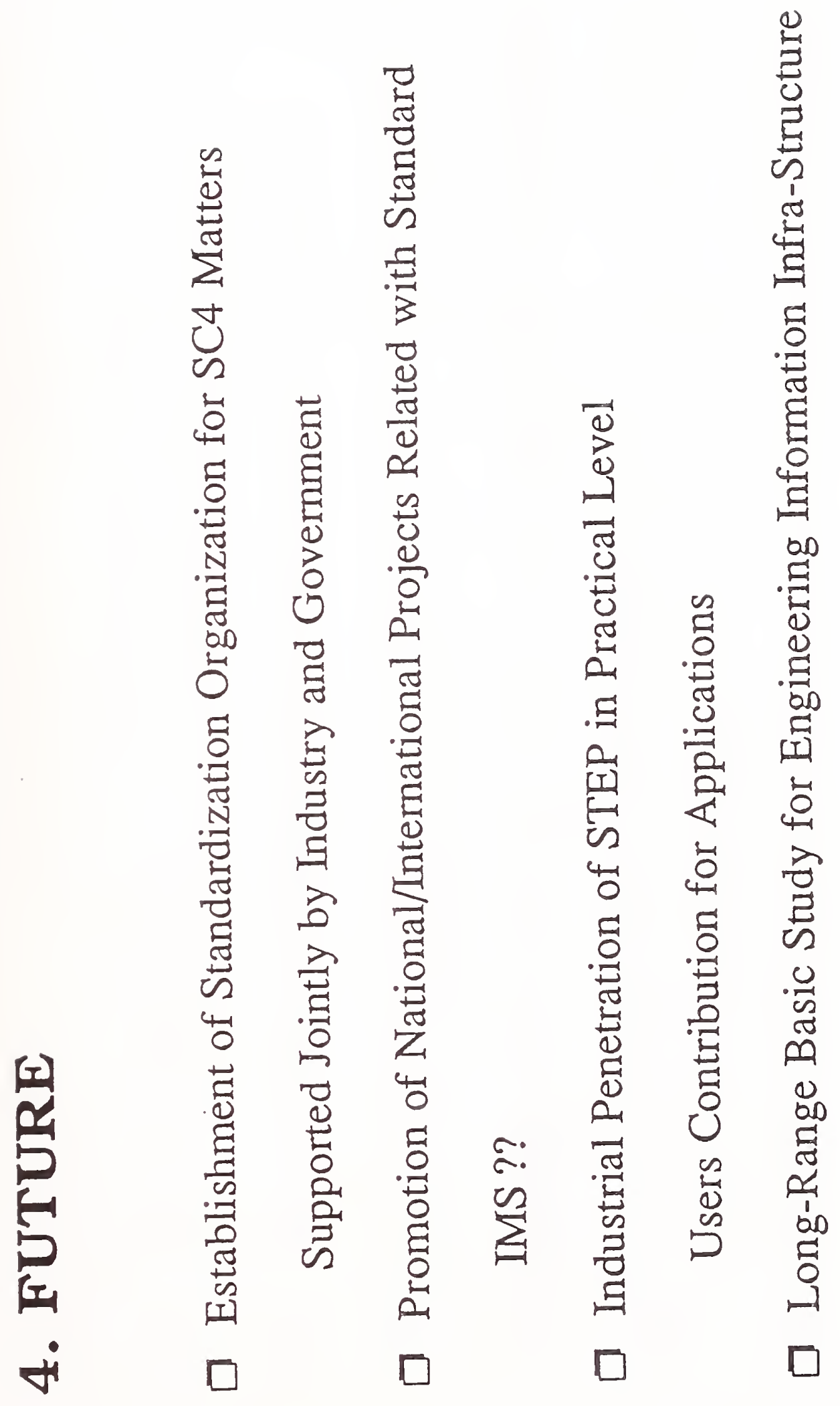




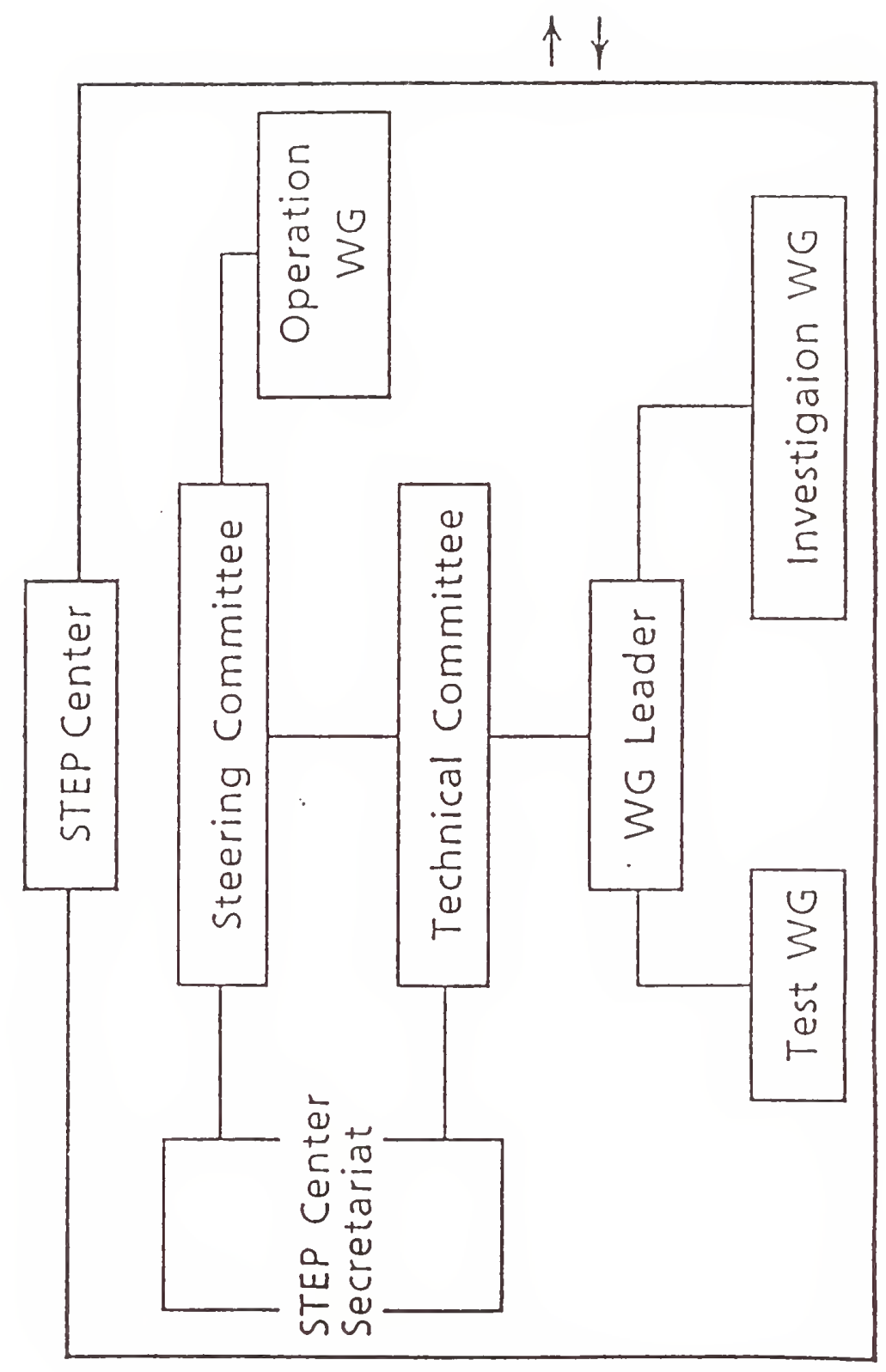




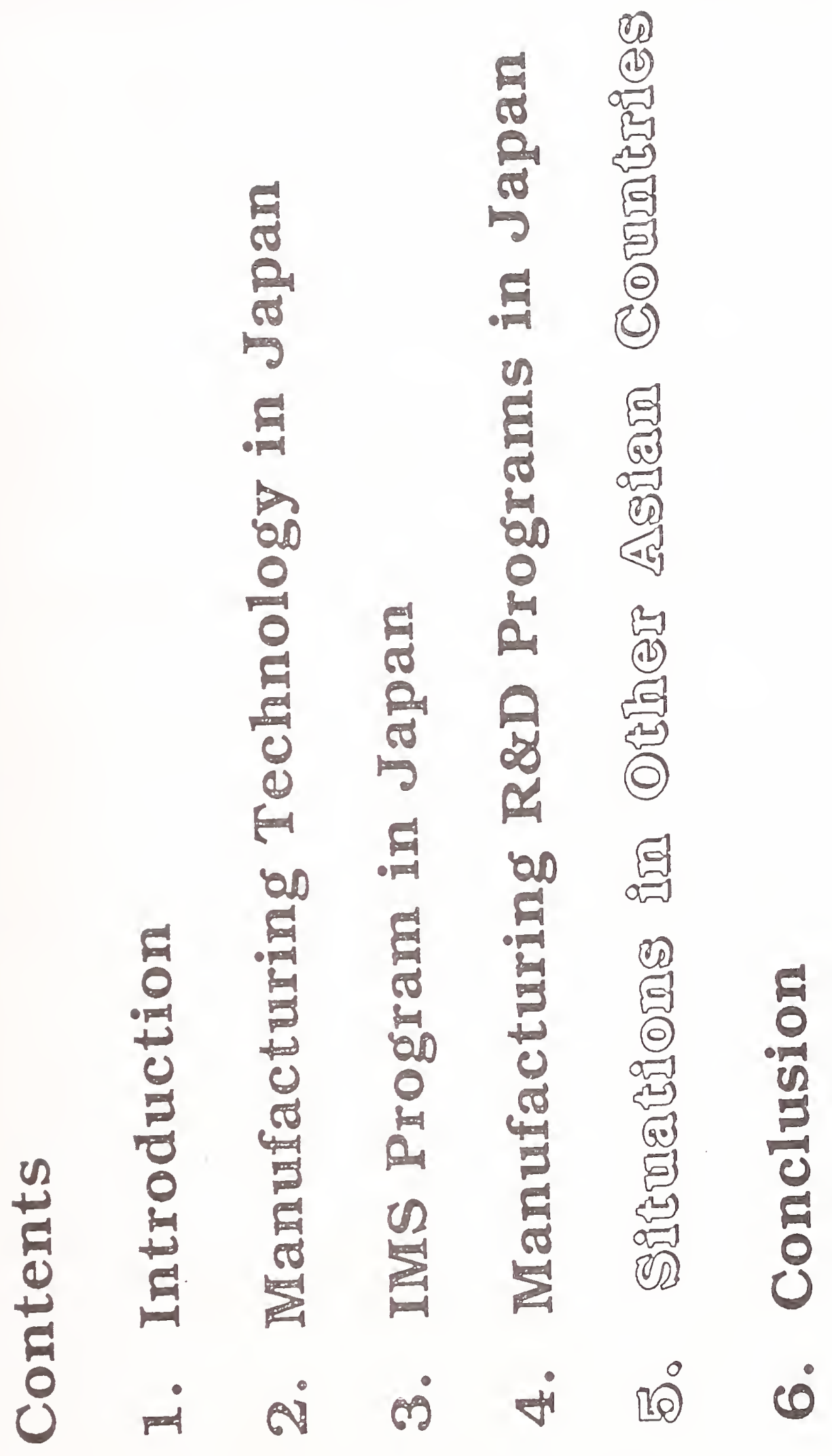


THE WESTERN PACIFIC COUNTRIES

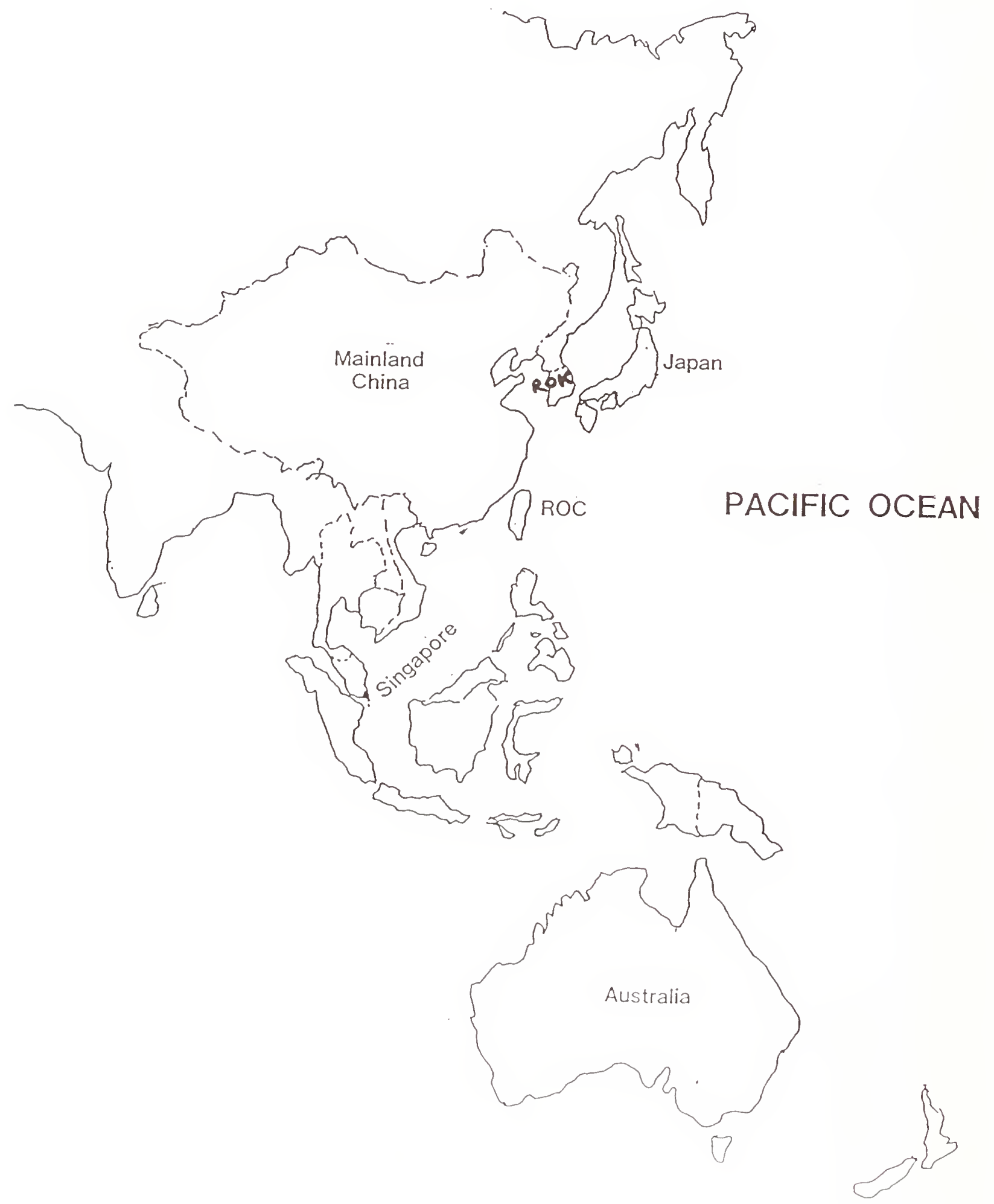




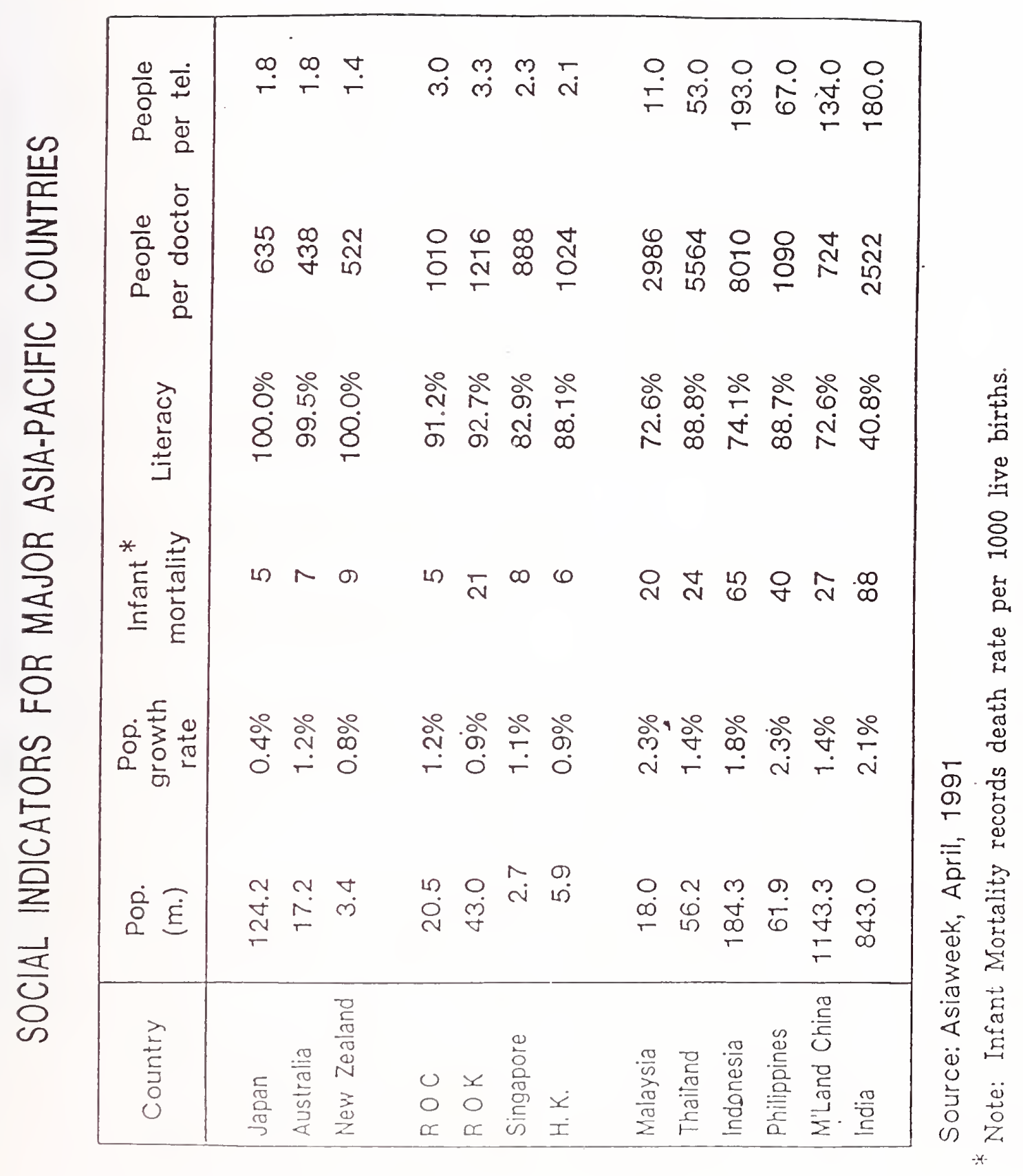




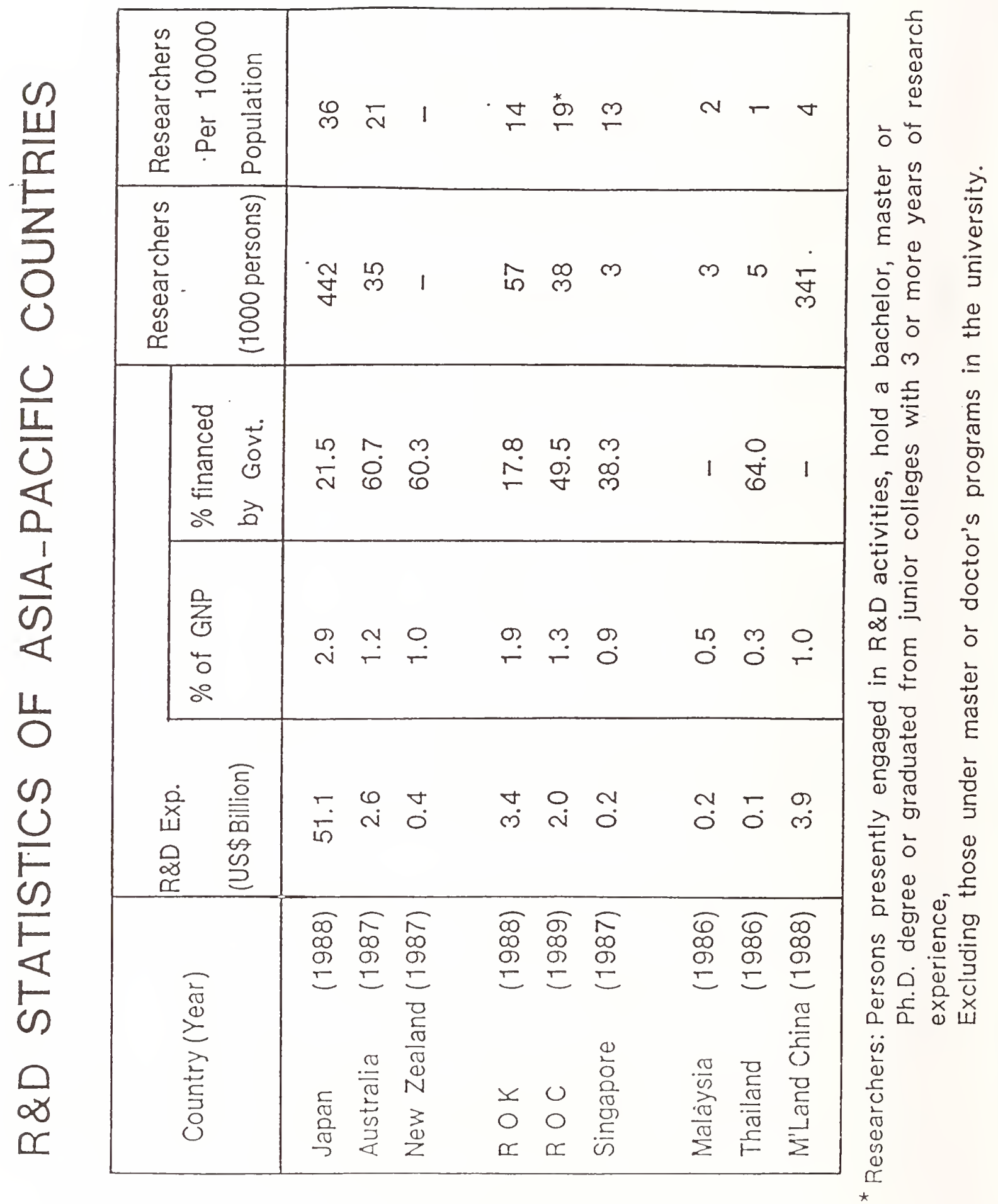




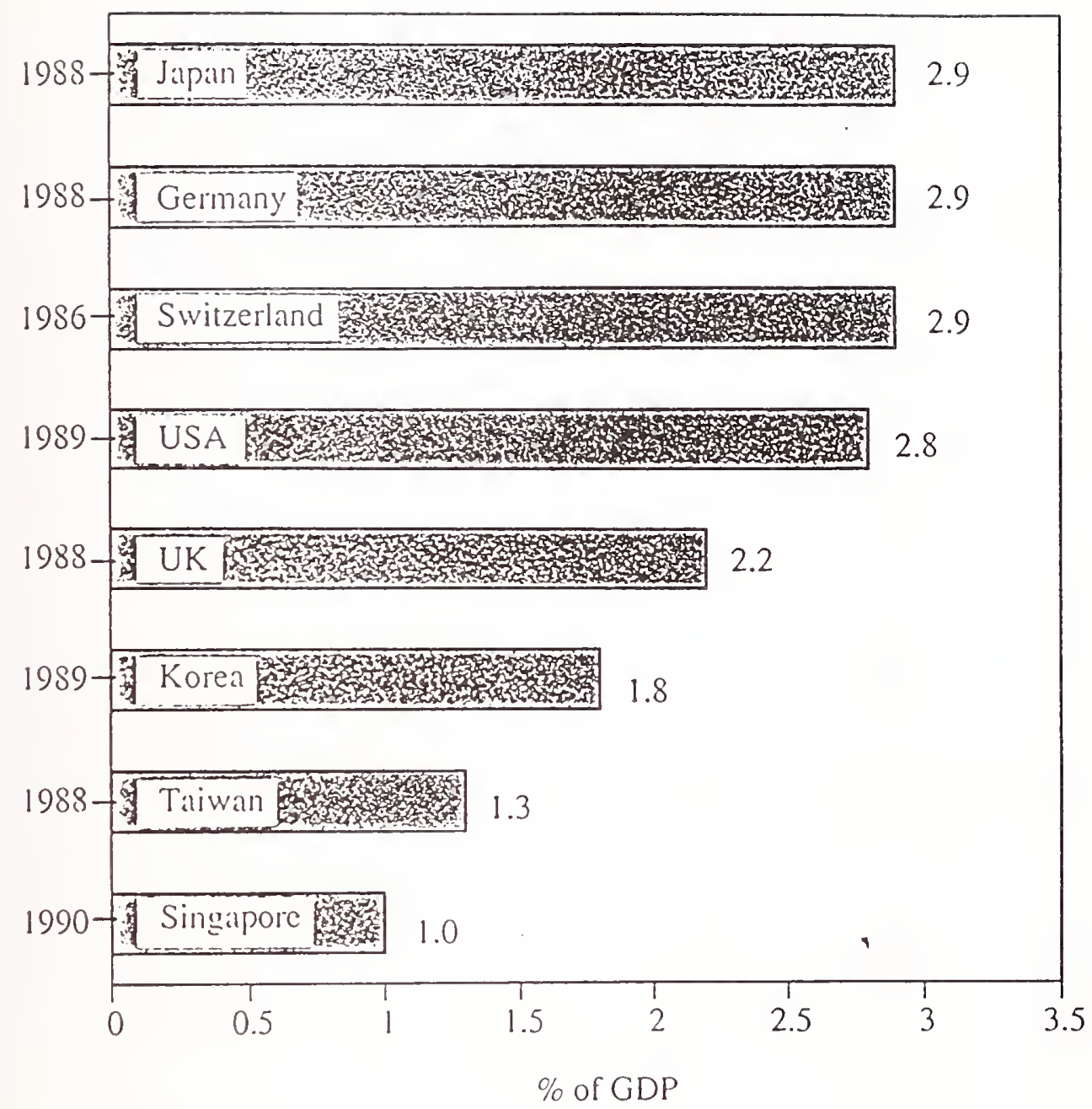

Figure 2.9 International Comparison: R\&D Spending

Source: World Competitiveness Report 1991 


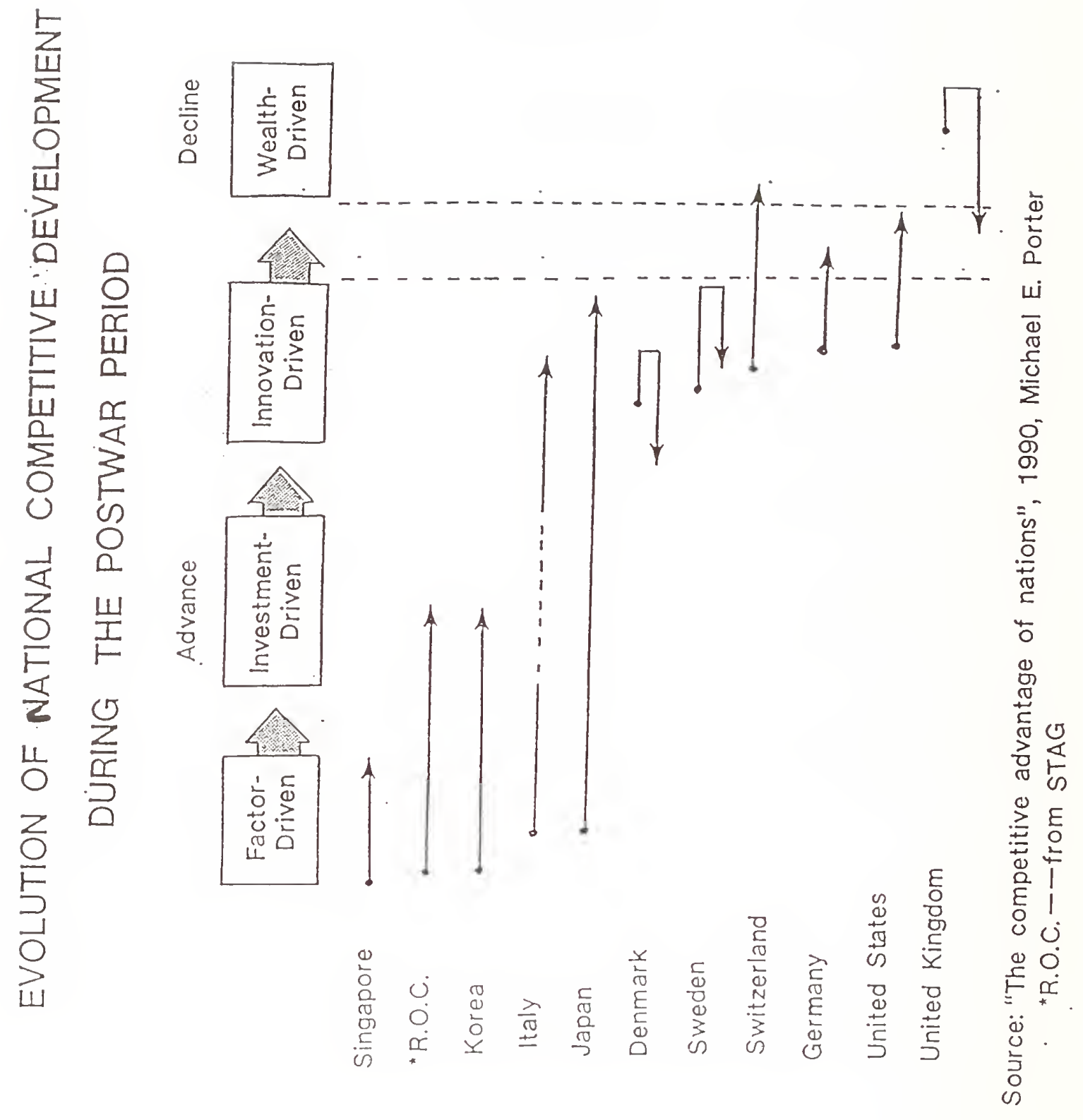




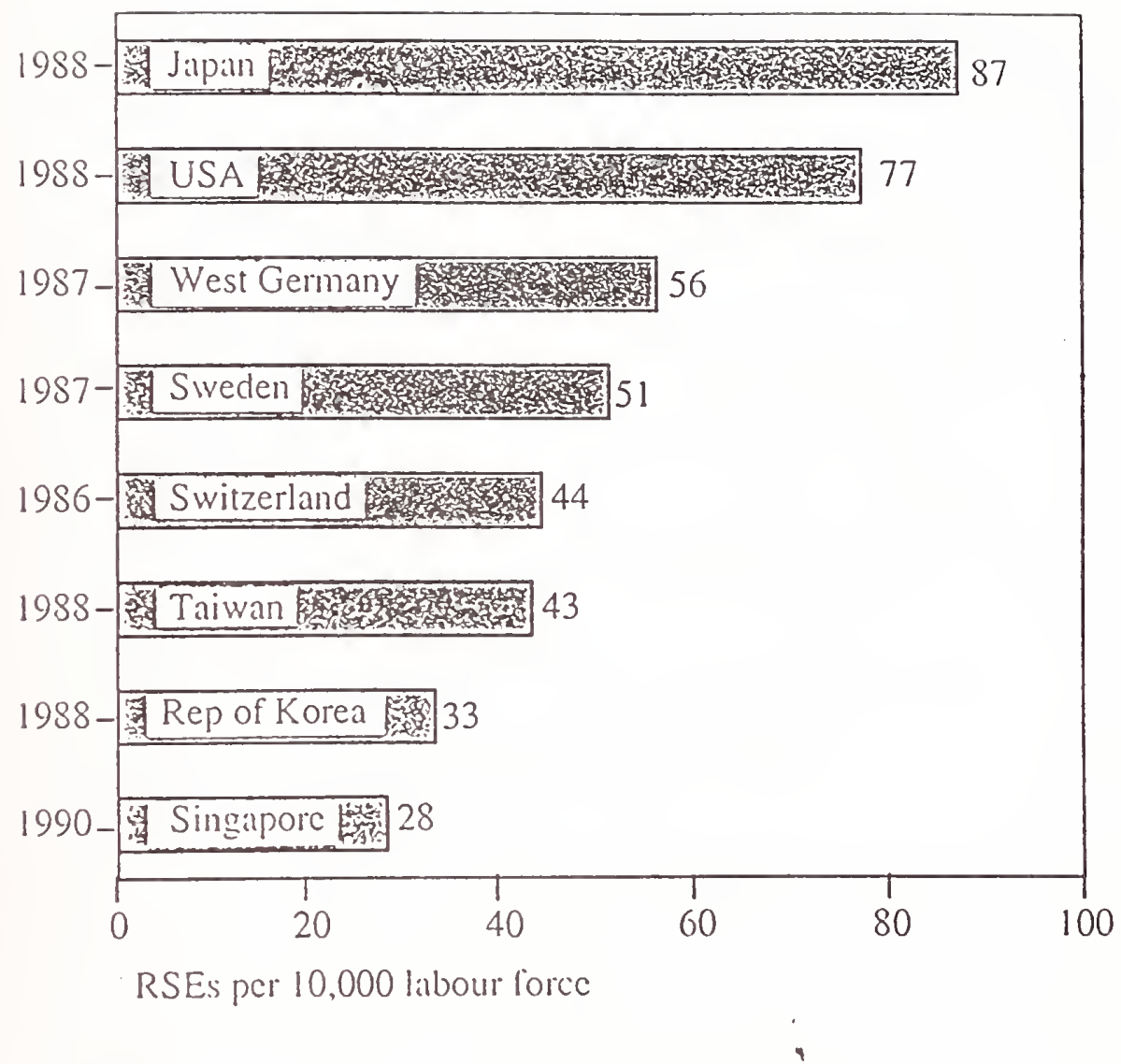

Figure 2.10 International Comparison: RSES Source: OECD \& Nattional Sources 


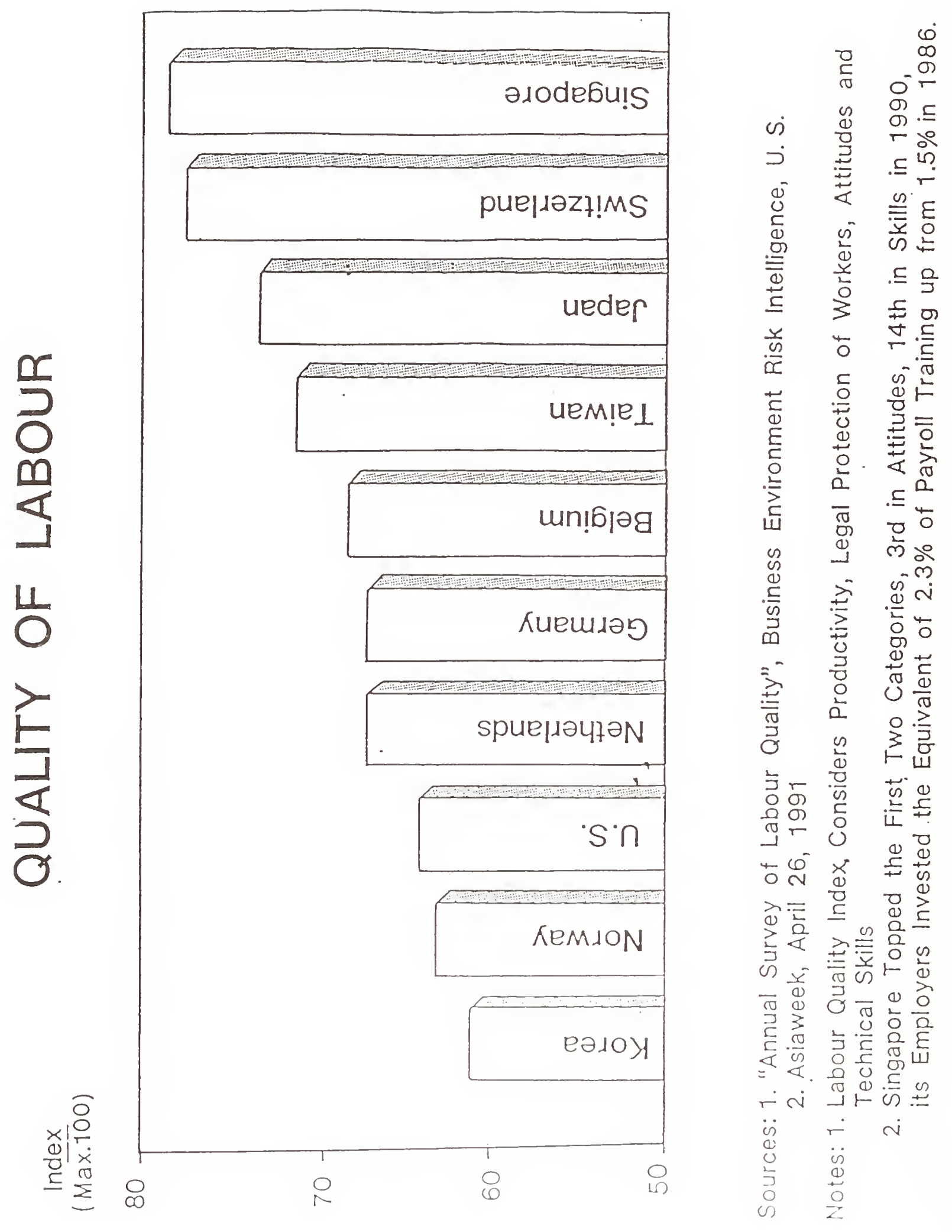




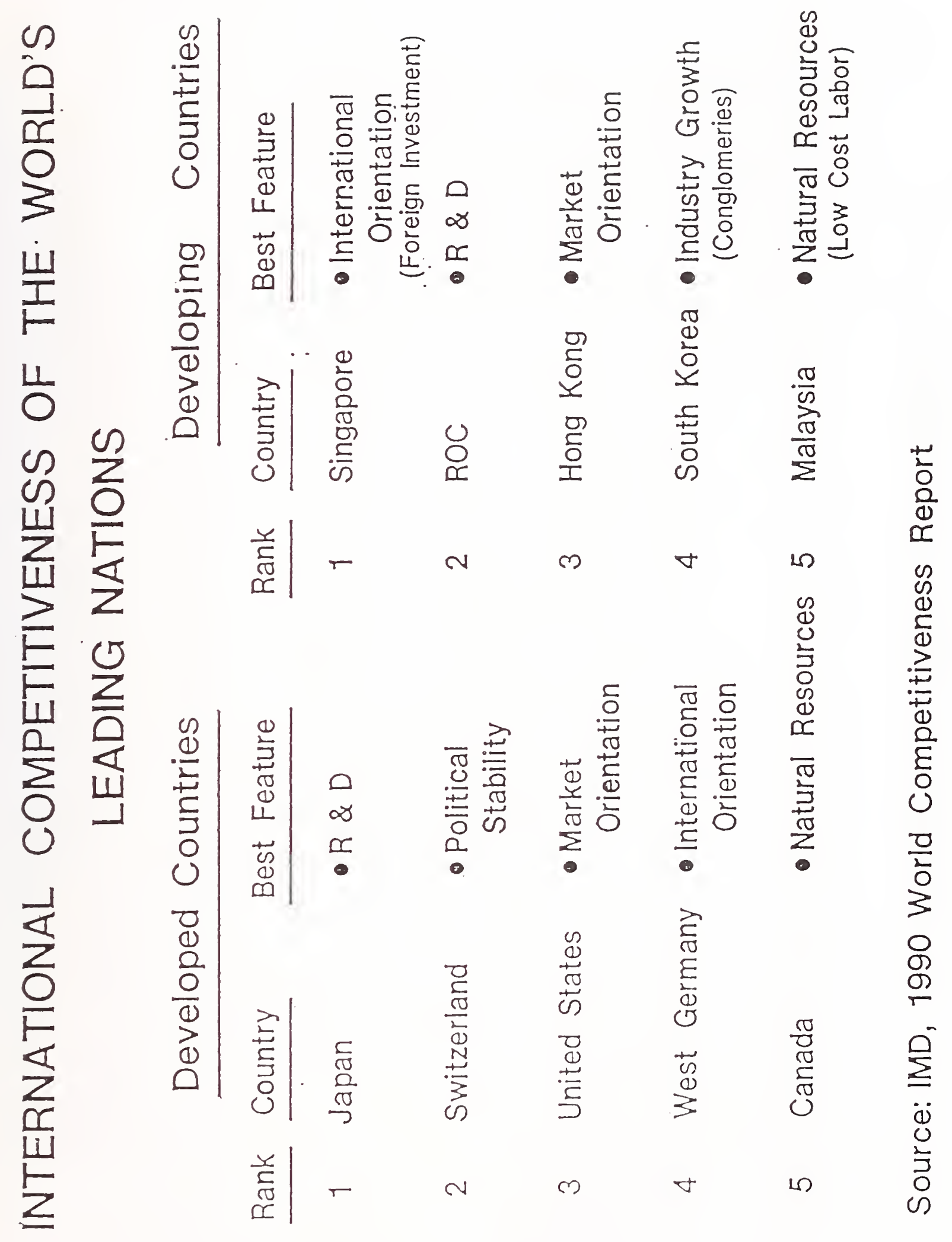




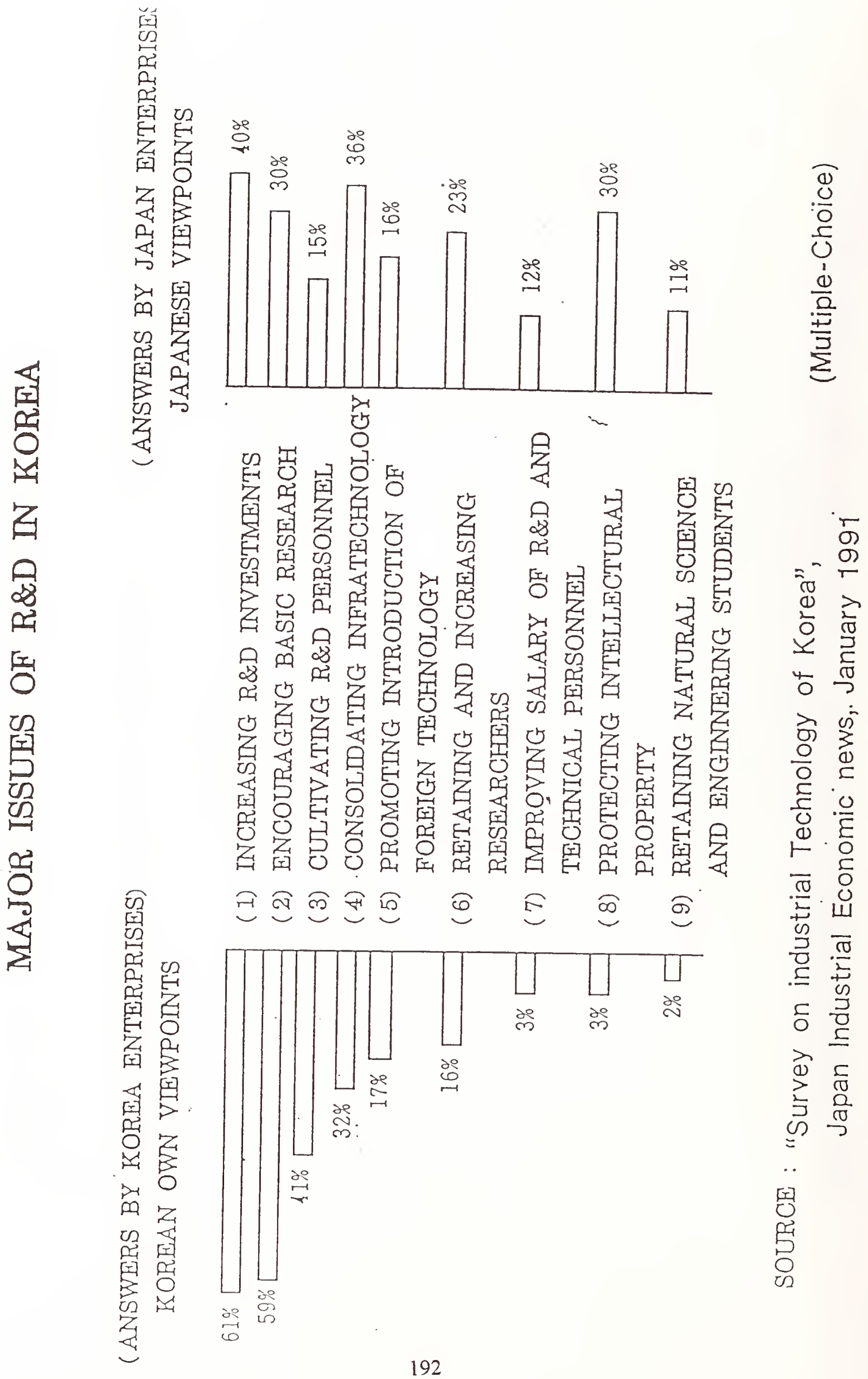




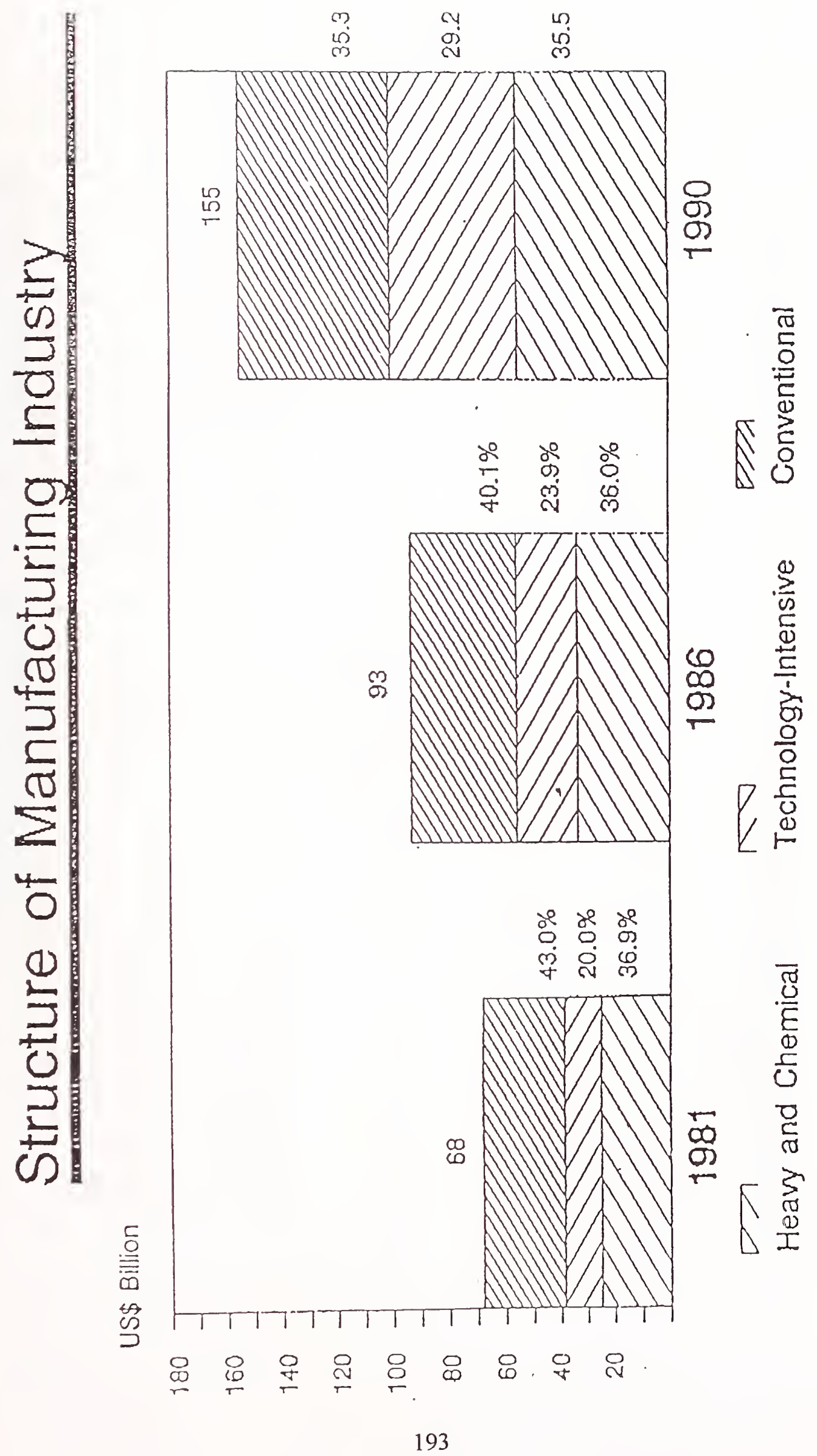




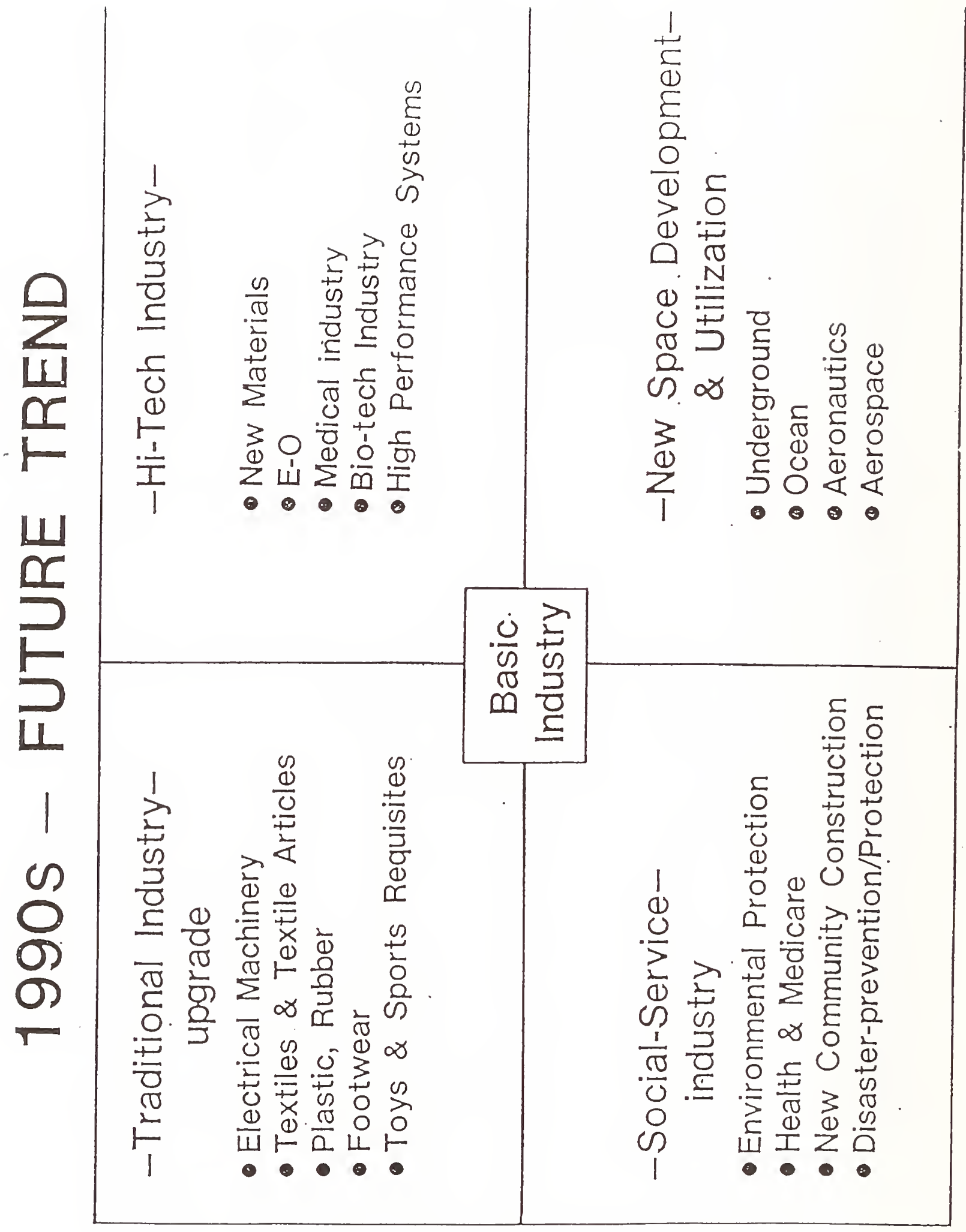




\begin{tabular}{|c|c|c|c|c|}
\hline $\begin{array}{l}\frac{Z}{0} \\
E \\
E \\
\frac{1}{E} \\
\frac{1}{0}\end{array}$ & $\begin{array}{l}\text { ने } \\
\Phi \\
\stackrel{1}{0} \\
\stackrel{2}{0} \\
0 \\
0 \\
0 \\
\square\end{array}$ & 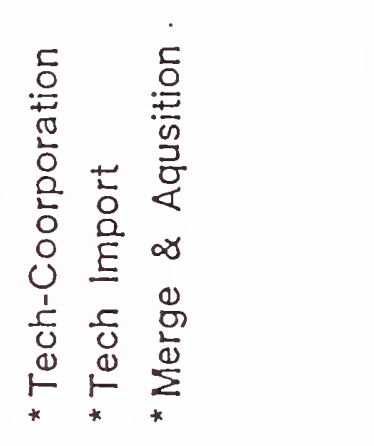 & 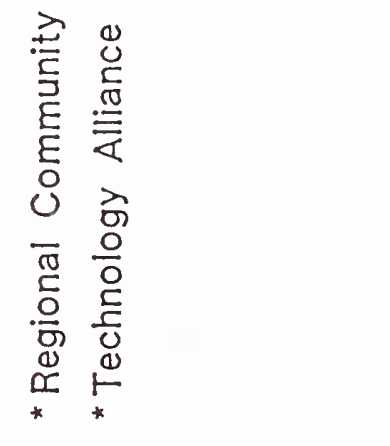 & 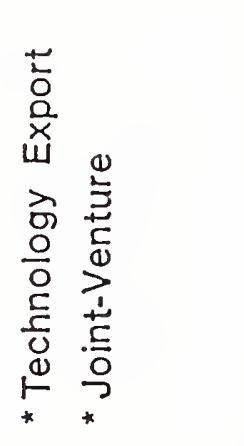 \\
\hline 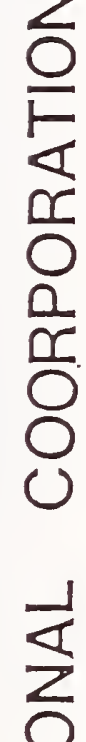 & 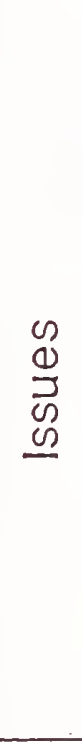 & 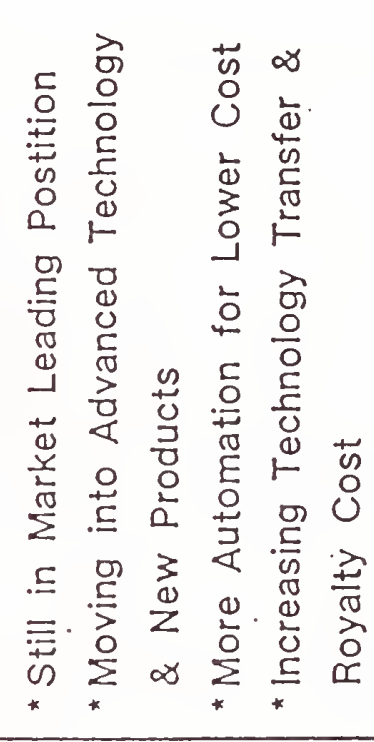 & 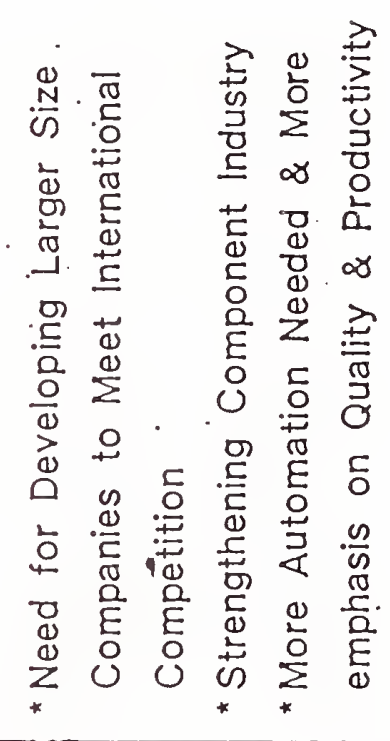 & 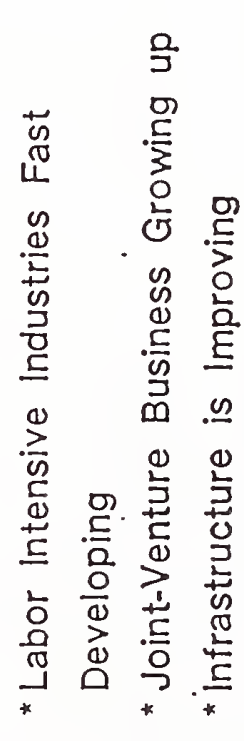 \\
\hline $\begin{array}{l}\frac{1}{E} \\
\frac{Z}{\alpha} \\
\frac{1}{1} \\
\frac{1}{z}\end{array}$ & 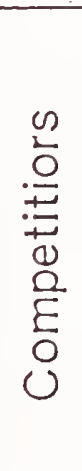 & 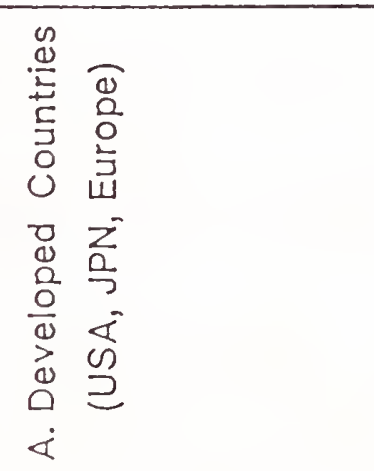 & 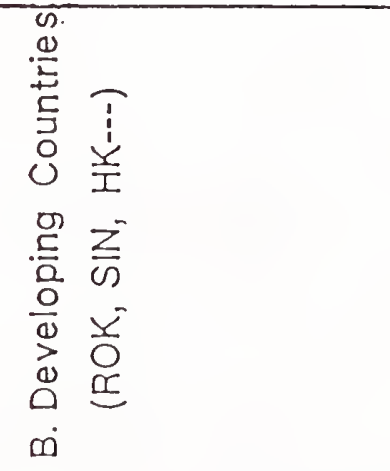 & 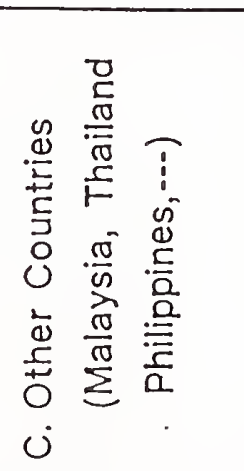 \\
\hline
\end{tabular}


Figure 14.1: R\&D Projects in Manufacturing Technology

(i) Development of a design methodology to ensure the successful implementation of CIM systems.

(ii) Methodology and Technology supporting Concurrent Engineering (framework, database management system, open system, design for manufacturing/autonation/testing).

(iii) Development of Manufacturing Planning Control System.

(iv) AI and Knowledge Based Systems applied to Quality Control/Industrial Engineering/Design.

(v) Development of expertise in communications networking for manufacturing.

(vi) Computer Aided Instruction for manufacturing system.

(vii) Man machine interfaces using multi-media and AI.

(viii) Sensors Technology.

(ix) Development of thin and thick film coatings.

(x) Development of laser technology for CNC machine.

(xi) Development of expertise in the design and development of high speed, and/or high precision assembly equipment.

(xii) Development of expertise in quick mould fabrication using stereolithography.

(xiii) Development of CAD/CAM linkage for metal moulds.

(xiv) Development of a generic low-cost automatic visual inspection system. 


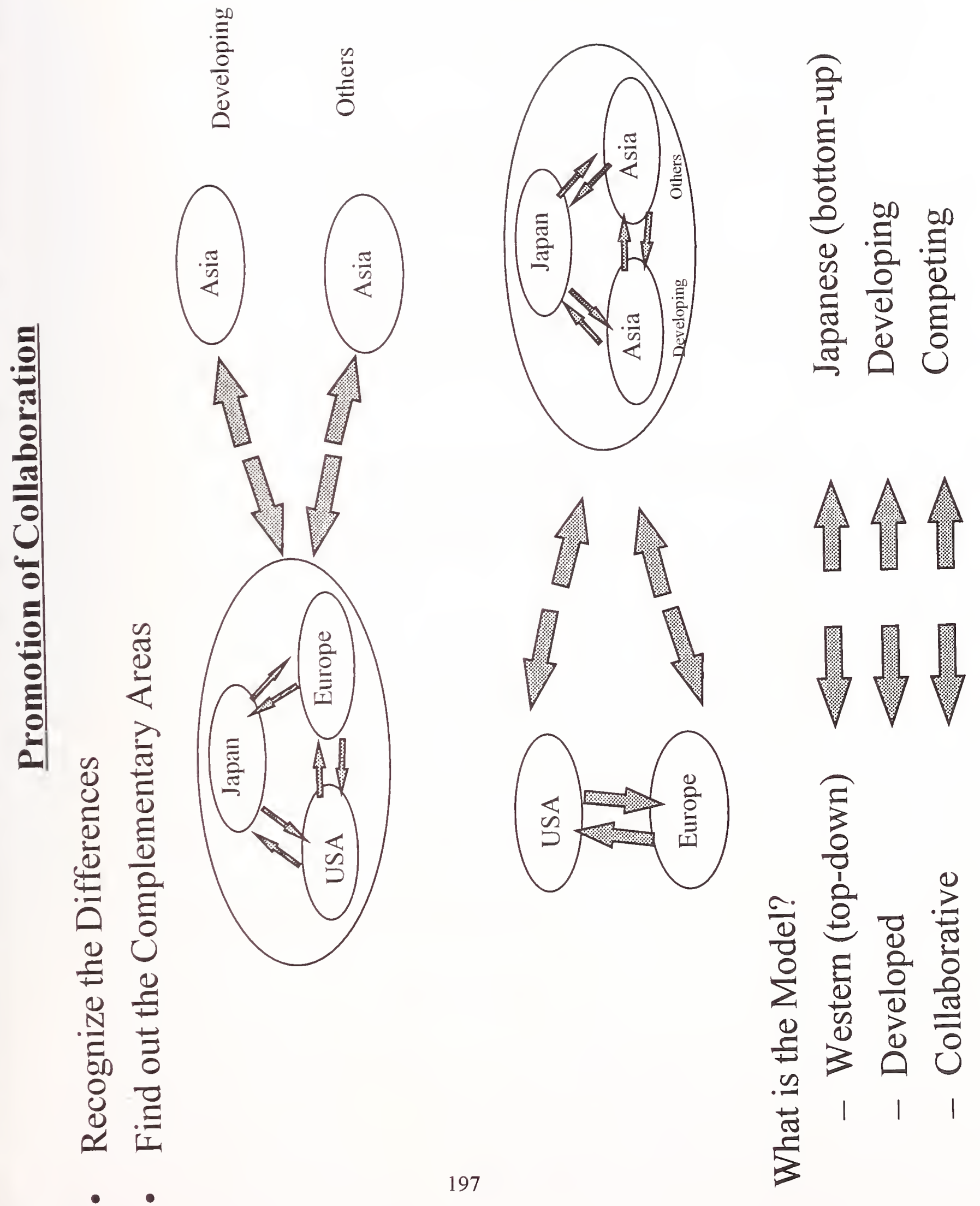


Korea:

ROC:

Singapore:
Rather Advanced Technology Intensive

\author{
Rapidly Developing \\ Intermediate State: \\ Primitive.... Developed
}

Knowledge Intensive

Scale Problem

Focused Development 


\section{Future Strategy for Japan}

- Manufacturing as a New Discipline

- $\quad$ Focus on High Technology

IIII) Profitable

- Globalization

IIIII Optimization in Globe-Scale

- Clean Manufacturing

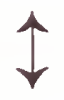

- $\quad$ Keep Country Profit

- Evolution of the World

- Important Factor: $\underline{\text { Human }}$

Development and Maintenance of Knowledge

$\rightarrow$ Attract Good Students to Manufacturing

$\Rightarrow \quad$ Share Generic Knowledge

IMS Program 


\section{Factors for Manufacturing $\mathbf{R} \& \mathbb{D}$}

Long Range Strategy

Japan: $\quad \square \quad$ Renovation of Manufacturing Technology (Ex. Ship-building, Textile, ...)

Others: $\quad \square \quad$ Focus on Product Design Technology

Government Committment

Japan: $\quad \square \quad$ Industry Leadership, Government Support

Others: $\quad \square \quad$ Strong Government Control

R\&D Sources

Japan: $\quad \square \quad$ University - National Labs - Industry

口 Different Roles

$\square \quad$ Bottom-up, Informal Contact

Others: $\square \quad$ Overlapping Roles

ㄴ Top-down, Formal Contact

Human Resource

Japan: $\quad \square \quad$ All-Round Player

$\square \quad$ Life-long Employment

Others: $\quad \square \quad$ Expert (Ph.Ds from foreign universities)

What is the Performance Measure? 


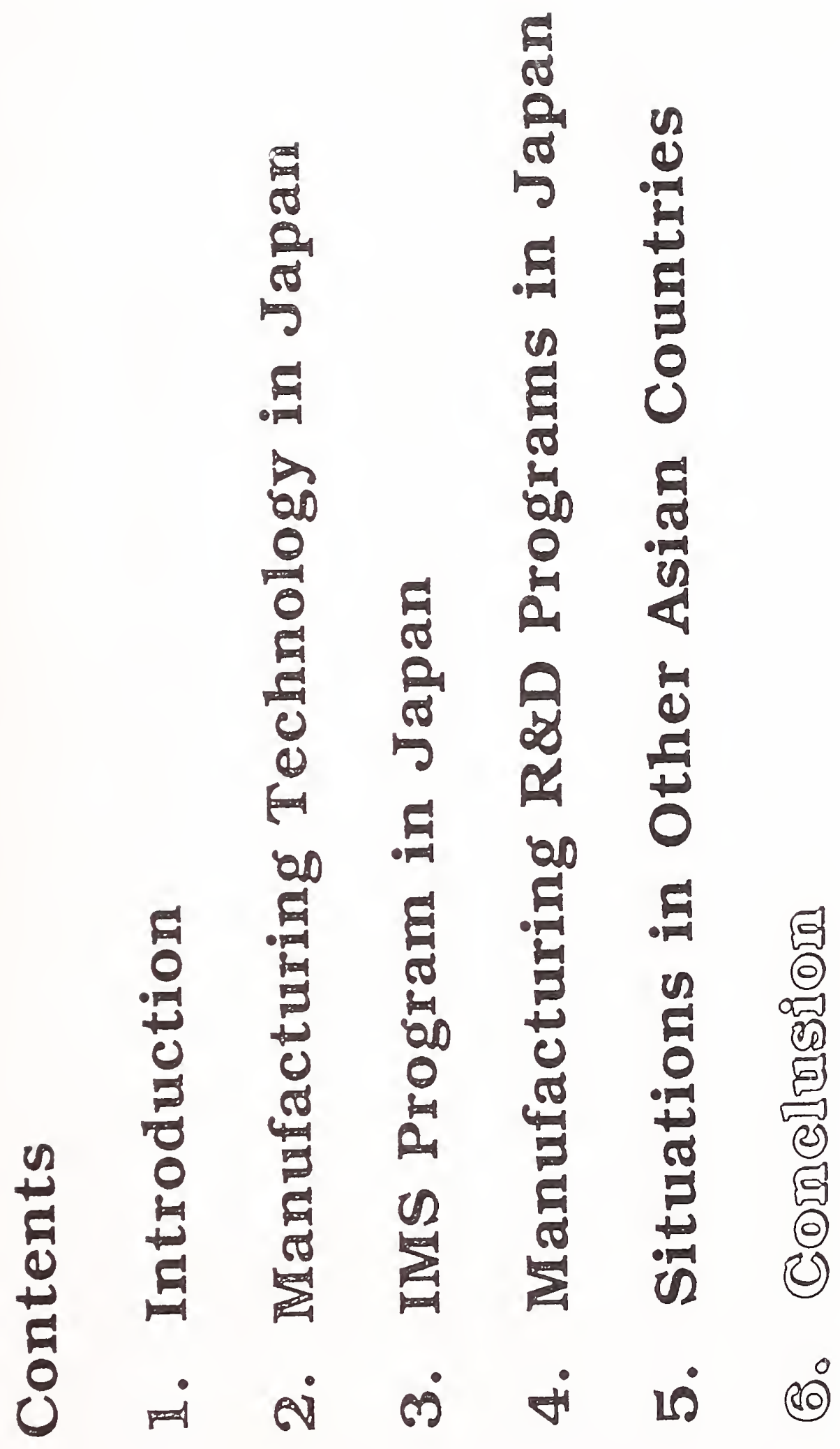




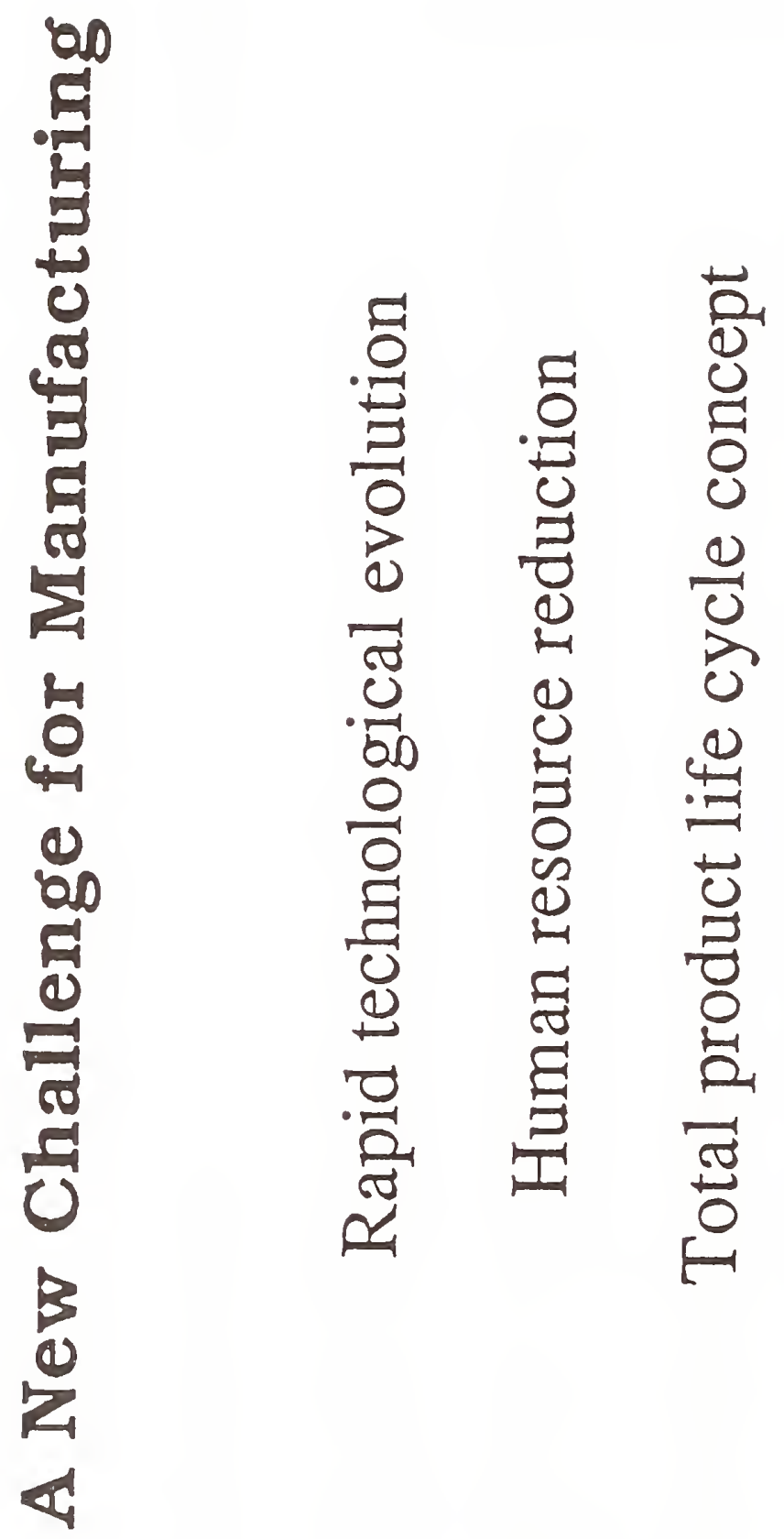




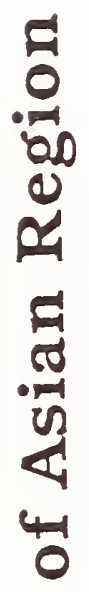

y

is

U

$+$

0

엉

인

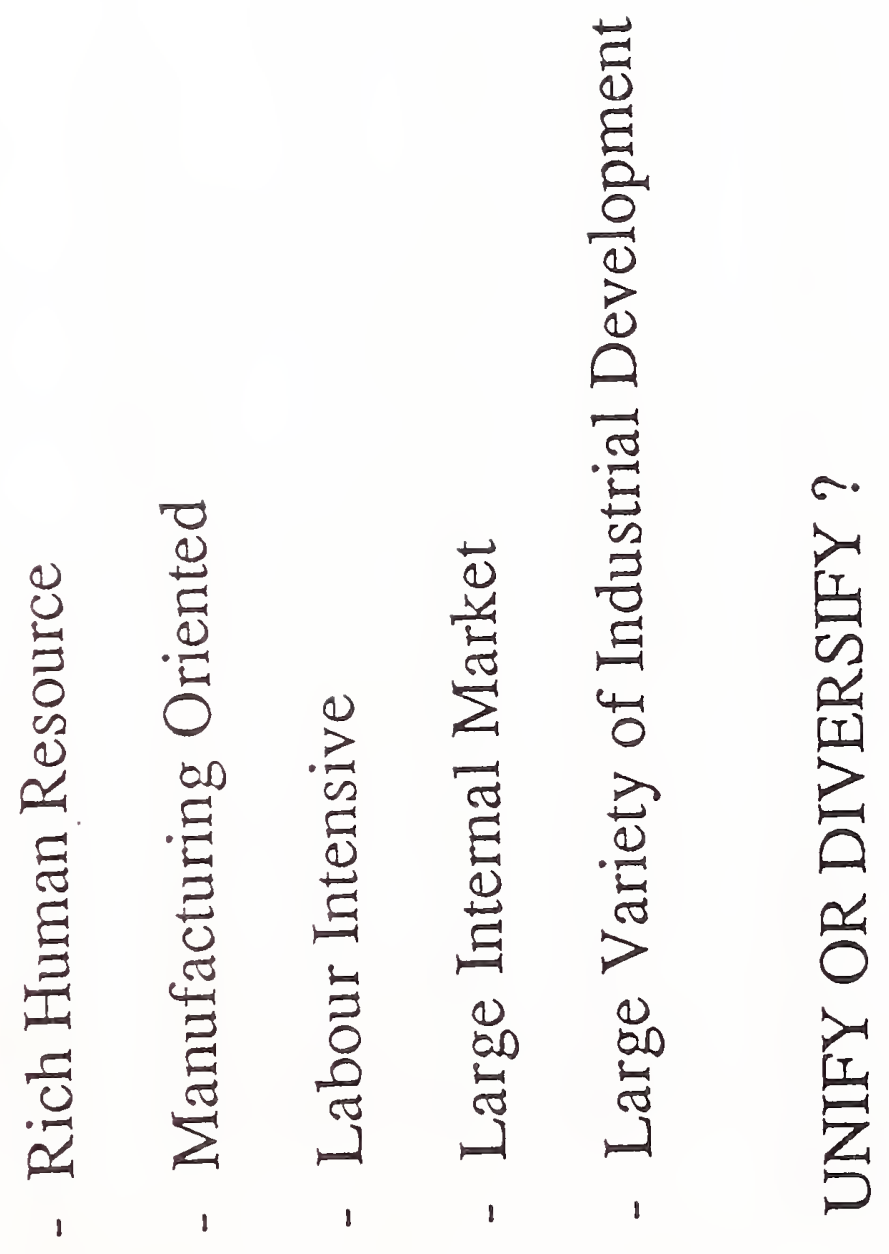




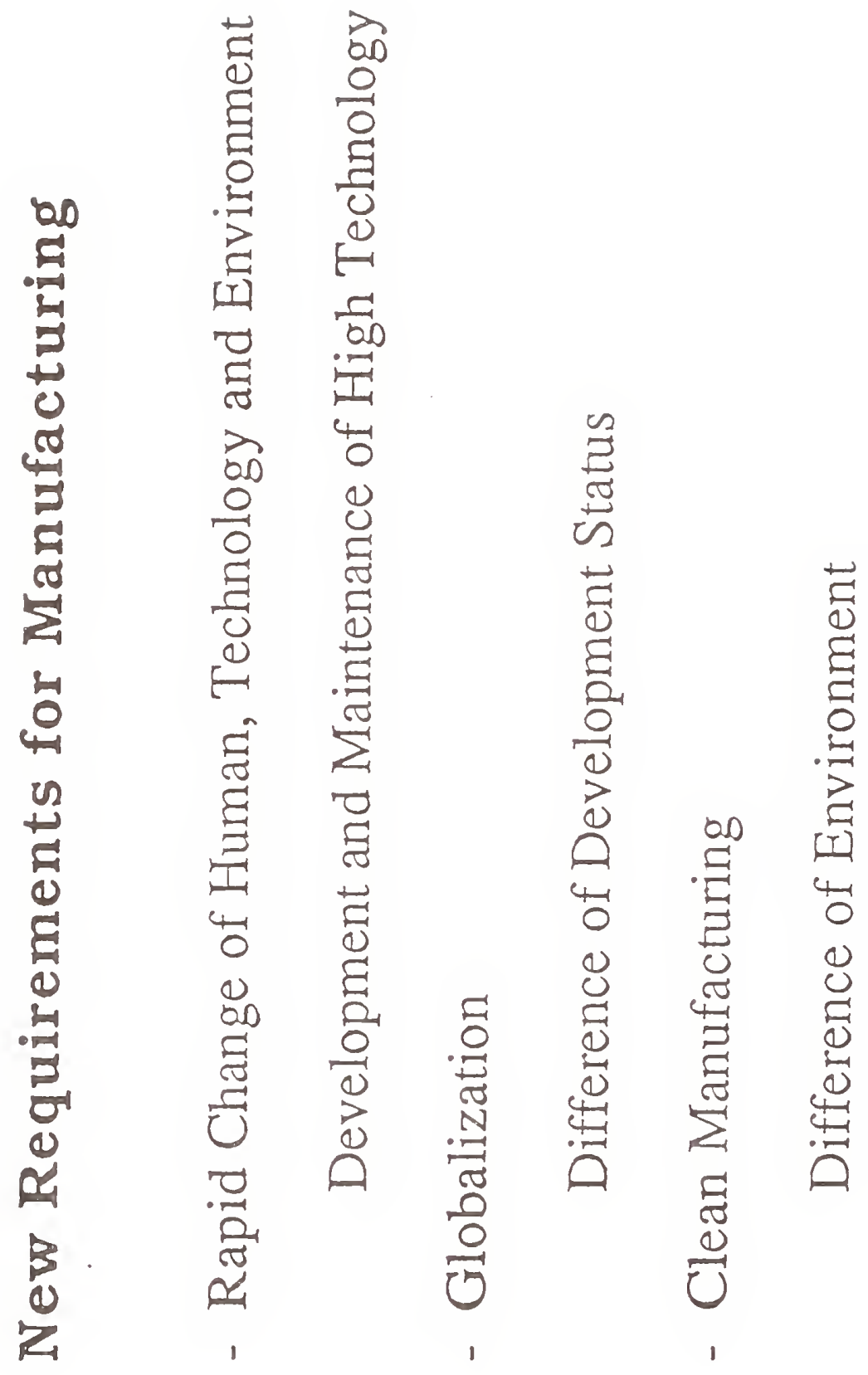




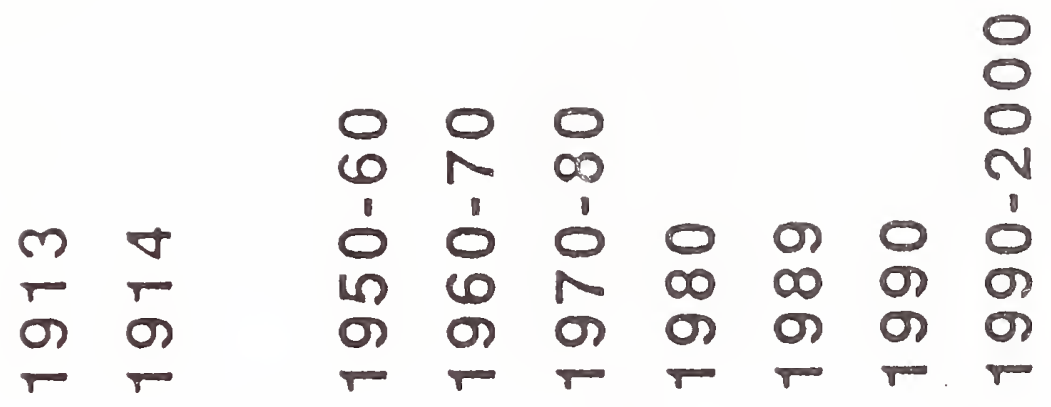

$\frac{1}{0}$

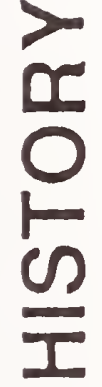

$\frac{0}{\frac{2}{2}}$

$\frac{11}{2}$
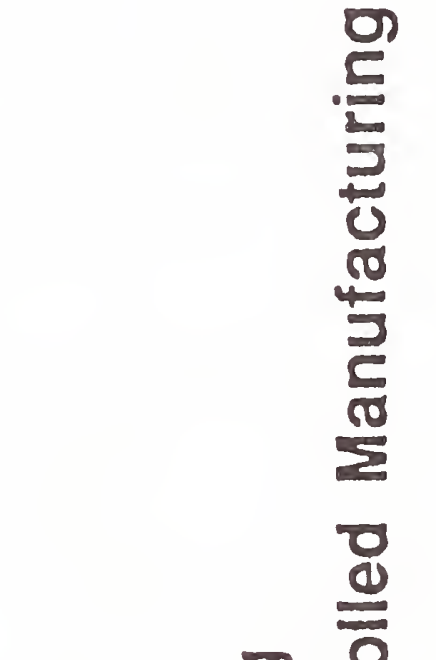

2

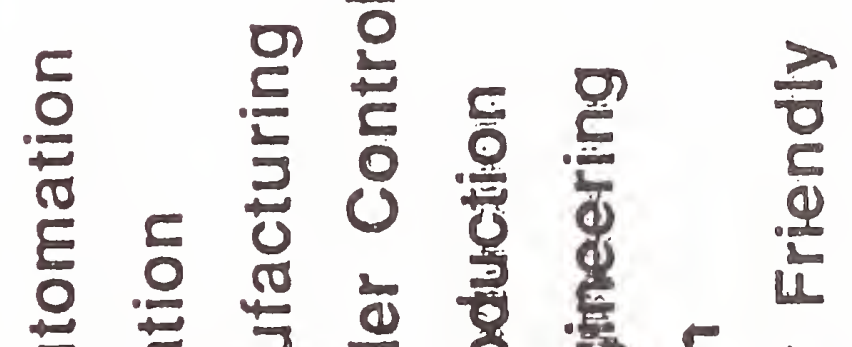

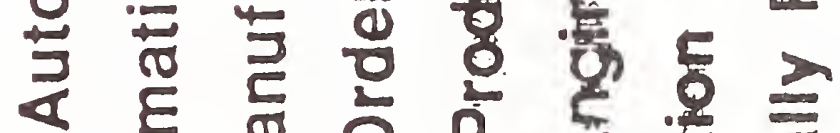

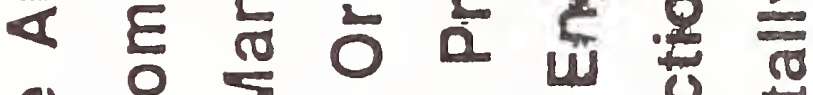

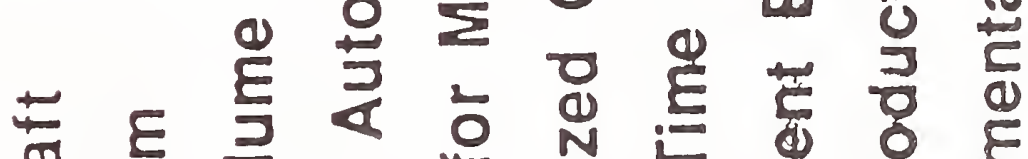

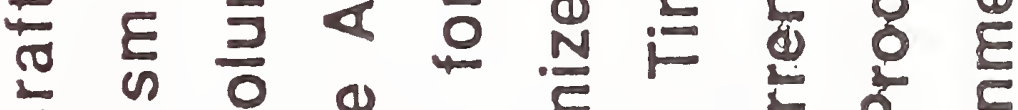

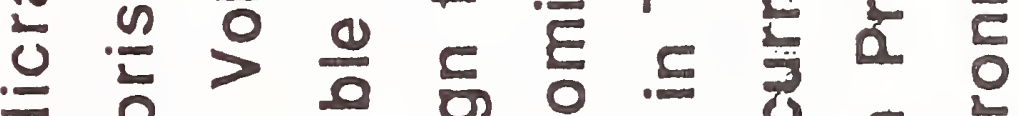

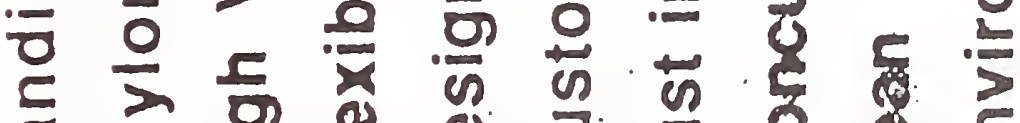

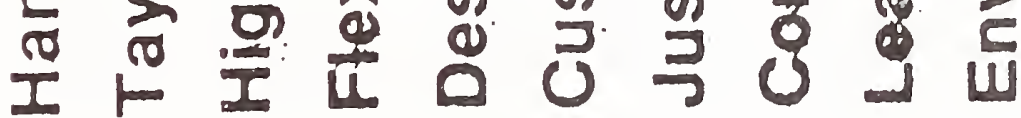




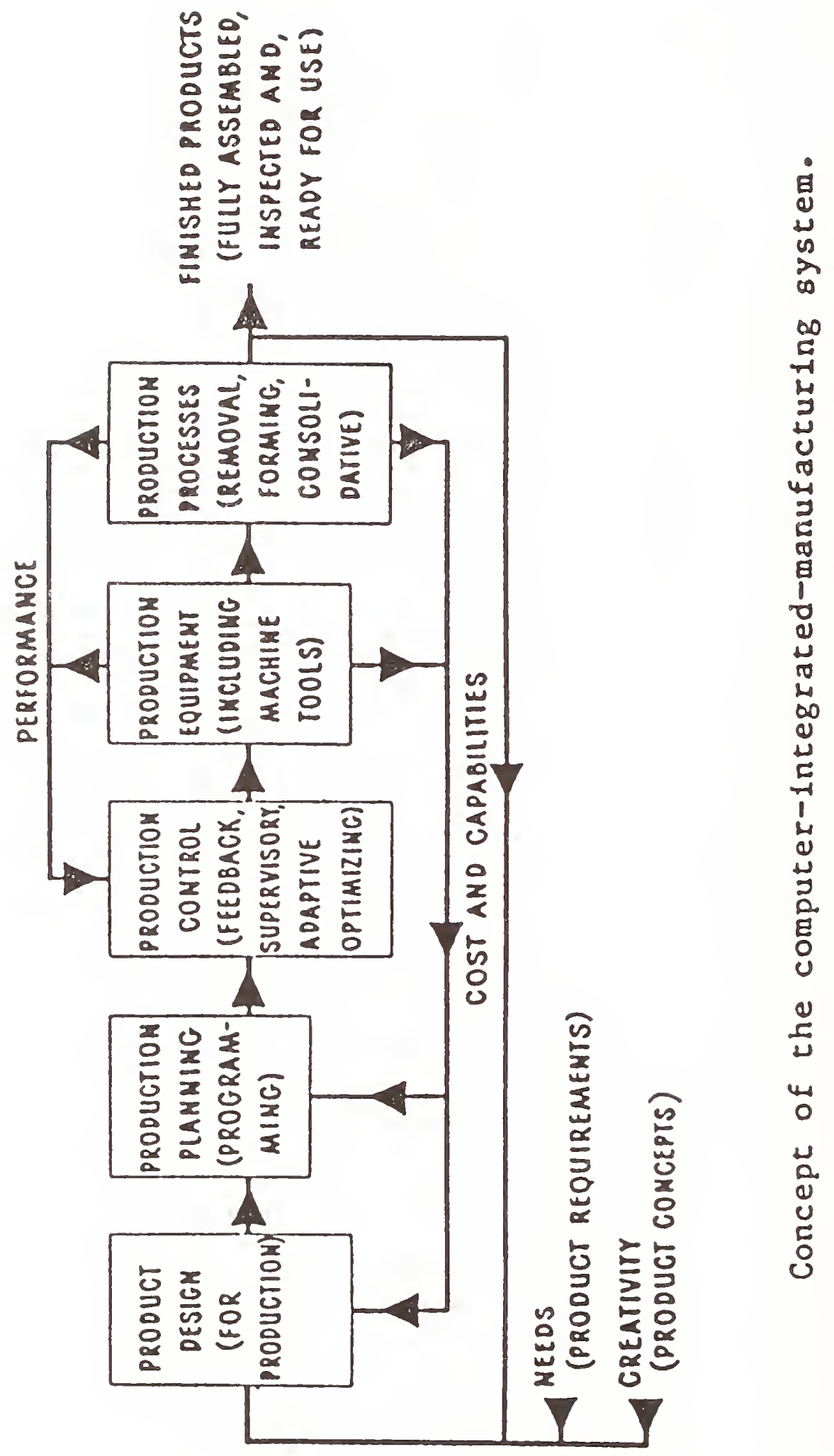



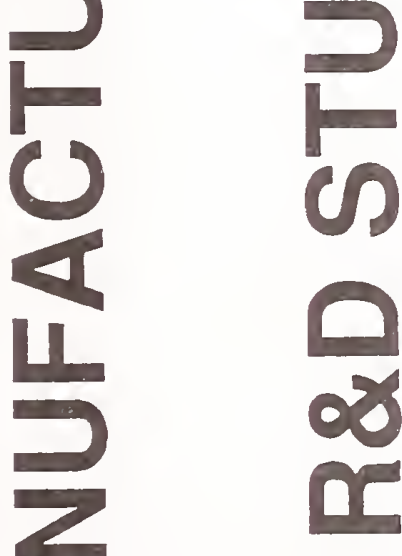

a 

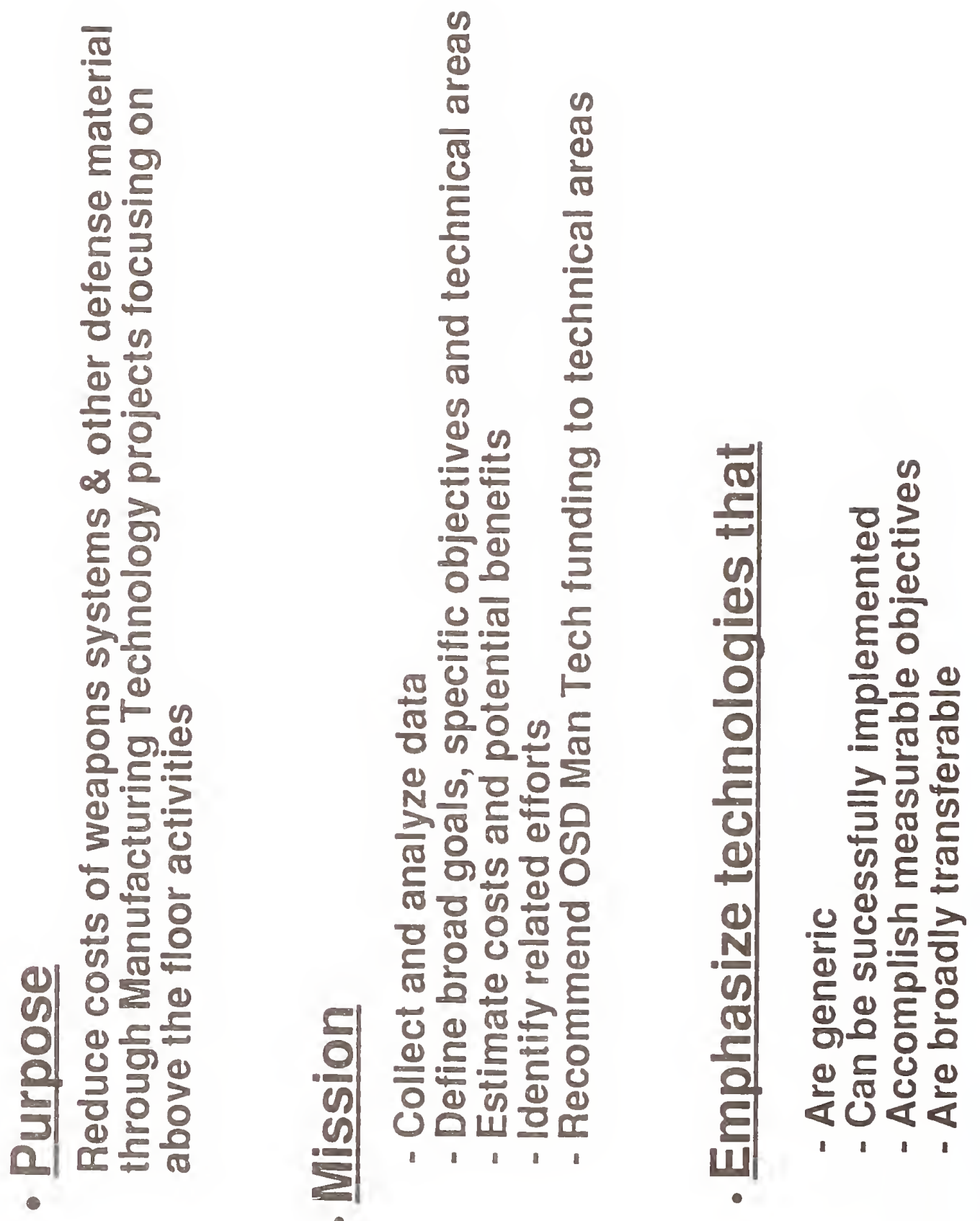


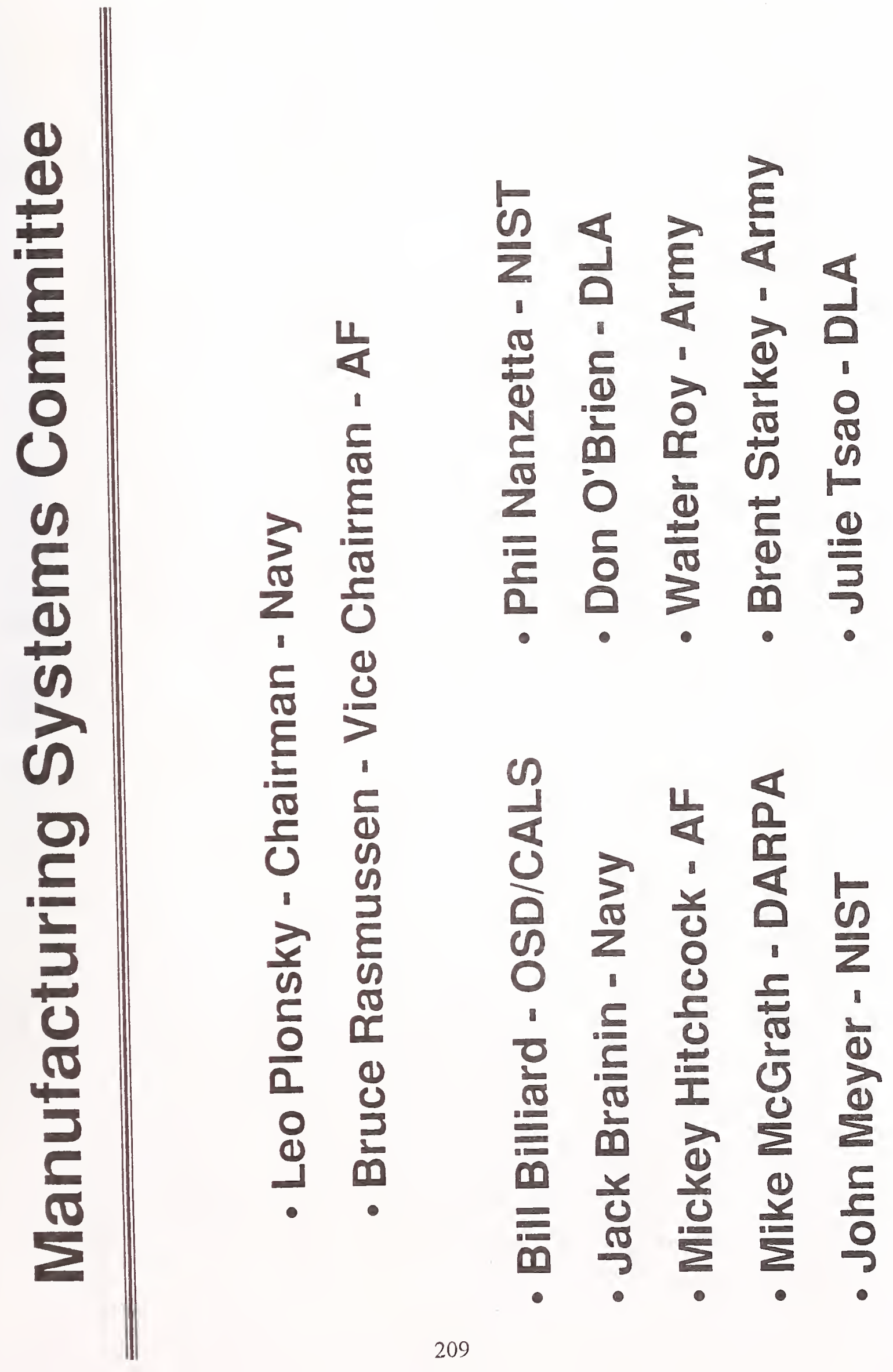




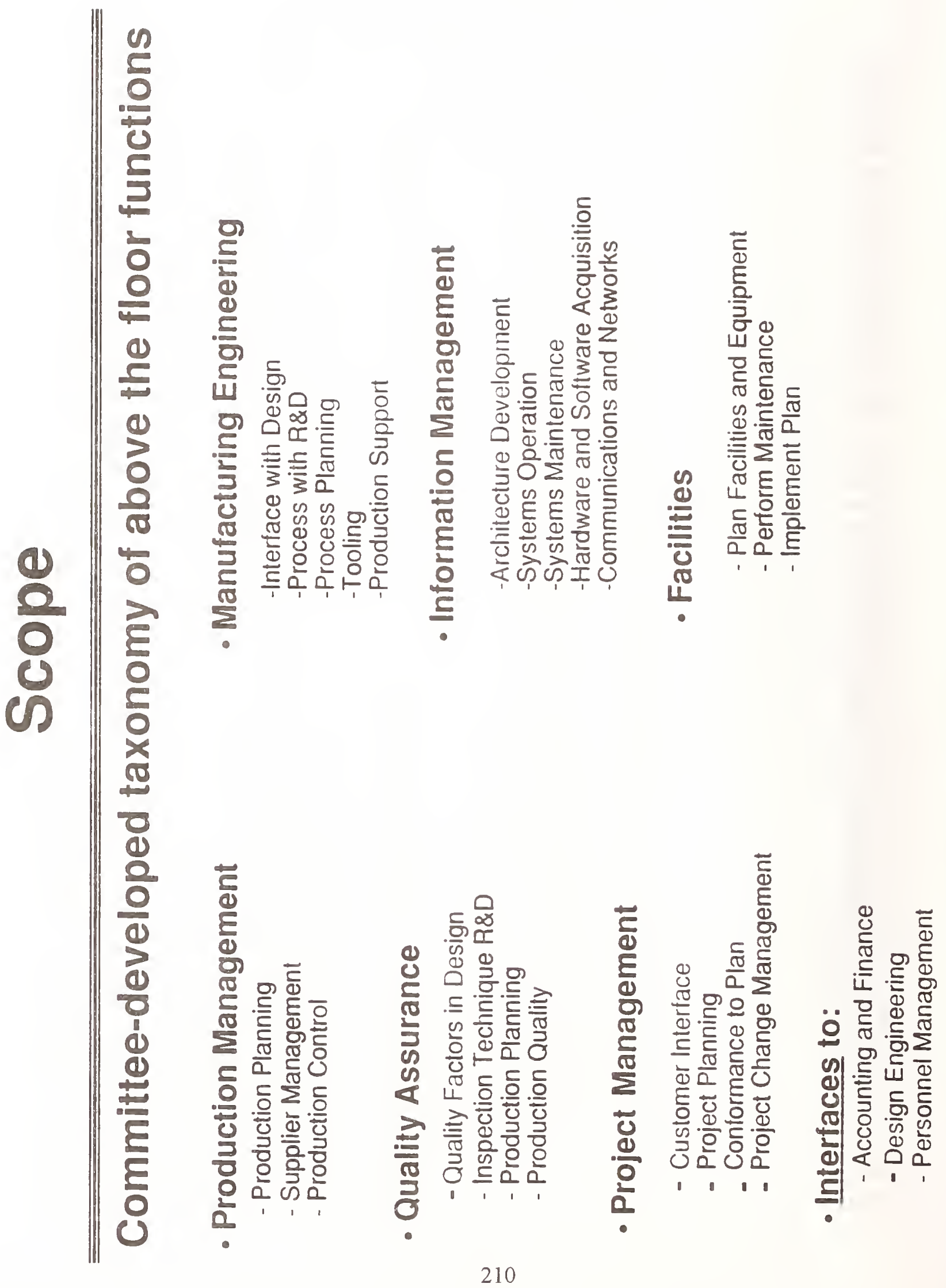




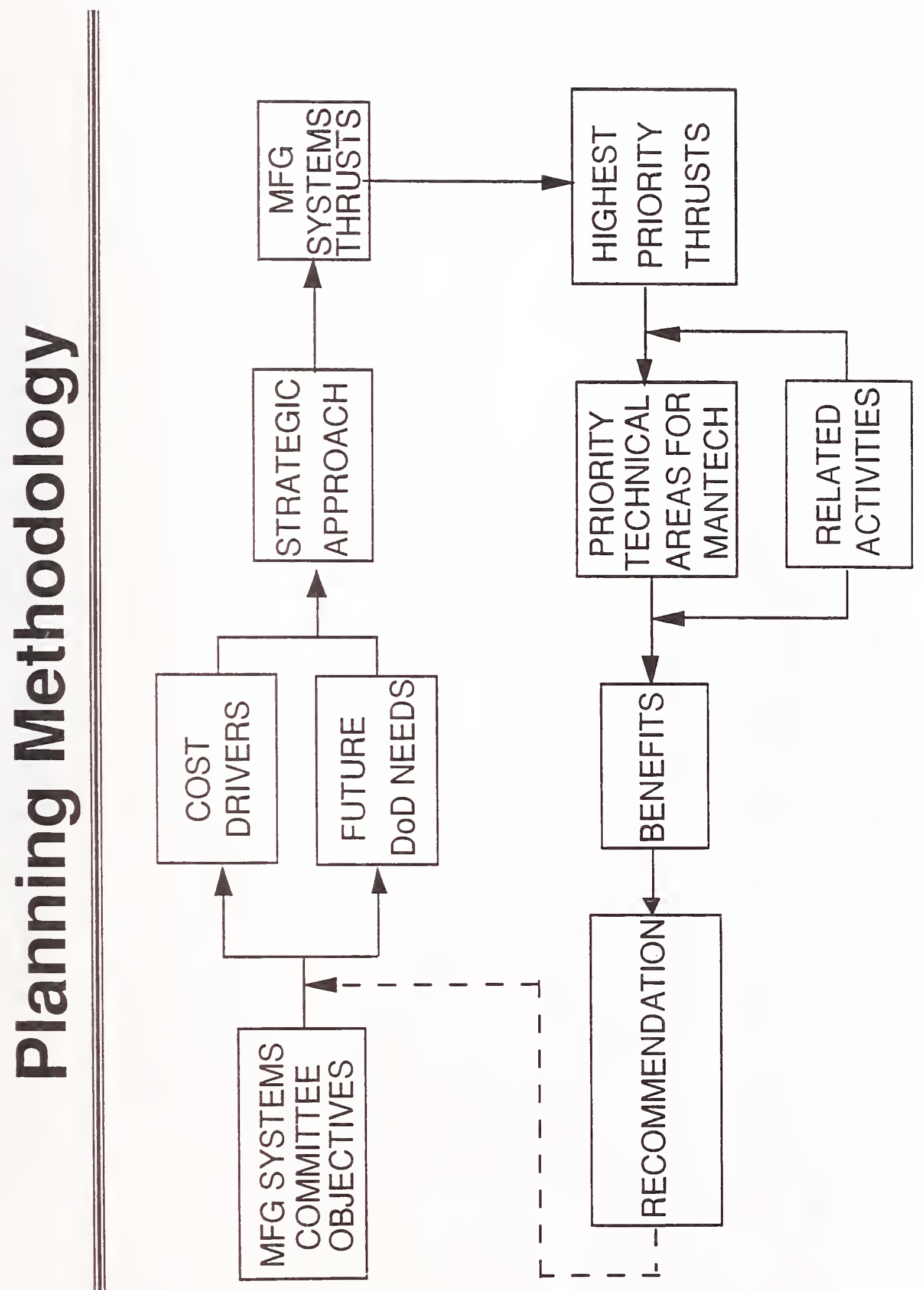




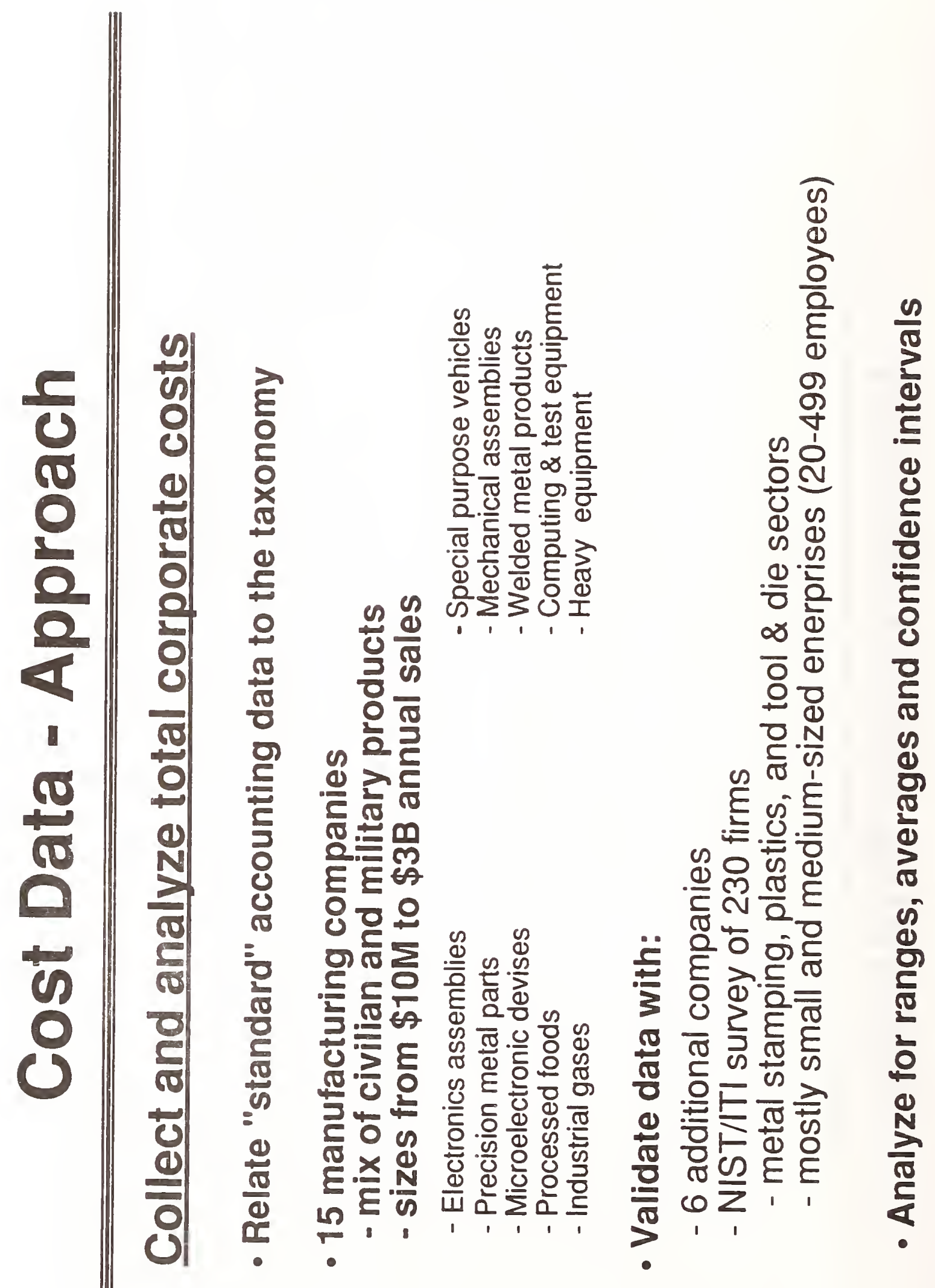




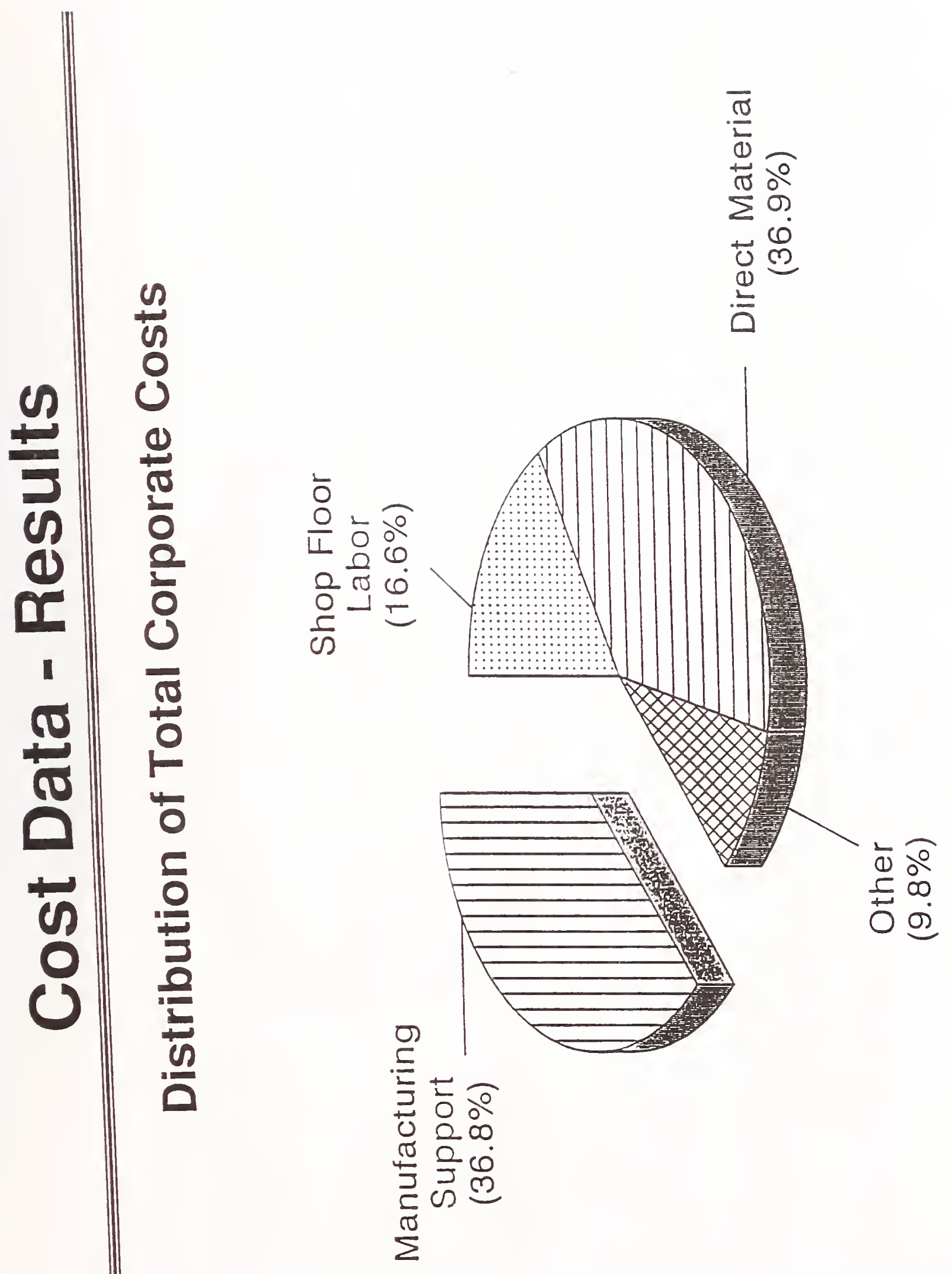



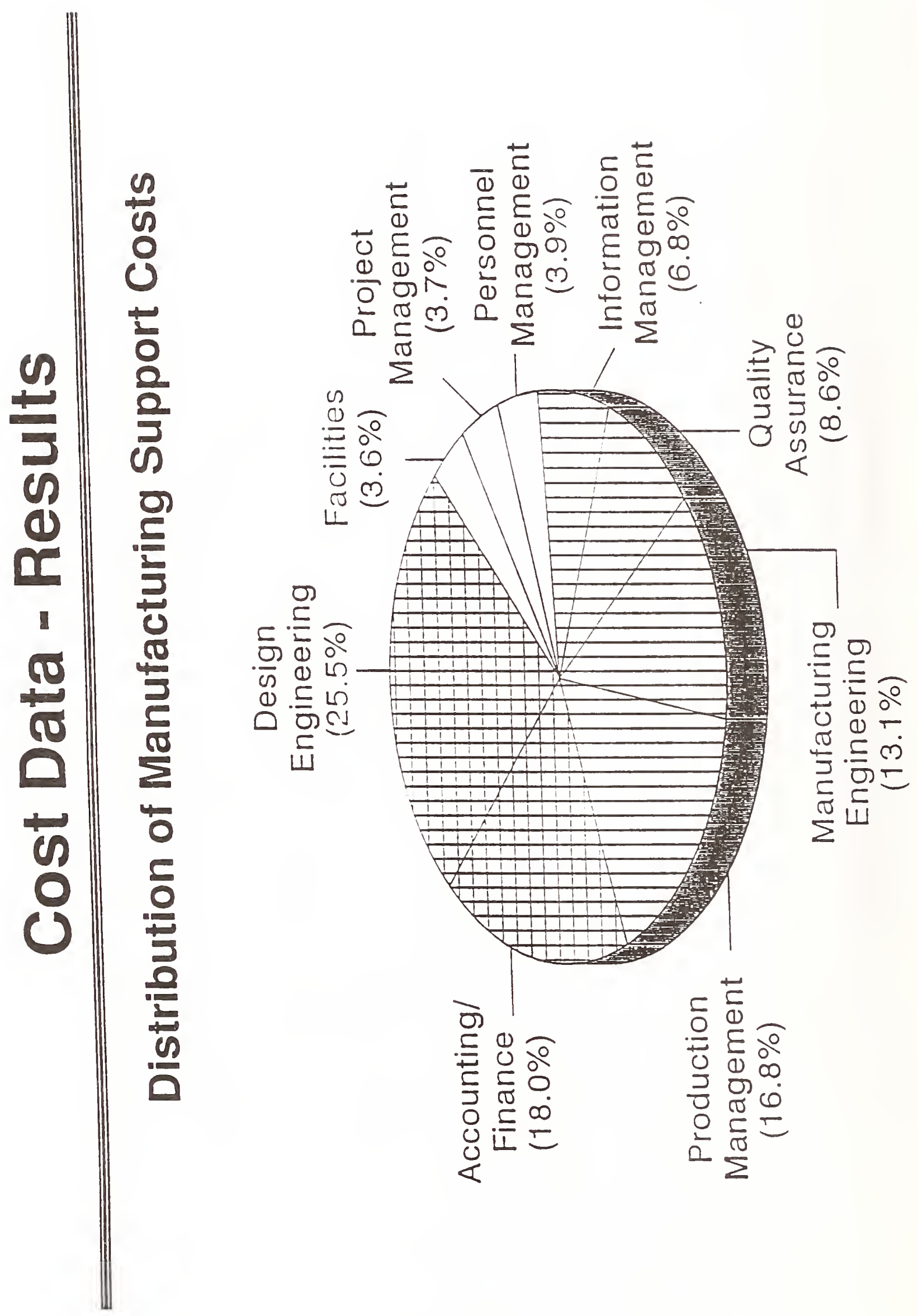


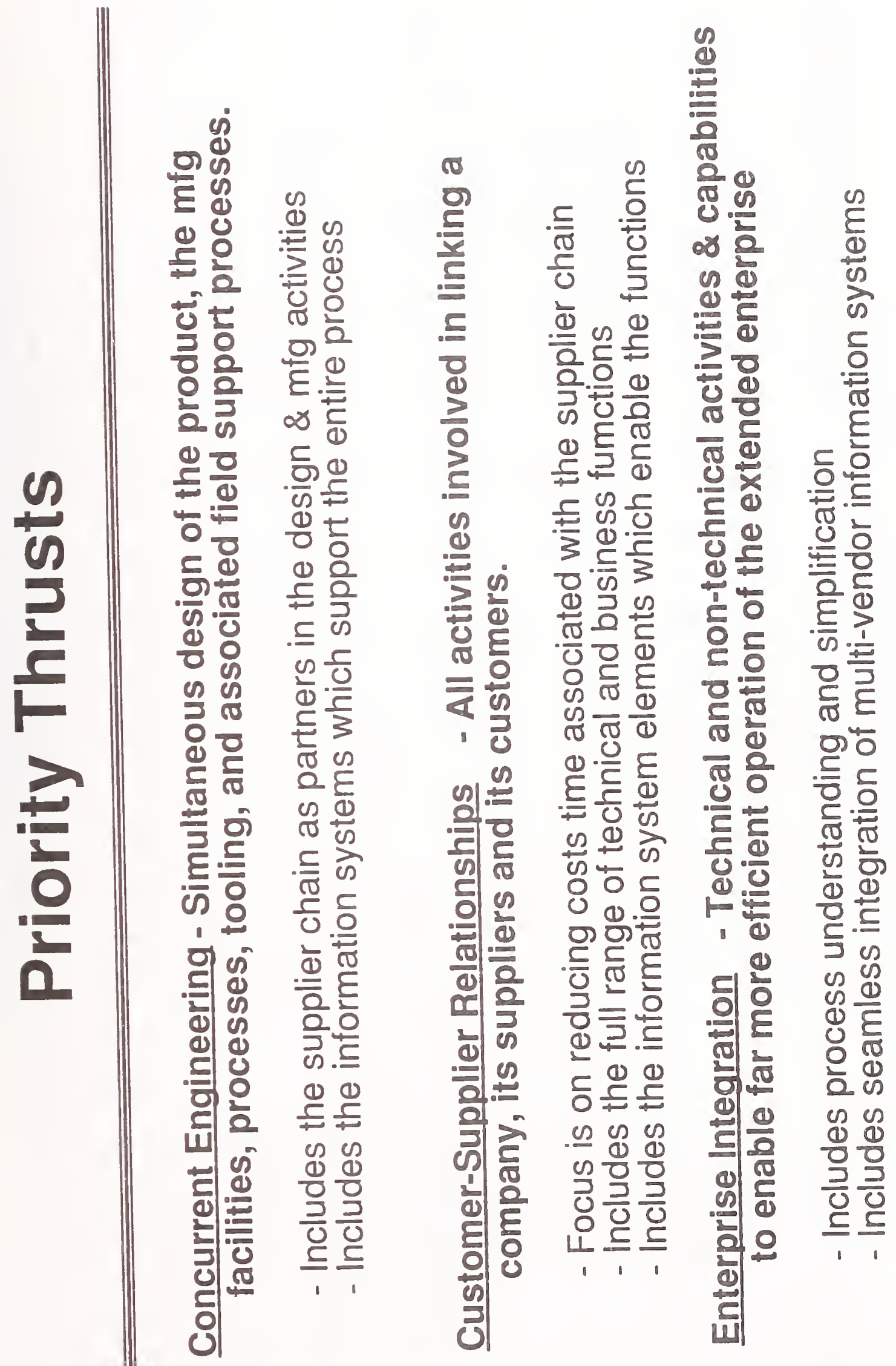




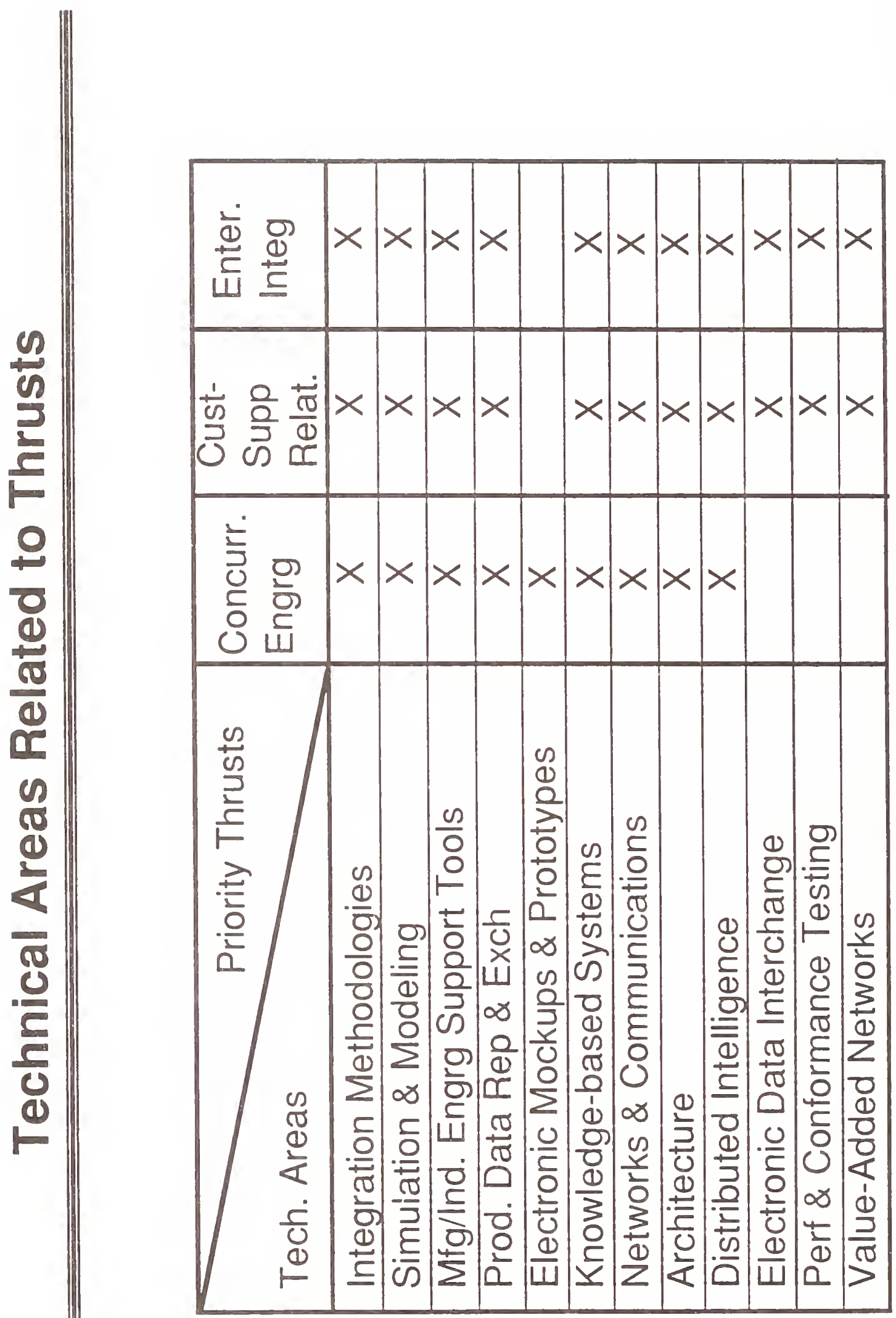




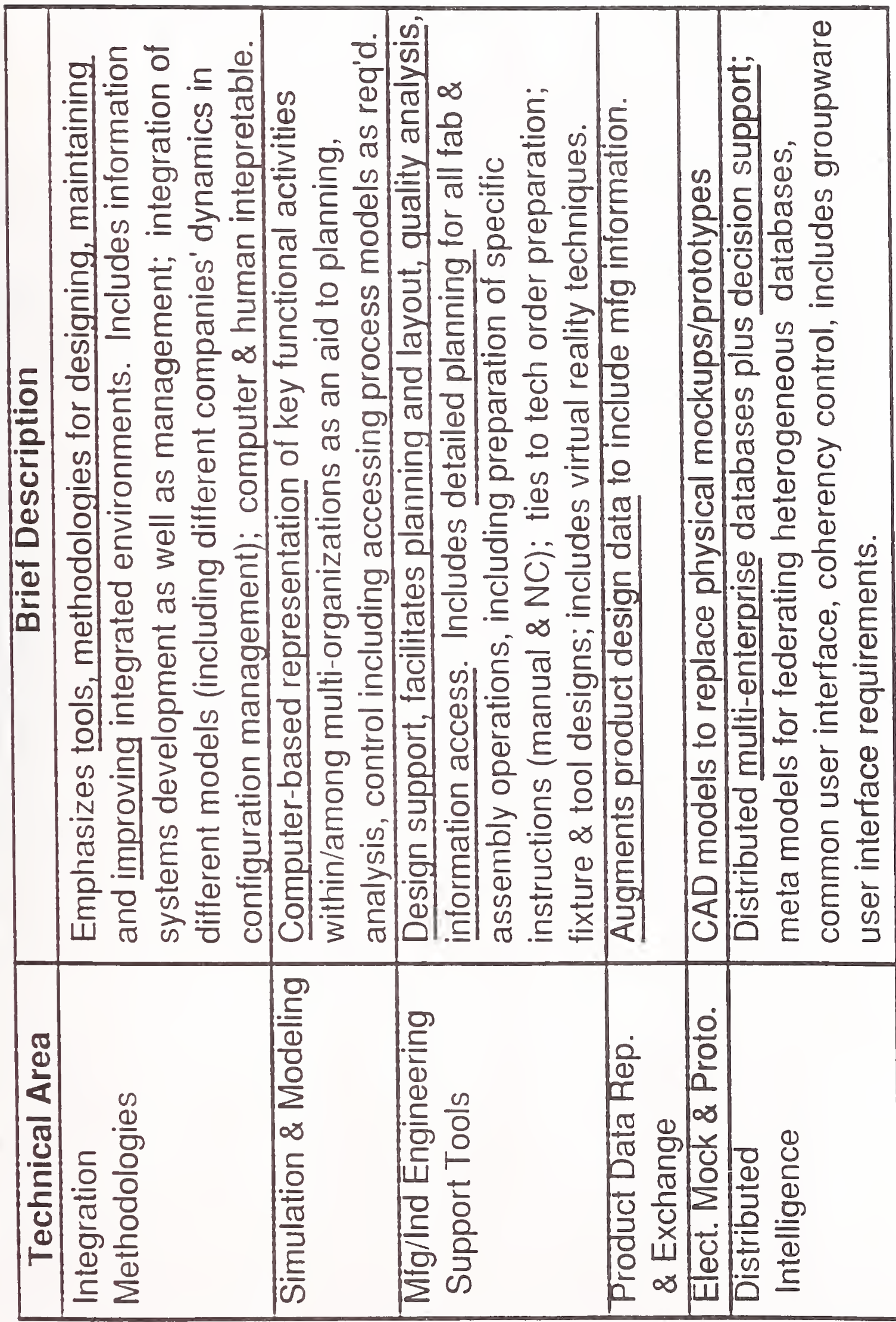




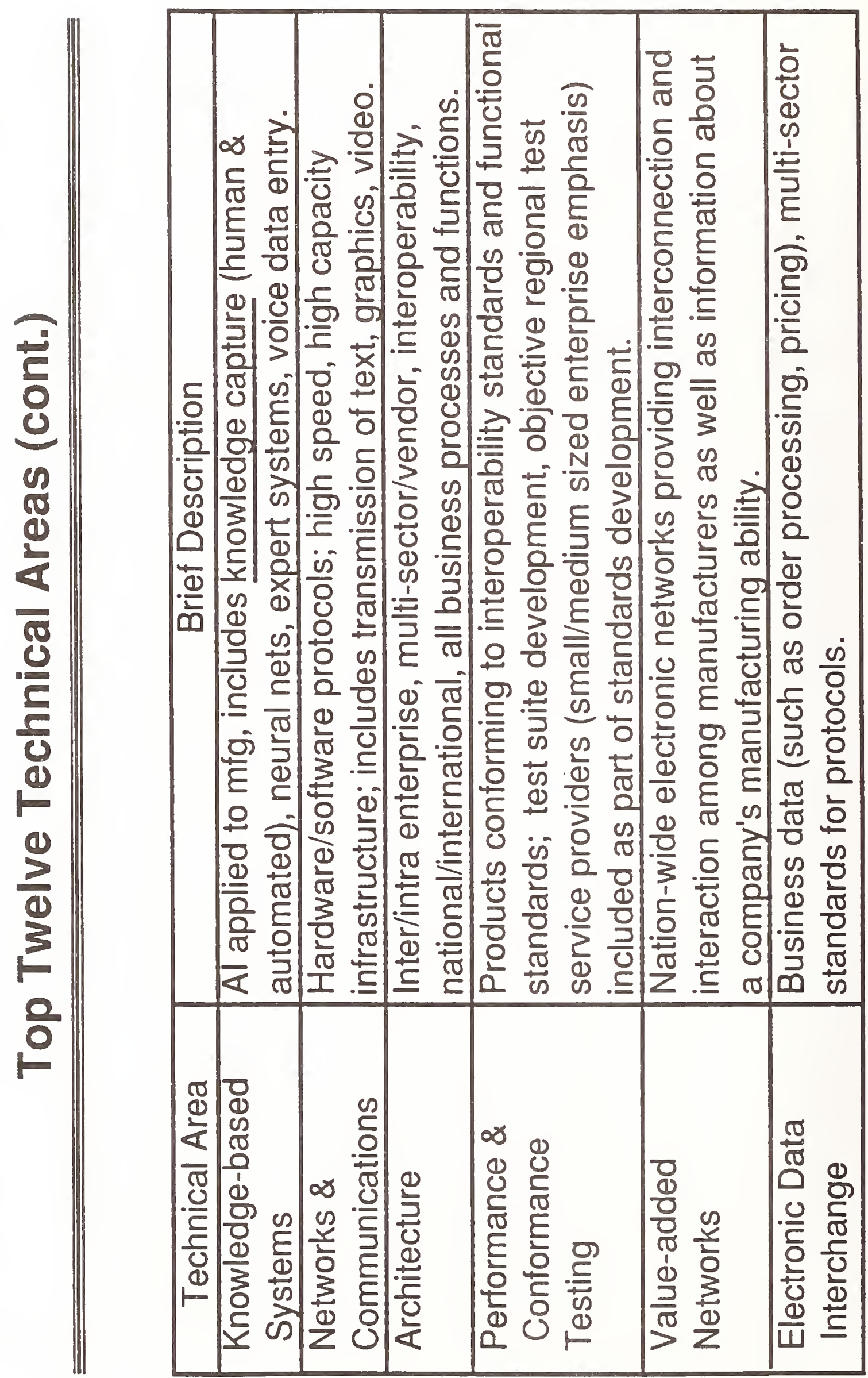




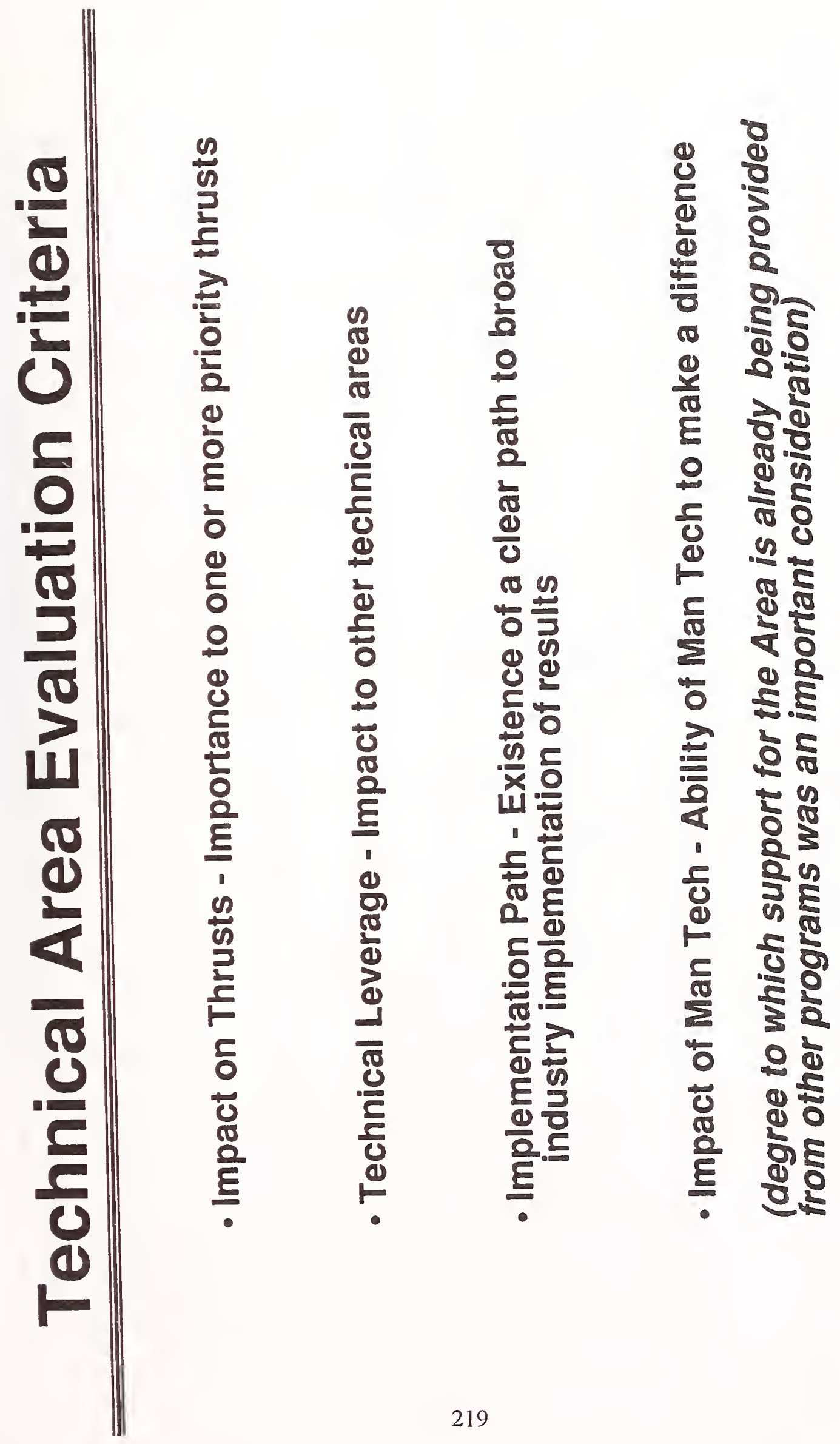




\begin{tabular}{|c|c|c|}
\hline $\begin{array}{l}\bar{\pi} \\
\stackrel{0}{0}\end{array}$ & I II & $\Sigma\lrcorner\lrcorner-\Sigma\lrcorner\lrcorner \Sigma\lrcorner$ \\
\hline 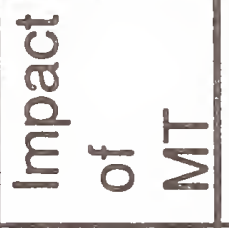 & $I I I$ & $\Sigma \Sigma\lrcorner\lrcorner \Sigma\lrcorner\lrcorner I\lrcorner$ \\
\hline 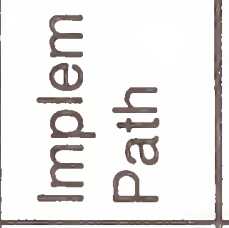 & III & $I \Sigma \Sigma I \Sigma \Sigma I \Sigma \Sigma$ \\
\hline 造 & $I \Sigma \Sigma$ & $\Sigma\lrcorner \Sigma I \Sigma \Sigma\lrcorner \Sigma\lrcorner$ \\
\hline 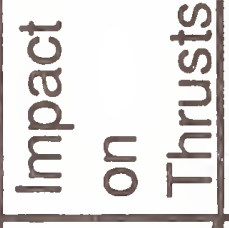 & $I \Sigma \Sigma$ & $I\lrcorner I I I I \Sigma \Sigma\lrcorner$ \\
\hline 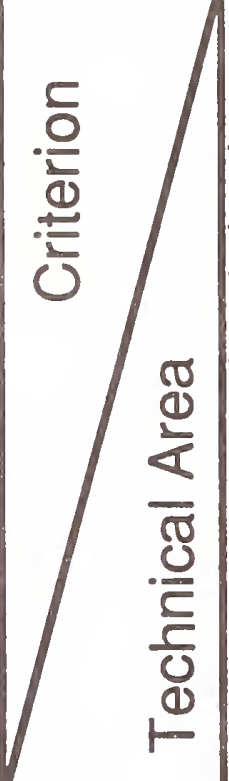 & 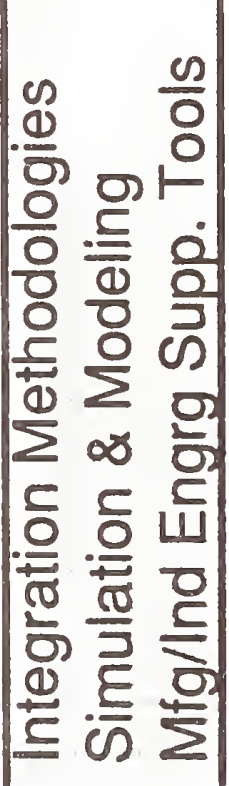 & 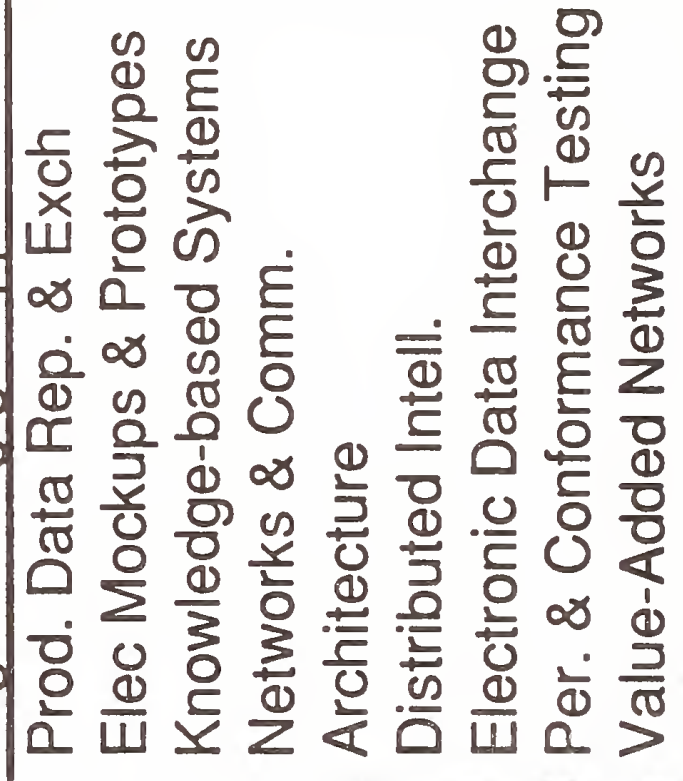 \\
\hline
\end{tabular}



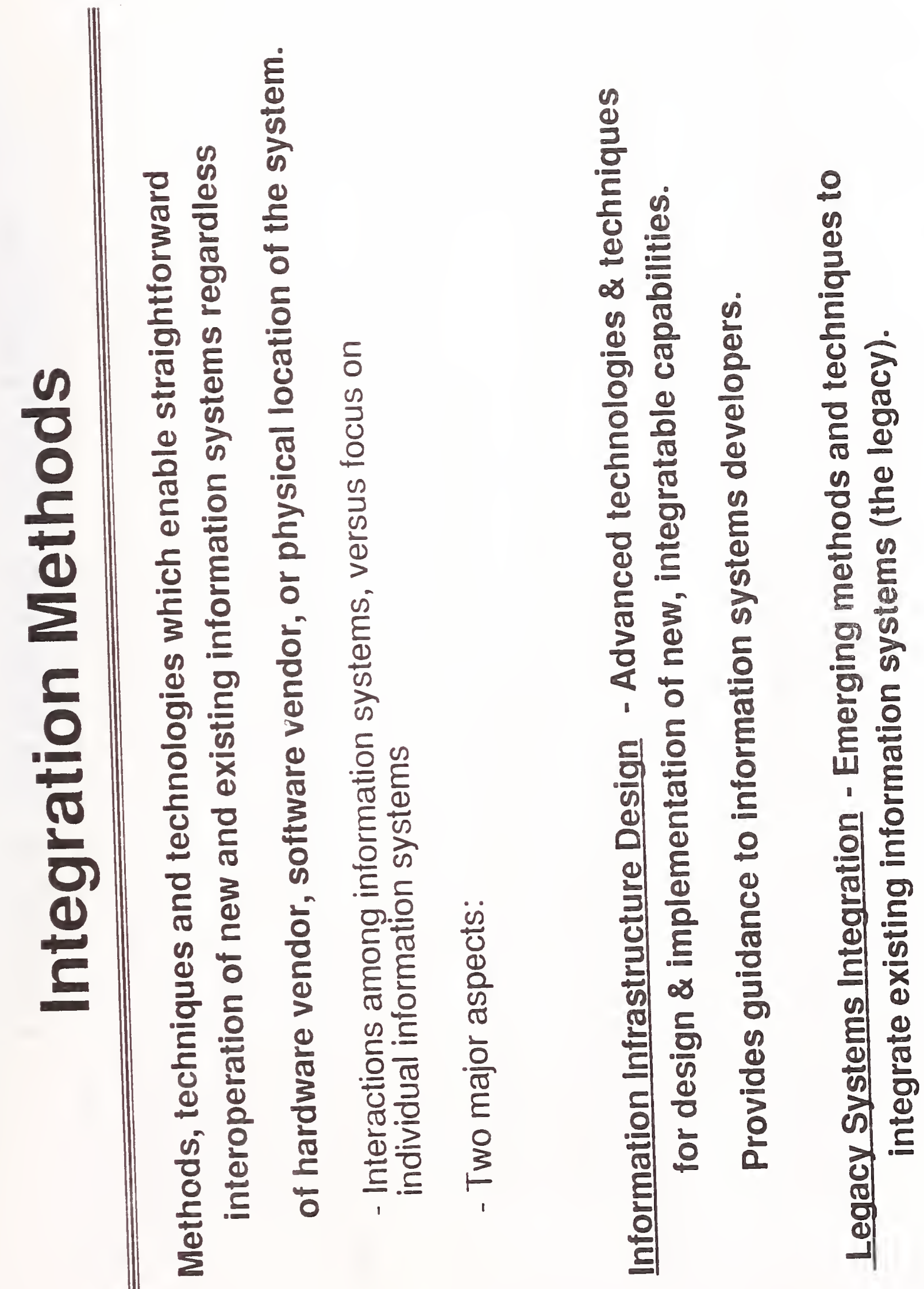

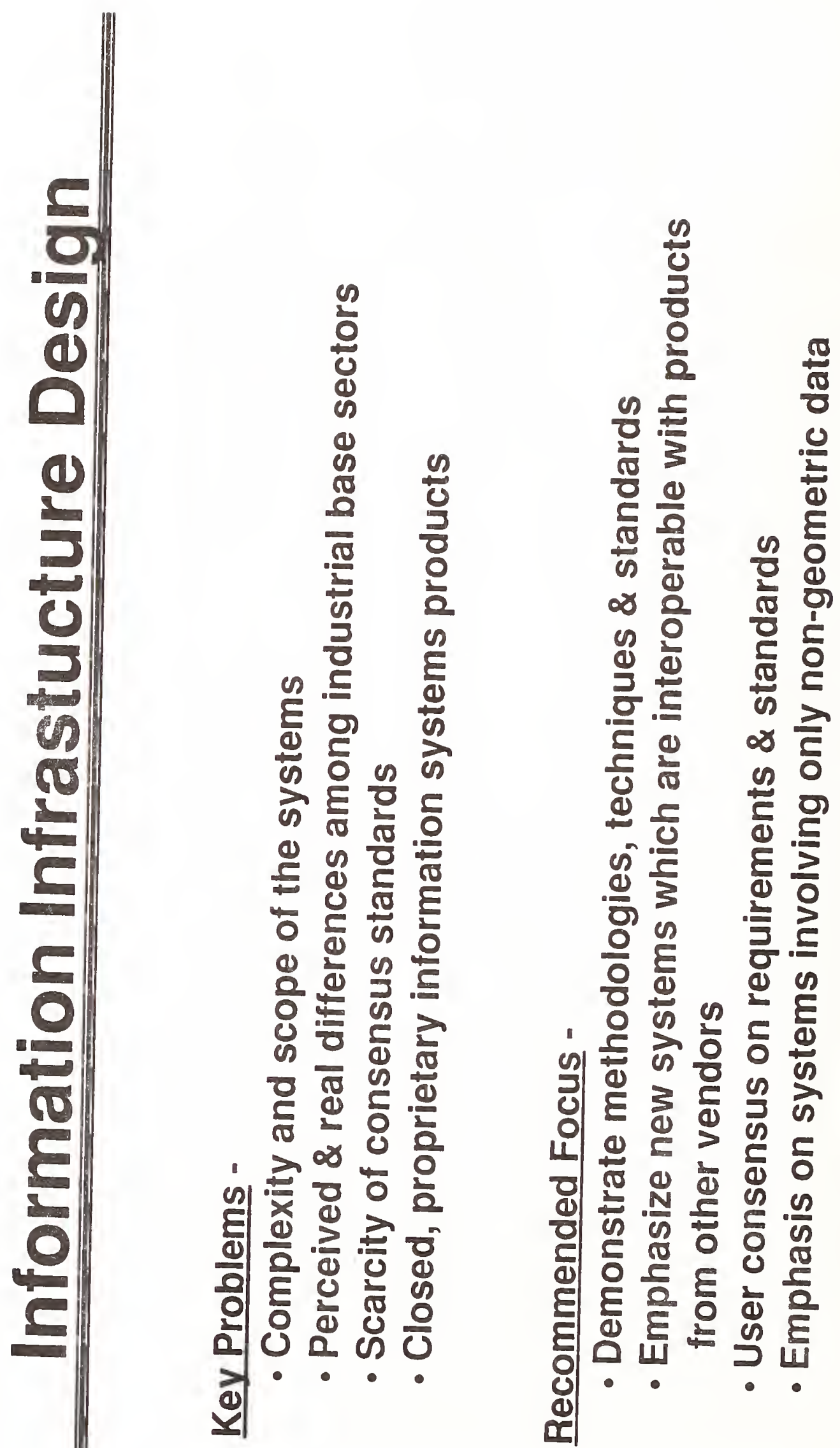


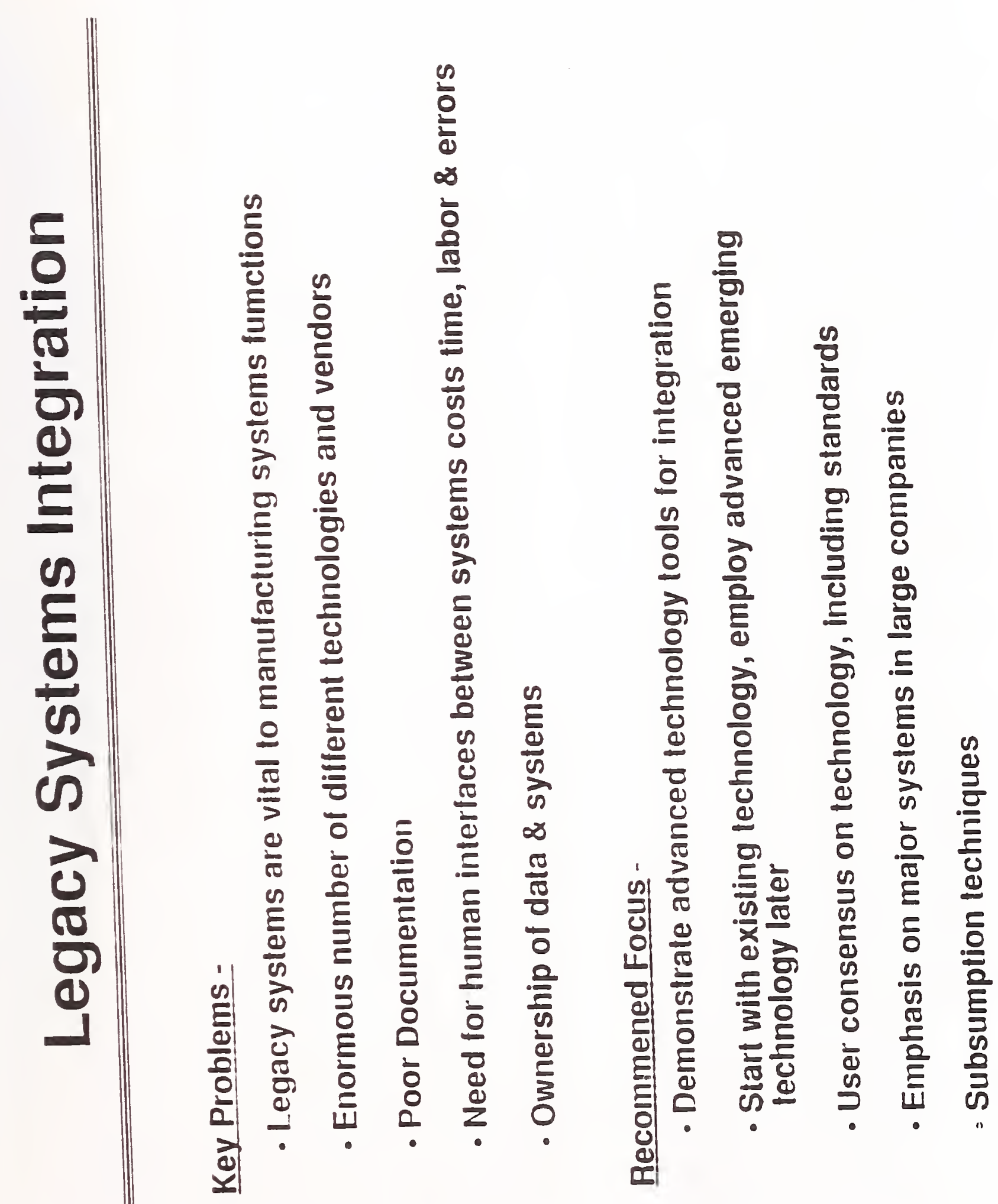



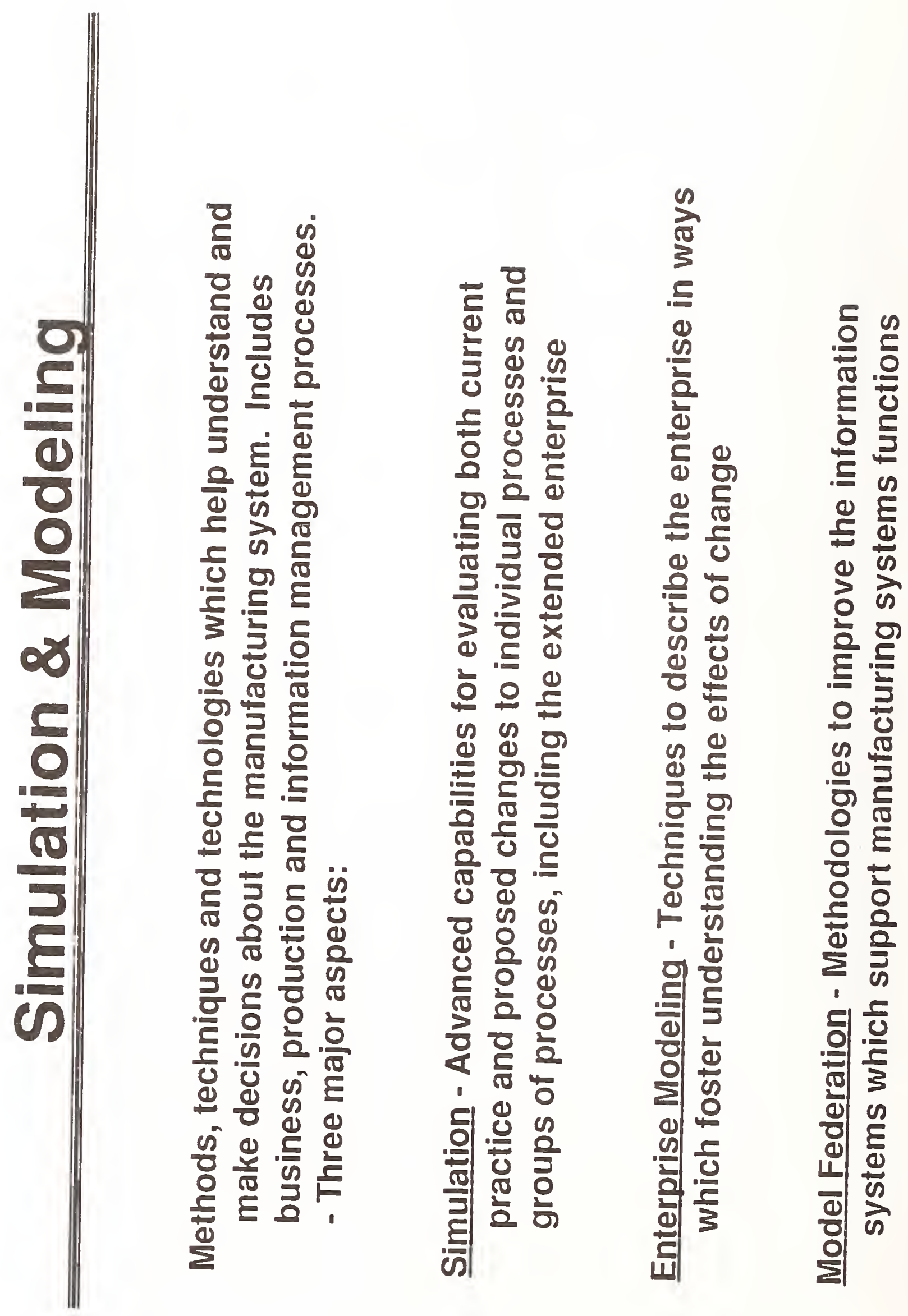

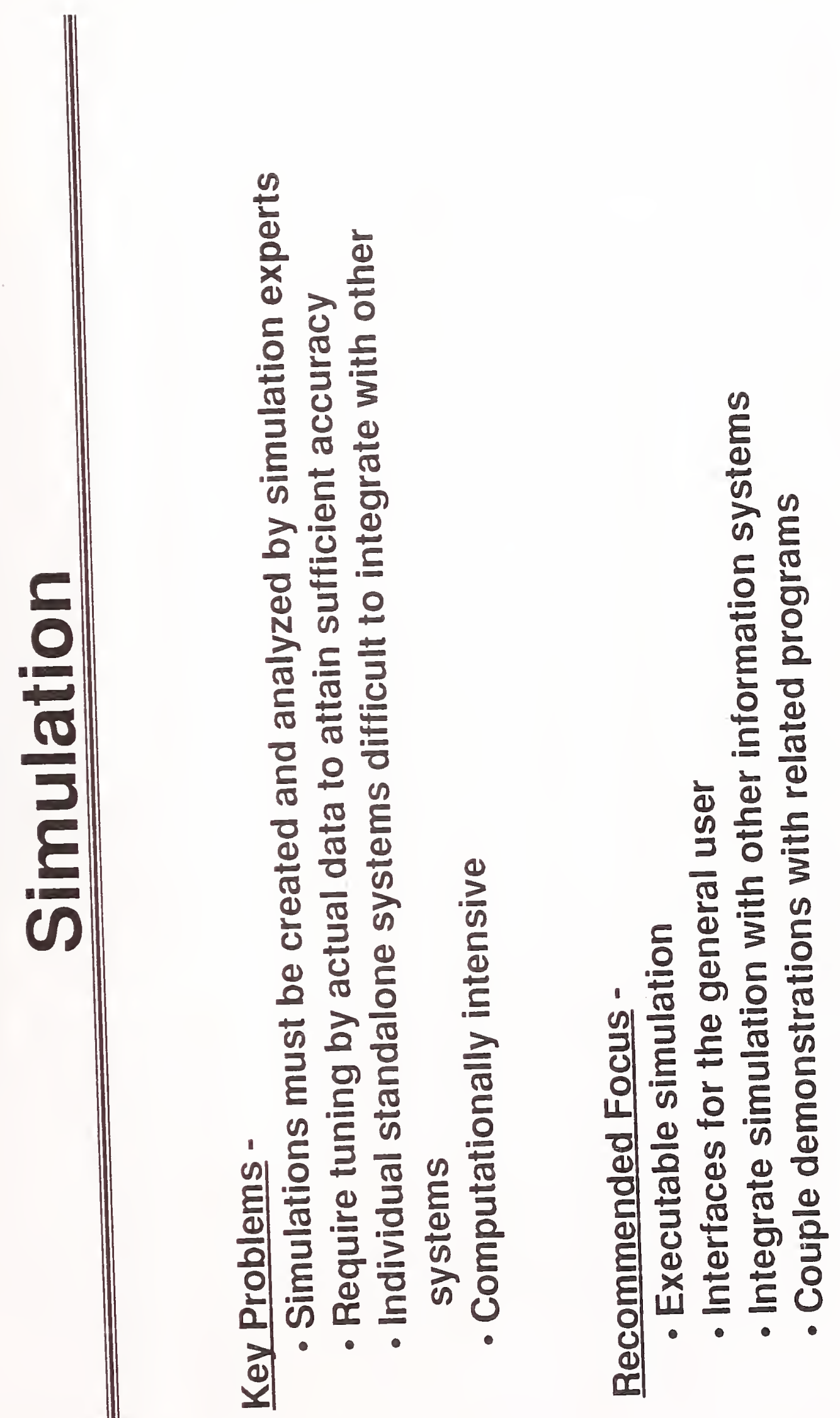

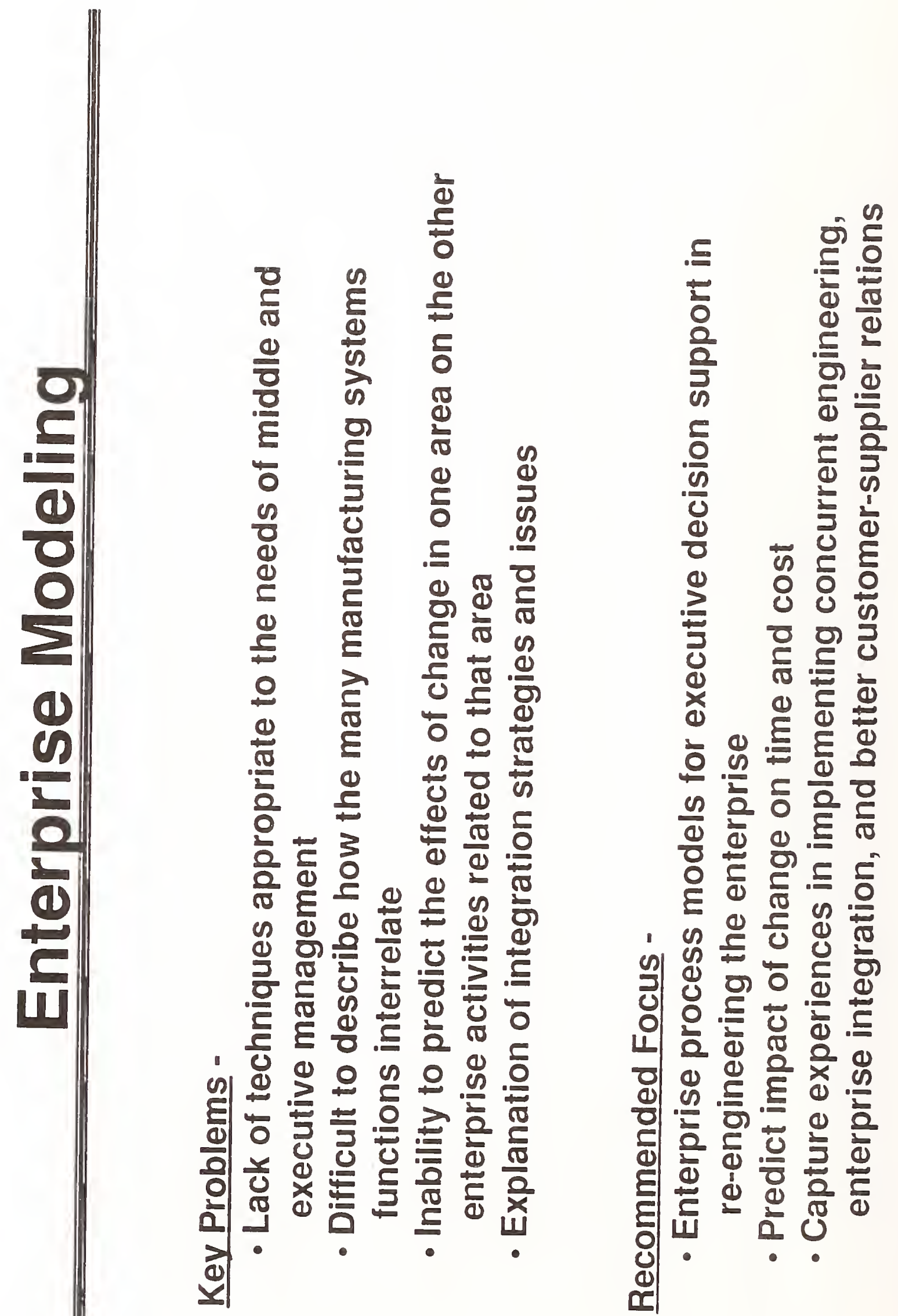

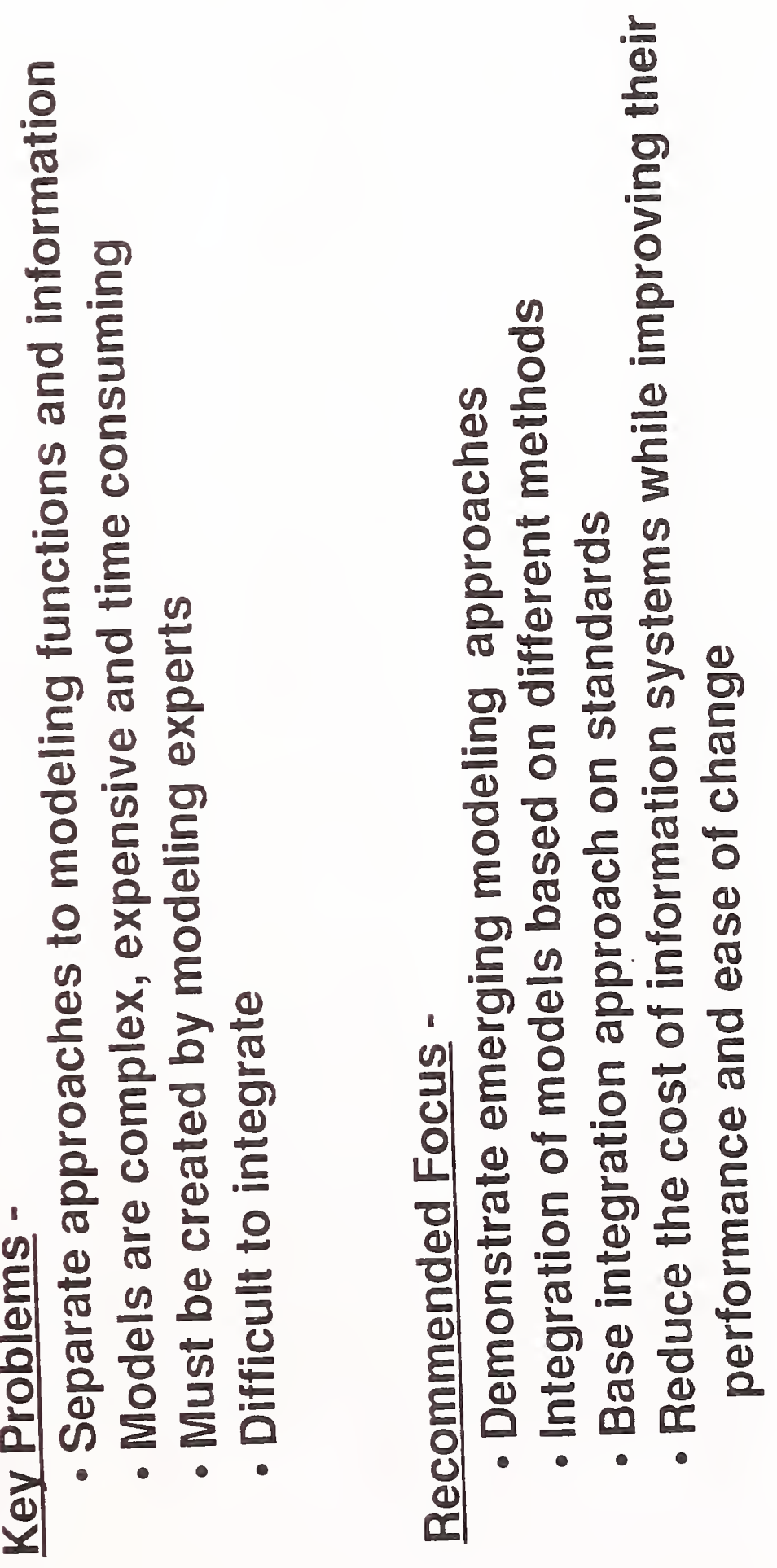

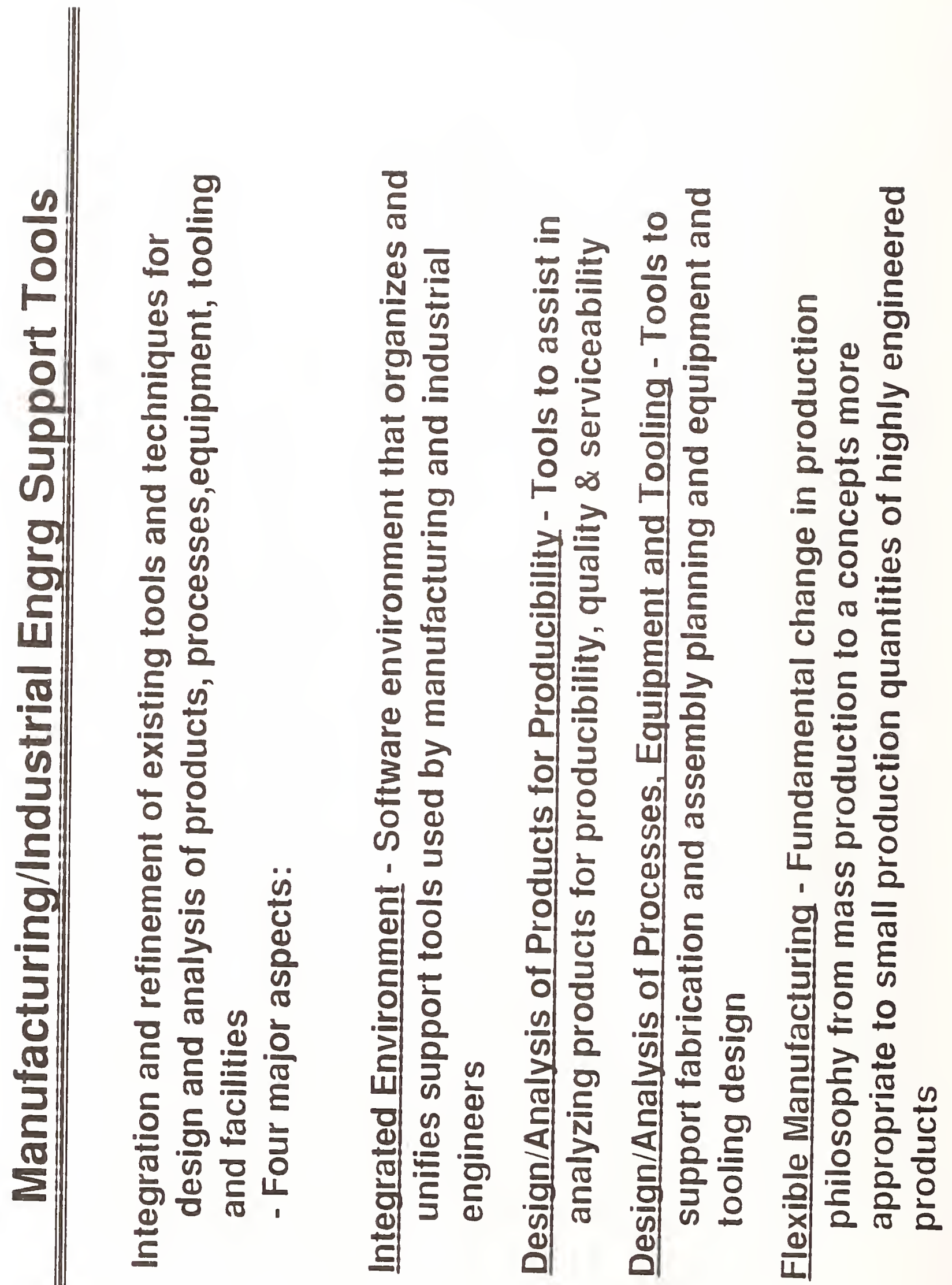

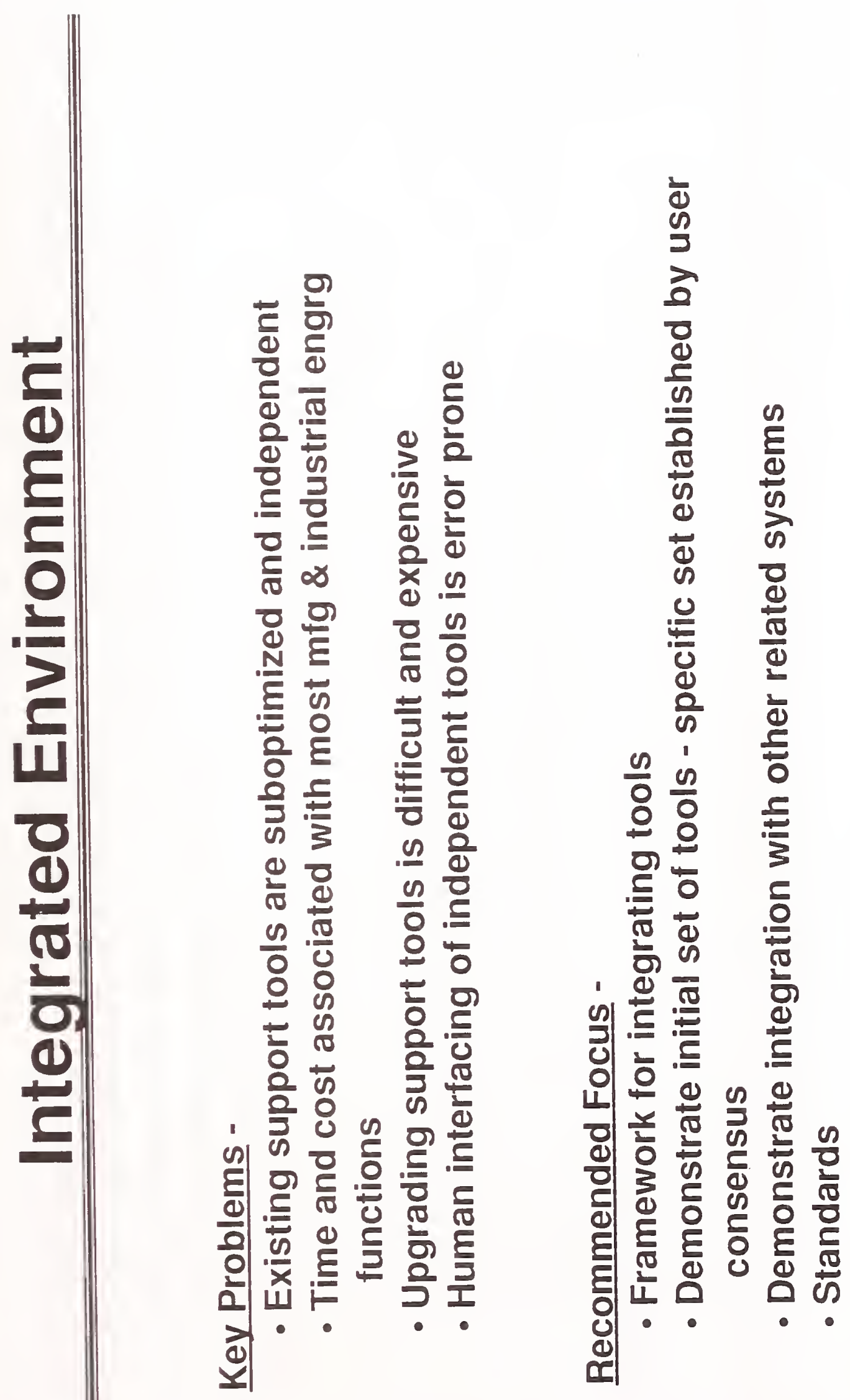

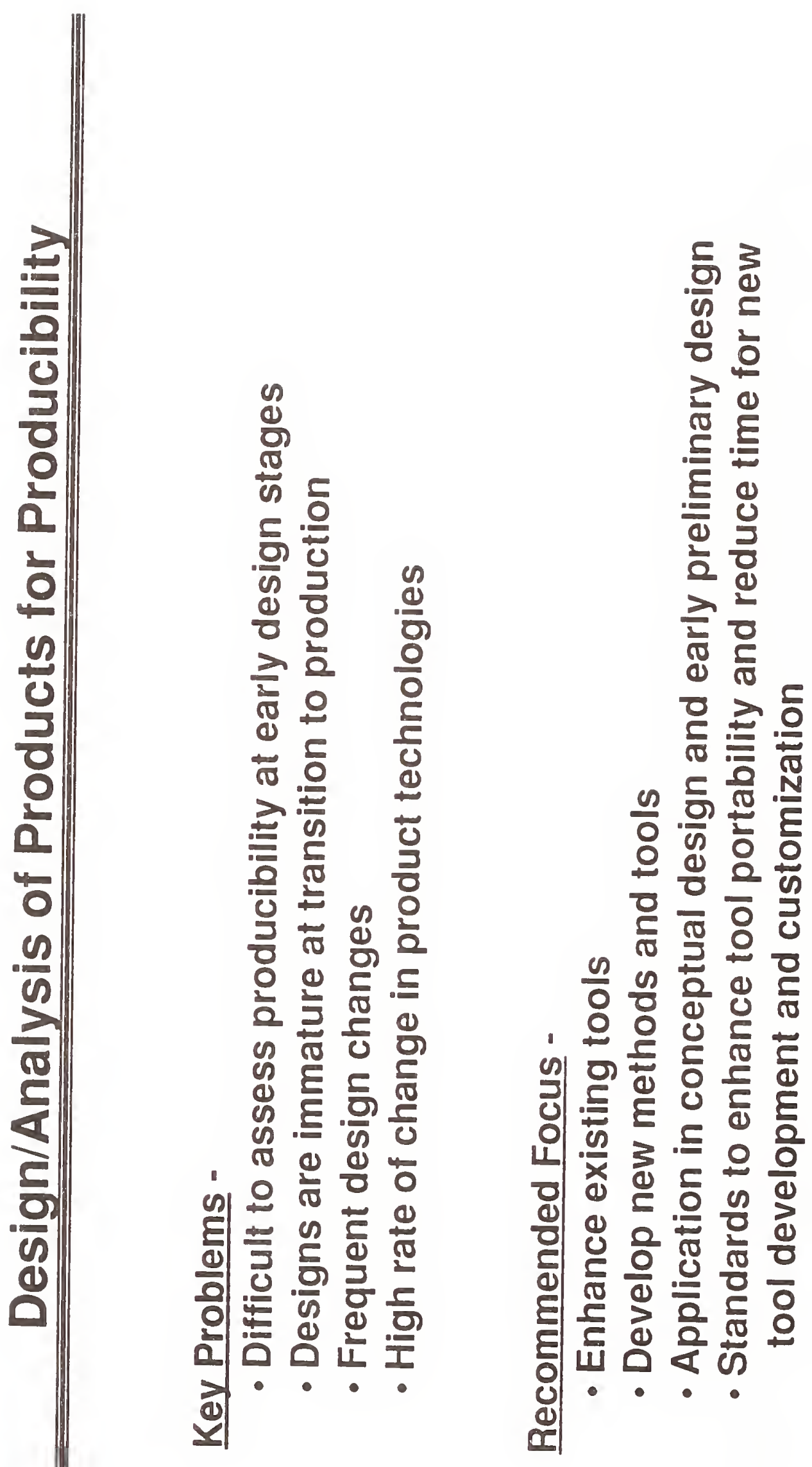

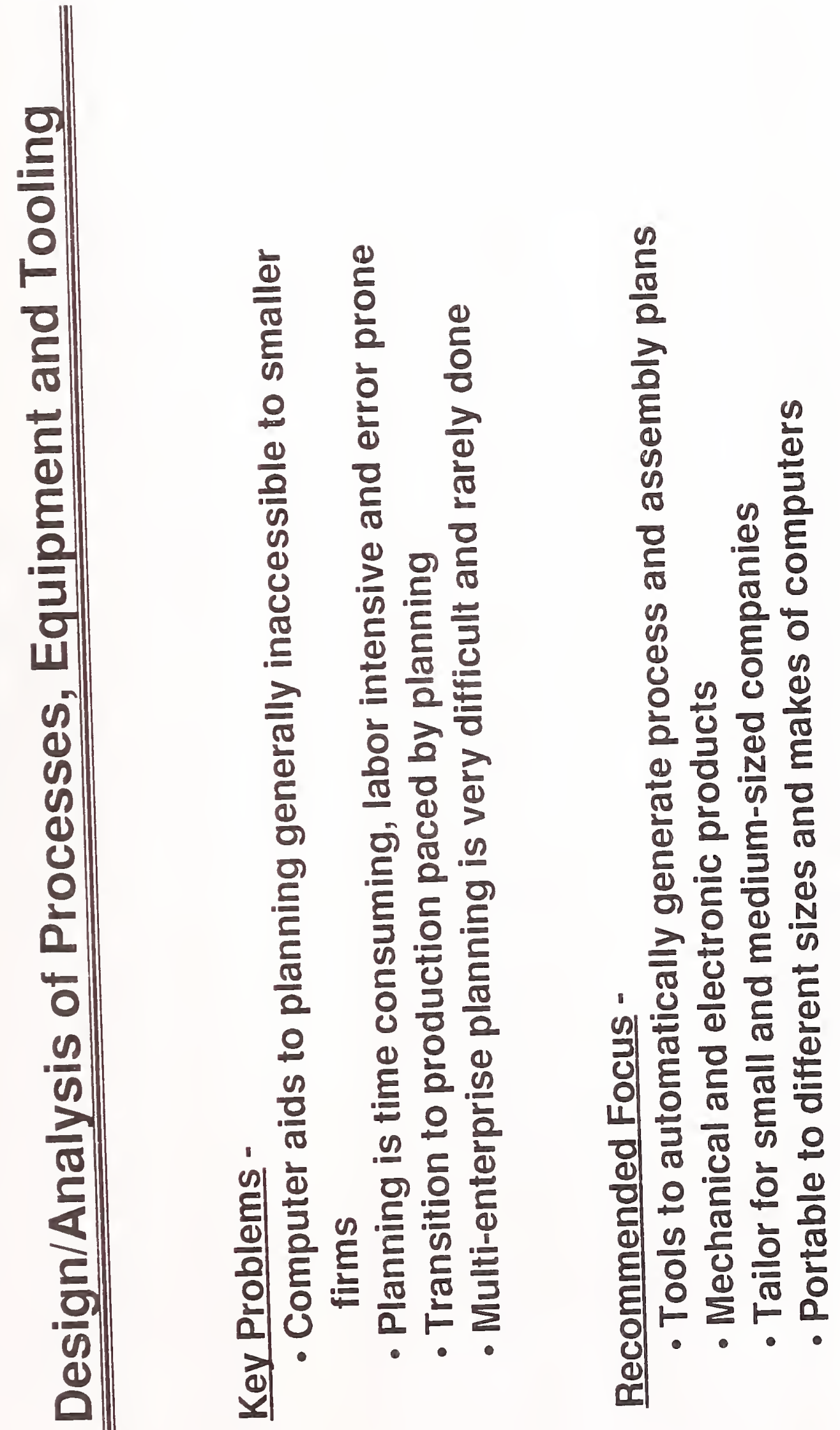


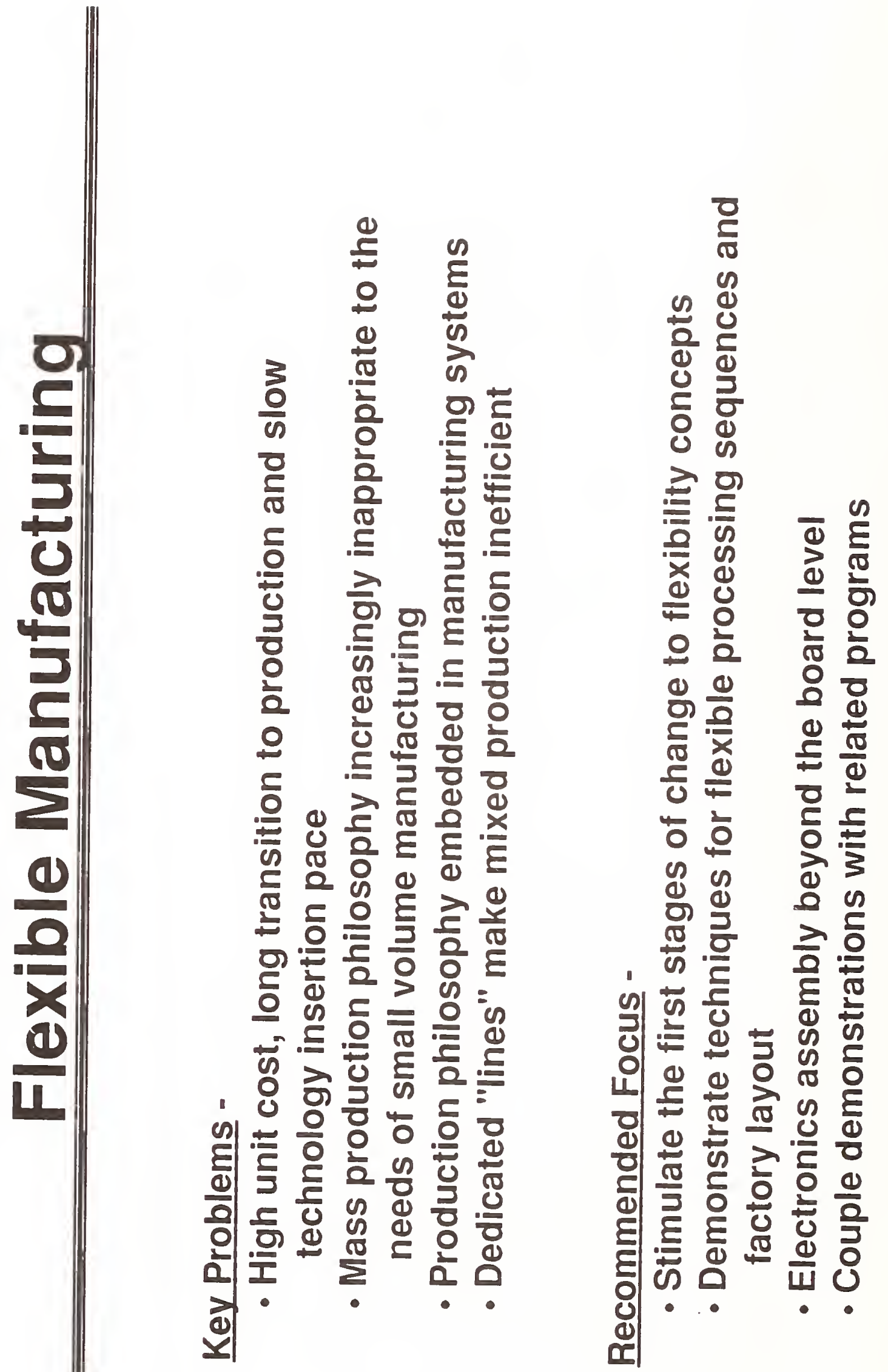




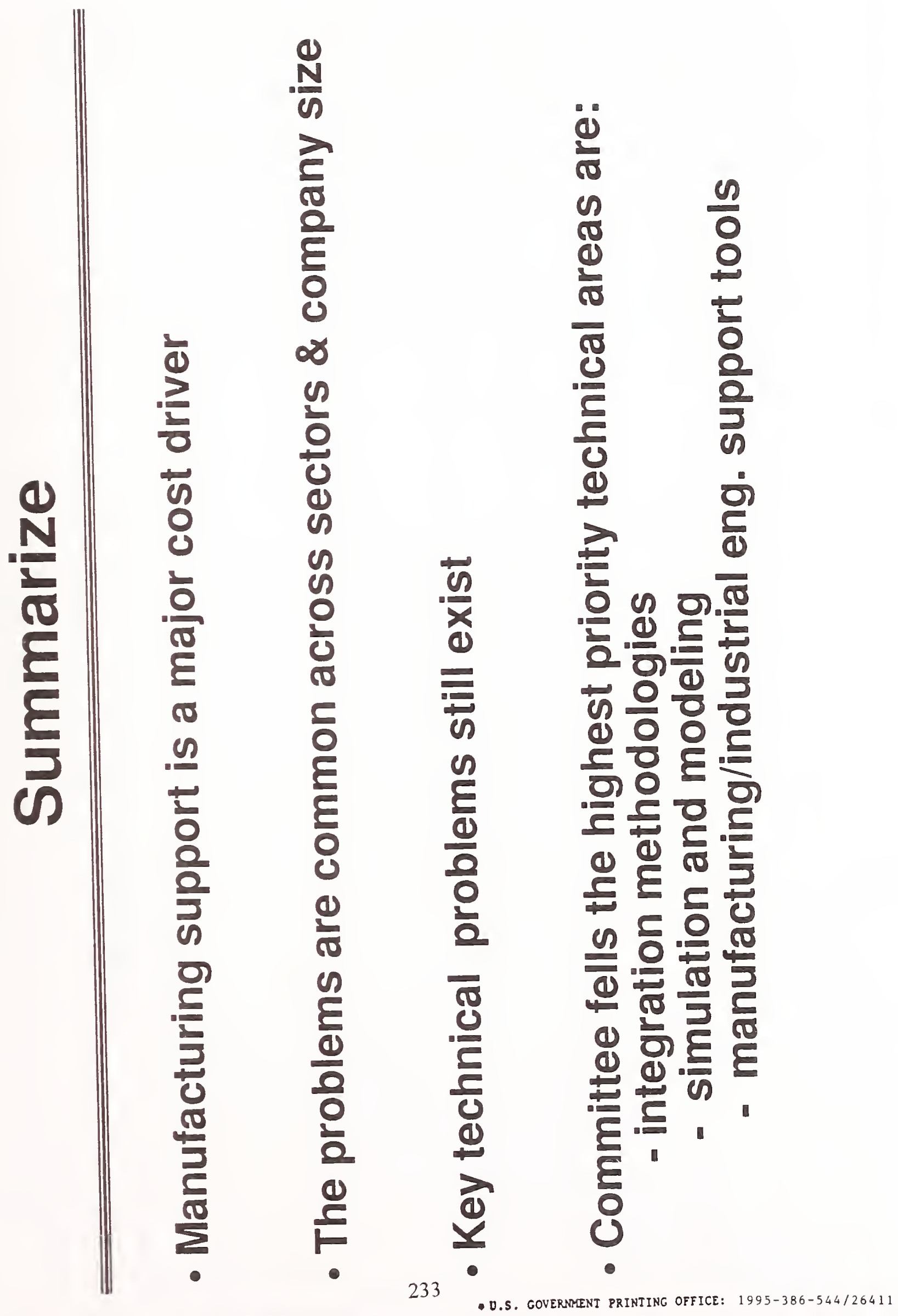







\section{NTSTT Technical Publications}

\section{Periodical}

Journal of Research of the National Institute of Standards and Technology-Reports NIST research and development in those disciplines of the physical and engineering sciences in which the Institute is active. These include physics, chemistry, engineering, mathematics, and computer sciences. Papers cover a broad range of subjects, with major emphasis on measurement methodology and the basic technology underlying standardization. Also included from time to time are survey articles on topics closely related to the Institute's technical and scientific programs. Issued six times a year.

\section{Nonperiodicals}

Monographs-Major contributions to the technical literature on various subjects related to the Institute's scientific and technical activities.

Handbooks-Recommended codes of engineering and industrial practice (including safety codes) developed in cooperation with interested industries, professional organizations, and regulatory bodies.

Special Publications-Include proceedings of conferences sponsored by NIST, NIST annual reports, and other special publications appropriate to this grouping such as wall charts, pocket cards, and bibliographies.

National Standard Reference Data Series-Provides quantitative data on the physical and chemical properties of materials, compiled from the world's literature and critically evaluated. Developed under a worldwide program coordinated by NIST under the authority of the National Standard Data Act (Public Law 90-396). NOTE: The Journal of Physical and Chemical Reference Data (JPCRD) is published bimonthly for NIST by the American Chemical Society (ACS) and the American Institute of Physics (AIP). Subscriptions, reprints, and supplements are available from ACS, 1155 Sixteenth St., NW, Washington, DC 20056.

Building Science Series-Disseminates technical information developed at the Institute on building materials, components, systems, and whole structures. The series presents research results, test methods, and performance criteria related to the structural and environmental functions and the durability and safety characteristics of building elements and systems.

Technical Notes-Studies or reports which are complete in themselves but restrictive in their treatment of a subject. Analogous to monographs but not so comprehensive in scope or definitive in treatment of the subject area. Often serve as a vehicle for final reports of work performed at NIST under the sponsorship of other government agencies.

Voluntary Product Standards-Developed under procedures published by the Department of Commerce in Part 10, Title 15, of the Code of Federal Regulations. The standards establish nationally recognized requirements for products, and provide all concerned interests with a basis for common understanding of the characteristics of the products. NIST administers this program in support of the efforts of private-sector standardizing organizations.

Order the following NIST publications - FIPS and NISTIRs-from the National Technical Information Service, Springfield, VA 22161.

Federal Information Processing Standards Publications (FIPS PUB)—Publications in this series collectively constitute the Federal Information Processing Standards Register. The Register serves as the official source of information in the Federal Government regarding standards issued by NIST pursuant to the Federal Property and. Administrative Services Act of 1949 as amended, Public Law 89-306 (79 Stat. 1127), and as implemented by Executive Order 11717 (38 FR 12315, dated May 11, 1973) and Part 6 of Title 15 CFR (Code of Federal Regulations).

NIST Interagency Reports (NISTIR)-A special series of interim or final reports on work performed by NIST for outside sponsors (both government and nongovernment). In general, initial distribution is handled by the sponsor; public distribution is by the National Technical Information Service, Springfield, VA 22161, in paper copy or microfiche form. 


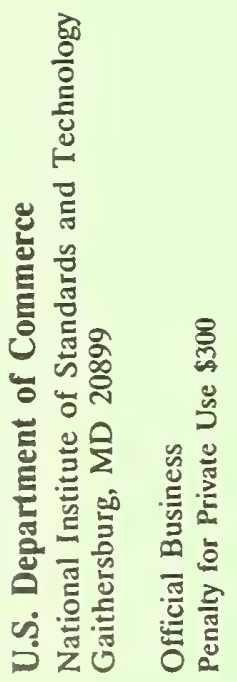

